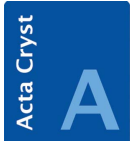

FOUNDATIONS ADVANCES

\section{Twenty-Third General Assembly and International Congress of Crystallography, Montreal, Canada, 5-12 August 2014}

Keywords: International Union of Crystallography; General Assembly; International Congress of Crystallography.

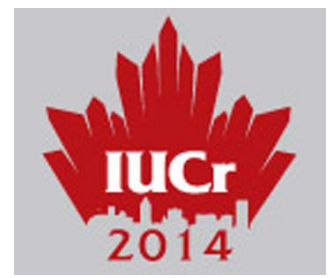

(C) 2016 International Union of Crystallography

\section{Introduction and Opening Ceremony}

By invitation of the National Research Council of Canada, the Twenty-Third General Assembly and International Congress of Crystallography were held at the Palais des Congrès de Montreal, Montreal, Canada, 5-12 August 2014.

The meetings were attended by 2425 participants from 67 countries.

The General Assembly and Congress were opened on the evening of 5 August at the Congress Centre. Welcoming Addresses were made by M. Cygler and A. Berghuis (CoChairs of the Local Organizing Committee), J. Ducharme (on behalf of J. McDougall, President of the National Research Council of Canada), S. Fortier (President of McGill University), P. Wood-Adams (Dean of Graduate Studies, Concordia University) and M. Nalecz (UNESCO). Presentations were interspersed with performances by Cirque Eloize. G. R. Desiraju (President of the IUCr) declared the meeting open. The Ewald Prize was then awarded to A. Janner (who had been unable to attend the meeting) and Professor T. W. J. M. Janssen who then presented the Ewald Award Lecture. The evening ended with a Welcoming Reception.

\section{Twenty-Third International Congress}

\subsection{Scientific programme}

Four Plenary Lectures, 36 Keynote Lectures, 112 Microsymposia, Open Commission Meetings and poster sessions were held. An easy-to-use mobile app and attendee web site were available to serve as the platform for the real-time Scientific Programme. After registration, attendees could maintain their own itinerary and view all scientific sessions, including abstract descriptions.

\subsection{Exhibitions}

A commercial exhibition comprising 63 companies and booksellers was organized.

\subsection{Social events}

Evening entertainments included a Jazz Night and the Congress Banquet. Various excursions were also arranged.

\section{Minutes of the Twenty-Third General Assembly}

These Minutes have been prepared by M. H. Dacombe, Executive Secretary, under the authority of L. Van Meervelt, General Secretary and Treasurer of the IUCr and Secretary of the General Assembly.

\subsection{Introduction and list of delegates}

Sessions of the General Assembly were held on the evenings of Wednesday 6 August, Thursday 7 August and Monday 11 August. The following attendance list gives the names of official delegates appointed by the Adhering Bodies and the alternates who substituted at one or more sessions. Dates of attendance are given in parentheses for those who were not present at every session. The names are listed by the countries to which the respective Adhering Bodies belong, and the number of votes of the Adhering Body is given in 
parentheses after the name of the country. The names of the Chairs of the delegations are given in bold where they are known; those of alternates are marked by an asterisk. There were no delegates from Egypt, Greece, the Regional Committee of Crystallographers from Latvia, Tunisia and Ukraine, or Serbia.

\section{Algeria (1): H. Merazig}

Argentina (1): D. G. Lamas

Australia (3): A. Vrielink (6 and 11 August), R. Garrett, B. Kennedy, S. Batten* (7 August)

Austria (1): K. Hradil

Belgium (2): J. Hadermann, Y. Filinchuk

Brazil (1): I. Torriani (6 and 7 August), N. Speziali* (11 August)

Bulgaria (1): B. Shivachev (7 and 11 August)

Cameroon (1): Kenfack T. Patrice

Canada (3): J. Schrag (11 August), M. James (6 and 11 August), D. Rose (6 and 7 August), M. Fraser*

Chile (1): M. Fuentealba (6 August)

China, People's Republic of (4): Song Gao (7 August), XiaoDong Su (6 August), Rong Yu (6 and 11 August), Lian-Mao Peng (7 August), Xiao-Ming Chen* (6 August), Junliang Sun* (11 August), Jie Su* (11 August), Ziqiang Wang* (11 August) China, The Academy of Sciences Located in Taipei (2): C.-D. Hsiao (6 and 7 August), H. S. Sheu, Yu Wang* (11 August) Costa Rica (1): M. Araya

Croatia (1): M. Daković (6 and 11 August), A. Visnjevac* (7 August)

Czech/Slovak Republics (2): R. Kuzel (6 and 11 August), J. Kozisek, (11 August), M. Jergel* (6 and 7 August), Z. Sourek (7 August)

Denmark (1): A. Ø. Madsen

Finland (1): K. Rissanen (6 August), S. Huotari* (7 August)

France (4): R. Guinebretière, P. Bordet, O. Perez, A. van der Lee

Germany (4): S. Schorr, W. Schmahl, J. Schreuer, C. Lehmann (7 August)

Hungary (1): G. Faigel

India (3): P. Chakrabarti, A. Nangia, D. Pandey

Ireland, Republic of (1): P. McArdle (11 August)

Israel (1): J. Sussmann (7 and 11 August), R. Diskin* (6 August)

Italy (3): C. Mealli, R. Oberti, M. Saviano

Japan (4): M. Takata, T. Inoue, A. Nakagawa (11 August), Y. Sugawara, E. Nishibori* (6 and 7 August)

Korea (1): E. E. Kim (7 and 11 August)

Mexico (1): L. Bucio Galindo

Morocco (1): A. Thalal

The Netherlands (2): M. Lutz, C. Reiss

New Zealand (1): S. Lott

Norway (1): C. H. Görbitz

Pakistan (1): S. S. Hasnain (6 and 11 August)

Poland (1): M. Gdaniec

Portugal (1): M. A. Carrondo (7 August)

Regional Committee: Bangladesh/Indonesia/Malaysia/Singapore/Thailand/Vietnam (1): J. J. Vittal
Russia (5): I. Makarova, I. Kamenskikh, V. Kvardakov, B. Roshchin, M. Zaporozhets

Slovenia (1): A. Meden

South Africa (2): D. G. Billing, C. Esterhuysen

Spain (3): E. Gutiérrez-Puebla (6 and 7 August), S. GarcíaGranda, F. Lahoz (6 and 7 August), F. Otalora* (11 August), B. Covelo* (11 August)

Sweden (2): E. Sauer-Eriksson, Xiao-Dong Zou (11 August)

Switzerland (2): P. Macchi, R. Cerny (11 August)

Turkey (1): Z. Sayers

UK (5): D. Keen (6 and 11 August), A. J. Blake (6 August), R. Cooper (6 and 11 August), J. R. Helliwell (7 August), C. Wilson (6 and 7 August), C. Schwalbe* (7 August), S. McKellar* (11 August), A. Thompson* (7 August), P. Saines* (11 August), G. Rosair* (11 August), A. Griffin (6 August), A. Warren* (7 August)

USA (5): B. H. Toby, C. L. Cahill (6 and 7 August), K. A. Kantardjieff, B. Matthews (6 and 7 August), J. Ng, S. K. Burley* (11 August), A. Sarjeant* (11 August)

Uruguay (1): A. Buschiazzo (6 and 11 August), L. Suescun* (7 August)

Venezuela (1): G. Diaz de Delgado

Present as members of the Executive Committee: G. R. Desiraju (President), C. Lecomte (Vice-President), L. Van Meervelt (General Secretary and Treasurer), S. Larsen (Immediate Past President), E. Boldyreva, H. A. Dabkowska, W. Depmeier, J. M. Guss, M. L. Hackert, J. M. Perez-Mato (Ordinary Members). M. H. Dacombe was in attendance as Executive Secretary.

Representatives (non-voting) from the Regional Associates were seated with the delegates.

\subsection{First Session, Wednesday 6 August 2014, 7:45 p.m.}

\section{(1) Introductory remarks by the President}

Professor G. R. Desiraju welcomed the delegates and observers. The President began by recalling the sad loss of Professor S. W. Wilkins who had died in early 2013. Professor Wilkins had organized the highly successful Bragg Centennial symposium in Adelaide in December 2012.

The President reviewed the financial state of the Union over the past triennium and emphasized that although the income from the publications remained strong and represented $86 \%$ of the Union's income, it would be important to find additional supplementary sources of income in the coming triennium. A Business Development Manager had been appointed so that new income-generating initiatives could be developed. The President outlined the significant developments for each of the journals, which had been reshaped under the aegis of a Journals Management Board, chaired by the Editor-in-Chief, to ensure that each journal was well placed to attract high-quality papers. In particular, the first four issues of the newly launched IUCrJ had been published. International Tables for Crystal- 
lography remained strong and new volumes were in preparation. The International Year of Crystallography was a great success. The three main initiatives were the Opening Ceremony, the Summit meetings (Karachi, Pakistan; Campinas, Brazil; Bloemfontein, South Africa) and the IUCrUNESCO OpenLabs. There were numerous other activities worldwide. The President also summarized the Union's various initiatives to support crystallographic activities through the Sub-committee on the Union Calendar (102 meetings in 34 countries had been supported in the triennium), Visiting Professorships and inter-regional bursaries.

The President announced that an IYCr Legacy Fund had been established that would be used to develop sustainable programmes in Africa, Asia and Latin America and enable other initiatives, such as the OpenLabs, to continue.

(2) Procedural matters

In order to verify the list of voting delegates, the President requested the General Secretary to read this list, and asked delegates to indicate their presence when their names were called. Delegates were also asked to complete an attendance form.

Two delegates, one from Argentina and one from Denmark, were appointed to act as tellers when votes had to be counted during the Assembly.

For the first time, electronic voting would be used for secret ballots.

\section{(3) Approval of Agenda}

The Agenda and Appendices to the Agenda had been distributed to Secretaries of National Committees in May 2014. The Agenda were approved.

(4) Amendments to Statutes and By-Laws affecting adherence to the Union

The President reported that there were no proposals.

(5) Applications for membership of the Union

Applications for membership of the IUCr had been received from Costa Rica (Category I), Pakistan (Category I), Turkey (Category I), Uruguay (Category I), Venezuela (Category I), Morocco (Category I), Malta (Category I), Cameroon (Category I), Algeria (Category I), Côte d'Ivoire (Category I) and Democratic Republic of Congo (Category I).

The applications from Costa Rica, Pakistan, Turkey, Uruguay, Venezuela, Morocco, Cameroon and Algeria were accepted by the General Assembly.

Delegates expressed the following concerns: the numbers of crystallographers in some of the countries applying were small, as indicated by entries in the World Database of Crystallographers; it was not clear in some cases that the Adhering Body adequately represented the crystallographic community of the country applying; there was insufficient clarity that there was a commitment to pay the membership subscriptions. The President reported that because some of the applications had been received at a late stage the Executive Committee had decided to allow all the applications to go forward without making a recommendation. The General Assembly decided that a decision on the applications from Malta, Côte d'Ivoire and Democratic Republic of Congo should be deferred. The President undertook to ensure that the Executive Committee would prepare guidelines for countries applying for membership so that there would be an adequate period for due diligence to be carried out. Malta, Côte d'Ivoire and Democratic Republic of Congo would be invited to re-submit their applications for the 2017 General Assembly.

(6) Withdrawal of Adhering Bodies

The subscriptions due from the Adhering Body in Chile, Comision Nacional de Investigacion Cientifica y Tecnolgia, had not been paid for the years 2009, 2010, 2011 and 2012. Accordingly, the membership of the Adhering Body for Chile had been automatically suspended in February 2013, in accordance with Statute 9.6. M. Fuentealba reported that there was a very active group of crystallographers in Chile and they had not been aware that the subscriptions had not been paid by the Adhering Body. A decision on whether to confirm the withdrawal was delayed until the third session of the General Assembly [see Minute (36)].

(7) Changes in names of Adhering Bodies

The change in name of the Adhering Body of the Regional Committee of Crystallographers from Bangladesh, Malaysia, Singapore, Thailand and Vietnam to the Regional Committee of Crystallographers from Bangladesh, Indonesia, Malaysia, Singapore, Thailand and Vietnam was accepted by the General Assembly.

The change in name of the Adhering Body of the Regional Committee of Crystallographers from Algeria, Latvia, Morocco, Tunisia, Turkey and Ukraine to the Regional Committee of Crystallographers from Latvia, Tunisia and Ukraine was accepted by the General Assembly.

(8) Changes in Category of Adherence of Adhering Bodies

The President reported that no application for a change in Category of Adherence had been received.

(9) Approval of Minutes of Twenty-Second General Assembly

The Minutes, which were contained in the published Report of the Twenty-Second General Assembly and International Congress of Crystallography [Acta Cryst. (2012), A68, 607-664], were approved and two copies were signed by the President and the General Secretary, in accordance with By-Law 1.13. There were no matters arising from the Minutes.

(10) Amendments to Statutes and By-Laws not affecting adherence to the Union

The President reported that there were no proposals.

(11) Report of Executive Committee

The Report of the Executive Committee on the activities of the IUCr since the Twenty-Second General Assembly had been submitted to the National Committees and the Commissions in May 2014, in accordance with Statute 6.8, and follows these Minutes as Appendix A1.

(12) Financial Report

A Financial Report, covering the calendar years 2011, 2012 and 2013, had been prepared by the Treasurer and had been submitted to the National Committees and the Commissions in May 2014. The Report follows these Minutes as Appendix A2. 
The Treasurer reported the composition of the Finance Committee. The Union operated in three currencies: member subscriptions were largely paid in CHF, one-third of the investments, income and most expenses were in GBP, and twothirds of the investments and some expenses were in USD. The accounts had to be prepared in CHF, which meant that a strong Swiss franc reduced the value of the assets given in the accounts when expressed in CHF. The annual turnover was about CHF 5000000 and assets at this level were required. The intention was to make a small profit so that the services provided to crystallographers through the Research and Education Fund, the President's Fund and the Ewald Fund could be maintained and developed. The operating loss incurred in 2013 was a result of investment in the International Year of Crystallography and reduced income from Acta $E$ when its coverage by ISI was lost. Acta $E$ was being restructured with the aim that its ISI status should be regained in the next triennium.

The income for the journals came from three main sources: subscriptions, consortial sales and open-access payments. The Treasurer presented plots showing how consortial income had increased during the triennium and how inclusion in consortial arrangements had greatly increased the exposure of the journals to the scientific community.

The Treasurer summarized the outlook for the coming triennium, including the work of the Journals Management Board and the Business Development Manager, new sources of income, restructuring of the investments and the positive momentum generated by IYCr 2014.

(13) Ewald Prize

Details of the Prize, awarded to Professor A. Janner and Professor T. W. J. M. Janssen at the Opening Ceremony, and the citation are given in Appendix A3.

(14) International Year of Crystallography

The Project Manager for IYCr 2014 (M. Zema) reported that it was largely due to the efforts of the Moroccan crystallographers that 2014 had been declared the International Year of Crystallography by the UN. There were a large number of initiatives worldwide with education being the underpinning aim. The successful Opening Ceremony had been funded by generous grants from member countries and the Young Crystallographers Session had been followed by a Declaration. Summit meetings in Asia, Latin America and Africa and the IUCr-UNESCO OpenLabs had been the two other major initiatives. Other activities included crystal-growing competitions for school children and a photographic competition. Exhibitions could be created from material downloaded from the IUCr web site. A brochure to help disseminate information was available in 15 languages. The sponsors and large-scale facilities were particularly thanked for their support (about USD 250000 had been raised).

The President thanked the Project Manager on behalf of the Executive Committee for being the single point of contact for all these activities. The success of the IYCr had exceeded all expectations. See Appendix A4

The President then adjourned the session at 10:40 p.m.
3.3. Second Session, Thursday 7 August 2014, 7:35 p.m.

\section{(15) Commission on Journals}

The Report of the Commission on Journals had been distributed to the National Committees and the Commissions in May 2014 and is reprinted in Appendix A5.

The Chair (S. S. Hasnain) commented that the intention of the Commission was to capture the best science in the journals so that the future was assured and the Union would be able to maintain its good works. It was as part of this vision that IUCrJ had been launched at the start of the IYCr. He welcomed the support of the community to make this journal a success.

The President thanked the Editor-in-Chief for the remarkable changes in the past two years and J. R. Helliwell congratulated the Editor-in-Chief for his splendid initiative concerning IUCrJ.

The General Assembly accepted the Report.

(16) Commission on International Tables

The Report by the Chair of the Commission on International Tables had been distributed to the National Committees and the Commissions in May 2014 and is reprinted in Appendix A5.

The Chair (Professor C. P. Brock) summarized the status of all the volumes and reported that there would be a new Edition of Volume A Space-Group Symmetry and a new Volume H Powder Diffraction available in 2015. The Editors of Volume B Reciprocal Space and Volume C Mathematical, Physical and Chemical Tables were working closely together on new Editions. A new Volume I XAFS was planned.

The General Assembly accepted the Report.

(17) Committee for the Maintenance of the CIF Standard (COMCIFS)

The Report of the Chair of the Committee for the Maintenance of the CIF Standard (COMCIFS) had been distributed to the National Committees and the Commissions in May 2014 and is reprinted in Appendix A6.

(18) IUCr Newsletter

The Report of the Editors of the IUCr Newsletter had been distributed to the National Committees and the Commissions in May 2014 and is reprinted in Appendix A7.

The President reported that the Editor and IUCr staff would investigate production of the Newsletter from the Chester office, with the possibility of making this webbased.

(19) Diffraction Data Deposition Working Group

The Chair of the Working Group (Professor J. R. Helliwell) reported on its recommendations concerning definition of metadata, a centralized crystallographic repository of raw data sets, metadata and linking of articles to raw data sets.

The President commended the Chair for his valuable work. (20) IUCr/Oxford University Press Book Series

The Report of the Chair had been distributed to the National Committees and the Commissions in May 2014 and is reprinted in Appendix A8. 
The President thanked the Chair and his Committee for their work.

\section{(21) Non-publishing Commissions}

The reports of the Commissions on their activities since the Twenty-Second General Assembly had been distributed to the National Committees and the Commissions in May 2014. The reports are reprinted in Appendix A5.

The President reported that the Executive Committee had held in-depth discussions with the Chairs.

W. Schmahl asked how the nominations for Chairs of Commissions were decided. The President referred to By-Law 8.3 that stated 'Recommendations from each Commission for the Chair and members of the Commission shall be made in writing to the General Secretary not less than seventy-two hours before the voting session of the General Assembly. These recommendations shall be approved by a majority of the members of the Commission and shall be accompanied by a written statement that the consent of the persons recommended has been obtained'. The General Assembly agreed that the Executive Committee should provide guidelines for Commissions detailing how such elections should be conducted. [See also Minute (37).]

The General Assembly accepted all the reports.

(22) Proposals for new Commissions

The Executive Committee had established an ad interim Commission on Crystallography of Materials in July 2012. The President reported that the Chair had been unable to attend the Congress. The Executive Committee considered that this would be an important Commission and the General Assembly accepted the recommendation that this Commission should continue with an ad interim status until the next Congress, when its status would be reviewed.

The President reported that a formal proposal had been received to establish a Commission on NMR Crystallography. The Executive Committee had considered the terms of reference and proposed membership and recommended that the Commission should be established with the revised title Commission on NMR Crystallography and Related Methods.

The General Assembly approved the formation of a Commission on NMR Crystallography and Related Methods.

(23) Review of existing Commissions

The President reported that the Executive Committee had considered the work of the Commissions and recommended that the name of the Commission on Synchrotron Radiation should be changed to Commission on Synchrotron and XFEL Radiation, as recommended by the Commission.

The General Assembly approved the change of name to Commission on Synchrotron and XFEL Radiation.

(24) Determination of number of elected members of each Commission

In accordance with Statute $5.10(d)$, the Assembly had to determine the number of persons to be elected on the Commissions until the Twenty-Fourth General Assembly; these numbers did not include Chairs, Co-editors or ex officio members. The numbers of elected members approved by the General Assembly (Chairs not included) are set out below:
1. Commission on Journals

2. Commission on International Tables

3. Commission on Aperiodic Crystals

4. Commission on Biological Macromolecules

5. Commission on Charge, Spin and Momentum Densities

6. Commission on Crystal Growth and Characterization of Materials

7. Commission on Crystallographic Computing

8. Commission on Crystallographic Nomenclature

9. Commission on Crystallographic Teaching

10. Commission on Crystallography in Art and Cultural Heritage

11. Commission on Electron Crystallography

12. Commission on High Pressure

13. Commission on Inorganic and Mineral Structures

14. Commission on Magnetic Structures

15. Commission on Mathematical and Theoretical Crystallography

16. Commission on Neutron Scattering

17. Commission on NMR Crystallography and Related Methods

18. Commission on Powder Diffraction

19. Commission on Small-Angle Scattering

20. Commission on Structural Chemistry

21. Commission on Synchrotron and XFEL Radiation

22. Commission on XAFS

(25) Reports of Representatives on Regional and Scientific Associates

In accordance with Statute 8.5, the reports of the Representatives on Regional and Scientific Associates had been circulated with the Agenda papers in May 2014. These reports are reprinted as Appendix A10.

All the reports were accepted.

(26) Application to become a Regional Associate

The President reported that a formal application had been received for the Latin-American Crystallographic Association to become a Regional Associate.

Professor I. Torriani made a presentation describing the history of the development of crystallography in Latin America. The Latin-American Crystallographic Association had been formed at the First Latin-American Meeting on Crystallography held in Cordoba, Argentina, in 2013.

The General Assembly unanimously accepted the recommendation of the Executive Committee that the LatinAmerican Crystallographic Association should become a Regional Associate.

(27) Reports of Representatives on bodies not belonging to the Union

In accordance with Statute 8.5, the reports of the Representatives had been circulated with the Agenda papers in May 2014. These reports are reprinted as Appendix A11.

All the reports were accepted.

(28) Sponsorship of meetings: Sub-committee on the Union Calendar 
The Report of the Chair had been distributed to the National Committees and the Commissions in May 2014 and is reprinted in Appendix A9.

The Committee was thanked with applause for its hard work collating a large amount of information, producing guidelines and ensuring the best use of IUCr funds.

(29) Date and place of Twenty-Fourth General Assembly

The Twenty-Fourth General Assembly would be held in Hyderabad, India, 21-28 August 2017, at the invitation of the Indian National Science Academy and the Indian Crystallographic Association.

(30) Determination of date and place of Twenty-Fifth General Assembly

In accordance with By-Law 1.3 the General Assembly could determine the place of the next but one General Assembly, namely the Twenty-Fifth General Assembly to be held in 2020 . The President announced that invitations had been received from the Czech and Slovak Crystallographic Association to hold the Congress in Prague, Czech Republic, and from the French Crystallographic Association to hold the Congress in Paris, France. He reported that the Executive Committee had considered the applications and found them to be in order. R. Kuzel presented the formal invitation for the Czech and Slovak Republics and R. Guinebretière, P. M. de Boissieu and C. A. Aude presented the formal invitation for France. A decision on which invitation to accept was delayed until the next session to give the delegates time to consider the choice [see Minute (31)].

The President adjourned the session at 10:05 p.m.

\subsection{Third Session, Monday 11 August 2011, 7:35 p.m.}

(31) Determination of date and place of Twenty-Fifth General Assembly (continued)

The General Assembly accepted the invitation to hold the Twenty-Fifth General Assembly in 2020 in the Czech Republic.

(32) Determination of general policy and timetable for period to Twenty-Fourth General Assembly

There were no comments on this item.

(33) Preliminary consideration of activities for period 20172020

There were no comments on this item.

(34) Budget estimates for period to Twenty-Fourth General Assembly: determination of unit contribution

These budget estimates had been distributed with the Agenda papers and are printed as Appendix A12 to these Minutes.

The General Assembly accepted the budget estimates and approved the recommendation of the Executive Committee to continue the unit contribution unchanged, at CHF 1000, for the years 2015, 2016 and 2017.

(35) Confirmation of appointments of Editors of publications of the Union

In accordance with Statute 7.1, the initial appointments and the reappointments of the Editors of the publications of the
IUCr were made by the Executive Committee and were subject to confirmation by the General Assembly.

The Assembly unanimously confirmed the following appointments and reappointments:

Editor-in-Chief of IUCr journals: S. S. Hasnain (UK)

Editors of Section A of Acta Crystallographica: S. J. L. Billinge (USA) and J. Miao (USA)

Editors of Section B of Acta Crystallographica: A. J. Blake (UK) and M. de Boissieu (France)

Editors of Section $C$ of Acta Crystallographica: A. Linden (Switzerland) and P. R. Raithby (UK)

Editors of Section D of Acta Crystallographica: E. N. Baker (New Zealand), Z. Dauter (USA), R. J. Read (UK) and S. Wakatsuki (USA)

Editors of Section E of Acta Crystallographica: W. T. A. Harrison (UK), H. Stoeckli-Evans (Switzerland), E. R. T. Tiekink (Malaysia), L. Van Meervelt (Belgium) and M. Weil (Austria)

Editors of Section $F$ of Acta Crystallographica: H. M. Einspahr (USA), W. N. Hunter (UK) and M. S. Weiss (Germany)

Editors of Journal of Applied Crystallography: A. J. Allen (USA), J. Hajdu (Sweden) and A. Kaysser-Pyzalla (Germany)

Editors of Journal of Synchrotron Radiation: G. E. Ice (USA), I. Schlichting (Germany) and F. van der Veen (Switzerland)

Editors of IUCrJ: E. N. Baker (New Zealand), G. R. Desiraju (India), C. R. A. Catlow (UK), S. Larsen (Denmark) and J. C. H. Spence (USA)

General Editor of International Tables: C. P. Brock (USA)

Editor of Volume A: M. Aroyo (Spain)

Editor of Volume B: G. Chapuis (Switzerland)

Editor of Volume C: T. R. Welberry (Australia)

Editor of Volume D: A. Authier (France)

Editors of Volume E: V. Kopský (Czech Republic) and D. B. Litvin (USA)

Editors of Volume F: M. G. Rossmann (USA), E. Arnold (USA) and D. M. Himmel (USA)

Editors of Volume G: S. R. Hall (Australia) and B. McMahon (UK)

Editors of Volume H: C. J. Gilmore (UK), J. A. Kaduk (USA) and H. Schenk (The Netherlands)

Editors of Volume I: C. T. Chantler (Australia), F. Boscherini (Italy) and B. A. Bunker (USA)

Editor of Volume A1: U. Müller (Germany)

(36) Withdrawal of Adhering Bodies (continued)

The President reported that since the first session of the General Assembly he had received a letter from the delegate from Chile indicating that because of administrative and communication problems payment of dues had been suspended in 2010. However, the crystallographers in Chile were in the process of forming a crystallographic association, which would become the Adhering Body, but that at present no commitment to pay the dues could be made. The President indicated that the General Assembly could either confirm the withdrawal of Chile (in which case the membership arrears would be written off and Chile could re-apply for membership 
in 2017) or allow the suspension of the membership to continue until such time as the arrears could be paid. G. Diaz de Delgado commented that Venezuela had accepted the first option (for withdrawal) in similar circumstances. D. G. Lamas commented that it would be difficult to confirm withdrawal for a country with an active crystallographic community, especially in IYCr. B. H. Toby looked forward to their rejoining at the earliest opportunity. The General Assembly decided that the suspension of the Adhering Body for Chile should be continued until such time as the community in Chile could reorganize and pay its arrears.

(37) Election of Chairs and members of Commissions

The nominations made by the Executive Committee for the Chairs and members of Commissions, after consultation with the Commissions through their Chairs, had been notified to delegates.

Since no other nominations had been made by the delegates, the persons recommended by the Executive Committee were considered elected.

The current full memberships of all the Commissions, including the ex officio members, together with the addresses of the Chairs, are given as Appendix C.

G. Diaz de Delgado commented that she was surprised that there was not greater representation from Latin-American countries on the Commissions. The President commented that the primary source for nominations was from the National Committees and that none of the Latin-American countries had sent nominations. All nominations received by the Executive Committee were forwarded to the Commissions, which could then make additional nominations. The President further noted that it was possible to appoint consultants at any time during the triennium.

E. Sauer-Ericksson thought that the procedure for elections should be clear and democratic. S. Schorr thought that the procedure should also be transparent with more information on nominations that had been received being made available to National Committees. The President undertook to raise these questions at the joint meeting of old and new Executive Committees that would be held the next day. [A Sub-committee to address these issues was subsequently formed.]

(38) Election of Representatives on bodies not belonging to the Union and on Regional and Scientific Associates

The nominations made by the Executive Committee for those Representatives to be elected by the General Assembly had been notified to delegates. As no other nominations were made, these persons were considered elected.

The names and addresses of the Representatives of the Union, including those appointed ex officio, are given in Appendix C.

\section{(39) Election of Officers of the Union}

The nominations made by the Executive Committee for Officers of the Union had been included in the Agenda papers distributed in May 2014. M. L. Hackert (USA) and C. Lecomte (France) were nominated for President, E. Boldyreva (Russia) and A. M. Glazer (UK) were nominated for Vice-President and L. Van Meervelt (Belgium) was nominated for General Secretary and Treasurer. Five nominations were made for the three six-year vacancies for Ordinary Members: W. Depmeier (Germany), S. GarciaGranda (Spain), K. A. Kantardjieff (USA), R. Kuzel (Czech Republic) and M. Takata (Japan). The same five nominations were made for the one three-year vacancy for an Ordinary Member (if necessary). As there was only one candidate for General Secretary and Treasurer this candidate was considered elected. Elections for the President, Vice-President, three ordinary members for the normal six-year term and one vacancy for a three-year term were held by secret ballot. The following nominees were elected:

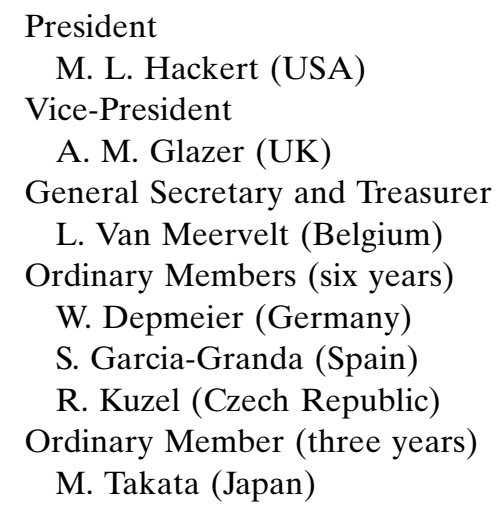

The President congratulated the new members of the Executive Committee and thanked those who would be retiring.

(40) Any other business

As there was no other business, the President declared the Twenty-Third General Assembly closed at 10:15 p.m.

\section{Closing Ceremony, Tuesday 12 August 2014}

M. Cygler and A. Berghuis (Co-Chairs of the Local Organizing Committee) presented a short review of the Congress and thanked all who had worked so hard. Poster Prizes were presented.

G. R. Desiraju thanked the organizers for making the Congress such a success. He thanked the retiring and the continuing members of the Executive Committee for their work and welcomed the new members. M. L. Hackert, the newly elected President, considered the crystallographic community to be an extended family that benefited from helping young scientists. He thanked the Executive Committee for all the hard work that they did and they would be addressing the concerns raised by the General Assembly. He was delighted with all the activities associated with the IYCr and to have everyone talking about crystallography. He thanked Michele Zema for his work as IYCr Project Manager. G. R. Desiraju said a great deal had been learnt from the Montreal Congress and that a warm welcome would await delegates in Hyderabad. The Twenty-Third General Assembly and Congress was then declared closed. 


\section{APPENDIX $A$}

Appendices to the Agenda of the Twenty-Second General Assembly

\section{A1. Report of the Executive Committee}

A1.1. Executive Committee and Finance Committee meetings

The Executive Committee met in Madrid, Spain, in August 2011 before and during the General Assembly, in Boston, USA, in July 2012 at the time of the American Crystallographic Association Meeting, in Adelaide, Australia, in December 2012 at the time of the Asian Crystallographic Association/CRYSTAL28 Meeting, and in Leuven, Belgium, in August 2013 at the time of the European Crystallographic Association Meeting (in Warwick, UK). The Finance Committee met in March 2011, March 2012, October 2012, March 2013 and August 2013, to prepare its advice and recommendations on finances, establishment and staff matters.

The most important items of business dealt with by the Executive Committee during the triennium at these meetings, and in postal and e-mail ballots between meetings, were:

(1) editorial policy, pricing policy and subscription rates, consideration of Report of Journals Review Committee, appointment of Editor-in-Chief, approval of establishment of a Journals Management Board, business plan for journals development, launch of $I U C r J$, relationship of Acta $B / C / E$, approval of appointments of Editors, approval of appointments of Co-editors, loss of ISI recognition for Acta E, archival policy, Special Issues, open access, facility information pages, proposal for an ACA journal, and other matters concerning the IUCr journals;

(2) review of contract with Wiley;

(3) approval of audited accounts;

(4) General Fund estimates and level of unit contribution, status of membership subscriptions;

(5) investment policy;

(6) funding and uses of Publications and Journals Development Fund, Research and Education Fund and President's Fund;

(7) revision of guidelines for the Sub-committee on the Union Calendar, sponsorship and financial support for meetings, young scientists' support, revision of internal guidelines;

(8) cooperation with databases, open-access databases;

(9) progress with Volumes A, A1, B, C, D, E, F, G and H of International Tables and development of associated software, appointment of Editors for Volumes $\mathrm{H}$, consideration of proposed new volumes;

(10) IUCr Newsletter, World Database of Crystallographers;

(11) promotional activities;

(12) International Year of Crystallography, including budget, Opening Ceremony, Summit meetings, OpenLabs and other activities;

(13) appointment of the Selection Committee for tenth Ewald Prize;

(14) sponsorship of other prizes;

(15) discussion of arrangements for Montreal Congress;
Table 1

Total annual number of pages published in IUCr journals.

\begin{tabular}{lrrr}
\hline & 2011 & 2012 & 2013 \\
\hline Acta Crystallographica Section A & 565 & 787 & 623 \\
Acta Crystallographica Section B & 581 & 685 & 633 \\
Acta Crystallographica Section C & 993 & 984 & 1566 \\
Acta Crystallographica Section D & 1177 & 1700 & 2584 \\
Acta Crystallographica Section E & 5523 & 5171 & 2637 \\
Acta Crystallographica Section F & 1674 & 1576 & 1442 \\
Journal of Applied Crystallography & 1306 & 1338 & 1913 \\
Journal of Synchrotron Radiation & 948 & 1066 & 1012 \\
Total & $\underline{12767}$ & $\underline{13307}$ & $\underline{12410}$ \\
\hline
\end{tabular}

(16) approval of membership of Programme Committee for Montreal Congress;

(17) level of financial support for Montreal Congress;

(18) consideration of progress with arrangements for Hyderabad Congress;

(19) nominations and election procedures for Officers of the IUCr and for Chairs and members of Commissions, proposals from National Committees for these positions.

Other items dealt with in this way were:

(20) implementation of the Crystallographic Information File (CIF) for Acta Crystallographica and other uses of CIF, work of Committee for the Maintenance of the CIF Standard (COMCIFS), provision of checking services to other publishers, chemical information;

(21) IUCr web site;

(22) collection of photographs;

(23) approval of publications, jointly with Oxford University Press, in the IUCr/OUP Book Series;

(24) establishment of an inter-regional bursary scheme;

(25) Crystallography in Africa;

(26) Visiting Professorship scheme;

(27) review of activities of Commissions;

(28) proposals for new Commissions;

(29) review of activities of Regional Associates;

(30) review of reports of IUCr Representatives on other bodies;

(31) appointment of an IUCr Representative to the International Organization for Standardization (ISO);

(32) relations with other Scientific Unions;

(33) review of activities of Diffraction Data Deposition Working Group.

Items concerning the Chester office were:

(34) staffing requirements in the IUCr office in Chester;

(35) appointment of an IYCr Project Manager and a Business Development Manager;

(36) risk analysis;

(37) upgrading office technology in the IUCr office in Chester, provision of internet services.

A1.2. Publications

The subscription prices of Acta Crystallographica, the Journal of Applied Crystallography and the Journal of Synchrotron Radiation were increased each year during the triennium.

The total annual number of pages published in 2011, 2012 and 2013 are shown in Table 1. 
All the IUCr journals are available electronically through the Crystallography Journals Online service, including all back issues of the journals from 1948, and also through Wiley InterScience.

For 2011-2013 the IUCr had two fully electronic journals available online only (Acta Crystallographica Section E launched in 2001 and Acta Crystallographica Section F launched in 2005). From January 2014 all journals have been available online only. Section E is a fully open-access journal. Section F is available free of charge to subscribers to Section D.

The IUCr home page on the web (http://www.iucr.org/) contains information in the following categories: The Union and its Components (including information on Adhering Bodies, Commissions, Regional Associates, Annual Reports, Congress Reports etc.); Journals, International Tables for Crystallography and Other Publications; News (including the IUCr Newsletter, announcements, meeting reports etc.); Education (including the Online Dictionary of Crystallography); People (including the photographic archive); Resources (including discussion lists); and the International Year of Crystallography.

Full details on the publication of volumes of International Tables for Crystallography are given in the Triennial Report of this Commission (Appendix A5.2 to the Agenda).

The World Database of Crystallographers continues to undergo development to provide increased functionality and to allow online amendments and additions to be made by individual crystallographers.

The IUCr Newsletter is distributed electronically free of charge to 587 libraries and more than 18000 crystallographers and other interested individuals in 102 countries. W. L. Duax is the Editor with the editorial office at the Hauptman-Woodward Medical Research Institute at Buffalo, New York, USA. A report on the IUCr Newsletter is given in Appendix A7 to the Agenda.

The IUCr/Oxford University Press Book Series continues to be successful. Details are given in Appendix A8 to the Agenda.

\section{A1.3. Sponsorship of meetings}

The Sub-committee on the Union Calendar considers and advises the Executive Committee on requests for $\mathrm{IUCr}$ sponsorship and financial support of meetings. The Chair of the Sub-committee is H. A. Dabkowska. A list of IUCrsponsored meetings is given in Appendix A9 to the Agenda.

Applications for sponsorship are considered if they are submitted at least nine months in advance of the date of the meeting. Applications will be considered by the Committee four times a year at the end of March, June, September and December. Applications for sponsorship should be timed accordingly. For example, for a meeting to be held in June an application should be submitted by September of the previous year at the latest.

Requests from satellite meetings must be submitted, and possible financial support requested, separately or through the organizing committee of the main meeting.

Meetings (other than satellite meetings) scheduled to be held within one month before or after an IUCr Congress will not be considered for sponsorship. For any meetings scheduled to be held between one and two months before or after a Congress, the application for sponsorship requires the approval of the Chair of the Congress Programme Committee. For meetings (other than satellite meetings) scheduled to be held, in the respective region, within one month before or after a meeting of a Regional Associate (American Crystallographic Association, Asian Crystallographic Association, European Crystallographic Association, Latin-American Crystallographic Association) the applicants for sponsorship must seek the approval of the Chair of the Regional Associate Organizing Committee.

IUCr sponsorship can only be given to meetings that are international in character and open to participants from all countries. The membership of the Programme Committee is a good indication of this. National meetings are only supported if held in developing countries.

Active crystallographers should be involved in the organization of the conference and one or more sessions should deal with specific crystallographic topics. This does not automatically include any session on condensed matter physics, materials science or symmetry not related to crystallography. According to these criteria all meetings organized by IUCr Commissions automatically qualify.

The IUCr continues to support and uphold ICSU's policy of non-discrimination and adheres to its decisions and procedures concerning free circulation of scientists. Organizers of any meeting seeking IUCr sponsorship and support must assure the Sub-committee on the Union Calendar that the authorities of the country in which the meeting is to take place guarantee free entrance of bona fide scientists from all countries.

Explicit support from the relevant IUCr Commission(s) is required for any international meeting (except for meetings of Regional Associates).

Travel support for young scientists is available for all meetings (including schools). This money should not be used for waiver of registration fees.

Consideration should be given as to whether the proposed meeting is appropriate in subject, form and timing with respect to other related meetings.

Except in special cases, IUCr funds should not be used to sponsor more than one event per year in the same location.

Registration fees should be the same for both local and nonlocal participants.

A1.4. Commissions of the IUCr

Each Commission Chair is required to provide a written triennial report to the General Assembly. These reports are included as Appendices to the Agenda. Financial assistance has again been offered to the Commission Chairs, to enable them to attend the General Assembly for the presentation and discussion of their reports and to meet the Executive Committee prior to the General Assembly.

A1.5. Regional Associates, Scientific Associates, and other bodies

The reports of the Representatives on these bodies are given as separate Appendices to the Agenda. 


\section{A1.6. IUCr staff}

The present members of staff in the IUCr offices in Chester are: M. H. Dacombe (Executive Secretary), M. J. Robinson and C. Jones (Administrative Assistants to the Executive Secretary), P. R. Strickland (Executive Managing Editor), B. McMahon (Research and Development Officer), C. A. Moore (Editorial Systems Developer), A. S. Berry (Technical Editor and Customer Support Officer), G. F. Holmes, L. E. Jones, J. K. Bradshaw, S. Conway, A. Weight, N. J. Ashcroft and L. Stephenson (Managing Editors), S. Glynn (Deputy Managing Editor), S. Froggatt and A. Hill (Technical Editors), M. A. Hoyland, D. Holden and D. Hoare (Systems Developers), L. Rathbone (Journals Production Assistant), C. Cook (Administrative Assistant), A. J. Sharpe (Promotions Officer), M. Zema (IYCr Project Manager) and J. Agbenyega (Business Development Manager).

A1.7. Acknowledgements

On behalf of the IUCr, the Executive Committee wishes to express its deep gratitude to the National Research Council of Canada for the invitation to hold the Twenty-Third General Assembly and International Congress of Crystallography in Montreal. It particularly wishes to thank J. Britten (Chair of the International Programme Committee) and A. Berghuis and M. Cygler (Co-Chairs of the Local Organizing Committee).

Finally, the Executive Committee wishes to thank all crystallographers who have assisted in the work of the IUCr in so many ways. This cooperation between crystallographers of different nationalities constitutes a most valuable aspect of the IUCr's activities.

\section{A2. Financial Report}

The accounts of the IUCr for the calendar years 2011 and 2012 have already been published [Acta Cryst. (2013), A68, 210-239 and (2014), A70, 385-415]. The accounts for 2013 have been audited and will be published in due course in Acta Crystallographica Section A. Extracts from the full financial statements for the three years 2011, 2012 and 2013 are summarized in Tables 2-4. All amounts are expressed in Swiss Francs. The notations used in this report for the various currencies of the IUCr's activities are CHF = Swiss Franc, GBP $=$ Pound Sterling, USD = US Dollar.

A2.1. General financial development

Table 2 shows a comparison of the fund accounts at the beginning and the end of the triennium. The total assets have decreased by CHF 62180 from CHF 4658722 to CHF 4596542 , or $1.3 \%$, over the triennium. These figures include the fluctuations in exchange rates. If the exchange-rate fluctuations are disregarded, the total assets decreased by CHF 449440 from CHF 5135199 to CHF 4685 759, or 9\%, over the triennium.

Table 3 shows the distribution of the assets. The great majority of the amounts under debtors and creditors have been settled since year end.

The total holding of investments at 31 December 2013 is CHF 2626051 at market value, as shown in Table 3. The IUCr bank accounts and short-term deposits are held with the Union Bank of Switzerland, the National Westminster Bank and Merrill Lynch, involving the currencies CHF, GBP and USD.

As an association incorporated in Switzerland, the IUCr is exempt from Swiss Federal and Geneva Cantonal Tax. Under the terms of the United Kingdom/Switzerland Double Taxation Agreement dated 8 December 1977, investment income arising within the UK under present circumstances is not subject to United Kingdom tax. Investment income received from other countries with which Switzerland has a Double Taxation Agreement is also exempt from tax. In October 1985, a recognition of tax-exempt status in the USA was received from the Internal Revenue Service, Department of the US Treasury.

Income and expenditure account. In order to present an overall picture of the state of the Union's affairs, an income and expenditure account for the triennium is included as Table 4. This shows that the Union was operating with a small profit in 2011 and 2012. The loss in 2013 is largely a result of additional expenditure connected with the International Year of Crystallography. The Union is predicted to continue to return to operating with a small profit in the coming triennium.

A2.2. General Fund

This fund carries the income and expenditure related to the IUCr's administration and its regular scientific activities, other than publications. Table 5 shows a comparison of the budget and accounts for the triennium. The income has two main sources: the subscriptions from Adhering Bodies and the interest income from investments and bank accounts. The subscriptions from Adhering Bodies are based on the unit contribution, which was CHF 1000 for 2011, 2012 and 2013. The income is $5 \%$ lower than the budgeted amount and the expenditure is $14 \%$ lower. It should be noted that the investments are held primarily for long-term gain. All investment income is assigned to the General Fund.

The administration expenses for the journals are calculated as $45 \%$ of the general administration costs of the IUCr, including the work of the Executive Secretary and his office and of the General Secretary and Treasurer. The Executive Committee met annually (twice in 2012), while the Finance Committee held one meeting in 2011 and two meetings in each of 2012 and 2013. The cost of these meetings varies depending on the location and the circumstances. These costs are included in the expenses of administrative meetings, together with the costs of the IUCr representatives on other bodies. The expenses of scientific meetings include the travel grants and other expenses for the Madrid Congress in 2011, the cost of the 2013 meeting of the Programme Committee for the Montreal Congress, the expenses of the non-publishing Commissions, financial support to meetings and schools, and the IUCr/FIZ Agreement (which generated income in each year of the triennium) and sales from miscellaneous books. Proportions of the research and development and promotion costs are charged to the General Fund. The financial support for young scientists attending meetings and schools is charged to the Research and Education Fund. 
Table 2

Balance Sheet, Fund Accounts (Swiss Francs).

\begin{tabular}{|c|c|c|c|}
\hline & $\begin{array}{l}31 \text { December } \\
2010\end{array}$ & $\begin{array}{l}\text { Fluctuations } \\
\text { in rates of } \\
\text { exchange }\end{array}$ & $\begin{array}{l}31 \text { December } \\
2013\end{array}$ \\
\hline General Fund & -1756091 & -80152 & -2787889 \\
\hline Journals Fund & 3975590 & 27608 & 5251599 \\
\hline International Tables Fund & -420756 & -2650 & -548618 \\
\hline $\begin{array}{l}\text { Publications and Journals } \\
\text { Development Fund }\end{array}$ & 969060 & 5992 & 877647 \\
\hline Newsletter Fund & 9421 & 809 & 37479 \\
\hline $\begin{array}{l}\text { General Assembly and } \\
\text { Congress Fund }\end{array}$ & 319305 & 2300 & 288459 \\
\hline Total accumulated balance & 4658772 & -36059 & 4596542 \\
\hline Excluding exchange rates & 5135199 & & 4685759 \\
\hline
\end{tabular}

Table 3

Balance sheet, Assets (Swiss Francs).

31 December 2010

31 December 2013

Fixed assets

Tangible fixed assets

Investments at market value

$\frac{2458959}{2511705}$

Current assets

Stock

93829

119459

Cash at banks and in hand

Current accounts $\quad 46360$

Deposit and savings accounts

1327174

9347

\begin{tabular}{rr} 
& 115221 \\
1382881 & 1542174 \\
18237 \\
\hline
\end{tabular}

1675632

Debtors, accrued income

1070171

428093

and payments in advance

Subscriptions due

Total current assets

Deduct Creditors and accrued charges

Net current assets

Total assets

The favourable deviation from budget of CHF 238082 is mainly accounted for by administration expenses, which were $12 \%$ lower than predicted.

\section{A2.3. President's Fund}

This Fund is intended mainly for use in emergencies and under special or difficult circumstances, to help crystallographers from countries with currency problems to take part in the activities of the IUCr (especially in connection with the triennial Congresses).

\section{A2.4. Journals Funds}

The total number of pages printed for Acta, JAC and JSR were 12 767, 13 307and 12410 in 2011, 2012 and 2013, respectively. The Finance Committee and the Executive Committee have monitored the financial development for all journals very closely. The Crystallography Journals Online service has been available throughout the triennium and is a great success. All journals have been online only from January 2014. For further details see the Triennial Report by the Chair of the Commission on Journals (Appendix A5.1 to the Agenda).

\section{A2.5. International Tables}

The eight-volume International Tables series was completed in 2005 with the publication of Volume G Definition and Exchange of Crystallographic Data. The new Volumne $\mathrm{H}$ Powder Diffraction will be published in 2015. International Tables Online was launched in 2007. For further details see the Triennial Report by the Chair of the Commission on International Tables (Appendix A5.2 to the Agenda).

A2.6. Publications and Journals Development Fund This Fund was established in 1984 and has been built up through transfers from other funds. During the triennium the major expenses have been related to the purchase of computer hardware and software, programming and development, 
Table 4

Income and expenditure.

20112012

2013

Income

Membership subscriptions

Sales

Journals, back numbers and single issues

Books

Open Access grant

Investment income

Income from investments

Bank interest

Profit/(loss) on sale of investments

Other income

Royalties and copyright fees

Advertising income

STAR/CIF income

Total income

\section{Expenditure}

Journals

Publication costs

Editorial expenses

Technical editing

Subscription administration

Books

Publication costs

Editorial expenses

Technical editing

Newsletter

Publication costs

Editorial expenses

International Year of Crystallography

President's Fund, other grants and young scientists support

General Assembly and Congress costs

Committee meetings and expenses

Publications and journals development

General

Editor meetings

STAR/CIF

IUCrJ development

Promotion

Subscriptions paid

Visiting Professorships

Administration expenses

General Secretary and Treasurer, including honorarium

Audit and accountancy charges

Legal and professional fees

Travelling expenses

Bank charges

Executive Secretary's office

Salaries and expenses

Travel expenses of IUCr Representatives on other bodies

Commission expenses

Sponsorship of meetings

IUCr/FIZ Agreement

Bad debts

Depreciation

Total expenditure

Excess (deficit) of income over expenditure

Realized fluctuations in rates of exchange on trading activities

(Deficit)/surplus of income over expenditure (after realized exchange rate losses)
165106

164497

162741

$\begin{array}{rrr}3574108 & & 3517553 \\ 124251 & & 170232 \\ 4883 & 3703242 & 4883 \\ & & 73387 \\ 73673 & & 1164 \\ 1123 & & 25475 \\ - & 74796 & 8641 \\ & & 203806 \\ 6721 & & 6845 \\ 171103 & & \end{array}$

276231

1265121

104225

2172792

37183

33211

76863

86614

92359

178973

178973

123179

153105

153105

483178

7699

182705

673582

14219

12542

9614

56575

7975

14864

5759

289389

5979

1226

7612

$-15457$

7498

296247

36496

3996101

139954

$-71566$

68388

$-53250$
540815

240742

317250

44439

80250

18304

104367

577492

263581

1242371

$2207019 \quad 109704$

2193148

42331

46507

$122671 \quad 62757$

128749

16392

$122671 \quad 112357$

128749

227681

207453

18572

30646

30646

18572

531979

434207

7809

24198

122486

119420

708120

677619

3901

6211

6271

17302

7683

58962

5297

13203

6880

265221

10603

4884

$-16252$

811

265267
29795

3911584

264899

72597

337496

6820

59739

2512

16674

8327

94072

274537

8219

4941

$-18088$

27048

301510

33234

4204692

$-417246$

$-5643$

$-422889$

24999

40727

Movement in market value of investments 
Table 4 (continued)

2011
42868
-14608

2012

Unrealized fluctuations in rates of exchange

Trading activities

Investment activities

28260
43398
4658722
4702120

\section{5}

$-13102$
2013

Total recognised (losses)/gains relating to the year

Accumulated balance at 1 January

Accumulated balance at 31 December
4702120

$-2337 \quad-18387$
-65187

$-83574$

360158

$-465736$

4702120

5062278

Table 5

General Fund. Comparison of budget and accounts for the years 2011-2013 inclusive (Swiss Francs).

\begin{tabular}{|c|c|c|c|c|c|c|}
\hline & Budget & & Accounts & & Difference & \\
\hline \multicolumn{7}{|l|}{ Income } \\
\hline Subscriptions from Adhering Bodies & 474000 & & 485922 & & 11922 & \\
\hline $\begin{array}{l}\text { Yield from investments and bank accounts } \\
\text { (including profit/loss on disposal of investments) }\end{array}$ & 300000 & 774000 & 249392 & 735314 & -50608 & -38686 \\
\hline \multicolumn{7}{|l|}{ Expenditure } \\
\hline Administration (net) & 1555500 & & 1375171 & & -179829 & \\
\hline Subscriptions to ICSU/ICSU bodies & 36000 & & 24393 & & -11607 & \\
\hline Administrative meetings & 305000 & & 312452 & & 7452 & \\
\hline Scientific meetings & 54000 & 1950000 & -38784 & 1673232 & -92784 & -276768 \\
\hline Favourable variant from budget & & & & & & 238082 \\
\hline Estimated profit or deficit & & -1176000 & & & & -1176000 \\
\hline Deficit of income over expenditure & & & & -937918 & & -937918 \\
\hline
\end{tabular}

promotion, Special Issue costs and projects related to the development of CIF-related products to facilitate deposition of data in crystallographic databases and submission to IUCr journals. It remains the policy of the Executive Committee to support and encourage the IUCr's highly qualified staff by supplying them with the best equipment. Also charged to this Fund are costs of putting news items on the IUCr web site, archiving and support for the Journal Grants Fund. As the programming and development activities underpin much of the Union's activity, in 1997 the Executive Committee decided that the associated costs should be assigned to the Journals Funds, the International Tables Fund and the General Fund. In 2001 this principle was extended to the promotion expenses.

A2.7. Research and Education Fund

The fund was also established in 1984 and, like the Publication and Journals Development Fund, has been built up through transfers from other funds. CHF 433352 was given as young scientists' support during the triennium. Other expenditure involved the Visiting Professorship Programme (CHF 36 055), the inter-regional bursary scheme (CHF 31 674) and the Crystallography in Africa initiative (CHF 53 765).

\section{A2.8. Ewald Fund}

This Fund is used to finance the triennial Ewald Prize.

\section{A2.9. Newsletter Fund}

The fund was established in 1994 following the successful launch of the IUCr Newsletter in 1993. The IUCr Newsletter is currently distributed electronically free of charge to 587 libraries and more than 18000 crystallographers and other interested individuals in 102 countries. The cost to the IUCr was CHF 63024 for the triennium.

A2.10. General Assembly and Congress Fund

The fund was established in 2007 so that the costs associated with the General Assembly and Congress could be spread over the triennium.

\section{A3. Ewald Prize}

The establishment of the Ewald Prize, for outstanding contributions to the science of crystallography, was announced in February 1986 and was given wide publicity. The name of the Prize was chosen with the kind consent of the late Paul Peter Ewald, to recognize Professor Ewald's significant contributions to the foundations of crystallography and to the founding of the International Union of Crystallography, especially his services as the President of the Provisional International Crystallographic Committee from 1946 to 1948, as the first Editor of the IUCr's publication Acta Crystallographica from 1948 to 1959, and as the President of the IUCr from 1960 to 1963.

Shortly after the death of Professor Ewald in 1985, his family informed the President that Professor Ewald had wished to make a bequest to the IUCr. After consulting Mrs Ewald, this generous bequest, together with a donation from the Ewald family and a donation from the IUCr, was used as starting capital for the Ewald Prize. The interest from this 
capital and further donations from the IUCr are used to finance the Prize.

The Prize consists of a medal, a certificate and an award of USD 30000 . It is presented once every three years during the triennial International Congresses of Crystallography. The first Prize was presented during the Perth Congress, being awarded jointly to J. M. Cowley and A. F. Moodie. The second Prize was presented during the Bordeaux Congress to B. K. Vainshtein. The third Prize was presented during the Beijing Congress to N. Kato. The fourth Prize was presented during the Seattle Congress to M. G. Rossmann. The fifth Prize was presented during the Glasgow Congress to G. N. Ramachandran. The sixth Prize was presented during the Geneva Congress to M. M. Woolfson. The seventh Prize was presented during the Florence Congress to P. Coppens. The eighth Prize was presented during the Osaka Congress to D. Sayre. The ninth Prize was presented during the Madrid Congress to E. Dodson, C. Giacovazzo and G. M. Sheldrick. The tenth Ewald Prize has been awarded to Professor A. Janner and Professor T. W. J. M. Janssen for the development of superspace crystallography and its application to the analysis of aperiodic crystals.

The presentation of the Ewald Prize was made during the Congress Opening Ceremony.

\section{A4. International Year of Crystallography}

In their resolution proclaiming 2014 as the International Year of Crystallography, the United Nations General Assembly recognized that 'humankind's understanding of the material nature of our world is grounded, in particular, in our knowledge of crystallography'. UNESCO and the International Union of Crystallography (IUCr) received a mandate from the United Nations to coordinate the activities of the International Year.

The major objectives of IYCr2014 are:

to increase public awareness of the science of crystallography and how it underpins most technological developments in our modern society;

to inspire young people through public exhibitions, conferences and hands-on demonstrations in schools;

to illustrate the universality of science;

to intensify the programme Crystallography in Africa and create similar programmes in Asia and Latin America;

to foster international collaboration between scientists worldwide, especially North-South contributions;

to promote education and research in crystallography and its links to other sciences;

to involve the large synchrotron and neutron radiation facilities worldwide in the celebrations of IYCr2014, including the SESAME project set up under UNESCO auspices.

Numerous activities are being held worldwide to celebrate IYCr. Those with direct IUCr involvement include the Opening Ceremony, Summit Meetings and OpenLabs.

The Opening Ceremony was held at UNESCO, Paris, 20-21 January 2014, and was attended by over 800 people. There was a full programme including talks, presentations and discus- sions. There was a session with presentations from the BRICS countries (Brazil, Russia, India, China and South Africa) concerning how science is developing in these countries. A panel of Young Talented Crystallographers of the World debated the challenges they and their peers are facing. In a signed declaration they brought some fundamental points to the attention of the World's governments: freedom to explore original and innovative directions and to think about longterm research goals; access to facilities, equipment, literature and funding; high-quality training opportunities; and exchanges and collaborations between developed and developing countries in mutually beneficial partnerships that result in the creation of jobs, laboratories or other infrastructure in the less wealthy partners.

The IUCr-UNESCO summit meetings are intended to bring together scientists from countries in three widely separated parts of the world, using a common crystallographic theme. There is a real necessity for scientists to think beyond political borders and other distinctions. Therefore the summit meetings, which will be attended by scientists in academia and industry, and by science administrators, are planned between countries that have hitherto been divided on the basis of geography, ethnicity, religion and politics. These meetings will focus on high-level science, also highlighting the difficulties and problems of conducting competitive scientific research in different parts of the developing world.

The first summit meeting was held in Karachi (Pakistan) and brought together scientists, policy makers, administrators from India, China and Pakistan under the umbrella of chemical crystallography and pharmaceutical sciences. The second summit will be held in Campinas (Brazil) under the theme of macromolecular crystallography and will bring together a similar group of scientists, administrators and policy makers in South and Central American countries. The third meeting will be held in Bloemfontein (South Africa) and will bring together government representatives from a large number of countries in Sub-Saharan Africa and North Africa, and will be preceded by a satellite workshop on applications of diffraction.

The IUCr-UNESCO OpenLab project is a network of operational crystallographic laboratories based in different countries worldwide, many in less endowed regions of Africa, South and Central America and South Asia. They are aimed at allowing access to crystallographic knowledge and technology in all parts of the world, key for the fruitful development of science, and to open possibilities for conducting high-level research. The OpenLabs are being planned in partnership with major equipment manufacturers.

The purpose of the OpenLab project is manifold:

in threshold countries, the idea is to encourage the purchase of advanced instrumentation;

in hub countries, the idea is to increase the technological base and spark interest in youngsters;

in less privileged countries, the idea is to start some crystallographic activity.

Details about all IYCr activities worldwide may be found via the IUCr-maintained web site at http://www.iycr2014.org. 
OpenLabs have been held (or are being held) successfully in Pakistan, Argentina and Morocco. So far others are scheduled for Ghana, Uruguay, Turkey and Algeria. There will also be OpenFactories (i.e. workshops held in the factories of diffractometer manufacturer companies) in France, Germany and Austria.

\section{A5. Reports of Commissions of the Union}

\section{A5.1. Commission on Journals}

\section{A5.1.1. Overview}

The triennium has seen some fundamental changes to the journals. At its meeting during the Madrid Congress, the IUCr Executive Committee set up a Journals Review Committee to consider the medium- and long-term development of the journals. The Committee was chaired by Sven Lidin and reported in early 2012. The journals started the triennium with Gernot Kostorz as Editor-in-Chief who stepped down in 2012. I was appointed Editor-in-Chief in August 2012. I am grateful to Gernot for a smooth handover and being available for advice when needed.

In August 2012, the Executive Committee approved the establishment of a Journals Management Board (JMB) comprising the Main Editors of each of the journals, the IUCr President (or his/her nominee), the IUCr General Secretary and Treasurer, the Editor-in-Chief and the Executive Managing Editor. The inaugural meeting of the JMB chaired by the Editor-in-Chief took place on 22 October 2012 and considered a detailed plan for journals development. The plan was further enhanced with input from all the IUCr Commissions, broad scientific communities that participate in the Congresses and General Assemblies, and presented to the Executive Committee during its meeting in Adelaide (in conjunction with the joint AsCA/CRYSTAL28 meeting). The Executive Committee approved the development plan for the journals in December 2012, including the launch of a comprehensive open-access journal in January 2014 bearing the name of the IUCr, simply called IUCrJ. Appointments of ten Main Editors were also approved signaling major changes that were to come in the rest of the triennium. Five Main Editors were appointed for existing journals (Simon Billinge, John Miao, Sandy Blake, Ilme Schlichting and Friso van der Veen) and five Main Editors were appointed for IUCrJ (Ted Baker, Richard Catlow, Gautam Desiraju, Sine Larsen and John Spence). The Executive Committee also decided to change the subtitle of Acta B to Structural Science, Crystal Engineering and Materials in order to extend the scope of the journal to the crystal engineering and materials chemistry communities and thus capture many of the important papers in these sub-disciplines. These plans were described at an AsCA Plenary session, where participants were encouraged to engage in reshaping the journals for the International Year of Crystallography (IYCr2014) and beyond.

Among the aims of the development plan is the extension and expansion of the scope of the journals to meet the needs and serve the interests of researchers in the crystallographic and wider scientific communities, who utilize structural information for addressing their scientific questions. The plan is to make the journals the natural home for many of the high-quality scientific publications that are currently published in journals such as Nature Structure and Molecular Biology, Structure, Proceedings of the National Academy of Sciences, Journal of the American Chemical Society, Angewandte Chemie, Chemical Communications, etc., where structural data underpin these publications. A policy of closer interaction with IUCr's Commissions is also planned. The central premise of the development plan is that our journals should cater for all of the best science resulting from communities that are served by our Commissions publishing original research articles as well as review articles in all areas covered by the Commissions. Each of the journals was assigned a dedicated Managing Editor so that these highly trained IUCr staff can be pro-active in the whole process of publications, community awareness and journals development.

During 2013, further new journal subtitles were introduced with a major plan for Special Issues to highlight the changes in scope of the journals. The subtitle of Acta A changed to Foundations and Advances with the launch of a new Advances section. Acta $C$ is now simply called Structural Chemistry. Acta $F$ received the shortened subtitle Structural Biology Communications to provide a clear message that the journal was the home for structural biology papers that were best presented as Communications. It also signaled to the community that it was not solely a journal for crystallization or preliminary results. The changes in subtitles have been accompanied by a great deal of activity, with the journals publishing Special Issues relevant to their new subtitles, and also Lead and Feature Articles. Additional Main Editors were appointed during 2013-2014, including Marc de Boissieu (Acta $B)$, Randy Read and Soichi Wakatsuki (Acta D), Bill Hunter (Acta F), and Andrew Allen and Janos Hadju (JAC), thus enabling our journals to have more than one Main Editor and as such enabling the scope of our journals to be widened. Much work remains to be done to transform the journals and make sure that authors appreciate the full range of publication choices.

While the strengthened teams of Main Editors, Co-editors and Managing Editors spearheaded these developments, ambitious plans for IUCrJ were put in place. The year 2013 saw the establishment of an Advisory Board (T. L. Blundell, P. M. Colman, J. B. Hastings, W. A. Hendrickson, B. Kobilka, Y. Ohashi, J. R. Schneider, W. G. Stirling and M. J. Zaworotko) and 20 Co-editors for the five broad sections of the journal. The objective of $I U C r J$ is to attract high-quality science papers of broad scientific significance from across all the scientific communities that use results obtained from diffraction methods. The goal for 2014 will be to publish 100 articles in $I U C r J$ covering as many aspects of structural methods development and applications as possible. The journal published its inaugural issue in January 2014 and has so far published nearly 40 papers. Many of the most important contributions at the Congress are being captured for the September and November 2014 issues of IUCrJ. 


\section{international union of crystallography}

\begin{tabular}{lllllll}
\hline & 2008 & 2009 & 2010 & 2011 & 2012 & 2013 \\
\hline No. of submissions (all) & 5765 & 7129 & 7033 & 7302 & 6628 & 4514 \\
$\quad$ without Acta E & 1919 & 2016 & 1905 & 1831 & 2023 & 2391 \\
Rejection rate (\%) & 24 & 22 & 22 & 22 & 21 & 23 \\
$\quad$ without Acta E & 39 & 33 & 33 & 32 & 30 & 30 \\
No. of published papers (all) & 4795 & 5440 & 5431 & 5650 & 5330 & 3481 \\
$\quad$ without Acta E & 1239 & 1274 & 1318 & 1206 & 1283 & 1517 \\
No. of open-access papers (all) & 3467 & 4245 & 4232 & 4571 & 4139 & 2177 \\
$\quad$ without Acta E & 89 & 79 & 119 & 127 & 78 & 213 \\
No. of pages (all) & 11295 & 12812 & 13156 & 12667 & 13307 & 12410 \\
without Acta $E$ & 7034 & 7704 & 7961 & 7144 & 8136 & 9773 \\
\hline
\end{tabular}

A final part of the development plan was the appointment of a Business Development Manager to work on the development and promotion of the journals. Jonathan Agbenyega took up this position in December 2013. Additional services to authors have been put in place. For example, facilitating promotional opportunities to authors for their articles is one of the areas that is being developed. While encouraging authors to submit their best work, we are undertaking to provide scientific commentaries (along the lines of News and Views articles in Nature or Perspectives articles in Science) on some of the outstanding articles that are published, and short Research News items are also being commissioned for distribution to the media. In addition, IUCr journals started to work with Kudos (www.growkudos.com) in 2014 to enable authors to enrich and share their publications for greater research impact.

In Spring 2012, Thomson Reuters announced that Acta E was to be de-listed from the Science Citation Index, giving a high self-citation rate as the principal reason for this action and also noting that the journal would not be reassessed until 2015. I set up a Working Party to consider future options for the journal. The Working Party consisting of Frank Allen, Sandy Blake, Bill Harrison, Tony Linden and Luc Van Meervelt (Chair), helped by Chester staff (Peter Strickland, Sean Conway, Gillian Holmes, Brian McMahon), reported to the Finance and Executive Committees in August 2013 for further comments. A detailed strategy for the re-launch of the journal has subsequently been developed. Acta E, to be called Crystallographic Communications from January 2015, will be served by five Main Editors. Luc Van Meervelt (Belgium) joins Bill Harrison (UK), Helen Stoeckli-Evans (Switzerland), Edward Tiekink (Malaysia) and Matthias Weil (Austria) to complete the board of Main Editors. A highly reputable International Editorial Advisory Board consisting of Stuart Batten (Australia), Gautam R. Desiraju (India), Larry Falvello (Spain), Santiago Garcia-Granda (Spain), Judith Howard (UK), Simon Parsons (UK), Ian Williams (Hong Kong, People's Republic of China) and Chen Xiao-Ming (Guangzhou, People's Republic of China) will guide the journal. Crystallographic Communications will publish two article types: a longer format than at present (Research Communications) and a short format (Data Reports) that is similar to current articles. An editorial written by the Editorin-Chief summarizing the comprehensive actions taken for the re-launch was published in June 2014 with new types of articles sought from 1 July 2014.
Though the total number of pages published in 2013 was very similar to 2011, the total number of papers published in 2013 decreased significantly owing to a decrease in articles published in Acta $E$ following its de-listing by the Science Citation Index in 2012. We note that the number of articles excluding Acta $E$ was about $30 \%$ of the total in 2013 but made up about $80 \%$ of the published pages. The number of articles for all other journals represented an increase of about $15 \%$, primarily owing to the increased attractiveness of Acta D (Biological Crystallography).

Three IUCr journals were included in the top five ranked crystallography journals, with Foundations and Advances (Acta A) having a five-year impact factor of 18.3, Biological Crystallography (Acta D) 7.5 and Applied Crystallography (JAC) 4.5. Acta $A, B$ and $C$, and $J A C$ had cited half-lives of $>10$ years. A total of 10 million downloads of journal articles were made from Crystallography Journals Online in the triennium.

Very few open-access papers are published in Acta $A, B$ and $C$, suggesting that a concerted effort to boost open-access publication could pay dividends. For our other journals, the proportion of open-access papers published has generally been in the range 10-20\%, with the highest proportions being in Acta D and JSR. Jonathan Agbenyega in consultation with other Chester staff has presented a strategy to deliver a near doubling of this by the end of the next triennium.

At the end of the triennium, more than 240 Editors and Coeditors worked on IUCr journals. The work of all these dedicated colleagues in ensuring the high standards of IUCr journals is highly appreciated. Their work was supported by the highly professional staff in Chester. The triennium marked the retirements of a number of editors as well as the appointment of replacement editors reflecting the broadening scope of our journals and emphasizing the scientific impact of crystallographic research in all of the mainstream science disciplines. We seek your support to create the equivalent of IUCr's PNAS (IUCrJ), while ensuring that all of our existing journals become the natural home for all of the best science resulting from communities that are served by our Commissions.

\section{S. S. Hasnain, Editor-in-Chief and Chair of Commission}

\section{A5.1.2. Acta Crystallographica Section A}

Acta Crystallographica Section A started the triennium with Dieter Schwarzenbach as Section Editor. Following his retirement at the Madrid Congress, Dieter was succeeded as Section Editor by Walter Steurer. Walter stepped down in 2012, and we took over in November 2012. We would like to thank Dieter and Walter for their unflagging service and support.

Following our appointment as Section Editors, the subtitle of the journal has been changed from Foundations of Crystallography to Foundations and Advances, and a new Advances section of the journal has been launched. As described in the November 2013 Editorial A New Vision for Acta Crystallographica Section A [Acta Cryst. (2013), A69, 
international union of crystallography

533-534], the aim of the Advances section is to offer rapid publication of high-impact papers. Certain papers in the Advances section will be highlighted. For these, scientific commentaries will be commissioned, describing the novelty and impact of the advance, and short news releases for a general audience will be written and released in conjunction with the publication of the paper. The first Advances article, Magnetic Pair Distribution Function Analysis of Local Magnetic Correlations, by B. Frandsen, X. Yang and S. J. L. Billinge, with an accompanying commentary article Reflections on the Magnetic Pair Distribution Function by W. Ratcliff, went online at the very end of 2013 as part of the January 2014 issue. Several other Advances submissions are now currently under review. The submission web pages have also been given a fresh new look as part of their development to include the voting system set up to allow the Section Editors to pre-filter Advances submissions before they are sent to a Co-editor for full peer review.

The scope of the journal has also widened over the triennium to welcome articles reporting fundamental advances in all areas of crystallography, including nanocrystals, metacrystals, amorphous materials, quasicrystals, synchrotron and XFEL studies, coherent scattering, diffraction imaging, timeresolved studies and the structure of strain and defects in materials. Traditional crystallography, as applied to periodic crystals, continues to be a rich and dynamic field. However, for Acta $A$ to overlook the exciting developments in crystallography more broadly defined above would be folly and would risk it losing its pre-eminent position as the premier journal describing foundations in structure science.

After two years of exceptionally high values (reflecting the high number of citations of the article on SHELX by George Sheldrick, which was published in 2008), the impact factor has returned to a more normal level of 2.24. The high number of submissions to the journal in 2011 and 2012 may be a consequence of the very high values of the impact factor for 2009 and 2010.

The triennium saw the publication of two Special Issues commemorating 100 years of X-ray diffraction. The January 2012 issue featured four articles and an editorial celebrating the Laue centennial. These articles were simultaneously published in Zeitschrift für Kristallographie, with Walter Steurer and Wolfgang Schmahl acting as joint Editors. Towards the end of 2012, the second Special Issue, a collection of articles contributed by speakers at the Bragg Centennial Symposium in Adelaide, Australia, on 6 December, was published online to coincide with the symposium, and then in print as the first issue of 2013. Steve Wilkins acted as Guest Editor for these articles. Both Special Issues have been very well received. A further virtual Special Issue on mathematical crystallography, with Guest Editors Massimo Nespolo and Greg McColm, is due to appear online in 2014, and will feature eight articles gathered in part from the 2013 SIAM Conference on Mathematical Aspects of Materials Science.

Since the start of 2011, several Co-editors have retired from Acta A: André Authier, Charlie Carter, Philip Coppens, Paul

\begin{tabular}{lllllll}
\hline & 2008 & 2009 & 2010 & 2011 & 2012 & 2013 \\
\hline No. of submissions & 96 & 116 & 100 & 134 & 143 & 97 \\
Rejection rate (\%) & 33 & 39 & 40 & 40 & 33 & 39 \\
No. of published papers & 81 & 56 & 81 & 68 & 83 & 71 \\
$\quad$ research papers & 42 & 41 & 66 & 56 & 64 & 58 \\
$\quad$ short communications & 6 & 5 & 3 & 5 & 5 & 1 \\
lead articles & 0 & 1 & 1 & 0 & 0 & 0 \\
$\quad$ feature articles & 24 & 1 & 1 & 0 & 1 & 0 \\
editorial & 0 & 0 & 3 & 0 & 0 & 2 \\
abstracts & 2059 & 735 & 734 & 2087 & 527 & 599 \\
$\quad$ other & 9 & 8 & 7 & 7 & 13 & 10 \\
No. of open-access papers & 0 & 0 & 2 & 6 & 3 & 4 \\
No. of pages & 702 & 548 & 724 & 565 & 787 & 623 \\
Average length (pages) & 10 & 10.3 & 9.8 & 9.0 & 10.2 & 9.6 \\
Average publication time (months) & 5.3 & 5.0 & 5.7 & 4.7 & 5.1 & 5.3 \\
Impact factor & 2.05 & 49.93 & 54.33 & 2.07 & 2.24 & \\
5 year impact factor & 2.1 & 20.64 & 24.72 & 30.65 & 18.32 & \\
Cited half life (years) & $>10.0$ & $>10.0$ & 6.2 & 3.9 & $>10.0$ & \\
\hline
\end{tabular}

Fewster, Rick Millane, Manuel Perez-Mato, Kiyoaki Tanaka and Helmuth Zimmerman are all thanked for their sterling work for the journal. Peter Paufler has also retired as BookReview Editor, and has been succeeded by Massimo Nespolo. We have also recently welcomed Dave Keen and Laurie Marks to the Editorial Board. We thank Dieter Schwarzenbach and Walter Steurer for their hard work and vision as Section Editors before us, and note the sad loss of Steve Wilkins at the start of 2013, only a few weeks after he completed work on the Bragg Special Issue.

\section{S. J. L. Billinge and J. Miao, Editors}

\section{A5.1.3. Acta Crystallographica Section B}

During the 2011-2014 triennium Acta Crystallographica Section B continued to publish six issues per year, attracting interesting articles describing the results of research in structural science. The number of articles (pages) published in 2011, 2012 and 2013 were 57 (581), 79 (685) and 73 (633), respectively. Over the period 2008-2014 the rejection rate has varied only slightly within the range $34-40 \%$. The average length of article (10.7, 9.6 and 9.3 pages, respectively) appears to be reducing, while the average time to publication has fallen to 4.9 months. The average impact factor has risen moderately during the triennium and was 2.2 in 2012 [it had previously peaked at 5.4 in 2004 (following a Special Issue on Databases in 2002), then dropped to 1.9 in 2005; it rose steadily to 2.3 in 2008, but then dropped to 1.8 in 2009 and 2010 before rising to 2.3 in 2011].

Acta $B$ is undergoing major changes in order to increase the amount and quality of relevant science it publishes. Perhaps the most obvious change is the new subtitle Structural Science, Crystal Engineering and Materials, which is designed to signal the main scientific areas we are aiming to cover: structural science of compounds and materials in the widest sense, recognizing that structural knowledge is crucial to the understanding of physical and chemical phenomena and to designing new materials and supramolecular devices. The journal is developing a strong programme of Invited Articles and Special Issues in order to announce its renewed interests in these areas. 


\begin{tabular}{lllllll}
\hline & 2008 & 2009 & 2010 & 2011 & 2012 & 2013 \\
\hline No. of submissions & 134 & 138 & 96 & 121 & 112 & 167 \\
Rejection rate (\%) & 35 & 34 & 40 & 40 & 34 & 36 \\
No. of published papers & 91 & 90 & 73 & 57 & 79 & 73 \\
$\quad$ research papers & 81 & 76 & 71 & 52 & 67 & 63 \\
$\quad$ short communications & 5 & 4 & 0 & 1 & 4 & 3 \\
$\quad$ lead articles & 0 & 0 & 0 & 0 & 0 & 3 \\
$\quad$ feature articles & 0 & 3 & 1 & 1 & 1 & 0 \\
$\quad$ other & 5 & 7 & 1 & 3 & 7 & 4 \\
No. of open-access papers & 1 & 2 & 3 & 5 & 0 & 5 \\
No. of pages & 791 & 790 & 706 & 581 & 685 & 633 \\
Average length (pages) & 9.3 & 9.6 & 9.8 & 10.7 & 9.6 & 9.3 \\
Average publication time (months) & 5.0 & 4.9 & 5.2 & 4.6 & 4.7 & 4.9 \\
Impact factor & 2.34 & 1.80 & 1.83 & 2.29 & 2.18 & \\
5 year impact factor & 2.33 & 2.03 & 2.03 & 2.00 & 1.89 & \\
Cited half life (years) & $>10.0$ & $>10.0$ & $>10.0$ & $>10.0$ & $>10.0$ & \\
\hline
\end{tabular}

The journal has introduced the new category of Research Perspective article, where the main or sole author is an established leader in the development of a particular field. Such articles will typically put a clear emphasis on the author's own contributions. The journal will normally publish one article in this category per year.

Three Invited Articles, on Charge Flipping, the Generalized Invariom Database, and Crystal Structure Prediction, were published in 2013 and these have been promoted by means of a special booklet at the European Crystallographic Meeting and elsewhere. Two Special Issues will appear in 2014 (one on Crystal Engineering edited by Andrew Bond in February, the other on Non-Ambient Crystallography jointly edited by Dave Billing and Andrzej Katrusiak, in June): both will be promoted at the Montreal Congress. We wish to record our thanks to these Guest Editors for their truly exceptional efforts in bringing about the Special Issues. It was notable that $23.9 \%$ of the content of the Crystal Engineering Special Issue was attributable to papers from the South Asia region, which compares favourably with an average of $1.5 \%$ for regular papers over the last 6 years: it is essential that this progress is followed up. Further Invited Articles and Special Issues are underway or are being planned for the period 2014-2016, with a particular emphasis on materials.

Identifying willing, qualified and competent reviewers remains a challenge as pressure on their time continues to increase, but their contributions are invaluable and we wish to express our appreciation for their efforts in improving the quality of submissions and identifying outstanding science.

Among the many Chester staff who have contributed to Acta $B$, we particularly acknowledge the work of Jill Bradshaw in the role of Managing Editor. She plays a pivotal role not only in editing articles but also in coordinating the work of the Editors and developing the journal for the future.

Since the Madrid Congress, there have been a number of retirements from the Editorial Board of Acta B: Sander van Smaalen (Editor 2012-2013), Manuel Perez-Mato and Tim White. We thank them warmly for their many contributions to the work of the journal.

\section{A. J. Blake and M. de Boissieu, Editors}

\section{A5.1.4. Acta Crystallographica Section C}

The strength of Acta $C$ for many years has been the rapid publication of high-quality studies of novel and challenging crystal and molecular structures of interest in the fields of chemistry, biochemistry, mineralogy, pharmacology, physics and materials science.

However, at the start of the triennium it was clear that the journal had been experiencing a steady decline in the number of submissions over a period of years. This coincided with a decision by the IUCr to review all of its publishing activities. As part of this process it was decided to look at how Acta C might be improved both in terms of appeal to a wider scientific audience and impact.

At the beginning of 2013, the Editor-in-Chief met in Chester with me and Sandy Blake (a Section B main editor) to lay plans for a revamp of Acta $C$. It was decided to broaden the scope of Acta $C$ and to make it more attractive to a broader range of scientists than just crystallographers. As the chemical sciences are a huge area in which structure plays an important role, it was felt that this was a principal community to orient Acta $C$ towards. The subtitle of the journal was changed to Structural Chemistry at the beginning of 2014 and the scope widened to reflect the fact that small-molecule crystallography undeniably plays a crucial role in most aspects of the chemical sciences. Acta $C$ now specializes in the rapid publication of articles that highlight interesting science and research enabled by the determination, calculation or analysis of small-molecule crystal and molecular structures, with a view to how the structural observations help the understanding of a chemical, physical or structural question being investigated.

In order to inaugurate the new scope of the journal and demonstrate to readers and potential authors the types of papers that the journal is keen to attract, an Editorial was published in April 2013 and four Special Issues were published between September 2013 and February 2014; we are very excited about the quality and breadth of papers in these issues. The Guest Editors did a splendid job of soliciting excellent papers for these Special Issues and it is anticipated that these papers will be highly cited and give a clear indication of the sort of work Acta $C$ would now like to publish. Some very positive comments have been received. For the time being, the traditional style and length of Acta $C$ papers will continue to be accepted, but the long-term aim is to bring Acta $C$ papers up to a similar level to those found in Acta B. The published Special Issues are described below.

The first Special Issue was on Scorpionates (Guest Editor: Glenn P. A. Yap, Department of Chemistry and Biochemistry, University of Delaware, USA; September 2013) and included contributions from some of the best authors in the field of this chemically important family of prolific and work-horse ligands wherein the structure has a palpable effect on reactivity.

The next Special Issue was titled Pharmaceuticals, Drug Discovery and Natural Products (Guest Editor: Christopher S. Frampton, Pharmorphix, Cambridge, UK; November 2013) and addressed and discussed the timeless questions of polymorphism, stereochemistry and $\mathrm{H}$-atom position. The structural data presented originates not just from X-ray analyses, 


\begin{tabular}{lllllll}
\hline & 2008 & 2009 & 2010 & 2011 & 2012 & 2013 \\
\hline No. of submissions & 751 & 687 & 592 & 479 & 504 & 609 \\
Rejection rate (\%) & 60 & 52 & 53 & 50 & 49 & 41 \\
No. of published papers & 332 & 331 & 284 & 239 & 232 & 354 \\
$\quad$ research papers & 328 & 328 & 280 & 234 & 229 & 345 \\
$\quad$ editorial & 1 & 1 & 0 & 2 & 2 & 4 \\
$\quad$ other & 3 & 2 & 4 & 3 & 1 & 5 \\
No. of open-access papers & 2 & 1 & 1 & 0 & 0 & 0 \\
No. of pages & 1197 & 1258 & 1134 & 993 & 984 & 1566 \\
Average length (pages) & 3.6 & 3.8 & 4.0 & 4.2 & 4.2 & 4.5 \\
Average publication time (months) & 1.8 & 1.9 & 1.9 & 2.0 & 2.0 & 2.1 \\
Impact factor & 0.56 & 0.78 & 0.75 & 0.52 & 0.49 & \\
5 year impact factor & 0.57 & 0.70 & 0.63 & 0.44 & 0.40 & \\
Cited half life (years) & $>10.0$ & $>10.0$ & $>10.0$ & $>10.0$ & $>10.0$ & \\
\hline
\end{tabular}

but also from NMR and computational studies, thus demonstrating the widened scope of the journal.

The effort on refocusing the journal in 2013 culminated in the third Special Issue, on Interplay of Crystallography, Spectroscopy and Theoretical Methods for Solving Chemical Problems (Guest Editors: Larry Falvello, Universidad de Zaragoza, Spain, and Alberto Albinati, Universita degli Studi di Milano, Italy; December 2013). This issue presented research articles and scientific comments demonstrating that the vast utility of structure determination is manifest in other techniques in addition to single-crystal diffraction analysis, and that a description of structure can derive immense leverage from physical measurements and computational modelling.

The beginning of 2014 saw the move to full electronic publication for Acta $C$ and the journal launch fully into its science-facing mission as an outlet for research in structural chemistry in its broadest sense. The most recent Special Issue, on Computational Materials Discovery (Guest Editor: Artem Oganov, Center for Materials by Design, State University of New York, USA; February 2014), highlights the two most important breakthroughs of this field, i.e. crystal structure prediction and electronic structure calculations, and their applications to specific problems of materials science.

In 2013, partly as a consequence of these Special Issues, Acta $C$ proudly published more pages than it has done since the year 2000. The fall in impact factor for Acta C in 2011/2012 is linked to the absence of Acta E from the citation analyses.

Two virtual Special Issues, one on polymorphism and one on absolute structure, were also published during the last triennium. A virtual issue on metal-organic frameworks will be published during 2014.

The Notes for Authors have been rewritten significantly and reduced in length. Much of the prescriptive material has been removed in an attempt to make the instructions less intimidating for non-specialist authors. Some of the removed material has been placed in help documents available in the web pages. It has been recognized that some authors, who are not specialist crystallographers, struggle to prepare their manuscripts entirely in CIF format and a myth has developed that it is very difficult and complex to prepare a paper for Acta $C$. To alleviate this, Acta $C$ now offers the option of submitting the text parts of a manuscript as a Word document and publCIF has been improved and extended to make preparing a paper in CIF format as simple as possible. Text written with Word can even be pasted into publCIF and it is automatically converted into the necessary CIF markup text. The advantage of publCIF is that it ensures the CIF syntax is retained and has many tools to help, for example, with creation of tables and ensuring that the reference list is consistent with the citations in the text.

A further plan is to establish a panel of reviewers, much along the lines of that already in use by Acta F. Potential panel members have already been approached and it is hoped the panel will come into operation during 2014. The use of a review panel should help to alleviate the severe difficulties many Co-editors face in being able to obtain even a single review on the papers they are handling, despite sending out several invitations. The poor etiquette of reviewers not even reacting to requests is a problem.

It is also envisaged that at least one additional Main Editor will be appointed for Section C during 2014, so as to have prime expertise in all of the areas the journal is covering, to make the journal more visible to authors and readers in these areas, and to relieve the burden on the existing Main Editor.

Through the above-mentioned endeavours, it is hoped to increase the attractiveness of Acta $C$ to prospective authors and to increase the impact factor of the journal to well above 1.0 within the next $2-3$ years. To this end it is imperative that Acta $C$ be promoted strongly and visibly by the IUCr Chester office. A strong advertising campaign and a presence of IUCr journals at some of the large and important chemistry conferences over the next few years will be very important. IUCr journals advertising material could be inserted into conference bags at these meetings. A steady stream of Special Issues is also being considered for the coming years.

I wish to thank warmly all the Acta C Co-editors who have given generously of their time, expertise and effort during the reporting period, as well as the many reviewers and authors, without whom the journal could not exist. I am also grateful to Sandy Blake (prior to 2013) and then Larry Falvello, Deputy Section Editors, for their input and assistance with the proofreading of manuscripts. The invaluable support of the Editorial Office staff is much appreciated, in particular the tireless efforts of Sean Conway, Mike Hoyland, Peter Strickland and the technical editors.

\section{A. Linden, Editor}

\section{A5.1.5. Acta Crystallographica Section D}

Section D of Acta Crystallographica has done extremely well in the past three years. Its impact factor has increased from 2.26 in 2009 to 14.10 for the year 2012, in spite of serious competition from many other well established and new journals publishing macromolecular crystallographic results. Section D continues to publish articles describing new methodological advances as well as results of structural studies relevant to biology and medicine. Whereas Acta $D$ is the primary venue for papers on crystallographic methods, it is in the structural arena where it faces strong competition from other journals. The increased impact factor has encouraged a 


\begin{tabular}{lllllll}
\hline & 2008 & 2009 & 2010 & 2011 & 2012 & 2013 \\
\hline No. of submissions & 191 & 205 & 201 & 239 & 340 & 433 \\
Rejection rate (\%) & 19 & 19 & 22 & 26 & 29 & 27 \\
No. of published papers & 152 & 160 & 167 & 131 & 193 & 274 \\
$\quad$ research papers & 135 & 136 & 148 & 119 & 173 & 250 \\
$\quad$ short communications & 13 & 16 & 11 & 5 & 8 & 9 \\
$\quad$ feature articles & 0 & 0 & 0 & 0 & 0 & 1 \\
$\quad$ editorial & 1 & 1 & 4 & 0 & 2 & 2 \\
$\quad$ other & 3 & 7 & 4 & 7 & 10 & 12 \\
No. of open-access papers & 33 & 43 & 37 & 27 & 39 & 78 \\
No. of pages & 1294 & 1349 & 1354 & 1077 & 1700 & 2584 \\
Average length (pages) & 9.1 & 9.1 & 8.7 & 8.8 & 9.4 & 10.1 \\
Average publication time (months) & 4.4 & 4.5 & 5.1 & 4.0 & 5.1 & 5.5 \\
Impact factor & 2.94 & 2.26 & 6.33 & 12.62 & 14.10 & \\
5 year impact factor & 1.83 & 2.01 & 4.10 & 7.04 & 7.54 & \\
Cited half life (years) & 9.7 & 9.4 & 9.0 & 6.9 & 6.6 & \\
\hline
\end{tabular}

huge increase in structural papers, including many of high biological importance. These will raise the profile of the journal further. The increased number of published papers, from 131 (1077 pages) in 2011 to 274 (2584 pages) in 2013 has had some impact on publication times, which have lengthened from 4.0 months in 2011 to 5.5 months in 2013. This suggests a need for debate as to whether rejection rates (currently just under $30 \%$ ) should increase to maintain more rapid publication.

One very popular feature of Acta $D$, highly appreciated by the community, is the traditional Special Issue each year documenting the proceedings of the CCP4 Study Weekends. These contain many important methodological papers, devoted each year to a selected topic of macromolecular crystallography. In 2011 the topic was Model Building, Refinement and Validation and proceedings were published in April 2012, guest-edited by the conference organizers Roberto Steiner and Bernhard Rupp. In 2012 the theme was Data Collection and Processing, with the conference Special Issue, in July 2013, organized by Johan Turkenburg and Katherine McAuley. This issue also contained four papers edited by Chris Morris, based on presentations delivered at the workshop Integrated Software for Integrative Structural Biology a year earlier. Most recently, the 2013 CCP4 Study Weekend, organized by Helen Walden and Pietro Roversi on Molecular Replacement, will be featured in a Special Issue of Acta D in mid-2014. We are very indebted to all Guest Editors, who helped to prepare these Special Issues of the journal.

Four short editorials were published in 2012/2013. The first highlighted a new set of guidelines for structural modelling based on small-angle-scattering data, which was published in the same issue of Acta D. The second commented on the Nobel Prize in Chemistry awarded in 2012 to Robert Lefkowitz and Brian Kobilka for their structural studies of Gprotein-coupled receptors. In 2013 we celebrated the 20th birthday of Acta $D$ with an Editorial, and later in the year joined with our Acta $F$ colleagues, Manfred Weiss and Howard Einspahr, to address the problems of expectation bias, which can lead to misinterpretations that could be avoided by proper validation of structural results.

Although 'Biological Crystallography' remains the main focus of Acta Crystallographica Section D, it was decided during 2013 to widen the scope by encouraging the submission of papers based on other biostructural techniques that complement crystallography, such as small-angle scattering and electron microscopy. A number of such papers have recently been submitted to Acta $D$, and we envisage that in the future we will see many more papers in which several approaches are combined to address the structures of large and important biological complexes. We would like Acta D to be a natural home for such papers.

The electronic system of submissions continues to work very well for authors as well as the editors and reviewers. The quality of the journal is very high owing to the expert work of Louise Jones and Simon Glynn at the Chester Office. We thank them and Executive Managing Editor Peter Strickland, and Samar Hasnain, Editor-in-Chief, for their valuable help.

Last, but not least, Soichi Wakatsuki from Stanford, USA, and Randy Read from Cambridge, UK, have joined the editorial board of Acta D as Section Editors in 2013. With this expansion of our team we hope to ensure further enhancement of the stature and respect that Acta D holds in the community.

\section{E. N. Baker, Z. Dauter, R. J. Read and S. Wakatsuki,} Editors

\section{A5.1.6. Acta Crystallographica Section E}

The years 2011-2013 have seen a number of developments for the journal, both positive and negative.

In 2011 we saw an increase of submissions and accepted papers of $c a 7.5 \%$. At the beginning of 2012 the number of submissions continued to be high but Thomson Reuters announced that Acta $E$ would no longer to be indexed in the Science Citation Index Expanded. The latest issue covered was February 2012.

This has had important consequences as the Science Foundations and grant awarding and promotion boards of some countries will no longer consider publications in journals with no Citation Index (CI) as significant scientific contributions.

The distribution of papers by country remained approximately constant for 2011 and 2012 but owing to the withdrawal of our CI in 2012 the number of papers from some countries, in Asia for example, fell dramatically.

In $201147 \%$ of papers had the authors from the People's Republic of China, $8 \%$ from India and Malaysia, 5\% from Pakistan, $4 \%$ from the USA and Germany, 3\% from Turkey and smaller percentages from other countries; in total, authors from 75 countries published in Acta E during 2011. There followed a sharp decrease in the submissions from the People's Republic of China to $38 \%$ of the total but this was adequately compensated by increased submissions particularly from Malaysia to $12 \%$ and with smaller increases from a number of other countries.

Despite these annual variations, the open-access environment of the journal is fully established but the future of the journal is insecure.

Significant developments in 2011. In August 2010, the Section Editor of the journal, Jim Simpson withdrew but has 


\begin{tabular}{lllllll}
\hline & 2008 & 2009 & 2010 & 2011 & 2012 & 2013 \\
\hline No. of submissions & 3846 & 5113 & 5128 & 5471 & 4605 & 2123 \\
Rejection rate (\%) & 16 & 18 & 18 & 19 & 17 & 15 \\
No. of published papers & 3556 & 4166 & 4113 & 4444 & 4047 & 1964 \\
$\quad$ research papers & 3533 & 4151 & 4091 & 4434 & 4039 & 1961 \\
$\quad$ editorial & 1 & 1 & 1 & 0 & 0 & 0 \\
$\quad$ other & 22 & 14 & 21 & 10 & 8 & 3 \\
No. of open-access papers & 3556 & 4166 & 4113 & 4444 & 4047 & 1964 \\
No. of pages & 4261 & 5108 & 5195 & 5523 & 5171 & 2637 \\
Average length (pages) & 1.2 & 1.2 & 1.3 & 1.2 & 1.3 & 1.3 \\
Average publication time (months) & 0.8 & 0.7 & 0.7 & 0.7 & 0.7 & 0.8 \\
Impact factor & 0.37 & 0.41 & 0.41 & 0.35 & & \\
5 year impact factor & 0.37 & 0.38 & 0.34 & 0.28 & & \\
Cited half life (years) & 2.4 & 2.7 & 3.1 & 3.3 & & \\
\hline
\end{tabular}

remained as our forensic advisor concerning potentially fraudulent structures, and also remains as a Co-editor.

He was replaced by Helen Stoeckli-Evans from Switzerland and Edward Tiekink from Malaysia, who complete the team with Bill Harrison from Scotland and Matthias Weil from Austria.

The year in general was very successful with 4444 published papers.

Significant developments in 2012. This year was marred by Thomson Reuters announcement that Acta E would no longer be indexed in the Science Citation Index Expanded. The fall in submissions was slow to take effect as many authors did not realize that eventually their Science Foundations and grant awarding boards would no longer consider publications in journals with no Citation Index (CI) as significant scientific contributions. This has a serious effect on their promotions prospects and so they are now looking to publish in other journals.

The checkCIF software is under continual development thanks to the efforts of Ton Spek and Mike Hoyland. With the introduction of the latest version of SHELX by George Sheldrick, who has incorporated a number of suggestions made by various editors of Acta journals, especially the incorporation of the *.res and *.hkl files in the CIF, tests on the structure analyses can be carried out quickly and efficiently.

Significant developments in 2013. This has been a challenging year for the journal with the consequences of the withdrawal by Thomson Reuters of the Citation Index in March 2012 being felt by the reduction of approximately 50\% in submissions. Already in the summer of 2012 the Section Editors began thinking of new ways of presenting the work published in the journal and a working party was also convened to look at this issue in summer 2013. The aim is to convince Thomson Reuters to review the situation and again include Acta E in the Science Citation Index Expanded, by the latest in 2016.

As always we are extremely grateful to our Co-editors for the excellent work they have done and cannot thank them enough. Without their commitment, generally acting as referees as well as Co-editors for the papers they receive, this journal would not exist. We have been particularly fortunate in the past year to recruit a number of new Co-editors to join the journal's hard-working team that now numbers 58, including the four joint Section Editors. We also gratefully acknowledge the work of several Co-editors who have retired over the past three years. Thanks also to a number of Coeditors who, having achieved nine years of tireless service to the journal, will also be leaving the team after the Montreal Congress. We are delighted to announce that the Executive Committee has appointed Luc Van Meervelt, as a new Section Editor from 2014.

As always we are extremely grateful for the excellent support that we receive from the staff in Chester, in particular Gillian Holmes, Sean Conway and Mike Hoyland, for their constant help and support, and to Peter Strickland for his sound advice and continued expert guidance.

\section{W. T. A. Harrison, H. Stoeckli-Evans, E. R. T. Tiekink and M. Weil, Editors}

\section{A5.1.7. Acta Crystallographica Section F}

Acta $F$ was launched as the IUCr's first online-only biological journal in 2005. In its third triennium, the journal solidified its position as the home for the rapid publication of structure and crystallization communications on biological macromolecules. In order better to reflect this in the title of the journal, the title was shortened from Crystallization and Structural Biology Communications to Structural Biology Communications at the beginning of 2013. In the years 20112013 the journal published 1082 papers and 4692 pages. This represents an increase of about $10 \%$ compared to the second triennium. The average time from submission to publication, including peer review, increased to a high of 3.9 months in 2011 and then decreased again to a more acceptable 2.8 months in 2013. The temporary increase may be a consequence of the publishing of structural genomics Special Issues, but it may also be due to an increase in the length of papers from 4.0 pages in 2008 to 4.4 pages in 2013. Despite our mandate for rapid publication, this trend toward increasing length is a welcome one if it offers greater detail about important aspects such as the inclusion of more biochemical or biological data.

An important achievement of the last triennium was the significant improvement of publBio. publBio is a publication tool developed in Chester that streamlines the drafting of standard crystallization or structural communications for authors. It also helps editors to process such papers and helps referees to evaluate them. Progress was such that submission of crystallization communications through publBio was made mandatory for authors as of the beginning of 2014. We expect these publBio-generated papers will prove to be even more useful to our readers and to the scientific community as a whole.

The referee panel, which was created in the second triennium, continues to function well. This group of about 30 experienced scientists, who have agreed to referee 12 papers a year, to reply to requests promptly, and to return reports within two weeks, can potentially provide half the number of referee reports needed in any publication year. The panel has also provided a pool of potential recruits for new Co-editors and a number of panel members were promoted to Co-editors 


\begin{tabular}{lllllll}
\hline & 2008 & 2009 & 2010 & 2011 & 2012 & 2013 \\
\hline No. of submissions & 349 & 422 & 421 & 401 & 375 & 380 \\
Rejection rate (\%) & 10 & 9 & 9 & 8 & 9 & 8 \\
No. of published papers & 302 & 333 & 377 & 385 & 362 & 335 \\
$\quad$ research papers & 293 & 328 & 362 & 365 & 351 & 321 \\
$\quad$ editorial & 5 & 2 & 4 & 3 & 3 & 5 \\
$\quad$ other & 4 & 3 & 11 & 17 & 8 & 9 \\
No. of open-access papers & 8 & 11 & 41 & 41 & 15 & 20 \\
No. of pages & 1187 & 1319 & 1684 & 1674 & 1576 & 1442 \\
Average length (pages) & 4.0 & 4.0 & 4.5 & 4.4 & 4.4 & 4.4 \\
Average publication time (months) & 2.6 & 2.8 & 3.6 & 3.9 & 3.2 & 2.8 \\
Impact factor & - & - & 0.56 & 0.51 & 0.55 & \\
5 year impact factor & 0.37 & 0.38 & 0.48 & 0.46 & 0.49 & \\
Cited half life (years) & 2.3 & 2.7 & 2.7 & 3.2 & 3.5 & \\
\hline
\end{tabular}

in the last triennium. Needless to say, other reviewers are asked for input as well, depending on the subject matter, and collectively the high standard of the reports and commitment from reviewers is a noteworthy strength of Acta F. We as Editors remain grateful to those community-minded individuals, who review with rigour and in a constructive manner, for their support of our journal.

Another item of note in the last three years is a metric we keep an eye on, but one we believe has not been remarked upon in previous reports. It shows the steady progress in increasing percentage of scientific peer-reviewed articles that are structure or laboratory communications or scientific comment. In the first triennium, that fraction averaged about $14 \%$, in the second it increased to roughly $20 \%$, helped by the first of our structural genomics Special Issues, but in the latest triennium, it hovered between 25 and $26 \%$ all three years. This welcome trend appears to be continuing, because, as of the first four issues of 2014, that fraction is $28 \%$.

Importantly, though, the journal remains a high-quality publication and has been included in Medline and other abstracting and indexing services. Its current impact factor (for 2012) is 0.55 . Currently, a detailed statistical analysis of all published papers is underway with the aim of learning where and when our papers are being cited. The ambition is to increase our visibility and raise the journal impact factor to 1.0 or above within the next triennium. Strategies towards this goal are presently being explored and discussed.

\section{S. Weiss, W. N. Hunter and H. M. Einspahr, Editors}

\section{A5.1.8. Journal of Applied Crystallography}

Over the past three years, Journal of Applied Crystallography has seen a steady rise in the number of submissions, and 2013 saw a significant increase in the page count and number of published articles. This increase was in part the result of the publication of three Special Issues in 2013/2014 but also reflects an underlying trend in standard article submissions. The impact factor remains good.

The journal's first virtual Special Issue, on X-ray Diffraction Microscopy (Guest Editor Andras Borbély), was published in March 2013. This issue collects together a series of specially commissioned articles that were originally published in the

\begin{tabular}{lllllll}
\hline & 2008 & 2009 & 2010 & 2011 & 2012 & 2013 \\
\hline No. of submissions & 258 & 282 & 309 & 266 & 321 & 432 \\
Rejection rate (\%) & 39 & 34 & 32 & 34 & 30 & 36 \\
No. of published papers & 161 & 172 & 222 & 180 & 180 & 255 \\
$\quad$ research papers & 117 & 126 & 165 & 131 & 127 & 193 \\
$\quad$ short communications & 9 & 9 & 11 & 8 & 6 & 11 \\
$\quad$ lead articles & 1 & 0 & 0 & 0 & 0 & 0 \\
$\quad$ computer programs & 21 & 19 & 26 & 24 & 26 & 22 \\
$\quad$ editorial & 0 & 0 & 2 & 0 & 0 & 2 \\
$\quad$ other & 13 & 18 & 18 & 17 & 21 & 27 \\
No. of open-access papers & 10 & 11 & 10 & 6 & 6 & 41 \\
No. of pages & 1197 & 1212 & 1543 & 1306 & 1338 & 1913 \\
Average length (pages) & 8.5 & 7.9 & 8.0 & 8.1 & 8.4 & 8.3 \\
Average publication time (months) & 5.8 & 5.4 & 5.7 & 5.1 & 5.4 & 5.7 \\
Impact factor & 3.21 & 3.02 & 3.79 & 5.15 & 3.34 & \\
5 year impact factor & 4.87 & 3.82 & 4.19 & 5.66 & 4.48 & \\
Cited half life (years) & $>10.0$ & $>10.0$ & $>10.0$ & $>10.0$ & $>10.0$ & \\
\hline
\end{tabular}

journal between August 2012 and April 2013. It focuses on novel diffraction methods that enable visualization of the internal structure of crystalline materials from the millimetre down to the nanometre scale.

The second Special Issue of 2013, published as part of the August 2013 issue, brought together some highlights of the 11th Biennial Conference on High-Resolution X-ray Diffraction and Imaging (XTOP), held in St Petersburg, Russia, in 2012. The Guest Editors were Paul F. Fewster, Marina V. Baidakova and Reginald Kyutt.

Finally, a second virtual Special Issue, on Small-Angle Scattering (Guest Editors Elliot P. Gilbert and Andrew J. Allen), was published in February 2014. The articles in this issue are based on work presented at the 15th International Small-Angle Scattering Conference (SAS2012) and provide an overview of the state of the art across the spectrum of small-angle neutron and X-ray scattering, covering the fields of application, theory, methods of analysis and instrumentation.

Two additional Main Editors were appointed in 2014: Janos Hajdu (Uppsala University) and former Deputy Editor Andrew J. Allen (NIST). The journal was also pleased to welcome four new Co-editors (Juan Manuel García-Ruiz, Václav Holy, Dhananjai Pandey and Thomas Proffen). The high level of submissions over the past year has meant that the Co-editors of the journal have seen a substantial increase in workload in this period. It is therefore intended that several additional new Co-editors will be appointed during 2014. We would like to take this opportunity to thank all of the Coeditors who have served the journal during this triennium for their hard work and dedication.

\section{A. J. Allen, J. Hajdu and A. Kaysser-Pyzalla, Editors}

\section{A5.1.9. Journal of Synchrotron Radiation}

In this triennial period the journal added two Main Editors: J. Friso van der Veen (Head of Research Department Synchrotron Radiation and Nanotechnology, Paul Scherrer Institut and Professor of Experimental Physics, ETH-Zürich, Switzerland) and Ilme Schlichting (Director, Department of 


\begin{tabular}{lllllll}
\hline & 2008 & 2009 & 2010 & 2011 & 2012 & 2013 \\
\hline No. of submissions & 140 & 166 & 186 & 191 & 228 & 245 \\
Rejection rate (\%) & 31 & 21 & 27 & 28 & 22 & 26 \\
No. of published papers & 120 & 132 & 114 & 146 & 154 & 155 \\
$\quad$ research papers & 73 & 109 & 96 & 123 & 124 & 130 \\
$\quad$ short communications & 37 & 8 & 5 & 8 & 6 & 8 \\
$\quad$ feature articles & 0 & 0 & 2 & 0 & 0 & 0 \\
$\quad$ beamlines & 0 & 0 & 0 & 1 & 9 & 4 \\
$\quad$ editorial & 0 & 0 & 0 & 2 & 1 & 1 \\
$\quad$ other & 10 & 15 & 11 & 12 & 14 & 12 \\
No. of open-access papers & 35 & 11 & 25 & 42 & 29 & 65 \\
No. of pages & 666 & 883 & 816 & 948 & 1066 & 1012 \\
Average length (pages) & 5.8 & 7.5 & 7.7 & 7.0 & 7.3 & 7.0 \\
Average publication time (months) & 6.4 & 5.3 & 5.2 & 5.4 & 4.9 & 4.7 \\
Impact factor & 2.33 & 1.99 & 2.34 & 2.73 & 2.19 & \\
5 year impact factor & 2.63 & 2.83 & 3.11 & 2.57 & 2.23 & \\
Cited half life (years) & 6.2 & 6.1 & 6.4 & 6.6 & 7.5 & \\
\hline
\end{tabular}

Molecular Mechanisms, Max Planck Institute, Heidelberg, Germany). Paul Zschack (Brookhaven National Laboratory, USA) has agreed to serve as Current-Events Editor together with Friso van der Veen.

The past years have seen a healthy growth of submissions at constant impact factor and rejection rate. In the category Beamline Papers there is further potential for growth. The purpose of these papers is to provide users of the beamline, notably in life sciences, a good reference to be included in their publications. It is important that beamline parameters at which user experiments are performed are properly on record. In addition, inclusion of such references in user publications provides proper credit to the facilities and their staff for their services. Last but not least, Beamline Papers have the potential to improve the journal's impact factor.

The advent of VUV and X-ray free electron lasers (FELs) provides a great opportunity for the journal to attract new readers and authors. The journal actively solicits FEL machine and instrumentation papers in this category, but the response within the community has been modest so far. Broader promotion to publish FEL papers in the journal is needed - for example, by attracting Co-editors working at FEL laboratories.

In the coming years new synchrotron radiation facilities will come online and existing ones will be upgraded substantially. So-called multi-bend achromat (MBA) enabled storage ring lattices will provide significantly higher brilliance and neardiffraction-limited conditions over a substantial wavelength range. It is important that the journal provides a platform for publications describing MBA technology and their applications in science. A Special Issue of the journal on DiffractionLimited Storage Rings and New Science Opportunities will appear mid-2014. Editors of this Special Issue are Mikael Eriksson and Friso van der Veen. It is hoped that the growing community building these sources or making use of them will see the journal as their prime publication medium for communicating results, not only on instrumentation and methods, but also on applications.

\section{G. Ice, I. Schlichting and J. F. van der Veen, Editors}

\section{A5.2. Commission on International Tables}

The book series International Tables for Crystallography is published by the IUCr in conjunction with Wiley. The series currently includes eight Volumes designated A (and A1) through G. All eight volumes are available in print and online.

A print edition of the Brief Teaching Edition of Volume A is available at a modest cost. Volume H Powder Diffraction will be published in 2014 .

Symmetry information is covered in Volumes A (SpaceGroup Symmetry), A1 (Symmetry Relations between Space Groups), and E (Subperiodic Groups). Information about the influence of symmetry on the physical and tensor properties of crystals and on their structural phase transitions is found in D (Physical Properties of Crystals). Information on superspace symmetry is currently located in C (Mathematical, Physical and Chemical Tables). An extensive electronic Symmetry Database is available to subscribers to the online version of the series.

Additional information of a general type is included in Volumes B (Reciprocal Space) and C, which can be traced back to Volume II of the original series (1937) and Volumes II-IV of the series with red covers (1959-1974).

The other Volumes of the series can be described as handbooks that cover more specific areas. These Volumes are F (Crystallography of Biological Macromolecules), G (DefiDefinition and Exchange of Crystallographic Data), and the nearly finished ninth Volume H (Powder Diffraction).

Developments in the triennium 2011-2013 include:

(1) Near completion of a new version of Volume A (edited by Mois Aroyo). The new electronic version will include Seitz symbols [see Acta Cryst. (2014) A70, (doi:10.1107/ S2053273314004495)], which have been a topic of considerable discussion in the Commission during the last several years. The Editors of Volume E (Vojtech Kopský and Danny Litvin) took leading roles in these deliberations.

(2) Very considerable development of the Symmetry Database (also edited by Mois Aroyo). This electronic resource simplifies discussion of non-standard space-group settings, which are often appropriate when phase sequences are being considered, and facilitates identification of group/ subgroup/supergroup relationships. The Editor of Volume A1 (Ulrich Müller) is also involved in the development of this database.

(3) Planning for substantial revisions of Volumes B and C. These two volumes are the successors of Volume II of the original series (1937) and Volumes II-IV of the 'red' series (1959-1974). Over the years the two Volumes have grown by accretion (especially $\mathrm{C}$ ) to the point of being difficult to describe. Furthermore, many of the tables (e.g., X-ray scattering factors) need no longer be printed although having them available in an authoritative electronic form is important. The current Editors (Gervais Chapuis, who was appointed for B in 2011, and Richard Welberry) are working closely together on very major revisions. The plan has been for $\mathrm{B}$ to focus on topics more related to its current title (reciprocal space) and for $\mathrm{C}$ to cover topics more connected to direct 
space, but it has become clear that such a simple division of topics is impossible.

(4) A revised edition of D (Editor André Authier) appeared online in late 2013 and will appear in print in 2014. It included one completely new chapter, new sections in two other chapters, and updates of a number of additional chapters.

(5) A substantially revised edition of Volume F (Editors Eddy Arnold, Daniel Himmel and Michael Rossmann) appeared in late 2011/early 2012. This second edition dropped five articles from the first volume, updated 26, and added 19. The revised volume covers a range of topics in macromolecular crystallography and in allied fields such as electron microscopy.

(6) Retirement of Syd Hall as an Editor of Volume G after the 2013 ECM meeting in Warwick during which a specialist workshop on building DDLm dictionaries and tools for CIF took place. Plans for the future are being discussed with Brian McMahon, who is the remaining Editor.

(7) Creation of Volume H (Powder Diffraction), which has gone from an outline to near publication during the triennium under the direction of Chris Gilmore, Henk Schenk and Jim Kaduk. Publication is expected during 2014. A novel feature will be the very extensive digital material that will be available with the electronic version. Many authors have included raw diffraction data discussed in their chapters so that the reader may reproduce the data processing that is discussed.

(8) Planning of a new Volume on XAFS. Editor Chris Chantler and Joint Main Editors Federico Boscherini and Bruce Bunker were appointed during the latter part of 2013.

(9) Discussions with the Commission on Magnetic Structures about a Volume covering their field. As a preliminary step Danny Litvin's tables of magnetic (or, black/white or, time-reversal) space groups have been published electronically by the IUCr (http://www.iucr.org/publ/978-0-95536022-0) and can be downloaded freely.

Further information about the volumes can be found at the home page of the Commission, http://www.iucr.org/resources/ commissions/international-tables. The Guided Tour available at http:/it.iucr.org/services/guidedtour/ is highly recommended because it shows what is available electronically. Access to the Tables of Contents of all the volumes is free, as are sample pages (including author lists and prefaces); see the home pages for the individual volumes (e.g., http://it.iucr.org/ $\mathrm{Fb} /$ ). Links to published reviews for the individual volumes are given at the bottoms of their home pages.

As mentioned above, Syd Hall (Editor of Volume G Definition and Exchange of Crystallographic Data) has announced his retirement from the Commission. Syd is very warmly thanked for his many contributions to the International Tables series and for his central role in developing the CIF format.

It is impossible to end this report without thanking the staff in Chester, and especially Nicola Ashcroft, for all that office does to help Editors and authors plan, produce, and revise the Volumes of this series. The people in Chester also create and maintain the web pages that explain and advertise the volumes.

\section{P. Brock, Chair}

\section{A5.3. Commission on Aperiodic Crystals}

The last three years were particularly exciting for the Commission, with the award of the 2011 Nobel Prize in Chemistry to our colleague Dan Shechtman for his discovery of quasicrystals, and the announcement of the upcoming award of the Tenth Ewald Prize to our colleagues Aloysio Janner and Ted Janssen for their development of superspace crystallography. The Nobel Prize, awarded almost 30 years after the discovery of quasicrystals, served to invigorate the whole community, and helped to introduce the notion of aperiodic crystals to the greater scientific community as well as to the general public. The Prize inspired the organization of special meetings and sessions throughout the last three years, as well as the publication of special journal issues and books dedicated to aperiodic crystals. We hope that the Ewald Prize will have a similar effect in promoting the study of aperiodic crystals within the wider crystallographic community.

Official meetings of Commission in the last triennium took place during the Madrid Congress and during Aperiodic 2012, held in September 2012 in Cairns, Australia. Other Commission business was conducted via e-mail, as well as through informal meetings of Commission members and consultants at various national and international conferences and workshops. As always, the Commission continued actively to promote aperiodic crystallography, in organizing, supporting, and promoting meetings, workshops, and educational activities worldwide. In doing so, the Commission continued its ongoing coordination of interaction between the various subcommunities and disciplines involved in the different aspects of research in aperiodic crystals.

During this triennium the Commission integrated its web site with the highly popular and active web site of the Special Interest Group (SIG) on aperiodic crystals of the European Crystallographic Association. The new joint web site is dedicated to all aspects of the crystallography of aperiodic crystals. It is maintained by Michal Dusek, and is now up and running and can be accessed at http://aperiodic.iucr.org/.

International Conferences. The central activity for the Commission in 2011 was its active participation and promotion of aperiodic crystals at the Madrid Congress. This included three very successful Keynote Lectures and six Microsymposia related to aperiodic crystals, which the Commission helped organize.

The central activity for the Commission in 2012 was its triennial flagship meeting Aperiodic 2012, which was held in Cairns, Australia, 2-7 September 2012. The meeting was organized by Ray Withers and Siegbert Schmid, with the Commission acting as its Scientific Programme Committee. More than 110 delegates attended the conference, coming from 23 different countries. Dan Shechtman delivered a special celebratory Nobel lecture on the 30th anniversary year of his pioneering electron-diffraction characterization of the first quasicrystal on 8 April 1982. An introductory tutorial talk by Ted Janssen highlighted the fact that we also celebrated half a century of work on aperiodic crystals, which could be considered as dating back to the pioneering work of Pim de Wolff around 1962 (published in 1964). The next meeting, 
Aperiodic 2015, will be held in Prague, Czech Republic, 30 August - 4 September 2015. Michal Dusek and Lukas Palatinus will organize the meeting, and Vaclav Petricek will chair the International Programme Committee, which will be composed of the members of the Commission.

Our central activity in 2013 was ICQ12 - the 12th International Conference on Quasicrystals, which was held in Krakow, Poland, 1-6 September 2013. Janusz Wolny from AGH University of Science and Technology chaired the Conference. Over 160 participants from 22 countries attended the conference, with many newcomers to the field of aperiodic crystals and a large group of young scientists. A special session was dedicated to celebrating the award of an Honorary Doctorate from AGH to Dan Shechtman, who was a distinguished guest of ICQ12. The scientific programme covered state-of-the-art advances in established aspects of quasicrystal research, as well as very new and exciting directions, such as the experimentally observed quasicrystalline thin films in perovskites, and the theoretically predicted quasicrystalline thin films in water and silicon. The next meeting, ICQ13, will be held in Katmandu, Nepal, in 2016, organized by Hem Raj Sharma and An-Pang Tsai.

Many conferences and sessions related to aperiodic crystals took place in addition to the above: (1) two Special International Symposia on Quasicrystals were held in 2011 to honour Dan Shechtman on his 70th Birthday. The first was organized by the Technion in Haifa, Israel, 12-13 January 2011, and the second was organized by Iowa State University in Ames, Iowa, USA, 29 July 2011. (2) A festive international conference on quasicrystals was held in Taipei, 7-9 May, 2012, Quasicrystals@TaipeiTech, celebrating the 30th anniversary of the discovery of quasicrystals, alongside the award of the 2011 Nobel Prize in Chemistry. (3) ECM27 - 27th European Crystallographic Meeting, which was held in Bergen, Norway, 6-11 August 2012, included a number of Microsymposia related to Aperiodic Crystals as well as a special Microsymposium dedicated to a review of state-of-the-art research on quasicrystals. (4) A number of symposia were dedicated to quasicrystals at the Fall Meeting of the Materials Research Society, held in Boston, USA, 25-30 November 2012, including a Plenary Lecture on quasicrystals given by Dan Shechtman. (5) ECM28 - 28th European Crystallographic Meeting, which was held in Warwick, UK, 25-29 August 2013, included two Microsymposia related to aperiodic crystals, a Keynote Lecture by Lukas Palatinus, as well as a Plenary Lecture on quasicrystals by Dan Shechtman.

The next important upcoming meeting for the Commission is the Montreal Congress, which will have a very good focus on aperiodic crystals, with 12 Microsymposia and 5 Keynote Lectures related to aperiodic crystals. There will also be a Plenary Lecture by Dan Shechtman, as well as the Ewald Prize ceremony with lectures by Ted Janssen and Aloysio Janner.

International Schools and Workshops. Our central educational activity of the triennium - the 2nd International School on Aperiodic Crystals - was held at the University of Bayreuth, Germany, 7-12 April 2013. Marc de Boissieu, Andreas Schönleber, and Sander van Smaalen organized this highly successful School, assisted by 7 additional lecturers, and attended by 40 students from 14 countries. The objectives of the School were to provide an overview of aperiodic order, of the basics of the mathematical description of both modulated structures and quasicrystals, of physical properties and chemical understanding of aperiodic crystals, as well as a working knowledge of structural analysis of aperiodic crystals.

In addition, the following educational activities took place during the triennium: (1) The 7th Workshop on Structural Analysis of Aperiodic Crystals, University of Bayreuth, Germany, 17-20 March 2011, organized by Sander van Smaalen and Andreas Schönleber. (2) The two-day satellite meeting Aperiodic Crystals for Beginners was organized after the Madrid IUCr Congress, in Alcala de Henares by Marc de Boissieu, Manuel Perez-Mato, and Marta Elena González Mosquera, and was aimed at giving an easy introduction to aperiodic crystals for beginners. (3) The series of ad hoc Workshops on JANA2006 continued with a record of well over a dozen workshops organized by Michal Dusek in Prague, Czech Republic, during the last three years.

The next upcoming educational activity of the Commission is a one-day workshop, Introduction to Aperiodic Crystals, to be held on 5 August 2014 in Montreal, as a satellite of the IUCr Congress.

\section{R. Lifshitz, Chair}

\section{A5.4. Commission on Biological Macromolecules} In 2010 and 2011, a central activity of the Commission (CBM) was to contribute to the design and invitation of speakers, including the 2009 Nobel Laureates in Chemistry, to give lectures at the Madrid Congress. The three macromolecular crystallographers who received the Nobel Prize for determination of the ribosome structure (V. Ramakrishnan, T. A. Steitz, A.Yonath) gave three individual Plenary Lectures with full attendance, marking the highlights of the Congress. During the Congress, CBM organized an Open Commission Meeting, and discussed issues such as: developing nextgeneration guidelines for crystallographic PDB depositions and data access - this effort will be led by Tom Terwilliger; CBM's preparation for the IYCr 2014 celebration and for the Montreal Congress; crystallographic education, popular science etc. Also discussed were possible future publishing policies, concerning (1) immediate release of the PDB coordinates upon publication and (2) inclusion of PDB validation reports with manuscript submissions. The consensus was that these policies, if implemented, should also be applied to all journals publishing in structural biology.

In 2011, CBM member Tom Terwilliger (USA) was appointed a member of the Diffraction Data Deposition Working Group (DDDWG), and worked as liaison between CBM and databases in an effort to promote communication between IUCr and the globally critical resources such as the Protein Data Bank that store and provide convenient access to biological structural data. Tom Terwilliger proposed that the CBM focuses on 'Next-generation deposition expectations for 
the PDB' and provided a high-level vision of key concepts for this discussion.

The ideas Tom Terwilliger has proposed and the CBM members found important and exciting are complementary to, and support the vision that the DDDWG has developed. Tom's key ideas are that (1) the crystallographic data are unchanging after collection, but the interpretation of those data can change over time; (2) original and subsequent interpretations of the data should be recorded and be accessible; (3) not only the final structure, but also the process used to determine that structure are critical for evaluating the quality of the structural results, so that this process and all information needed for a complete re-determination of a structure should be recorded. The CBM membership enthusiastically supported Tom's ideas and has chosen this as one of the top focuses for our Commission's future work. The CBM has appointed Tom as the leader of this effort within the CBM. Tom Terwilliger has done a great deal of DDDWG-related work during 2012, and Commission members have often discussed DDDWG issues.

During 2011-2014, Commission members held frequent discussions over the internet, and the Chair has personally written more than 10 supportive letters for many meetings concerning macromolecular crystallography (some of these are listed below).

The Chair and Manfred Weiss went to Cario (Hurgada), Egypt, in November 2012, representing the IUCr at the Egyptian Society of Crystallography (ESCA) meeting to support local crystallography in Egypt (several months before that meeting we also had a discussion to invite people to go to Egypt for this local ESCA meeting).

The Chair has also organized a meeting on behalf of the Chinese Crystallographic Society (CCrS) in Xi'an, People's Republic of China: International Workshop on New Developments of Methods and Software for Protein Crystallography, 24-27 August 2012.

The CBM has also played active roles during the 2012 Adelaide AsCA meeting and Bragg Centennial celebration meeting, and held some discussions on various issues in Australia.

The CBM also had extensive discussions over IUCr's new idea to change Acta D and Acta F's journal directions, and the overwhelming view among the CBM members was that we should keep the status of these journals as they are now, since Acta $D$ is really doing very well; the issue should be how to keep Acta $D$ as it is and not to change it to an unknown direction.

The CBM has also had extensive discussions on the preparation for the Montreal Congress, and proposed/nominated Tom Terwilliger and a few others [Mariusz Jaskolski (Poland), Silvia Onesti (Italy) and Hanna Yuan (Taipei)] as members for the IPC (International Programme Committee); there were good proposals and suggestions from CBM's point of view for the (Keynote) $\mathrm{KN}$ and (Microsymposia) MS speakers and Chairs; for example, a proposal for a half-day symposium in honour of Professor David Eisenberg was discussed and agreed upon by all CBM members.
Since 2013, one of the central activities of CBM was to contribute to the organization and design and invitation of speakers of the Montreal Congress. We held numerous discussions about what kinds of MS and KN concerning CBM should be organized and which Chairs and speakers should be invited, and so on. Structural-biology-related crystallographers Tom Terwilliger, Hanna Yuan and Silvia Onesti are members of the IPC, two being current CBM members; they have been all working hard to organize the Programme and we look forward to having a well balanced Programme for the meeting.

Some meetings that have been supported by CBM:

Celebration of 100 Years of X-ray Diffraction and (Macromolecular Structure of Biological and Non-Biological Materials) Workshop, Hergada, Red Sea, Egypt, 18-22 November 2012. This workshop was held and organized by ESCA (Egyptian Society of Crystallography), which is a very active crystallographic society in Africa.

Biomolecular Forms and Functions: A Celebration of 50 years of the Ramachandran Map, which was held at the Indian Institute of Science, Bangalore, India, 8-11 January 2013.

Macromolecular Crystallography School 2013: From Data Processing to Structure Refinement and Beyond, at the Institut Pasteur de Montevideo, Montevideo, Uruguay, 8-16 April 2013.

RapiData 2013, Brookhaven, USA. This is one of the most important recurring schools for macromolecular crystallography and has been offered every year since 1999. The Director of this school is Robert M. Sweet of Brookhaven National Laboratory and he is assisted by course lecturers Chris Nielsen (ADSC), Z. Dauter (NIH/SER-CAT), E. Garman (University of Oxford), Lonny Berman (BNL), Jim Pflugrath (Rigaku Americas), Frank von Delft (SGC, University of Oxford), Howard Robinson (BNL), Matt Benning (Bruker/Nonius), Tom Terwilliger (LANL), C. Flensburg (Global Phasing), C. Vonrhein (Global Phasing), P. Fitzgerald (Merck), Alexei Soares (BNL), Allen Orville (BNL), and John Skinner (BNL).

International Conference on Structural Genomics 2013, Sapporo, Hokkaido, Japan, 29 July - 1 August 2013. This meeting belongs to a series of Conferences, and is the 7th of the biennial International Structural Genomics (ICSG) meeting series and is organized by the International Structural Genomics Organization (ISGO) designed to serve as a forum to discuss the most recent developments in structural genomics and its impact on research in biology, medicine and disease.

Synchrotron Radiation Techniques and Nanotechnology: a Synergic Approach to Life Sciences and Medicine, Cape Town, South Africa, 11-22 November 2013.

Structural Basis of Pharmacology: Deeper Understanding of Drug Discovery through Crystallography, Erice, Italy, 30 May - 8 June 2014.

Macromolecular Crystallography School 2014: From Data Processing to Structure Refinement and Beyond, Sao Carlos, Brazil, 8-16 April 2014. 
Celebrating the International Year of Crystallography by Encouraging Young People to Macromolecular Crystallography and Fostering International Collaborations, Turin, Italy, 16-17 October 2014.

Structural Biology: Using Synchrotron Radiation to Visualize Biological Molecules, Trieste, Italy, 2-6 June, 2014.

2014 Kuo Symposium on 3D Cryo-Electron Microscopy Molecular Imaging and the 7th K. H. Kuo Summer School of Electron Microscopy and Crystallography, Shanghai, People's Republic of China, 26-30 September 2014.

Current Trends in Structural Biology and 7th International Conference of the Hellenic Crystallographic Association, Crete, Greece, 19-21 September 2014.

\section{X.-D. Su, Chair}

A5.5. Commission on Charge, Spin and Momentum Densities

The Commission organized (or co-organized) the two main conferences of the triennium dedicated to the field of electron densities: the Sagamore Conference on Charge, Spin and Momentum Densities and the Gordon Research Conference on Electron Distribution and Chemical Bonding, as well as the sessions related to this field at the international and regional (mainly European) conferences on crystallography. Most Commission members also actively contributed to the promotion of the field by teaching in schools or workshops. Another important part of Commission activities concerns the development of new collaborations with other IUCr Commissions, i.e. the Commission on Electron Crystallography and the Commission on Synchrotron Radiation, through common projects.

Conferences and workshops. Symposium on Time Resolved and Charge Density in Honour of Philip Coppens, New Orleans, May 2011. This symposium was in honour of Professor P. Coppens (Buffalo, USA), who is one of the pioneers and most prominent leaders of our field. Among the invited speakers, C. Lecomte (Nancy, France), Vice-President of the IUCr, reported on the recent achievement of the first combined refinement of charge and spin densities from X-ray and polarized neutron diffraction data, initiated by P. Coppens and P. Becker (Paris, France).

Madrid Congress. At the Madrid Congress, the Commission (CSMD) organized five scientific Microsymposia, among which four were devoted to charge density: Descriptors of Electronic Structure and Chemical Bonding (MS34), Advanced Approaches in Charge Density Analysis and Derived Properties (MS41), Density Functional Methods for Electronic Structure Calculations (MS76), Hydrogen Bonding: From the Solid State to Solution (MS90), and one Microsymposium on Electron Momentum and Spin Densities in Correlated Electron Systems (MS48). Most of the sessions received a large audience and gave rise to animated discussions. Two Microsymposia were co-proposed jointly with other Commissions (Aperiodic Crystals, Neutron Scattering and Synchrotron Radiation) on Atomic Dynamics (MS55) and Magnetism (MS96) using X-rays and neutrons.
A Keynote Lecture (KN21) was given by Bo Iversen (Aarhus, Denmark), where he reported on recent advances in charge density studies for materials sciences, illustrating the potentiality of the International Center for Material Crystallography created in 2010 as a unique platform combining synthesis, charge density characterization and theoretical modelling.

Sagamore XVII Conference on Charge, Spin and Momentum Densities, Hokkaido, Japan, July 2012. The most important event in 2012 was the Sagamore XVII conference. The conference was organized by M. Takata (SPring-8), Y. Sakurai (SPring-8) and Yu Wang (NTU), with the support of the Commission. The role of advanced probes for nextgeneration science on charge, spin and momentum density was discussed during the conference, hosted by the RIKEN SPring- 8 Center at the RIKEN Harima Institute and cohosted by the national Neutron and Synchrotron Institutes in Japan and in Taiwan (NSRRC). Around 100 participants, about half from Japan, attended. The Conference started with a session dedicated to the Century's pioneers in the field of charge, spin and momentum densities on the occasion of the centennial of Laue's discovery of X-ray diffraction by crystals in 1912, the Bragg's demonstration of crystal structure determination by X-rays in 1913 and also the birth of crystallography in Japan by Terada's demonstration of X-ray diffraction [T. Terada (1913) Nature, 91, 135-136] and Nishikawa's report on X-ray patterns of fibrous, lamellar and granular substances [S. Nishikawa \& S. Ono (1913). Proc. Tokyo Math-Phys. Soc. II-7, 131-138]. A special evening session was given in honour of Professor R. Bader, who developed the quantum theory of atoms in molecules, a real breakthrough in the domain of electron density analysis, which permitted the building of a fruitful dialogue between crystallographers and theoreticians for studying chemical interactions.

In addition to the sessions on new trends in charge, spin and momentum density science, an important part of the programme was devoted to the study of dynamics in novel materials, including high- $T_{c}$ superconductors, multiferroics and chiral magnets by inelastic X-ray and neutron scattering. A fascinating session showed the potentiality of the new XFEL sources.

European Crystallography Meeting: ECM-27, Bergen, Norway, August 2012. At ECM-27, the field of charge density was represented by one Keynote Lecture (KN14) given by M. Spackman on Charge Density and Crystal Engineering, and two Microsymposia, proposed by the SIG2 interest group, entitled New Perspectives for Charge Density Analysis: Materials Properties from Inorganic to Macromolecules (MS18), and The Importance of Low Temperature in Charge Density Studies: History and Future (MS19).

6th European Charge Density Meeting (ECDM6), High Tatras, Slovakia, September 2012. The 6th European Charge Density Meeting gathered about 80 participants, mainly from Europe. The meeting was organized by S. Biskupic and J. Kozisek (Bratislava University). 
International Workshop on Single-Crystal Diffraction with Polarized Neutrons (Flipper 2013), Grenoble, France, January 2013. This three-day International Workshop gathered more than 80 participants. A wide range of scientific applications was covered: spin densities in smart materials such as giant magnetoresistant oxides, magnetic shape memory alloys, molecule-based magnets or multiferroics, solution of complex magnetic structures, including chirality problems, study of short-range magnetic/nuclear correlations in frustrated systems and spin susceptibility in superconductors.

Gordon Conference, Les Diablerets, Switzerland, June 2013. The Gordon Conference on Electron Distribution and Chemical Bonding chaired by P. Macchi (University of Bern, Switzerland) and W. Scherer (University of Augsburg, Germany) attracted 101 participants, which is the highest participation since the beginning of the series in 1978. The theme of the 2013 conference was: Pushing the Limits of Experimental and Theoretical Charge and Spin Density Studies. It has been extremely successful in many aspects such as the high level and novelty of the scientific contributions and the large interest of a broad audience in the individual discussion sessions. Two strong positive points are the large number of young lecturers (aged under 35) who provided nearly exclusively excellent talks and the participation of scientists from related scientific disciplines, where the electron or spin density distribution is apparently not the main focus of research, but is fundamental. For example, Professor Franz Giessibl (Regensburg, Germany) has attracted enormous interest by highlighting a way to achieve charge density distributions at subatomic resolution via AFM microscopy. Despite the success of this GRC and the increase of the audience over the last events, the Gordon Foundation has decided to discontinue this series of 12 conferences owing to insufficient participation over the last three conferences, considering that a minimum of 150 participants is now required for GRCs (instead of 100 as previously).

IXS2013, Stanford, USA, August 2013. The 8th International Conference on Inelastic X-ray Scattering (IXS2013) was held in SLAC National Accelerator Laboratory, California, USA, 11-16 August 2013. This conference brought together 133 researchers from all over the world and provided discussion on electronic excitations by resonant and non-resonant IXS, phonons and molecular vibrations by high-resolution IXS, ground-state electronic and magnetic structures by charge and magnetic Compton scattering. The oral and poster presentations include latest developments in experiment and theory, including XFEL as well as synchrotron results. Because of accelerated developments in this field, the IXS conference series has been changed to be held every two years, and the next IXS conference (IXS2015) will be held in Taiwan in late 2015.

European Crystallography Meeting ECM-28, Warwick, UK, August 2013. Two sessions were organized by the special interest group SIG2 on CSMD research: (MS29) Getting More from Your Electron Density and (MS13) Charge and Spin Density Measurements of Materials. Another Microsymposium (MS30) Beyond Harmonic Treatment was co- organized with SIG9 on Crystallographic Computing and was really successful as it gathered approximately 60 participants despite the fact that the session was scheduled for the last day of the conference. One Keynote Lecture (KN4) was given by Professor D. Stalke (Göttingen, Germany) on chemical applications of charge density research entitled What a Synthetic Chemist Learns from Charge Density. The charge density field was also well represented at the young crystallographers satellite meeting by a Plenary talk given by B. Dittrich (Göttingen, Germany) on the current state and future directions of invarioms.

Commission meetings. The Commission held one closed meeting each year of the triennium, on the occasions of the three main Congresses (IUCr 2011, Sagamore XVII and the Gordon Conference). These regular meetings allowed lively discussions inside the Commission about the forthcoming meetings and the progress of the Commission projects. The last closed meeting in June 2013 was particularly successful as it gathered up to nine members and consultants. The organizers of the next conferences, Sagamore XVIII in 2015 (C. Gatti, Milan, Italy) and ECDM7 in 2016 (K. Woszniak and P. Dominiak, Poland) were invited to present the status of the pre-organization and P. Nakashima (Australia), responsible for the QCBED charge density project, reported on the progress of the project.

Schools. One of the priorities of the Commission is the formation of a new generation of researchers, or more experimental scientists, in the field of electron densities. The international charge density school in 2011, satellite meeting of the Madrid Congress, received a large success. Europe is still the most active region in the CSMD field but educational efforts are also undertaken to reactivate this field in North America - for instance, the synchrotron charge density school at APS (Argonne, USA) in 2013 - and develop it in Asia, as shown by the first Asian Charge Density Meeting, organized by Professor Guru Row, which will be held in 2015 in Bangalore, India.

International School on Charge Density, IUCr2011 satellite, Jaca, Spain, 30 August - 4 September 2011. This School was organized by C. Lecomte and F. Lahoz, current Chair of the Commission on Structural Chemistry. This School covered all aspects, in theory and in practice, of the methods for charge density determination through accurate high-order X-ray diffraction experiments, from data-collection procedures to the analysis of derived properties. Extensive software training was provided. The School gathered fifteen tutors, international recognized specialists in the field and main software authors, and more than fifty attendees, among whom was Professor G. R. Desiraju, President of the IUCr.

Synchrotron Charge Density School, APS, Chicago, USA, 9-15 March 2013. This School was organized at ChemMatCars of Advanced Photon Source, ANL, Chicago, IL, USA in March 2013 by Y. S. Chen (ChemMatCars), C. Hoffmann (SNS) and T. Koritsanszky (Middle Tennessee State University). Commission members or consultants comprised half the twelve international teachers. The aim of the five-day School was to provide young researchers with hands-on experience 
enabling them to utilize new crystallographic instruments and data interpretation techniques to investigate the structure of matter at the atomic/electronic level. The meeting attracted over 40 participants. There were 24 lectures covering topics from synchrotron data collection through data reduction and refinement to topological analysis of experimental electron densities. In addition, there were three tutorial sessions devoted to the $X D$ computer program package. Three days of beam time was available prior to the School, so applicants had the opportunity to collect synchrotron data on their own sample, analyze these data and present the results during the meeting.

Commission projects. The IUCr Project entitled Constrained Experimental Wavefunction, involving seven groups since 2005 to probe the possibilities of the TONTO program for analyzing charge-density quality $\mathrm{X}$-ray diffraction data, was completed in 2011. D. Jayatilaka, leader of the project, reported on the final results at the Open Commission meeting at the Madrid Congress (report to be published in Acta Cryst.).

This Commission and the Commission on Electron Crystallography decided to support jointly an IUCr project on electron distribution in the metallic bond by QCBED techniques and X-ray diffraction, proposed by $\mathrm{P}$. Nakashima (Monash University, Australia), who is leading the project. The work was organized as follows: distribute the metals to the six different involved groups in Norway, Germany, USA, Japan and Australia (two groups for each metal) and meet once a year (during 3 years).

A round robin test on charge density studies on a molecular compound using synchrotron radiation was undertaken in 2012 in collaboration with the Commission on Synchrotron Radiation. The chosen compound is a molecule-based compound, manganese formate dihydrate, $\mathrm{Mn}(\mathrm{HCOO})_{2}\left(\mathrm{H}_{2} \mathrm{O}\right)_{2}$, for which several data collections on different SR beamlines (APS, DESY) and conventional X-ray sources are already available from Professor Bo Iversen (Denmark), who agreed to share his data for the project. The test involves three synchrotron groups at SPring-8 (Japan), APS (USA) and Soleil (France) and four groups working with conventional sources in France, Germany, UK and Canada. Crystal batches were prepared at the LMI (Laboratory of Materials and Interfaces), Lyon University, France, for distribution to the different groups. The various measured data sets will be transmitted to Jacob Overgaard (University of Aarhus, Denmark) who will perform the charge density refinement on each data set in a systematic way in order to enable a valuable comparison.

\section{B. Gillon, Chair}

A5.6. Commission on Crystal Growth and Characterization of Materials

During the triennium the composition of the Commission changed because Hanna Dabkowska decided to step down as a member and was replaced by Ewa Talik. Moreover, at the end of August 2012, we learnt of the passing away of Arkady
Glikin, who was a great scientist, and also consultant of this Commission. New consultants were added to the Commission: T. Kuech (USA), and T. Bekker (Russia).

Members and consultants of the Commission met three times: in 2011 during the Madrid Congress, in 2012 in Glasgow, UK, during the 4th European Conference on Crystal Growth, and in 2013 in Warsaw, Poland, during the 17th International Conference on Crystal Growth and Epitaxy (ICCGE-17). Apart from these events, discussion among members was carried out by e-mail. The next Commission meeting will take place on 6 August 2014, during the Montreal Congress.

One of the main tasks for our Commission was to promote crystal-growth-related conferences and schools. This was done also by strengthening even more the cooperation with the International Organization for Crystal Growth (IOCG). Many of our Commission members/consultants (K. Kakimoto, J. G. Ruiz, J. Wang, S. Baldochi, T. Duffar, A. Moreno and E. Vlieg) are active inside IOCG. The most important meeting for the crystal-growth community was ICCGE-17, Warsaw, Poland, 11-16 August 2013 (http://science24.com/event/iccge17/). For the first time, three sessions of the IOCG Conference were officially co-organized by IUCr representatives, Abel Moreno, Kullaiah Byrappa and Thierry Duffar, who respectively coChaired the sessions: Biological and Biogenic Crystallization, Industrial Crystallization, Defect Formation/Elimination. The IOCG Executive Committee accepted our proposal to keep this initiative for the next IOCG conference, which will be organized in Nagoya, Japan, in 2016. The Conference was preceded by the 15th International Summer School on Crystal Growth (ISSCG-15), Gdansk, Poland, 1-7 August 2010 (http:// www.isscg14.org.cn/). The School was chaired by Commission member Ewa Talik. Both venues were supported financially by the IUCr.

After about 20 years, the European Conference on Crystal Growth (ECCG-4) was held in Glasgow, UK, 17-20 June 2012. The event was supported by the IUCr and by the work of many Commission members and consultants. The next European Conference (ECCG-5) will be organized in 2015 in Bologna, Italy, and chaired by myself. The organization of crystal-growth conferences in Europe is important in order to keep alive crystal-growth activities in Europe.

Other important crystal-growth events organized or coorganized by Commission members/consultants during the triennium were: Third International Conference on Crystallogenesis and Mineralogy, Novosibirsk, Russia, 27 September - 1 October 2013; Meeting of the Italian-Spanish-Swiss Crystallographic Associations, Como, Italy, 9-12 September 2013; 8th International Workshop on Bulk Nitride Semiconductors 2013 (IWBNS VIII), Kloster Seeon, Bavaria, Germany, 30 September - 5 October 2013. Moreover, the Commission supported the Italian Crystal Growth Conference, 14-15 November 2013.

Both during the meeting in Madrid in 2011, and during the recent meeting in Warsaw, a careful planning of crystal-growth schools was undertaken in cooperation with members of IOCG, with the aim to distribute these events in the most rational way both in time and in different continents. The most 
important crystal-growth schools supported by the IUCr and co-organized by Commission members/consultants were:

1st International School of Crystallization and Polymorphism, San José, Costa Rica, 27-31 January 2014;

15th International Summer School on Crystal Growth (ISSCG-15), Poland, 1-7 August 2010;

4th International School on Biological Crystallization (ISBC2013), Granada, Spain, 26-31 May 2013;

International School of Crystallography, Erice, Italy, 30 May - 8 June 2013;

International Summer School on Crystal Growth and Photovoltaic Materials, Brasov, Romania, 27 August - 1 September 2012;

3rd International School on Crystallization: Drugs, Foods, Agrochemicals, Minerals, New Materials (ISC2012), Granada, Spain, 21-25 May 2012.

During 2013 the Commission was busy with preparations for the Montreal Congress. Koichi Kakimoto represented the Commission on the International Programme Committee (IPC). We then held discussions (by e-mail) in order to define the most interesting topics for MS and brilliant scientists to suggest for Plenary and Keynote speakers. We are very happy that the IPC finally accepted several of our MS proposals (actually the remaining proposals were combined with others, so that all of our ideas were actually accepted), and also our suggestions for the Plenary and Keynote speakers. I really wish to congratulate all the Commission members and consultants for having made good proposals, and, in particular, Koichi Kakimoto, who was able to transfer our enthusiasm and our ideas to the IPC.

2013 was also characterized by a great deal of work for the organization of the events related to IYCr. In particular, the Commission organized a web site (http://www. iycr2014.org/participate/crystal-growing) intended to show people a photo-gallery of artificially grown crystals. Together with the pictures, information is given on the crystal structure, growth method, and possible applications. The scientific committee of the web site comprises members/consultants of this Commission with an important participation of member representatives of IOCG. All scientists and non-professionals are invited to submit their best crystal pictures: the number of pictures on the web site increases every day. The web site is intended for celebration of the IYCr, but also as a permanent tool to diffuse crystallography in the coming years. I wish to take the opportunity to thank Brian McMahon for the extraordinary work that he did with us to set up the web site.

Moreover, most Commission members/consultants are involved in the organization of national initiatives to celebrate the IYCr.

On a personal note, it was a great pleasure and honour for me to Chair the Commission during the period 2011-2013. I believe that promoting understanding of crystal growth is essential for progress in materials science, and I wish the Commission the best in future challenges.

\section{A. Zappettini, Chair}

A5.7. Commission on Crystallographic Computing There were two changes in the membership of the Commission in 2012. The Chair R.W. Grosse-Kunstleve resigned in June 2012. He was replaced by vote of the Commission and IUCr Executive Committee approval by R. B. Von Dreele; P. Mercier was appointed to take his place as a new Commission member. The full roster of members and consultants is posted on the Commission web site on the IUCr server (http:// www.iucr.org/resources/commissions/crystallographic-computing/ members).

Eight Microsymposia are planned for the 2014 Montreal Meeting; most are co-sponsored with other Commissions:

MS03: Maximum Entropy in Crystallography [with Commission on Charge, Spin and Momentum Densities (CCSMD)] - This should feature any application of MEM to crystallography and new developments are particularly encouraged.

MS19: Computational Methods for Charge Density Studies (with CCSMD) - New computational methods and approaches for charge density studies are especially desired.

MS22: Improving Your Crystallography: Best Practices and New Methods - This session will present foundations and recent advances in how to determine macromolecular structures, covering best practices for data collection, data analysis and structure determination. It can include how to choose what crystal to use, how to optimize data collection, how to collect the data, how to monitor and adjust data collection based on radiation damage, as well as new methods and algorithms for structure determination.

MS30: Data to Knowledge: How to Get Meaning from your Result (with Commission on Biological Macromolecules) Use of database information to exploit fully the results of a new structure determination. The session will cover ways to find out if structural features in your structure have been seen before, ways to identify binding sites, active sites, ligands, ions and other features in your structure.

MS52: Remote Controls for Crystallography at Synchrotrons and Neutron Sources (with Commissions on Synchrotron Radiation, Biological Macromolecules, Powder Diffraction and Neutron Scattering) - The focus is on systems created to handle large numbers of samples from, for example, a mail-in program, automated sampling systems, and highthroughput crystallography systems. The session should also include remote 'lab-to-lab' operation of instrumentation for data collection. Talks should focus on advances in technology for allowing remote data collection but should include practical information for users on the features of these remote systems and how they can use them.

MS96: New Computational Approaches to Structure Solution and Refinement - New computational methods and approaches are especially desired here for all structural fields of crystallography.

MS100: Beginner's Guide to Validation of Crystallographic Results (with CBM) - This is intended as a tutorial session on validation: what is validation, what are the key criteria for validation of small-molecule and macromolecular structures, how to interpret a validation result including expected 
values and how to identify what is an error and what is a an unusual feature, and what to do next if errors or unusual situations are found. A variety of software tools for validation and the tools provided by archives such as the Protein Data Bank will be described.

MS112: New Approaches to Crystal Structure Prediction (with Commissions on Crystallography of Materials and Structural Chemistry) - Methods and techniques that can be applied to either 'organic' and/or 'inorganic' structures are of interest here. Compare and contrast methods, predictions of stable compounds under ambient and non-ambient conditions, co-crystal stability, polymorph prediction and drug design, and related problems.

The Computing School planned for the Congress unfortunately had to be cancelled owing to insufficient registrations.

A suggestion was made to the Google team that is responsible for the appearance of themes on the main Google search web page for something to honour the 100th anniversary of X-ray diffraction. The emphasis seems to be on birthdays, national days and major holidays. They appear both globally and also focused on specific countries. For example, a previous Google 'Doodle' was for Rosalind Franklin's 93rd Birthday (25 July 2013) (http://www.google.com/doodles/ rosalind-franklins-93rd-birthday). Perhaps others could write to proposals@google.com with crystallographic suggestions. Their web site at https://www.google.com/doodles/about gives details.

\section{R. B. Von Dreele, Chair}

A5.8. Commission on Crystallographic Nomenclature

(1) Meeting in Madrid. The Commission held a closed meeting at the Madrid Congress on 27 August 2011.

(2) Online Dictionary of Crystallography (http://reference. iucr.org/dictionary/Main_Page). Editing a current definition of the Online Dictionary is by limited access only. For that reason, an IUCr discussion forum has been created which allows members of the community at large to comment on current definitions or propose new ones (Crystallography Definitions).

(3) Discussion forum for the Commission on Crystallographic Nomenclature. A forum has been created for discussion of nomenclature issues by members of the Commission, with A. M. Glazer as moderator (Crystallographic Nomenclature), but there has been unfortunately very little response by Commission members, despite repeated reminders.

(4) Proposal for the addition of Seitz Notation for Symmetry Operations to the Symmetry Operations Subtables of International Tables for Crystallography Volume A. Two proposals have been submitted for inclusion of Seitz symbols in International Tables, one by D. B. Litvin and V. Kopsky, the other by A. M. Glazer, differing by the symbols used. The Commission decided the Seitz symbols should not be included in the printed version of the Tables, but may be included in the online version.
During 2013, A. M. Glazer's proposal was reformulated in cooperation with M. Aroyo, the Editor of Volume A of International Tables. The two proposals, by D. B. Litvin and V. Kopsky, and by A. M. Glazer and M. Aroyo, were discussed by the Commission, and the discussion was followed by an e-mail ballot, which gave the following result $(2$ members voted for both proposals):

\begin{tabular}{llll} 
& Yes & No & Abstain \\
\hline Inclusion of Seitz symbols & 35 & 0 & 1 \\
Glazer and Aroyo proposal & 33 & 2 & 1 \\
Kopsky and Litvin proposal & 4 & 29 & 3
\end{tabular}

Since the composition of the Commission changed slightly during the triennium, both the members originally appointed in 2011, and those appointed since were polled.

As a consequence, the Glazer and Aroyo proposal for inclusion of the Seitz symbols in the online version of Volume A of International Tables was adopted. A short paper describing the adopted notation for Seitz symbols was published in the IUCr section of Acta A [Acta Cryst. (2014) A70, 300-302].

The main other nomenclature problem that was discussed in the course of 2013 was a proposal to use the symbol $\overline{2}$ instead of $m$ with the argument that this notation is more consistent from a mathematical point of view and adds clarity to the relationships between rotations and rotoinversions. Although in general the arguments in favour of the $\overline{2}$ symbol were accepted, the vast majority of Commission members did not support the proposal because of the intuitiveness of the symbol $m$, its popularity and its long tradition of usage by the crystallographic community. Nevertheless, because of the pedagogical benefits of the $\overline{2}$ symbol, it is recommended that the definition of $m$ as $\overline{2}$ is emphasized whenever the opportunity arises.

\section{A. Authier, Chair}

\section{A5.9. Commission on Crystallographic Teaching} Community outreach. Social media. Since the Madrid Congress, the Commission (CCT) has continued its efforts to reach out to the crystallographic community, the scientific community, and the community at large by using social media. The Commission's Facebook page (http://www.facebook.com/ IuCrCommissionOnCrystallographicTeaching) has 157 'likes' (an increase of $80 \%$ ). Our Twitter feed (@IUCrTeach) has 25 followers (up 92\%). The Commission continues to increase activity on both social media outlets to better disseminate exciting findings and important information, particularly in the International Year of Crystallography and leading up to the Montreal 2014 Congress.

Web resource pages. We are also reviewing our web pages on the IUCr web site, examining resources for utility and audience, reorganizing content as appropriate, and updating information. Our objective is to make our communication channels and information more targeted and relevant to specific audiences. 
Action item: Reorganization and updating of web resources will be a high priority for the next triennium.

Action item: Commission members will be tasked to assist with contributing to and monitoring social media feed, as well as moderating discussion boards and managing the resource page contents.

Sponsorship of professional programming. The Commission Chair, Katherine Kantardjieff, represented the Commission on the International Programme Committee for the Montreal Congress. The Commission is sponsoring three Microsymposia:

Eric Reinheimer (USA) and Juanma García-Ruiz (Spain) are co-Chairing Spreading the Word. Introducing Crystallography to the Public, MS68, which is scheduled on 10 August 2014 in the morning session.

Saulius Grazulis (Lithuania) and Amy Sarjeant (USA) are co-Chairing Crystallography Education and Training in the 21st Century: New Pedagogies, New Paradigms Part 2, MS92, which is scheduled on 10 August 2014 in the afternoon session.

Clyde Smith (USA) and Tim Gruene (Germany) are coChairing Crystallography Education and Training in the 21st Century: New Pedagogies, New Paradigms Part 1, MS84, which is scheduled on 11 August 2014 in the morning session.

These Microsymposia will provide a platform for speakers to make presentations on a wide variety of topics, from technology, to K-16 education and outreach, to community engagement, to post-baccalaureate innovations. We hope that these sessions will also provide a venue for individuals and groups to showcase their ongoing efforts during the IYCr. The CCT has also agreed to co-sponsor the Microsymposium Beginners Guide to Validation of Crystallographic Results sponsored by the Commission on Crystallographic Computing. The CCT continues to explore effective strategies for education and outreach during the International Year of Crystallography in 2014, and its members are consulted as appropriate.

Action item: The CCT Chair, Katherine Kantardjieff, is working with all six Microsymposia co-Chairs to write and submit 1-3 manuscripts for IUCrJ based on content from MS 68,84 and 92 that describe outreach best practices and also review the current state of affairs in crystallographic teaching (how it spans the sciences and how advanced crystallography has become a bit too easy). These manuscripts will also highlight the Commission's efforts to revamp the web teaching resource pages and solicit contributors. These contributions should be drawn from peer-reviewed materials in Journal of Applied Crystallography that have demonstrated assessment of successful learning outcomes.

$I Y C r$. Since the Madrid Congress, the CCT has explored effective strategies for education and outreach during the International Year of Crystallography in 2014. Review of the web resource pages has been motivated by a strong need to improve the quality and quantity of educational materials at all levels, academic and general, during and post-IYCr.

Action item: Several manuscripts that have not been suitable as full research manuscripts for $J A C$ have recently been redirected to the Commission for reposting on the web.
The CCT proposes that we work together with the JAC editorial office to capture these kinds of efforts.

For the IYCr, the Commission suggested a format for talks aimed at the general public, the 'speed round' format. Here, during a 90 minute period, a moderator will introduce eight crystallographers/diffraction scientists, each of whom will have five minutes to talk about a topic of their choice, which is followed by five minutes of questions. This format is used regularly during national science festivals in the USA, and this type of event is highly entertaining, engaging, and illuminating. A series of public talks in Montreal have been organized based on this idea.

Review of workshop and summer school proposals. In the past three years, the Commission has reviewed and written supporting letters for 18 proposals of variable quality and made recommendations for workshops and summer schools focused on areas relevant to the discipline. Another application proposed establishment of an award for young scientists to be launched in 2014. A summary of the proposals reviewed by the CCT appears at the end of this section.

During the past three years, the proposals received by the CCT have varied considerably in quality. Proposers often send in documents at the last minute, which are vague in details, missing supporting data, and/or do not justify the funds requested. Furthermore, proposers expect immediate response and an automatic endorsement at full funding levels. This is entirely unrealistic, and the crystallographic community needs to be informed and coached about IUCr funding mechanisms and expectations.

During the past year and a half, the CCT has attempted to develop and implement more formalized rubrics for evaluating proposals, along with criteria and guidelines to be presented to those individuals or groups making proposals to the IUCr for support. Guidelines will enable proposers to make the best possible case in their request. Rubrics will enable the CCT to determine more easily whether the proposals meet the mission and goals of the IUCr, to better compare and contrast the proposals, and to provide more useful feedback to the Sub-committee on the Union Calendar so that precious funds can be invested wisely and with maximum return.

Action item: To facilitate best practices and high impact educational experiences, the CCT respectfully proposes to the Executive Committee that a letter of support from the CCT should be required for all schools and workshops proposals, along with additional letter(s) from the appropriate subject matter Commission(s).

Zürich School of Crystallography 2013 - Bring Your Own Crystals, Zürich, Switzerland, 9-22 June 2013.

14th British Crystallographic Association/Chemical Crystallography Group Intensive Single Crystal Teaching School in X-ray Structure Analysis, University of Durham, UK, April 2013.

Workshop on Resonant Elastic X-ray Scattering in Condensed Matter, Diamond Light Source, Oxford, UK, July, 2013. 
Fourth Argentinian Crystallographic Association School: $\mathrm{X}$-ray Powder Diffraction: Fundamentals and Applications, Santa Fe, Argentina, 5-9 November 2012.

International School on Fundamental Crystallography, Gjulechitza, Bulgaria, 30 September - 5 October 2012.

International Workshop on New Developments of Methods and Software for Protein Crystallography, Xi'An, People's Republic of China, 25-27 August 2012.

I Latin-American Meeting on Crystallography and IX Annual Meeting of the Argentinian Crystallographic Association, 29 October - 1 November 2012.

V School of the Argentinian Crystallographic Association, 4-8 November 2012.

X-ray Powder Diffraction: Fundamentals and Applications, Santa Fe, Argentina. 5-9 November 2012.

School of Crystallization and Crystallography for Latin America ECRISLA2013, Florianópolis, Brazil, 14-25 October 2013.

III International Conference on Crystallogenesis and Mineralogy, Novosibirsk, Russia 27 September - 1 October 2013.

5th Moroccan School of Crystallography - EMC5, Oujda, Morocco, 27-30 October 2013.

International Conference of the African Material Research Society, Addis Ababa, Ethiopia, 8-13 December 2013.

School of Crystallization and Polymorphism, San José, Costa Rica, 27-31 January 2014.

European Crystallography School, Pavia, Italy, AugustSeptember 2014.

VI School of the Argentinian Crystallographic Association (AACr), Mar del Plata, Argentina, November 2014.

15th British Crystallographic Association/Chemical Crystallography Group Intensive Single Crystal Teaching School in X-ray Structure Analysis, University of Durham, UK, March 2015.

47th International School of Crystallography: Structural Basis of Pharmacology: Deeper Understanding of Drug Discovery Through Crystallography, Erice, Italy, May-June 2014.

Young Person's Prize in Crystallography, an annual award or prize for young people. The general idea behind the award would be to attract students receiving a scientific education to increase their own knowledge and contribute their ideas to crystallography and related scientific fields. It is suggested that the Commission evaluate where such an award might have the best impact.

Future meetings. The CCT regularly 'meets' in cyberspace via e-mail discussion. While this has worked generally well, given differences in time zones, it is always beneficial to have a meeting face to face during the triennial Congress. Despite the fact that several members will not be in attendance, the CCT is in the midst of scheduling a face-to-face meeting among members present in Montreal.

K. A. Kantardjieff, Chair
A5.10. Commission on Crystallography in Art and Cultural Heritage

A summary of activities is given below.

Maintenance of the Commission web site at http://crysac.visual-chemistry.net/.

Prague's Strahov Monastery will host the 5th ALMA Interdisciplinary Conference on Interpretation of the Fine Art Analysis in Various Contexts, 20-21 November 2014.

Publication of The 'Rose Windows' as a Unique Treasure of Symmetry, Art, and Cultural Heritage in the 2014 Spring issue of the $A C A$ Newsletter

Publication of ACA Living History - A Crystallographic 4Simplex - Edgar Meyer in the 2014 Spring issue of the $A C A$ Newsletter. See http://molecular-sculpture.com/.

The exhibition In the Unusual World of Crystals, May-June 2014, shows the beauty of crystals, the history of their investigations and their various applications. See http://www2. chemia.uj.edu.pl/krysztaly_wystawa/.

5th Meeting on X-ray and Other Techniques in Investigations of the Objects of Cultural Heritage, celebrating the International Year of Crystallography and the 650th Anniversary of Jagiellonian University, Krakow, Poland, 14-17 May 2014. See http://www.chemia.uj.edu.pl/nauka-i-badania/ konferencje/x-ray.

Publication of The Beauty of Rose Windows and the Different Meanings of Symmetry [C. Abad-Zapatero (2014) Acta Cryst. D70, 907--911].

Crystals in Human Life (February-May 2014) was a contest for secondary-school and University students, to increase public awareness of (i) the presence of crystals in everyday life and (ii) the way in which crystallography underlies most technological developments in our modern society. See http:// www2.chemia.uj.edu.pl/konkurs_krysztaly/.

293rd edition of the one-day Rozhovory seminar (discussions on problems of X-ray and neutron structure analysis), 11 February 2014. See http://www.xray.cz/xray/csca/r293_en.htm.

The web site www.crystaledges.org, inaugurated in Fall 2013, demonstrates connections between crystallography and, in particular, the symmetry aspect, and the Arts as manifested in the Gothic Windows of the Medieval Cathedrals of Europe. Collaboration with Painton Cowen to extend and expand his web site www.therosewindow.com, which contained over 500 Gothic Roses windows, to a larger number (over 1500 currently) and including a rigorous description of the symmetry elements (and plane symmetry groups) in them. An example of the current status (still not public) is at http://www.therosewindow.com/TheRoseWindow2/Rose-1Frame.htm.

Edition of a calendar for IYCr2014 (2013). Prague's Strahov Monastery hosted the 4th ALMA Interdisciplinary Conference on Knowledge and Experience in the Fine Art - From Understanding Materials to Technological Applications, 21-23 November 2012.

The Metropolitan Museum of Art of New York, the Conservation Center at the Institute of Fine Arts of New York University, the Winterthur Museum, Cornell University, Brookhaven National Laboratory and members of the 
Commission organized the Fifth International Conference on Synchrotron Radiation in Art and Archaeology (SR2A 2012), New York City, USA, 5-8 June 2012. See http://www.bnl.gov/ sr2a/.

4th Meeting on X-ray Techniques in Investigations of the Objects of Cultural Heritage, celebrating the 100th anniversary of crystal X-ray diffraction, Krakow, Poland, 17-19 May 2012. See http://crysac.visual-chemistry.net/picts/ 2012_Krakow/Abstrakty_WEB.pdf.

\section{E. Dooryhée, Chair}

\section{A5.11. Commission on Electron Crystallography}

While electron crystallography has been seen to grow rapidly in the last three years, in terms of new publications, citations, and activities, five out of nine Commission members (L. M. Peng, A. Avilov, J. Etheridge, U. Kolb and J. M. Zuo) will reach the limits of their terms and be replaced by new members.

The past triennium witnessed the most exciting developments in biological electron microscopy in the past twenty years. Yifan Cheng and co-workers from the University of California at San Francisco solved a long-standing problem in single particle cryo-electron crystallography that limited its resolution, i.e. specimen movement. Using Gatan's new K2 camera, this group was able to correct specimen movement by averaging subframes. This results in a much improved signalto-noise ratio, yielding the $3.4 \AA$ structure of the heat sensor TRPV1 channel. This is the first time that the structure of a $\sim 340 \mathrm{kDa}$ biological macromolecule without high internal symmetry was determined at an atomic resolution, something that was previously only achievable by X-ray crystallography from well ordered crystals. The triennium also witnessed steady progress on some conventional techniques such as precession electron diffraction, as well as rapid developments for fast electron crystallography techniques, allowing dynamical behaviours of inorganic and organic materials to be investigated with unprecedented resolution.

The past triennium was marked by the exciting event that the Noble Prize in Chemistry was awarded to an outstanding electron crystallographer, Daniel Shechtman, for 'The Discovery of Quasicrystals'. The decision has also been made by the Sub-committee on the Gjønnes Medal to award the next Gjønnes Medal to John Steeds (Department of Physics, University of Bristol, UK) and Michiyoshi Tanaka (Tohoku University, Japan) for their outstanding contributions to convergent-beam electron diffraction that revolutionized electron crystallography, and other major pioneering contributions to the development and application of electron diffraction and spectroscopy of materials.

The Commission also reorganized its Sub-committees: in particular, a new Sub-committee on Biological Cryo-Electron Microscopy was established by D. N. Wang (Chair, USA), Yoshinori Fujiyoshi (Japan) and Henning Stahlberg (Switzerland). The Sub-committee aims to promote teaching and information exchange of cryo-electron microscopy of biological macromolecules and their complexes, and the combined applications of cryo-electron microscopy with X-ray crystallography, nuclear magnetic resonance spectroscopy, and various biophysical and computational techniques.

Numerous workshops and symposiums have been organized around the world. To name a few, in Asia, The International Workshop of 3D Molecular Imaging by Cryo Electron Microscopy was organized with support from the Commission in the University of Science and Technology of China. This workshop offered hands-on training of cryo electron microscopy, tomography and 3D reconstruction, and attracted more than 200 participants from North America, Europe and Asian countries.

In the USA, the Workshop on Ultrafast Electron Sources for Diffraction and Microscopy Applications was held at the University of California, Los Angeles, 12-14 December 2012, with the aims to inform the broad scientific communities accelerator, electron scattering and ultrafast science, about the latest developments in ultrafast electron sources, and to identify critical technologies and high impact scientific opportunities. In Europe, members of the Commission formed a Special Interest Group (SIG) and organized several national or international schools. These included Applications of Precession Electron Diffraction, Manchester, UK, 14-15 September 2012, which was mainly concerned with the theory and application of precession electron diffraction to a wide range of crystallographic research areas and first-hand experience of using the technique.

The Commission also played a leadership role in reviewing the current contents of International Tables for Crystallography for content relevant to electron crystallography.

\section{M. Peng, Chair}

\section{A5.12. Commission on High Pressure}

The Commission relies on its unusual size (ten members plus Chair) to maintain sufficient expertise throughout the broad range of different scientific disciplines - from biology through materials science and engineering to solid state physics - that contribute to the interdisciplinary field of high-pressure crystallography.

The role adopted by the Commission in this multidisciplinary and dynamically evolving field is to facilitate and enable the exchange of new ideas and developments. The main tools available to the Commission to achieve this goal are annual workshops on high-pressure crystallography. The Commission also helps to shape a strong high-pressure programme at the triennial IUCr Congresses. In addition, Commission members and consultants are heavily involved in organizing summer schools dedicated to high-pressure crystallography.

Symposia and Workshops. Madrid Congress. The Commission was represented on the Programme Committee by F. Fabbiani. The Commission organized seven scientific Microsymposia, three of which were co-organized jointly with other Commissions (Inorganic and Mineral Structures, Structural Chemistry, Powder Diffraction). In addition to the Microsymposia, two Keynote Lectures were presented by 
prominent high-pressure scientists: K. Hirose (Japan) and E. Boldyreva (Russia).

The high-pressure programme at the 2011 Madrid Congress was as follows:

MS5: Non-Ambient Powder Diffraction.

MS12: Non-Covalent Interactions in Molecular Crystals and Biomolecular Systems under Pressure.

MS19: Synthesis, Structure and Properties of Novel Materials at High Pressure.

MS40: Pressure-Induced Phase Transitions.

MS47: Advances in High-Pressure Techniques and Instrumentation.

MS60: Solid State Reactivity.

MS75: Liquids, Amorphous and Nanocrystalline Solids at High Pressure.

KN9: Kei Hirose, High-Pressure Geoscience/Mineralogy (with Particular Reference to Post-Perovskite).

KN29: Elena Boldyreva, Molecular Crystals at High Pressure.

2012 Commission Workshop in Mito, Japan. The 2012 Commission workshop, entitled Advanced Crystallography at High Pressures, was held in conjunction with the International Symposium of the Quantum Beam Science Directorate (QuBS), Japan Atomic Energy Agency (JAEA) in Mito, Japan, 23-27 September 2012. The Local Organizing Committee was chaired by Commission member Yoshinori Katayama (QuBS, JAEA), and Toyotaka Osakabe (QuBS, JAEA) acted as conference secretary. The workshop was well attended (95 participants from 14 countries). The topics of this workshop covered the whole range of activities of the Commission, and ten scientific sessions were held: (1) crystal structures, phase transitions, and dynamic phenomena, (2) amorphous, liquid, non-crystalline and nanocrystalline phases, (3) magnetic and electronic phenomena at high pressure, (4) organic and biological systems, (5) water, ice and other molecular systems, (6) materials science, (7) chemistry, (8) geosciences and planetary sciences, (9) theory and computation, (10) techniques for high-pressure studies. Each session was organized by two Chairs. At least one of the Chairs was selected from Commission members or consultants. The programme consisted of 1 Keynote Lecture, 25 invited talks, 11 contributed talks and 44 posters. A tour to the Japan Proton Accelerator Research Complex, J-PARC, took place after the scientific sessions, and a newly built high-pressure neutron beamline, PLANET, at the Materials and Life Science Experimental Facility, MLF, was shown to the participants. The tour was followed by a banquet at a hot spring inn in Fukuroda. The Proceedings were published as a special section in the journal High Pressure Research. The meeting was financially supported by JAEA, through the project Earth Science Based on the High Pressure and Temperature Neutron Experiments (Grant-in-Aid for Scientific Research on Innovative Areas from MEXT), the Japan Society of High Pressure Science and Technology, the IUCr and the ICDD. The meeting web site can be found at http://nsrc.jaea.go.jp/ iucrhp2012/.
2013 Commission Workshop in Hamburg, Germany. The 2013 Commission workshop on Advances in Static and Dynamic High-Pressure Crystallography took place at DESY in Hamburg, Germany, 8-11 September 2013. The Local Organizing Committee was headed by Hanns-Peter Liermann (DESY) and Norimasa Nishiyama (DESY). This conference covered the whole range of activities of the Commission. The meeting was attended by 93 scientists from 17 countries, as well as 8 exhibitors. The scientific sessions included:

(1) Crystallographic controls on rheology and elasticity (Chairs: Simon Redfern and Nori Nishiyama).

(2) Polymorphism and crystal chemistry (Chairs: Kamil Dziubek and Przemyslaw Dera).

(3) Computational approaches (Chairs: Nandini Garg and Rajeev Ahuja).

(4) Amorphous, liquid, non-crystalline and crypto-crystalline solids (Chairs: Andrew Goodwin and Vadim Brazhkin).

(5) Materials science (Chairs: Wilson Crichton and Vladimir Turkevich).

(6) Chemistry (Chairs: Vladimir Solozhenko and Alexandr Talyzin.

(7) Studies of organic and biological systems (Chairs: Andrzej Katrusiak and Elena Boldyreva).

(8) New frontiers in extreme conditions crystallography (Chairs: H.-P. Liermann and Ingo Loa).

(9) Rising stars (Chairs: Yoshinori Katayama and Francesca Fabbiani).

(10) Electronic and magnetic phenomena (Chairs: B. Winkler and K. Kamenev).

Travel grants enabling students and young scientists to participate in the workshop were made available through generous contributions from the IUCr, the DGK and DESY. The meeting web site can be found under: https://indico. desy.de/conferenceDisplay.py? confId=7443.

Plans for a 2016 Erice International School on High-Pressure Crystallography. A member of the Commission, Francesca Fabbiani, together with former Commission member John Parise, are in the process of organizing a training event for students and young researchers - Erice School on HighPressure Crystallography - that will take place in May/June 2016 and has been endorsed by the Commission. This will be the 3rd event in Erice dedicated to the field of high-pressure crystallography and follows in the footsteps of the previous successful editions of 2003 and 2009. The 2016 school is planned to run over a course of eight days, with approximately 35 lectures in addition to demonstrations and workshops. Funding for the school is sought from a variety of sources, including NATO, as well as other national and international organizations and industry.

Commission meetings. The Commission held three closed meetings: during the Madrid Congress, and during the highpressure workshops in 2012 in Mito, Japan, and in 2013 in Hamburg, Germany.

Plans and Preparations for the Montreal Congress. The Commission has been represented on the International Programme Committee by P. Dera. The Commission is participating in the organization of ten scientific Microsymposia. 
The Commission was a primary sponsor of six of these Microsymposia and a co-sponsor with other Commissions (Inorganic and Mineral Structures, Neutron Scattering, Crystal Growth and Characterization of Materials, Structural Chemistry, Powder Diffraction) of the remaining four:

MS22: MS-CIMS-1 Phase Transitions in Functional Inorganic Materials and Minerals (Chairs: Pam Thomas and Vladimir E. Dmitrienko).

MS106: MS-CNS-2 From Exo-Planets to Explosives: Ices and Other Molecular Compounds Under Pressure (Chairs: Werner Kuhs and Hiroyuki Kagi).

MS39: MS-CHP-3 High-Pressure Crystallography of Periodic and Aperiodic Crystals (Chairs: Vasily Minkov and Clivia Hejny).

MS41: MS-CHP-5 Advances in Experimental Techniques and Data Analysis for Science at Extreme Conditions at Synchrotron and Neutron Sources (Chairs: Simon Redfern and Stanislav Sinogeykin).

MS40: MS-CHP-4 Electronic and Magnetic Phenomena at Extreme Conditions (Chairs: Karen Friese and Karel Prokes).

MS42: MS-CHP-6 High-Pressure Solid State Chemistry and Materials Synthesis (Chairs: Vladimir Solozhenko and Haozhe Liu).

MS86: MS-CCGCM-4 Multiferroics and Other MultiFunctional Materials: Synthesis, Properties and High-Pressure Behaviour (Chairs: Edmondo Gilioli and Lars Ehm).

MS28: MS-CSC-2 Non-Ambient Crystallographic Studies of Nanoporous Materials (Chairs: H.-C. Zhou and Stephen Moggach).

MS37: MS-CHP-1 Liquids, Amorphous and Nanocrystalline Solids at Extreme Conditions (Chairs: Yoshinori Katayama and Dennis Klug).

MS38: MS-CHP-2 Biomolecular Systems Under Pressure in memory of Roger Fourme (Chairs: Thierry Prange and Nick Brooks).

In addition to the above Microsymposia, the Commission proposed two Keynote Lectures to be given by L. Dubrovinsky and F. Nestola, which were approved.

Plans and preparations for the 2015 Commission Workshop. The Commission plans to hold another annual workshop in 2015, and the location of this event is currently being discussed.

\section{P. Dera, Chair}

A5.13. Commission on Inorganic and Mineral Structures This report summarizes the activities of the Commission (CIMS) during its fourth triennium of existence, after its establishment at the Geneva Congress in 2002. The aims pursued by CIMS since its inception include: to strengthen the links and interactions of structural inorganic scientists with the crystallographic community; to promote the organization during the IUCr meetings of Microsymposia specifically dedicated to the Commission's purposes; to promote, support and organize conferences, symposia, workshops and schools of interest to the crystallographic inorganic community; and to promote the publication of inorganic crystallography matters in the IUCr journals and book series, and elsewhere.

Members and consultants of CIMS discussed various issues via e-mail. Other forms of communication took place at meetings or conferences, or by using the web site. The latter is kindly maintained by M. Nespolo (http://www.crystallography.fr/cims/). The Commission on Structural Crystallography, CSC, and CIMS maintain their links. A. Beatty is the representative of CSC in CIMS while P. Mercier represents CIMS in CSC.

P. Mercier continues to act as liaison officer of CIMS with the IUCr Newsletter. He is also representative of CIMS in the IUCr Working Groups on Database Users and on Diffraction Data Deposition. Strong links exist between CIMS and the Special Interest Group 5 of the European Crystallographic Association (ECA SIG5, http://sig5.ecanews.org/). At present, the Secretary of SIG5 is O. Siidra, the Chair S. Krivovichev and F. Hatert Vice-Chair.

There are very good relationships between CIMS and the European Mineralogical Union (EMU, http://eurominunion. org/); R. Oberti (EMU Past President since 2013) is a member of CIMS and also Commissioning Editor of EMU Notes in Mineralogy.

Co-organization of scientific meetings. The following meetings and conferences have been proposed/organized by CIMS. The activities of members and/or consultants of CIMS as organizers/conveners/lecturers are indicated. Here, no reference is made explicitly to the CIMS contribution to the organization of the Madrid Congress because this work pertains to the previous CIMS report.

(1) Second SMARTER (Structure elucidation by coMbining mAgnetic Resonance, compuTation modEling and diffRactions) Crystallography Workshop, University of Aveiro, Aveiro, Portugal, 23-27 May 2011 (http://smarter. web.ua.pt). J. Rocha chaired the Organizing Committee. This event was attended by 115 researchers from 12 countries. The IUCr sponsored seven young scientists to enable them to attend this meeting.

(2) Third SMARTER Crystallography Workshop, Versailles, France, 10-13 September 2012 (http://www. smarter3.uvsq.fr). J. Rocha was one of the organizers (member of the Board Committee). Almost 100 people attended and 34 lectures were delivered.

(3) 2011 General Assembly of the European Geosciences Union (EGU; Vienna, Austria, 3-8 April 2011). R. Oberti was convener of session GMPV21/GD2.15 Rock Forming Minerals: Properties, Information and Constraints on Petrological Processes and Numerical Models.

(4) XVII International Conference on Crystal Chemistry, X-ray Diffraction and Spectroscopic Studies of Minerals (CCXRDS), St Petersburg, Russia, 20-24 June 2011 (http:// onlinereg.ru/ccxrds). G. Ferraris and O. Yakubovich were members of the Programme Committee, and O. Yakubovich and W. Depmeier presented Plenary Lectures.

(5) Advances in Inorganic Crystal Chemistry: NonConventional Approaches, New Techniques, Structure Modelling and Prediction, RFBR-DFG-CNRS Trilateral 
Scientific Seminar, St Petersburg, Russia, 24-25 June 2011. O. Yakubovich and W. Depmeier gave oral presentations.

(6) Full-day Rietveld Session at the 60th Annual Conference on Applications of X-ray Analysis (http://www. dxcicdd.com/11/index.htm), 1-5 August 2011, organized by P. Mercier.

(7) Madrid Congress. O. Yakubovich gave an oral presentation in the Microsymposium Minerals as Advanced Materials and W. Depmeier gave an oral presentation in MS25.

(8) Italian two-day symposium celebrating The Centennial of X-ray Diffraction (1912-2012), co-organized by the Accademia Nazionale dei Lincei, the Accademia delle Scienze di Torino and AIC (Rome, 8-9 May 2012). R. Oberti and G. Ferraris were members of the Organizing Committee. This symposium obtained the patronage of the ECA. More than 100 persons attended the lectures (delivered by outstanding scientists among whom were two Nobel laureates and one recipient of the Ewald Prize), which focused on the history of crystallography and its revolutionary impact on many scientific disciplines. The lectures have been published in Rendiconti Lincei (2013), 24 (Supplement No. 1); G. Ferraris acted as Co-editor.

(9) 2013 Goldschmidt Conference, Florence, Italy, 25-30 August 2013. R. Oberti was co-Chair of the theme The Cutting Edge in Mineralogy and Mineral Physics and a member of the Organizing Committee. The theme organized nine sessions, including GEOLIFE - Geomaterials for Environment, Technology and Human Activities convened by R. Oberti [with R. Gieré (Freiburg), S. Quartieri (Messina) and R. Wogelius (Manchester)]. A Special Issue of Mineralogical Magazine devoted to the same theme is in preparation. Another session in the scope of CIMS organized in the framework of the theme was High-Pressure Mineral Physics: A Key to Study Earth's Dynamics, convened by P. Comodi (Perugia), L. Dubrovinsky (Bayreuth), T. Balic-Zunic (Copenhagen) and R. Caracas (Lyon).

(10) O. Yakubovich, who was co-Chair of Microsymposium MS19 at the 28th Meeting of the European Crystallographic Association, Warwick, UK, 25-29 August 2013, also gave a talk in MS18 entitled A Polysomatic Series of Two-Dimensional Vanadates, Arsenates and Phosphates.

Co-organization of the following 2014 meetings:

(1) CIMS has been much involved in the preparation of the Montreal Congress; CIMS chair J. Rocha attended the IPC meeting in Montreal on 6-8 May 2013. In particular, CIMS is organizing three Microsymposia: (i) MS1: P. Thomas is chairing (with K. Sugiyama) Phase Transitions in Functional Inorganic Materials and Minerals; (ii) M15: O. Yakubovich is chairing (with S. Pereira) The Role of Defects in Crystal Structure Formation, Organization and Stability; (iii) MS74: P. Mercier is chairing (with R. Peterson) Mineralogical Crystallography. Moreover, D. Pandey will deliver a Keynote Lecture entitled The World of Perovskites: the Earth's Lower Mantle Material to Exotic Advanced Materials.

(2) J. Rocha is a member of the Organizing Committee of conference SMARTER4, to be held in Durham, UK, 1-4 September 2014.
(3) M. Nespolo and S. Krivovichev represent CIMS on the Advisory Committee of the 2014 Meeting of the International Mineralogical Association, to be held in Gauteng, South Africa, 1-5 September 2014, where CIMS is in charge of the Mineralogical Crystallography sessions.

(4) R. Oberti is co-Chairing the Organizing Committee of the 1st ECA European Crystallographic School entitled Reinforcing Foundations to Build the 2nd Century of Modern Crystallography, Pavia, Italy, 28 August - 6 September 2014. This event is funded by Erasmus IP, and will be accompanied by talks open to the general public to celebrate the International Year of Crystallography (IYCr).

(5) G. Ferraris and R. Oberti are members of the Scientific Committees for the organization of two meetings to celebrate IYCr in Italy: (i) Impact of Crystallography on Modern Science, organized by the Accademia delle Scienze di Torino, to be held in Torino on 25 June 2014, with a talk by Robert Hubert, Nobel Laureate 1988, entitled Beauty and Fitness for Purpose: the Architecture of Proteins, the Building Blocks of Life (R. Oberti will give a talk on The Impact of Crystallography and Crystal Chemistry on Petrology and Geochemistry); (ii) Challenges in Crystallography, organized by the Accademia Nazionale dei Lincei, to be held in Rome, 13-14 October 2014 (CIMS chair, J. Rocha, will give a talk on Materials and Crystallography).

(6) D. Pandey is Chair and M. Nespolo a member of the Programme Committee of the Workshop on Symmetry Relationships Between Crystal Structures with Application to Structural Phase Transitions, Varanasi, India, 27-31 October, 2014 (both are also lecturers).

Support of meetings. CIMS supported the application for financial funding by IUCr of the following meetings:

2012 Gordon Research Conference on Crystal Engineering, Waterville Valley Resort, New Hampshire, USA, 10-15 June 2012 (http://www.grc.org/programs.aspx?year=2012\&program =crystaleng).

Computational Discovery for Novel Crystal Structures and Advanced Materials Using the USPEX Code, Lausanne, Switzerland, 21-27 October, 2012.

Bragg Symposium: Celebrating 100 years of Crystallography, Adelaide, Australia, 6 December 2012 (http:// sapmea.asn.au/conventions/crystal2012/index.html).

III International Conference Crystallogenesis and Mineralogy, Novosibirsk, Russia, 27 September - 1 October 2013.

EMU School on Minerals at Nanoscale, Granada, Spain, 36 June 2013.

1st ECA European Crystallography School, Pavia, Italy, 28 August - 6 September 2014.

Workshop on Symmetry Relationships Between Crystal Structures with Application to Structural Phase Transitions, Varanasi, India, 27-31 October 2014.

XVIII International Conference on Crystal Chemistry, Diffraction and Spectroscopic Studies of Minerals, Yekaterinburg, Russia, 13-15 October 2014.

CIMS also gave 'moral' support to the following meetings: 
Gordon Research Conference on Crystal Engineering, Waterville Valley Resort, New Hampshire, USA, 10-15 June 2012.

Short Course on Uranium: Cradle to Grave, organized under the auspices of the Mineralogical Association of Canada, Winnipeg, Canada, May 2013.

GEOLIFE - Geomaterials for Environment, Technology and Human Activities, included in the theme The Cutting Edge in Mineralogy and Mineral Physics of the 2013 Goldschmidt Conference, Florence, Italy, 25-30 August 2013.

J. Rocha, Chair

\section{A5.14. Commission on Magnetic Structures}

The Commission was established by the General Assembly at the last triennial Congress (Madrid, Spain, 2011). This new Commission's consideration encompasses a broad range of magnetic structure types, including commensurate magnetic structures, modulated and otherwise aperiodic magnetic structures, low-dimensional magnetic structures, disordered magnetic structures, etc. The original terms of reference presented with the request to create the Commission are as follows:

(1) Establish standards for the description and dissemination of magnetic structures and their underlying symmetries (representations of propagation vector group, 'complete' representation of the group necessary for multi- $k$ structures, 3D magnetic Shubnikov space groups, superspace symmetry...), and promote these standards within the $\mathrm{IUCr}$ and among other research communities that rely on magnetic structure information.

(2) Develop CIF standards for magnetic structures and promote their use in crystallographic software. This activity will be developed in collaboration with the IUCr Committee for the Maintenance of the CIF Standard (COMCIFS).

(3) Develop a database for magnetic structures based on the sharing of magnetic CIF files.

(4) Cooperate with other IUCr Commissions in establishing and maintaining standards of common interest, such as magnetic symmetry-group tables, magnetic nomenclature and magnetic form factor data.

(5) Encourage communication and cultivate consensus among research communities that have independently developed diverse approaches to characterizing and describing magnetic structures.

(6) Promote the sponsorship and organization of magneticstructure sessions, symposia, workshops and schools at triennial Congresses of the IUCr, at the meetings of its Regional Associates, and at the meetings of other professional societies that tend to rely heavily on magnetic structure information. This should include sessions dedicated to the analysis of neutron scattering data and magnetic X-ray scattering data.

Following the inaugural Commission meeting at the Madrid Congress in 2011, CMS has conducted its business primarily through e-mail correspondence. We have also conducted two internet-video conferences that spanned 16 time zones (10 October 2013 and 11 February 2014).
In 2012, CMS reviewed and approved the new book, Magnetic Group Tables, authored by Commission member Daniel Litvin (Pennsylvania State University, USA) for online publication by the IUCr. These extensive tables contain almost twelve thousand pages of tabulated data and graphics, which include magnetic point groups in 1,2 and 3 dimensions, magnetic space groups in 1,2 and 3 dimensions, magnetic Frieze groups, magnetic rod groups and magnetic layer groups. The data presented for each group includes graphical and tabulated information following the format of International Tables for Crystallography Volume A, and also includes standard sets of coset representatives, maximal subgroups of index $\leq 4$, and a comparison of Belov-Neronova-Smirnova and Opechowski-Guccione symbols. The tables are accompanied by a 100-page book, which contains examples that guide the user in the interpretation and use of each type of table. This monumental work took many years to complete, and is of great value to all who work with magnetic symmetry and/or magnetic structures. The complete tables are made freely available at http://www.iucr.org/publ/978-0-9553602-2-0 as part of the celebration of the 2014 International Year of Crystallography.

Near the end of the year, the CMS created a new web site at http://magcryst.org, which, in addition to providing basic information about the Commission and its activities, provides a flexible means of advertising and supporting a variety of conferences and workshops. In addition to specific pages for events organized, sponsored, or otherwise advertised by the Commission, we also provide an extensive list of other meetings where high-quality magnetic-structure research is to be presented (http://magcryst.org/meetings/).

In 2012, the CMS conducted a review of the coordinate systems used to describe magnetic structures, and of the refinement packages that implement each one. The system that employs projections of the moment (in Bohr-magneton units) onto the possibly non-orthogonal axes of the unit cell is favoured for publication and dissemination, though each of the other systems can be important in computations and some intuitive descriptions. A summary of this discussion is available on the Commission wiki at http://cmswiki.byu.edu/wiki/ Magnetic_Coordinates.

During the past three years, the Commission has actively discussed three common methods of describing a magnetic structure: the supercell description, the wave description (also known as propagation-vector description), and the representational (group-theoretical) description. Each description type has a distinct parameter set, which, if treated in a fully general way, can be converted into any of the other descriptions. And each description can be executed with or without taking magnetic symmetry into account. We are working to define the minimal components that make each description complete and unambiguous, and to define standard procedures for converting between different descriptions. Such standards will make the communication of magnetic structures much more reliable. The Commission has already begun to discuss an outline for a new volume of International Tables that would focus on magnetic 
structures, though there is much to do before undertaking this project.

In 2013, we saw a great deal of software development in support of magnetic symmetry and various types of magnetic structural analysis, examples being FULLPROF, JANA, the Bilbao Crystallographic Server, and the ISOTROPY suite. As these tools continue to develop and interact, the importance of the pending magnetic CIF standard is growing. Commission efforts to establish the most basic components of a magnetic CIF dictionary that accommodates both commensurate and incommensurate magnetic structures have intensified in early 2014. A first-draft proposal to COMCIFS should be ready prior to the Montreal Congress. Based on these developments, J. M. Perez-Mato and his colleagues at UPV/EHU in Bilbao have begun the difficult task of preparing an online database of magnetic structures, which is expected to utilize the new magnetic CIF standard. Primary resources in this effort include the book Magnetic Structures Determined by Neutron Diffraction by Andrzej Oles, and the structure collection of Wieslawa Sikora. We note the recent passing (18 January 2014) of Professor Oles with sadness.

From 2011 to 2013, the members and consultants of the CMS have furthered the goals of the Commission through the organization, sponsorship or support of conferences, symposia, workshops, schools and courses at nearly 25 research venues covering a broad range of topics. Many of these meetings were not specifically organized under the auspices of the Commission, but substantially furthered its objectives of promoting magnetic neutron scattering and magnetic structure determination. At most of these events, Commission members and consultants played a key organizational role.

Wieslawa Sikora (AGH University of Science and Technology, Krakow, Poland) represented our Commission on the International Programme Committee of the Montreal Congress. At the spring 2013 IPC meeting in Montreal, she was instrumental in the planning of an impressive array of lectures and Microsymposia related to magnetic crystallography (http://magcryst.org/meetings/iucr-congress-2014/). This will be an exciting and important Congress for researchers in this field.

In celebration of the International Year of Crystallography, the CMS has also organized a three-day workshop on The Role of Magnetic Symmetry in the Description and Determination of Magnetic Structures (http://magcryst.org/meetings /cmsworkshop2014). This satellite meeting of the Montreal Congress will be held 14-16 August 2014 at the Brockhouse Institute for Materials Research at McMaster University, which is located in the city of Hamilton near Toronto, Canada. In addition to addressing the theoretical foundations of magnetic crystallography, the workshop will include hands-on software tutorial sessions and a number of applications lectures that demonstrate the effectiveness of magnetic symmetry to simplify structural description and analysis.

\section{B. Campbell, Chair}

A5.15. Commission on Mathematical and Theoretical Crystallography

Meetings and schools. In the years 2011-2013 the Commission (MathCryst) has organized or co-organized ten events, in four continents.

(1) Madrid Congress: one Keynote Lecture (KN03: Davide Proserpio: Topological Characterization of Coordination Networks and Metal-Organic Frameworks) and three Microsymposia (Beyond Space-Group Symmetry in Periodic Structures; Diffuse Scattering in Partially Ordered/Disordered Systems; Topological Correlations and Crystal Structure Interconnections).

(2) ITOn! 2011 - Satellite Workshop of Madrid Congress, Bilbao, Spain, 31 August - 3 September 2011, dedicated to introducing the current state and the future developments of the new Online Edition of International Tables for Crystallography Volume A: Space-Group Symmetry, and Volume A1: Symmetry Relations between Space Groups. Didactic material is available from the workshop web site: http://www.cryst. ehu.es/ITschool/ under 'Resources'.

(3) Workshop on Mathematical Crystallography, Manila, Philippines, 2-6 November 2011. This was the first Workshop organized by the IUCr in this country and has been a major event for the University of the Philippines. Didactic material is available from the workshop web site: http://www. crystallography.fr/mathcryst/manila2011.php and a selection of photographs is available at the ad hoc section of the IUCr web site (http://www.iucr.org/gallery/2011/mathematicalcrystallography-manila).

(4) Workshop on Crystallographic Software, Tokyo, Japan, 12-16 December 2011. The workshop was devoted to introduce the approaches and algorithms behind some known as well as less known software packages: Vesta, MoPro, Jana2006, Chardi, Geminography, as well as the Bilbao Crystallographic Server. The workshop was originally scheduled for May but the earthquake and nuclear accident in Fukushima obliged us to postpone it to December. Didactic material is currently being uploaded on the workshop web site: http://www.crystallography.fr/mathcryst/tokyo2011.php and a selection of photographs is available at the IUCr web site (http://www.iucr.org/gallery/2011/mathcryst-software).

(5) School on Fundamental Crystallography, Mahdia, Tunisia, 9-13 April 2012, in cooperation with the IUCr Commission on Crystallographic Teaching (CCT): http://www.crystallography.fr/mathcryst/mahdia2012.php. This school was originally planned in April 2011 but due to the events commonly known as 'Arab Spring', it was postponed by one year. Lectures were partly delivered in French to reduce the difficulties related to the language barrier. A selection of photographs is available at the IUCr web site (http://www.iucr. org/gallery/2012/mathcryst,-mahdia).

(6) Third School on Fundamental Crystallography in Latin America, Uberlândia, Brazil, 25 November - 3 December 2012: http://www.crystallography.fr/mathcryst/uberlandia2012. php. After the schools held in Havana (2007) and Montevideo (2010), the series of schools in Latin America continues with a biennial frequency (the fourth and fifth being planned in 
Argentina in 2014 and in Ecuador in 2016). A selection of photographs is available at the IUCr web site (http://www.iucr. org/gallery/2012/mathcryst,-uberlandia).

(7) A Special Session on Modeling Crystalline and QuasiCrystalline Materials at the American Mathematical Society Section Meeting in Tampa, Florida, USA, 10-11 March 2012 (http://www.ams.org/meetings/sectional/2188_program_ss5. html\#title), organized by Commission consultant Gregory McColm, with invited lecturers Massimo Nespolo, Commission Chair, and Marjorie Senechal, former Commission consultant. A selection of photographs is available at the IUCr web site (http://www.iucr.org/gallery/2012/mathcryst,-tampa).

(8) Conference on Mathematical Aspects of Materials Science, Philadelphia, USA, 9-12 June, 2013, organized by the Society for Industrial and Applied Mathematics (SIAM), with Massimo Nespolo (MaThCryst Chair) and Gregory McColm (MaThCryst consultant) as conveners of three Minisymposia:

MS9 Mathematical Crystallography: Geometric Foundations http://meetings.siam.org/sess/dsp_programsess.cfm ?SESSIONCODE $=16322$ );

MS36 Mathematical Crystallography: Beyond Classical Crystal Symmetry (http://meetings.siam.org/sess/dsp programsess.cfm?SESSIONCODE=16325);

MS90 Mathematical Crystallography: Structure-Building Principles (http://meetings.siam.org/sess/dsp_programsess.cfm ?SESSIONCODE $=16326$ ).

Photo gallery at http://www.iucr.org/gallery/2013/mathcryst, -siam.

(9) Topological Methods in Crystal Chemistry and Materials Science, CECAM-HQ-EPFL, Lausanne, Switzerland, 913 September 2013. Organizers were Vladislav A. Blatov and Commission member Davide M. Proserpio. Web site http:// www.cecam.org/workshop-869.html.

(10) International School on Fundamental Crystallography, Glulechitza, Bulgaria, 30 September - 5 October 2013 (http:// www.crystallography.fr/mathcryst/bulgaria2013.php). Photo gallery at http://www.iucr.org/gallery/2013/mathcryst-bulgaria.

Publications. Special Issue on Mathematical Crystallography is in press for Acta A, with Guest Editors Massimo Nespolo and Gregory McColm.

The book Graph Theory in Crystallography and Crystal Chemistry (an IUCr/OUP Monograph on Crystallography), has been rescheduled for 2014. A school is planned after publication.

Didactic material and abstracts. Didactic material and abstracts from oral and poster presentations at MaThCryst schools and satellite meetings are available from the respective web sites, and the addresses given above.

Future activities. Fourth MaThCryst School in Latin America, La Plata, Argentina, 27 April - 3 May 2014 (http:// www.crystallography.fr/mathcryst/laplata2014.php).

School on Topological Methods for Expert Systems in Materials Science, Samara Center for Theoretical Materials Science, Samara, Russia, 12-16 August 2014 (http:// www.crystallography.fr/mathcryst/topos2014.php).

IUCr Congress Satellite Workshop on the Role of Magnetic Symmetry in the Description and Determination of Magnetic
Structures, Hamilton, Canada, 14-16 August 2014, in cooperation with the Commission on Magnetic Structures, the Commission on Neutron Scattering and the Commission on Aperiodic Crystals (http://magcryst.org/meetings/cmsworkshop2014/).

Second South African School on Fundamental Crystallography, also Satellite Meeting of the 21st Meeting of the International Mineralogical Union, Bloemfontein, South Africa, 25-29 August 2014 (http://www.crystallography.fr/ mathcryst/SouthAfrica2014.php).

Workshop on Mathematical Crystallography: Symmetry Relationships Between Crystal Structures with Application to Structural Phase Transitions, Banaras, India, 27-31 October 2014 (http://www.crystallography.fr/mathcryst/index.php).

Thematic School on Electron Crystallography (Antwerp, Belgium, 2016).

Fifth MaThCryst School in Latin America, Quito, Ecuador, 2016.

Second Philippines Workshop: Mathematical Crystallography (Philippines): originally planned for late 2014, it has been rescheduled to 2015 (precise dates to be decided) owing to the flood that severely affected the country.

Workshop on the Manifold Description of Modulated Structures and the Use of Differential Geometry to Describe Crystal Structures has been proposed by Commission member Stephen Hyde, but has yet to be scheduled.

\section{Nespolo, Chair}

\section{A5.16. Commission on Neutron Scattering}

Two focal points have shaped the activities of the Commission (CNS) during this three-year period: the organization of the two IUCr conferences marking the beginning and end of the Commission cycle (Madrid 2011 and Montreal 2014) and the celebration of the International Year of Crystallography in 2014 (IYCr2014).

Regarding the IUCr Conferences, we are satisfied that neutron research was and will be well represented at both meetings, not only in terms of the number of Keynote Lectures (KN) and Microsymposia (MS) directly organized by the Commission, but also through the even higher number of $\mathrm{KN}$ and MS shared with other Commissions that are directly related to the use of neutron scattering. For the next conference in Montreal, up to six neutron-related Keynote speakers (including two members of CNS, P. Langan and J. RodriguezCarvajal) and four MS proposals have been retained and the Commission is supporting a further 13 proposals on topics relating to the use of neutron techniques.

In 2011 the Commission held an open meeting in Madrid attended by eight of its members and many interested observers. A second closed meeting involving six of its members was convened during the International Conference on Neutron Scattering in Edinburgh, UK. On both occasions, the aim of the discussions was to identify new ways to increase the use of neutron scattering in the world of crystallography and to define how best to participate in the celebrations of the International Year of Crystallography in 2014. 
The most effective way to increase awareness of the power of neutron techniques is to train new generations of scientists to use neutrons. Many neutron schools, such as the Berlin School on Neutron Scattering, the Oxford School on Neutron Scattering, and the Canadian Neutron Scattering Summer School have become regular annual events. In the last three years, however, training courses and workshops have also emerged devoted to a more focused use of neutron techniques; for example, the Course on Neutron Scattering Applications in Structural Biology at Oak Ridge, USA, as well as several schools covering combined analysis using X-ray and neutron scattering, and the application of neutron scattering to the study of engineering or energy-related materials. Several members of CNS contribute at different levels to the promotion of these schools and workshops worldwide and the Commission also gave its support to the 6th International Conference of the African Materials Research Society (6th IC-Africa-MRS, Zimbabwe, 11-16 December 2011) and to the 6th AONSA Neutron School (Serpong, Indonesia, 12-17 October 2014) to be sponsored by the IUCr.

A notable contribution has been the book by P. G. Radaelli: Symmetry in Crystallography. Understanding the International Tables, which was published in 2011 in the series IUCr/OUP Texts on Crystallography. This concise work is aimed at providing a basic introduction to crystallographic symmetry to help with the understanding and use of International Tables for Crystallography.

To coincide with the start of the IYCr, P. G. Radaelli also published an opinion article in Nature entitled Crystallography Needs a Governing Body in which he called for the setting-up of an international organization of facility users to give the crystallographic community a voice in decisions on investments in large-scale facilities. This would also help 'to disseminate the results of research in crystallography and related fields and to clarify the link with technology and innovation, so that the general public appreciates how worthwhile and costeffective public investments are'.

Concerning the second focal point of this three-year period, the celebration of the IYCr in 2014, the Commission has undertaken a variety of activities, which are listed below in a non-exhaustive fashion.

The Commission on Neutron Scattering together with the Commission on Magnetic Structures is organizing a satellite meeting at the Montreal Congress.

The remaining IYCr2014 activities are being carried out through collaborations between CNS members with different local crystallographic associations.

In 2012 the CNS participated in the organization of two events to celebrate the centenary of the Laue/Bragg discoveries [a Laue day at the 20th Annual Meeting of the German Crystallographic Society (DGK) in March 2012 and a Laue day in Grenoble at the Institut Laue-Langevin in November 2012].

Starting at the end of 2012, we organized a series of 'dual conferences' by three renowned figures from the world of crystallography, each of whom gave a lecture aimed at an academic audience followed by an open public lecture: Nobel laureate Dan Shechtman spoke about the discovery of quasicrystals, CNRS gold medallist Gérard Férey focused on chemical engineering, and Nobel Laureate Ada Yonath discussed protein crystallography.

The Bragg Symposium - on Neutron and X-ray Crystallography in Life Sciences - took place in November 2013 and involved a video link between ANSTO in Australia and ILL, ESRF and IBS in France.

During the International Conference on Neutron Scattering in Edinburgh, UK, the Commission organized the Young Scientists Prize awarded by the IUCr for work on crystallographic studies with neutrons.

The Commission also collaborated on the enhancement of the poster collection A Journey into the Heart of the Crystal (initiated by J. L. Hodeau) with the translation of all of the posters into English, Spanish and Arabic, and the addition of posters about neutron crystallography in collaboration with the Commission on Charge, Spin and Momentum Densities.

For 2014 several Crystallography Workshops are being organized in various parts of the world (USA, Canada, Japan, France...) and the members of the Commission are working with local committees to increase as much as possible the visibility of crystallography with neutrons at different science events (e.g. science festivals in various countries).

We are also participating in the development of a number of 'crystallography games' and at the ILL we are in the process of developing interactive learning material on crystallography and diffraction experiments for a multimedia platform.

Finally, several members of CNS (V. Aksenov, M. T. Fernandez-Diaz, S. Kennedy, P. G. Radaelli), together with the Directors of a number of neutron centres (ILL, LLB, ANSTO, PIK), took part in the Opening Ceremony of the International Year of Crystallography at the UNESCO Headquarters in Paris, France, in January 2014. We also took part in the public event Festival de la cristallographie organized in Paris ahead of the IYCr2014 Opening Ceremony, and in the lectures $L a$ cristallographie, une clef de la connaissance held immediately afterwards.

\section{T. Fernandez-Diaz, Chair}

\section{A5.17. Commission on Powder Diffraction}

Once again the triennium could be described as long periods of relative calm interspersed with shorter periods of frantic activity. The calmer periods often included the usual ebb and flow of requests for support for IUCr meeting sponsorship. Over the three-year period requests were received from every continent, but Europe, Asia and South America were particularly well represented. There seemed to be a growing trend for applications from individual symposia within larger meetings, which were generally not looked upon favourably by the membership.

One highlight of the triennium was the fourth in the series of Accuracy in Powder Diffraction held at NIST in April 2013; these meetings are held approximately every 10 years, looking back at developments in the field. Many Commission members past and present were involved in the organization in one way 
or another. Together with Bill David a productive meeting was held with representatives from Chester (Mike Hoyland and Nicola Ashcroft) on the issues and future directions of the powder CIF dictionary. The powder CIF is known to have significant issues currently but given the direction powder diffraction is moving in, the challenges will only increase. The need to capture increasing complexity and non-crystallographic information from parametric and other types of surface refinement was acknowledged, although the mechanism to achieve it is still unresolved.

Volume H of International Tables for Crystallography has been progressing steadily - thanks to ongoing efforts by Chris Gilmore, Jim Kaduk and Henk Schenk for pushing this forward. It is sure to be a common sight on the shelves of laboratories worldwide when it is published.

The Commission (CPD) was most ably represented at the IYCr Opening Ceremony by past-Chair Bill David. As part of efforts to support diffraction in Africa during the IYCr, the Commission organized the Southern African Powder Diffraction Conference and Workshop at the University of Witwatersrand in Johannesburg, South Africa, in January 2014. In the continuing tough environment for those organizing meetings we were very pleased with the eventual 90 delegates for the workshop. Particular thanks must go to Dave Billing and the other local organizers for a very strong programme, the international speakers for making the long trip, and the sponsors for their support.

A previous attempt at organizing a European workshop at the 2012 EPDIC meeting in Grenoble (October 2012) on validation of crystal structures solved from powder diffraction data was less successful. Logistical issues forced a change of location from the ECM in Bergen. Despite a growing number of overseas registrants, the lack of submitted abstracts and local registrants made the meeting unviable so unfortunately we were forced to cancel. This decision was not taken lightly given the work that had already been carried out.

In collaboration with the IUCr webmaster the CPD web site has seen a large expansion in educational content. The excellent resource in the form of the videos from the powder diffraction Erice school were in danger of being lost from the commercial streaming web site on which they were hosted. Although a few videos could not be recovered, most were retrieved and are now hosted on the IUCr servers for posterity, available via the Schools and Workshops. Educational content from two other workshops (the Canadian Powder Diffraction Workshop and the Patras International Workshop) are also linked from the page.

Similarly, efforts are being undertaken to ensure the CCP14 web site is properly archived. It lost funding a number of years ago and is no longer actively maintained. There is a wealth of material and tutorials that would be sorely missed if a servercrash wiped all the information. Although the CPD does not have the funds to resume full operation we can at least ensure that it will still be available as a resource in the future.

For me personally it was a pleasure to be invited to the 2014 AXAA meeting held in Perth, Australia, in January 2014. It will forever be a special place in the history of the CPD as the
Commission was formed at the Perth Congress in 1987. Being part of a morning session celebrating the International Year of Crystallography, following Bill David (CPD past-Chair) and Bob Von Dreele (CPD past-member), was a great honour. Given the active role Australian crystallographers have played in the CPD round robins over the years it was also an opportunity to revisit the old ones and conspire for possible new ones in the future (watch this space?).

\section{P. Whitfield, Chair}

\section{A5.18. Commission on Small-Angle Scattering}

The details of the Commission's activities are presented in the Annual Reports of the Commission. The present report aims at providing an overview of these activities.

Meetings. The International Conference on Small-Angle Scattering (SAS) has taken place on a roughly triennial basis since 1965. It is the main occasion for scientists practising small-angle scattering to meet and exchange ideas related to the technique, across the boundaries of the scientific disciplines represented by the broad range of SAS applications. The 2012 SAS conference, SAS2012, took place in Sydney, Australia, and was chaired by Elliot P. Gilbert of ANSTO. Several Commission members and consultants were members of the Scientific Programme Committee (Co-Chairs, J. Trewhella and D. McGillivray) and the International Advisory Committee.

The Conference was attended by over 400 delegates from 26 countries. The scientific programme included 9 Plenary Lectures and 9 Young Researcher Lectures. In all there were 228 oral presentations and 260 poster presentations (divided between two dedicated poster sessions), all centred around 16 major themes. These themes addressed all aspects of smallangle scattering, including both traditional SAS topics and emerging SAS applications. Lunchtime sessions included discussion of publication guidelines for SAS-derived biomolecular structure interpretation, discussion of common data formats and inter-calibration of data between facilities, and an open Commission meeting. The conference also included two evening workshops providing an introduction to SAS methods, and guidelines for more advanced data analysis.

In coordination with the organizers of SAS2012, the Commission made a call to the SAS community to prepare applications from scientific institutions willing to host the SAS Conference in 2018: SAS2018. (It had been decided during SAS2009 to hold the next SAS conference, SAS2015, in Berlin, Germany.) Together with the SAS2012 organizers, the Commission formed a Committee with the task of evaluating bids received. After a presentation by those submitting a bid, and discussion among SAS2012 delegates, Traverse City, Michigan, USA, was selected as the venue for SAS 2018. Commission members were active before, during, and after the Conference, and took part in the Award Committees. The Prize for Lifetime Achievement in SAS (the 'André Guinier Award') was awarded to Professor Otto Glatter, University of Graz, Austria, for his dedicated development, application and dissemination of SAS methods over 40 years, for his 
pioneering work on the development and application of the indirect Fourier Transform method, and for his service to the worldwide SAS community, including a widely used teaching text.

Following the SAS2012 conference, a group of Guest Editors and Co-editors of the Journal of Applied Crystallography $(J A C)$ was formed (including Commission members and consultants), co-Chaired by A. J. Allen (JAC Editor and Commission Chair) and SAS2012 Chair, E. Gilbert, to assemble a SAS2012 Special Issue. Following pre-selection and rigorous review, 24 papers were accepted; these appeared in regular $J A C$ issues in late 2013 and early 2014, followed by SAS2012 Special Issue publication in early 2014.

A dialogue has commenced between Commission Chair, A. Allen, and SAS2015 Conference Chair, D. Clemans, regarding publication of SAS2015 papers, the process for selecting a venue for SAS2021, and the process for awarding the Guinier prize at SAS2015. The possibility of a Guinier Award lecture (by the awardee) at the conference, itself, has been raised. Consultant D. Svergun is a member of the SAS2015 Scientific Programme Committee.

Commission members were actively involved in the Madrid Congress and J. Trewhella served on the International Programme Committee. A Keynote Lecture on Structural Characterization of Applied Organic Materials and Soft Matter was given by Commission consultant I. Torriani. Several Microsymposia were suggested by the Commission and involved Commission member or consultant participation. Those on 'Industrial Applications of SAXS and SANS to Hard Materials' and 'Standardization, Validation, and Automation in Modern Biological Small-Angle Scattering' were especially well attended, with lively discussions. The Commission has continued to work with E. Gilbert, who is serving on the International Programme Advisory Committee for the Montreal Congress. He has coordinated with Commission members to propose an SAS-focused Keynote Lecture and a record number of SAS-related Microsymposia.

Education. Commission members remain active in organizing and participating in summer schools and tutorial workshops to promote small-angle-scattering techniques (see Annual Reports for details). Since several Commission members are instrument-responsible for SAXS or SANS instruments, they interact regularly with users, including new users, so that they educate and train students and post-docs in SAS methods, data reduction and analysis. For example:

From Europe. D. Svergun has organized a biennial EMBO Practical Course on Solution Scattering from Biological Macromolecules (Hamburg, Germany, 2011 and 2013). An international extension of this has been the EMBO Global Exchange Lecture course, including a first-of-its-kind event in India in 2012. D. Svergun has also given educational lectures in 2011, 2012 and 2013 at events in various countries, including Spain, Korea, USA, Russia, Germany, France, Sweden, Italy, Poland and Brazil. J. Pedersen has continued to educate undergraduate and graduate students in small-angle scattering techniques by his lectures at Aarhus University, including hands-on applications of SAS to protein samples and to soft matter. J. Pedersen has continued to support many new users at his laboratory SAXS facility at Aarhus University, Denmark, from the universities and research institutes in Denmark, Scandinavia and the rest of Europe. D. Babonneau has presented lectures on GISAXS characterization. R. Serimaa has presented lectures and lecture courses on SAXS at the University of Helsinki. She has also taught scattering methods at a Summer School for undergraduate researchers in the University of Helsinki's Department of Physics.

From Japan. N. Yagi has served on Local Organizing Committees (Chair in 2012 and 2013) and conducted SAXS beamline practicals, for the annual SPring- 8 summer schools, and for the 5th, 6th and 7th AOFSRR (Asia/Oceania Forum for Synchrotron Radiation Research) Cheiron schools at SPring-8, also held on an annual basis.

From North America. P. Jemian has been involved in the biennial SAXS course 'Beyond RG' (Advanced Photon Source, USA,) and the annual National School on Neutron and X-ray Scattering (held jointly with APS and the Spallation Neutron Source, Oak Ridge National Laboratory, USA). He has also assisted in courses on Irena, Indra, and Nika software packages in Igor Pro for SAS analysis given at the Advanced Photon Source, Argonne, and at the Australian Synchrotron.

From Russia. V. Volkov has delivered various semester lectures each year in the Physics Department of the Moscow State University on the theory and application of SAS methods, especially those relevant to solution scattering of protein macromolecules (2011, 2012, 2013).

From Latin America. I. Torriani has presented educational lectures, organized by the Center for Nanotechnology BrazilArgentina, at the University of Buenos Aires, Argentina. She has also presented a Plenary Lecture at the School for Advanced Studies in Crystallization and Crystallography for Latin America - ECRISLA 2011, in Florianópolis, Brazil, sponsored by the IUCr, and participated in an EMBO school with D. Svergun in Sao Paulo, Brazil, lecturing on 'SAS in Brazil'. She has also been active in translating and distributing the exhibition: Voyage dans un cristal, which has now been shown at several scientific meetings and educational institutions and museums all over Brazil and Latin America.

Software development. P. Jemian has continued to work with both the NeXus and canSAS communities on developing standards for exchanging SAS data and metadata, and ultimately ensuring transparency in common data formats and integrity of published SAS data. (NeXus is aimed at supporting X-ray neutron and muon users in general.) Following previous recommendations by P. Jemian and others, NeXus additions have been developed for the HDF5 data format for SAS. While SAS data reduction will likely remain somewhat instrument and facility dependent, several SANS and SAXS facilities are in various stages of adopting the $\mathrm{NeXus/HDF5}$ approach for data analysis. Within this context, the need for freely available open source code, capable of running on all three commonly used platforms (PC, Mac, Linux), has also been recognized, and several facilities are moving to coding analysis routines in Python to address this requirement - see http://www.sasview.org. 
At the same time, P. Jemian, and D. McGillivray have been active in the canSAS group, which held a major workshop during 2012. For some years, this group of SAXS and SANS beamline scientists, users and software developers has been working to reduce impediments for researchers using multiple instruments at different facilities. This includes exploring the scope for common data formats for SAXS and SANS, and comparing instruments against an agreed measurement standard. In 2013, the canSAS group released version 1.1 of the canSAS standard for storing 1-D SAS data and metadata in $\mathrm{XML}$ files (see http://smallangle.org/content/resources). This allows better portability of SAXS and SANS data between instruments and experiments, and will help in establishing guidelines for 'recommended' and 'required' information to be incorporated into the metadata (resolution, wavelength, geometry, etc.) accompanying actual SAS data. Another aspect to the canSAS work is to simplify access to SAS information, using the newly developed web-portal at http:// smallangle.org. Work by this group continues on coordinating the goals of the canSAS standard for multidimensional SAS data within the scope of the NeXus standard.

Meanwhile, the main program package for biological SAS analysis remains the ATSAS suite, provided and continually updated by D. Svergun's group, for which version 2.5.2 is the most recent release. It provides possibilities for data processing and advanced data analysis with emphasis on biomacromolecules in solution. The package is publicly accessible for academic institutions and has a huge user group worldwide.

Community building. The Commission and SAS community in general continue to use the SAS list-server at the IUCr web site for communication among subscribing SAS users. The support provided by S. King, ISIS, Oxford, UK, has ensured a reliable use of this list-server by the community.

Consultant D. McGillivray and Chair A. J. Allen have been exploring ways to modernize and revise the SAS Commission web page, and to link it with the 'SAS Portal' to provide a greater level of educational and reference information to SAS researchers. Changes should be implemented in time for the Montreal Congress.

Many Commission members and consultants serve on scientific planning and beamtime allocation committees at large-scale facilities, both national and international, in many countries, including Germany, France, UK, Italy, Denmark, USA, Japan, Taiwan, Australia and Brazil. These activities involve both evaluation of beamtime applications, and active participation in important discussion on the future development of instrumentation and other major upgrades at the various facilities. Commission members and consultants further contribute to the widening of the SAS user community in their home laboratories and at large-scale facilities, offering service, help in data collection and analysis as well as hands-on courses.

I. Torriani served on the Organizing Committee of the First Latin-American Crystallographic Meeting in Cordoba, Argentina, 2013, giving a Keynote Lecture on Soft Matter Physics and Food Science. Following on from this, she is working on the Statutes of the new Latin-American Crystal- lographic Association (LACA), which will help a new group of Latin-American countries apply for membership of the IUCr as a Regional Group.

Technical issues. Chaired by J. Trewhella and including D. Svergun, the world-wide Protein Data Bank (wwPDB) SmallAngle Scattering Task Force (SAStf) met in 2012 to consider whether deposition of SAS-based models would be of value to the structural biology community, and what kinds of accompanying data and validation would be required. The SAStf includes experts in crystallography, NMR spectroscopy, electron microscopy, and molecular modeling (http:// www.wwpdb.org/workshop/sasTaskForce.html). While SAS is a long-established technique for structural characterization, the capacity to generate $3 \mathrm{D}$ models from SAS data is a relatively recent development. Thus, it was timely for the community to work to establish agreed guidelines for publication that will aid in reviewing and evaluating modelling results. Draft publication guidelines for structural modelling of SAS data from biomolecules in solution were developed by the Commission and adopted by the IUCr journals (http:// journals.iucr.org/d/issues/2012/02/00/me0456/index.html). A paper describing the basis for the guidelines was published in Acta D (Jacques et al., 2012): and is available at: http:// journals.iucr.org/d/issues/2012/06/00/be5200/index.html. These guidelines were developed explicitly to inform those performing or evaluating the results of $3 \mathrm{D}$ biomolecular structural modeling. Members of the IUCr SAS and Journals Commissions, the wwPDB and the SAStf led a discussion of the draft guidelines and the SAStf recommendations at the SAS2012 conference. There was general support for the guidelines but a request for a mechanism for community input. To that end, a web site was established with the SAS2012 presentation material and the capacity to accept submissions (http://sas.wwpdb.org/), which has been announced through the sa_scat SAS list-server.

It is hoped that journal editors may wish to consider using the guidelines as an aid in the review process; noting that they were developed not to impede publication of SAS results, but to ensure that sufficient detail is provided for adequate review and confidence in the results presented, and for others usefully to test and develop models with further experiments. Communication of the guidelines followed in 2013 with a letter sent on behalf of the SAS Commission to the editors of many of the high-impact journals that publish papers on biological structure applications of SAS. All responding editors were positive regarding the guidelines outlined. However, an easy 'table' form of the guidelines has been requested, which is under development. Recommendations of the SAStf were published in the journal Structure (Trewhella et al., 2013, available for download at http://www.cell.com/ structure/abstract/S0969-2126\%2813\%2900150-0). Detailed recommendations for further actions of the SAStf can be found in the 2013 Annual Report.

Various SAS-related review articles have been published by several Commission members and consultants, and A. J. Allen has contributed a chapter on heterogeneous and disordered materials to the new International Tables for Crystallography 
Volume H. Following previous work on a prototype standard reference material for SAXS intensity calibration, based on glassy carbon, A. J. Allen, with others at NIST and at the APS at Argonne, have worked to develop a NIST standard reference material, which should be available to the community later during IYCr2014. A. J. Allen has contributed to successive drafts of an ISO TC24/SC4 (Particle Size Committee) SAXS particle size (best practice) standard. This is also intended for issue during IYCr2014.

A. J. Allen is now one of the three main editors of the Journal of Applied Crystallography and G. Kostorz remains a Co-editor.

International Year of Crystallography (IYCr2014). Several Commission activities discussed above will achieve milestones during IYCr2014, including work on data formats, biological SAS publication standards, a SAXS intensity standard reference material, and a record number of SAS-related Microsymposia at the upcoming Montreal Congress. I. Torriani attended the IYCr2014 Opening Ceremony at UNESCO headquarters in Paris, and serves on the Organizing Committee of the Latin-American Summit Meeting for IYCr2014, which will take place in Campinas, Brazil.

\section{A. J. Allen, Chair}

\section{A5.19. Commission on Structural Chemistry}

Commission membership and tasks. During the Madrid Congress the Commission (CSC) was partially renewed for the triennium 2011-2014. Some tasks were distributed among members to try to achieve more effective connection with other Commissions: A. Beatty worked as link from the CSC to the Commission on Inorganic and Mineral Structures (CIMS), while P. Mercier acted as link from CIMS to CSC. J. L. Flippen-Anderson was appointed to liaise with the $I U C r$ Newsletter. Elna Pidcock acted as the link between the CSC and the Cambridge Crystallographic Data Centre. As a novelty, O. Almarsson, representing the crystallographic industrial community, has worked to detect shared interests between academia and industry in the context of chemical crystallography. During the first half of 2013, S. E. Bourne and F. Lahoz collected inputs for the Programme for the Montreal Congress.

Commission activities. During the Madrid Congress a Commission meeting took place with the presence of most of the old and new members. All the participants exchanged points of view concerning the working system of the Commission, the special tasks to be assumed and future projects and objectives of the Commission. A discussion topic was the possibility of organizing an International School on Chemical Crystallography that could change location each year.

Since 2011, some members of the Commission have been participating in the activities of the IUCr Diffraction Data Deposition Working Group (DDDWG) led by John Helliwell and Brian McMahon. All the information developed by this group has been exchanged among Commission members and some (J. L. Flippen-Anderson, P. Mercier and F. Lahoz) have contributed to the workshops organized by DDDWG during the triennium.

Different members of the Commission have been active as organizers, tutors, lecturers or participants in most of the events endorsed by the Commission. In most cases they have sent informal reports to the Commission Chair evaluating the appropriateness of the Commission support. Topics underpinned went from non-covalent interactions, crystal engineering, dynamic structural science and photocrystallography to proper crystallization.

The activities during 2012 and 2013 have been mainly addressed to the contribution of the Commission to the Scientific Programme of the Montreal Congress, trying to obtain a strong and attractive programme in the chemical crystallography sector. Two Commission representatives were members of the International Programme Committee (S. E. Bourne and P. R. Raithby) and they collected proposals from the chemical crystallographic community together with those from Commission members. A total of 12 Microsymposia suggested by the CSC representatives, strictly related to CSC topics, were included in the Programme, together with three additional Microsymposia with shared interests; three Keynote Lectures and one Plenary Lecture are also directly connected to the concerns of the Commission. A couple of workshops, closely related to CSC topics, complete the offer for chemical crystallographers.

Regarding IYCr2014, the Commission exchanged several mails considering the possibility of organizing some events supported and organized directly by the Commission. Unfortunately, none of the proposals arrived to a proper end, although most have been organized by members of the Commission on a national scale (edition of videos, preparation of exhibitions, crystal growth contests, etc.).

Unfortunately, the expected reinforcement of potentialities between CSC and other Commissions through the existence of consultants from other Commissions on the CSC has not worked as smoothly as we had expected. Very limited interaction has been established with other Commissions and with scientists working in industry. We are hardly convinced this system could put more energy into the running of the IUCr, and consequently a major effort should be made in the future to secure the interchange of initiatives, opinions and documentation among Commissions.

Some points still need to be addressed by CSC. Old topics to be revisited are the contents of the IUCr dictionary/ nomenclature service, work to be done in clear and close collaboration with the Commission on Crystallographic Nomenclature, and the analysis of the convenience of an IUCr-supported International School on Structural Chemistry.

Events endorsed by the Commission. Several requests for support by the CSC were received during the triennium. All the applications have been carefully examined and discussed among Commission members. When the support has been granted, the Commission has always suggested indications to improve the programme, and stressed that the organizers should take particular attention to encourage the participation of young researchers from less advantaged countries, and to 
work in order to have a gender balance in the scientific programme.

Events that have received formal support from the CSC:

Gordon Research Conference on Crystal Engineering, Waterville Valley Resort, New Hampshire, USA, 10-15 June 2012, organized by Robin D. Rogers.

Indaba 7 Meeting: Insights from Structure, Skukuza, Kruger National Park, South Africa, 2-7 September 2012, organized by Len Barbour and Peter Comba.

3rd International School on Crystallization: Foods, Drugs and Agrochemical Compounds, Granada, Spain, 28 May - 1 June 2012, directed by Juan Manuel García Ruiz and Jaime Gómez Morales.

The Future of Dynamic Structural Science, Erice, Italy, 30 May - 8 June 2013. Programme Committee: Judith A. K. Howard (Durham, UK), Paul R. Raithby (Bath, UK), Hazel A. Sparkes (Durham, UK) and Andrei V. Churakov (Moscow, Russia).

PASI: Direct-Space Methods for the Structural Analysis of Molecular Materials from X-ray Powder Diffraction Data, Montevideo, Uruguay, 28 May - 6 June 2013. Scientific Committee: Leopoldo Suescun (Uruguay), Peter Stephens (USA), Allen Hunter (USA), Silvia Cuffini (Brazil), Silvina Pagola (USA).

2013 Workshop on Dynamic Structural Photo Crystallography for Chemistry and Materials Science, Buffalo, New York, USA, 16-20 June 2013, organized by Philip Coppens.

MISSCA 2013 - Joint Meeting of the Italian, Spanish and Swiss Crystallographic Associations, Villa Olmo, Como, Italy, 9-12 September 2013, chaired by Norberto Masciocchi.

1st International Symposium on Halogen Bonding (ISXB1), Porto Cesareo, Lecce, Italy, 18-22 June 2014, organized by Pierangelo Metrangolo and Giuseppe Resnati.

\section{F. Lahoz, Chair}

\section{A5.20. Commission on Synchrotron Radiation}

Introduction. The aim of the Commission is to promote access and awareness of crystallographers worldwide to the world's synchrotron radiation (SR) facilities. To this end, the Commission broadly promotes the development of crystallographic instrumentation, technology and standards, and the synergies between storage-ring-based and LINAC-based nextgeneration sources such as X-ray Free Electron Lasers (XFELs) and Energy Recovery Linacs (ERLs). The bulk of the Commission's work is carried out via e-mail, with occasional face-to-face meetings held at selected conferences attended by sufficient of the Commission members.

Synchrotron radiation and free electron laser facilities. The progress of synchrotron radiation and FEL-based user facilities and science continued at a rapid pace during the triennium. In particular, the two operating X-FEL facilities, LCLS in the USA and SACLA in Japan, are beginning to make very significant impacts in crystallography, especially in structural biology where the techniques of nano-crystallography and serial femto-second crystallography are maturing. The past three years have seen these techniques advance from test experiments involving well known structures to the first determination of an unknown structure, Trypanosoma brucei cysteine protease cathepsin B (TbCatB) [Redecke et al. (2013), Science. 339 (6116), 227-230]. These techniques are being supported by rapid technical advances in sample delivery, improving the hit rate (proportion of X-FEL pulses which hit a crystal and produce diffraction data), detectors, data indexing and analysis software etc. In addition, novel crystallography techniques continue to be developed, such as the SLAC development of two colour laser pulses, and work continues at many institutions towards the goal of single molecule imaging.

Demand for access to LCLS and SACLA is high and continues to grow rapidly, and new FEL sources are under construction or being planned. The European X-FEL in Hamburg, Germany, is scheduled to begin user operation in 2017, the Swiss FEL project has a similar schedule, and the Pohang Accelerator Laboratory X-FEL is under construction in South Korea and expected to start commissioning in 2016. Soft X-ray FEL facilities are also continuing to produce high impact science, at facilities such as FLASH in Hamburg and FERMI in Trieste, Italy.

The X-FEL sources offer performance far in advance of today's storage-ring-based synchrotron radiation facilities. Current XFEL sources offer peak brightness 9-10 orders of magnitude greater, pulse lengths 1000 times shorter, and much higher coherence than the best third-generation light sources. However, the development of storage-ring-based light sources is continuing, and promises to 'fill in' at least part of the large performance gap to the FEL sources. Several new highbrightness storage-ring facilities are in their final stages of construction and commissioning, led by the NSLS II at Brookhaven National Laboratory, USA, and the Taiwan Photon Source in Hsinchu, Taiwan; both offer significant brightness upgrades from current sources. However, this triennium has seen a major theoretical advance in storage-ring design brought into reality. New designs, termed 'ultimate storage rings', featuring many more but lower field bending magnets, allow the brightness of synchrotron X-rays to be increased by many orders of magnitude. These designs raise the prospect of a diffraction limited hard X-ray synchrotron storage ring light source, which would have obvious and farreaching applications in many areas, including potential crystallographic applications. The first such storage ring, MAX IV, is under construction in Sweden, and features seven bending magnets per 'cell', compared with two or three in current light sources. The original third-generation hard X-ray facilities, ESRF, APS and SPring-8, are either undertaking or planning significant upgrade programmes based on these new designs.

Commission membership and proposed name change. The outgoing Chair (Soichi Wakatsuki) and proposed new Chair (Richard Garrett) represented the Commission at the IUCr Executive Committee meeting at the Madrid Congress. The General Assembly approved an increase in the membership by 1 , to even out representation from the three major regions (Europe, the Americas and Asia-Oceania), and the inclusion of additional consultants to bring expertise on the X-ray free 
electron laser facilities into the Commission. Ultimately Tomas Tschentscher from the European X-FEL, Takaki Hatsui from SACLS/SPring-8, Japan, and David Fritz from LCLS/SLAC, USA, accepted consultant membership.

In recognition of the increasing significance of free electron laser sources to crystallography, the Commission additionally proposes to modify its name to the Commission on Synchrotron and XFEL Radiation. This change was discussed and unanimously supported by Commission members in 2013.

Madrid Congress. The Commission organized Microsymposium 37 on X-ray Lasers and Other New Frontiers in Synchrotron Applications to Structural Science, in which the latest developments in the utilization of the new generation photon sources were presented. The Microsymposium was chaired by Commission members Soichi Wakatsuki and Janet Smith, and comprised five invited oral presentations covering topics from ultra-fast protein dynamics to progress towards the goal of structure determination from single molecule diffraction. In addition, 12 posters were presented in the associated poster session. Sakura Pascarelli, a consultant and now full member of the Commission, represented the Commission on the International Programme Committee of the Madrid Congress.

The Commission also held an Open Meeting during the Congress, on Friday 26 August, which was attended by 20 Commission members and Congress delegates. Issues discussed included the recognition of beamline scientists, which is a particular concern in the case of protein crystallography beamline staff, and is increasingly a matter of concern generally. The offer by the Journal of Synchrotron Radiation to publish short-format beamline papers was agreed to be a positive development. Jean-Louis Hodeau presented a multi-language display on crystallography, which had been developed for the International Year of Chemistry and which will be updated for the International Year of Crystallography.

It was noted that one combined Microsymposium proposal was accepted for the Madrid congress: SR-XAS. The meeting agreed that additional joint sessions should be proposed for the next Congress, for example synchrotron-neutron combined methods and cultural heritage applications. The Commission agreed to propose such symposia to the International Programme Committee for the Montreal Congress.

SRI 2012, Lyon, France. The Synchrotron Radiation Instrumentation conferences are the peak international meetings, staged triennially, bringing together synchrotron facility staff and users from around the world to report on instrumentation and scientific developments. The SRI meetings are always hosted by a major synchrotron user facility, or facilities, and the 2012 conference was jointly hosted by the ESRF and Soleil.

SRI 2012 was attended by six members or consultants of the Commission, and a lunch-time meeting was arranged during the conference to discuss issues relevant to the Commission. The major topic of discussion was the recurring problem of recognition and career advancement of beamline scientists at synchrotron facilities.
The Commission Chair attended the International Advisory Committee (IAC) meeting at SRI 2012; the IAC is composed of the directors of all major synchrotron user facilities. The Chair and Professor Sine Larsen addressed the meeting about the role of beamline staff scientists and how best their work can be acknowledged and credited by the community. This is a long-standing issue in fields of core interest to the Commission and the Union as a whole, such as protein crystallography, small molecule crystallography, powder diffraction and XAFS, and has been a long-standing area of concern for the Commission. As these techniques have matured it has become less and less common to give proper acknowledgement to the scientists who have developed and operate the methods/ instruments. This can significantly impact career advancement, especially for scientists contemplating a transfer to a University/academic career, and general job satisfaction. The presentation was successful in triggering a lengthy discussion and some subsequent follow-up communication, but the issue is a complex one and no clear solutions were forthcoming.

The Chair also took the opportunity to promote the shortformat beamline publication facility available in Journal of Synchrotron Radiation.

The International Year of Crystallography. The synchrotron community in general has embraced the IYCr in a number of capacities. The synchrotron light source facilities are particularly supportive, with around 15 directly sponsoring the IYCr and all planning to host special events, dedicated sessions at their user meetings etc. In addition, many X-ray and synchrotron relevant conferences in 2014 are planning similar commemorative sessions, and some events were held in late 2013 as a lead-in to the IYCr. Two examples are: the Australia-France video link 'Bragg Symposium - Crystallography for Life' hosted jointly at ANSTO in Australia and the ILL in France on 28 November 2013 (members of both the SR and Neutron Scattering Commissions were involved in planning this event); and the International Conference on Structural Genomics (ICSG) held in Tsukuba, Japan, in 2013 (Soichi Wakatsuki chaired the Organizing Committee), which included a special session on the 100th year of X-ray crystallography.

Commission member Jean-Louis Hodeau has been particularly involved in planning a number of European activities to celebrate the IYCr and the associated centenary of the Laue-Bragg discoveries. This includes events for the general public: Le monde á l'envers, 100 ans de cristallographie - ou comment voir le cristal, la matière, la vie in France; and translating and producing crystallography based games (e.g. Symmetry Mirror Rules), and exhibitions at the Opening Ceremony for the IYCr in Paris, France.

Commission involvement in the Montreal Congress. The Commission was represented by Richard Garrett on the International Programme Committee for the Montreal Congress. Following on from the Open Commission Meeting held at the Madrid Congress, where the participants suggested that more joint symposia be proposed for future Congresses, the Commission worked with a number of 
relevant Commissions to propose symposia for the Montreal Congress. The following Microsymposia were successfully proposed:

High-Resolution Charge Density using SR, jointly proposed with the Commission on Charge, Spin and Momentum Densities (MS-CCSMD-7);

Advances in Experimental Techniques and Data Analysis for Science at Extreme Conditions at Synchrotron and Neutron Sources, jointly with the Commission on High Pressure (MS-CHP-5);

Applications of Anomalous Small-Angle X-ray Scattering to Soft Materials and Bimolecular Systems, jointly with the Commission on Small-Angle Scattering (MS-CSAS-2);

Time-Resolved Spectroscopic Studies with Synchrotron Radiation and Free Electron Laser Sources, jointly with the Commission on XAFS (MS-CXAFS-1);

XFEL Macromolecular Crystallography, jointly with the Commission on Biological Macromolecules (MS-CSR-1);

$\mathrm{X}$-ray, Muon and Neutron Studies of Magnetic Structure in Materials, jointly with the Commissions on Neutron Scattering and Materials Science (MS-CNS-5).

In addition, the Commission successfully proposed the following Microsymposia:

Advances in X-ray FEL Coherent Scattering and Diffraction (MS-CSR-2);

Advances in X-ray, Neutron and Electron Detectors (MSCSR-3);

and successfully proposed two Keynote presentations: Future Light Sources and their Impact on Structure Studies by Edgar Weckert (DESY) and Use of Two Colour XFEL Modes for SAD/MAD Phasing and Improved Intensity Measurements for de novo Macromolecular Structure Determination by Soichi Wakatsuki (SLAC).

In recognition of the increasing impact of the X-FEL facilities in crystallography, and of the need to inform the world community of crystallographers of what is possible and how to access these sources, the Commission proposed and is organizing a one-day workshop on 5 August 2014 entitled Crystallography at XFEL Sources, which is WK-05. The aim of this workshop is to introduce Congress participants to the new capabilities of the XFEL sources, and to provide information and advice on how best to carry out a successful XFEL experiment.

Supported meetings, schools and workshops. The Commission provided letters of support and endorsement for the following meetings:

The RapiData course on automated data collection at NSLS, Brookhaven National Laboratory, NY, USA, to support participation of Latin-American students. The Commission has supported this annual event each year of the 2011-2013 triennium, for schools held in April 2012, 2013 and 2014.

International School/Conference on Resonant Elastic Xray Scattering in Condensed Matter, Aussois, Savoie, France, 13-17 June 2011, and the seventh edition of the School on Crystallography and X-ray Diffraction, Havana, Cuba, 21-26 November 2011.
International Workshop on New Developments of Methods and Software for Protein Crystallography, Xi'An, People's Republic of China, 25-27 August 2012.

The Sagamore XVII Conference, Kitayuzawa, Hokkaido, Japan, 15-20 July 2012.

International Conference on Small-Angle Scattering (SAS2012), Sydney, Australia, 18-23 November 2012.

AsCA '12/CRYSTAL28 and the Bragg Symposium, Adelaide, Australia, 2-6 December 2012.

International Workshop on Resonant Elastic X-ray Scattering, Diamond Light Source and Oxford, UK, July 2013.

International Workshop on Dynamic Structural Photocrystallography in Chemistry and Materials Science, Buffalo, USA, June 2013.

International Conference on Structural Genomics, Sapporo, Japan, 29 July - 1 August 2013.

11th International Conference on Biology and Synchrotron Radiation (BSR), Hamburg, Germany, 8-11 September 2013.

Innovation in Polymer Science and Technology 2013 (IPST2013), Yogyakarta, Indonesia, 7-10 October 2013.

Symposium on the Applications of in situ Synchrotron Radiation Techniques in Nanomaterials Research, held as part of the Materials Research Society Spring Meeting, San Francisco, USA, April 2014.

Structural Basis of Pharmacology: Deeper Understanding of Drug Discovery through Crystallography, Erice, Italy, May/ June 2014.

This triennium has seen a significant increase in the number and variety of events requesting endorsement from the Commission. In general, the Commission has strongly supported IUCr sponsorship for the purpose of assisting attendance by young researchers and scientists from developing countries.

Collaboration with other Commissions. The Commission has been in discussion with the Commission on Charge, Spin and Momentum Densities regarding a proposed round-robin test for determining high-resolution electron density on a small molecular compound using different synchrotron sources. It is intended to propose this round robin as a common IUCr project by the two Commissions. A moleculebased compound, manganese formate, has been proposed as the sample for the round robin.

The primary collaboration with other Commissions took the form of proposals for joint Microsymposia at the Montreal Congress (see above for details).

Asia-Oceania Forum for Synchrotron Radiation Research. The Asia-Oceania Forum for Synchrotron Radiation Research (AOFSRR) is an international network whose mission is to foster collaboration among synchrotron radiation facilities and user communities in Asia and Oceania, as well as promoting collaborations with facilities and communities in America and Europe. The eight facility-operating nations in the region are full members of the AOFSRR, and the Forum's mission includes promotion of synchrotron-based science throughout the region. To this end, Malaysia, New Zealand and Vietnam are associate members of AOFSRR. Several members of the Commission play active roles in the organi- 
zation, including Richard Garrett (Executive Committee member and Treasurer), Shih-Lin Chang (representative of Taiwan on the AOFSRR Council) and Soichi Wakatsuki (representing the Photon Factory to 2012). The AOFSRR holds an annual conference/workshop, hosted by each full member nation in turn. The workshops in the period 20112013 were hosted by Thailand (2012) and Japan (2013), with the 2011 event postponed owing to the serious flooding in Bangkok.

One of the core activities of the AOFSRR is the Cheiron School, a two-week international synchrotron school, which has been held annually at SPring-8 since 2007. The curriculum is very broad, covering both the fundamentals of synchrotron radiation generation and the various applications, including all the common crystallographic applications. Between 50 and 60 young students and post-docs from countries in Asia and Oceania attend the school each year. Members of the Commission are involved in the Programme Committee and lecturing.

\section{R. F. Garrett, Chair}

\section{A5.21. Commission on XAFS}

During 2011 the Commission (CXAFS) was strongly involved in the organization of the Madrid Congress and organized the very successful Q2XAFS workshop in Tsukuba, Japan. CXAFS gave a significant contribution in organizing and coorganizing a number of Microsymposia; moreover, following the successful tradition started in 2008 , it organized a very well attended pre-Congress workshop on XAFS Tutorials for Crystallographers and Beginners: General Introduction and Analytical Methods for Crystallographers and Beginners in the Field of XAFS, chaired by Isabella Ascone and Joaquin García-Ruiz. The Commission intends to continue organizing such tutorial events during IUCr Congresses since they increase the appreciation and visibility of XAFS in the crystallographic community. Further work on the Dictionary definitions for XAFS continued and results were reported well by the IUCr online Newsletter. More work is needed to continue, to develop and to integrate this into http:// reference.iucr.org/dictionary/Main_Page, but results are available on the CXAFS web site at http://www.iucr.org/ resources/commissions/xafs/xafs-related-definitions-for-the-iucrdictionary.

The Q2XAFS meeting, the International Workshop on Improving Data Quality and Quantity for XAFS Experiments, co-chaired by I. Ascone (CXAFS) and H. Oyanagi (International XAFS Society, IXAS), held in Tsukuba, Japan, in December 2011, was a huge success. The new third-generation synchrotron-radiation sources have enabled high quality and throughput XAFS measurements and new types of experiments. These require new standards and criteria for XAFS spectroscopy, and this was the driving force behind the Q2XAFS workshop. The aim of the workshop was to establish new standards and criteria for XAFS experiments and analyses as well as to establish a new data format, and a database for data deposition. It was attended by 71 people, including 25 from outside Japan (USA, UK, France, Italy, Germany, Canada, Australia, Korea, People's Republic of China and Thailand). The workshop was held with five oral sessions and one poster session. A Special Issue of Journal of Synchrotron Radiation reporting the proceedings of Q2XAFS was published [JSR (2012), 19, 849-1066]; this is an important achievement for the XAFS community and for our Commission, as several members contributed to this issue.

The Commission supported and had strong visibility at the 15th International X-ray Absorption Spectroscopy Conference in Beijing, People's Republic of China, 22-28 July 2012. C. T. Chantler was the CXAFS observer at the IXAS Executive Council Meeting, a great statement of the effective relations between the two organizations and a comment on our capacity to work together to further the field. Commission members and consultants (C. T. Chantler, B. Hedman) were on the International Advisory Committee and the International Programme Committee (P. Glatzel). Commission member P. Glatzel was elected Vice-President of the IXAS. As a particular highlight, the IXAS agreed on the importance of continuing the Q2XAFS meetings to develop and define standards and reporting of structures. Another highlight was the progress on data deposition format investigation, reported by several speakers; and a particular highlight was the announcement that the winning conference bid for the 2018 (or 17) IXAS meeting was that of Poland, led by K. Jablonska, also a Commission member.

The 12th International Symposium on Radiation Physics, ISRP12, 7-12 October 2012, Rio de Janeiro, Brazil, also held a joint IUCr/CXAFS and ISRP session; the ISRP was financially supported by the IUCr. From the front page of the web site for the conference: 'The ISRP12 shall include a Joint Session with the International Commission on XAFS (CXAFS) from the International Union of Crystallography which links up to both XAFS and development and applications together with the fundamental physics and chemistry underlying XAFS and XANES. It will deal also with contributions from Crystallography, Data Deposition, and other areas of interest to the Radiation Physics Community and IUCr'. The joint session had the following programme: XAFS and Developments for the Future. Speakers included Y. Joly on theory, J. Hester on data formats and C. T. Chantler on accuracy and opportunities. The Scientific Programme Committee included members of the Commission (C. T. Chantler) and senior members of the IUCr. Proceedings of the Conference were published in the 2014 January issue of Radiation Physics and Chemistry.

At the beginning of 2013 the organization of CXAFS changed, with C. T. Chantler (University of Melbourne, Australia) taking over responsibility as Chair. During 2013 CXAFS put forth a strong proposal for its activities at the Montreal Congress; the goal of these activities - a wideranging list of Microsymposia and a one-day 'Tutorial for Crystallographers and Beginners' - is to increase the appreciation and visibility of XAFS in the IUCr community. The proposal was discussed and approved at the meeting of the International Programme Committee held in Montreal and attended by the CXAFS Chair. The programme of the 
Montreal Congress will include a record number of six MS related to XAFS; these MS are organized by CXAFS in collaboration with other Commissions.

Another major activity was the preparatory work for the proposal of Volume I of International Tables for Crystallography dedicated to X-ray absorption spectroscopy. Following discussions within CXAFS it was agreed that topics to be included are (preliminary contents): XAS theory, experimental methods, processing of experimental data, data analysis, survey of packages in common usage for data collection and reduction, theoretical prediction and data analysis, data exchange and deposition, application, useful tables and definitions of XAS related terms. The Commission believes that publication of this volume of International Tables will greatly strengthen the standing of XAFS in the crystallographic community, and also the reception and development of XAFS and the Commission work in the international XAS community. The Editors of Volume I of the Tables will be C. T. Chantler (University of Melbourne, Australia, and CXAFS Chair), F. Boscherini (University of Bologna, Italy) and B. Bunker (University of Notre Dame, USA).

During this three-year period Commission meetings were held whenever possible at major international conferences, usually at least two per year. Finally, the Commission web site was maintained and the compendium of XAFS beamlines was kept updated.

\section{T. Chantler, Chair, and F. Boscherini, Secretary}

\section{A6. Committee for the Maintenance of the CIF Standard}

Introduction. COMCIFS is responsible for maintaining and developing the Crystallographic Information Framework (CIF) on behalf of the IUCr. COMCIFS activities include development and approval of new dictionaries as well as development and support of the underlying standards for syntax and dictionary construction. Work in the previous triennium (2008-2011) was primarily devoted to incremental improvements in existing dictionaries and development of a new set of standards underpinning CIF Dictionaries.

A key aspect of the CIF project over the last two decades has been codification of crystallographic knowledge into machine-readable dictionaries. Once approved, dictionary management passes to a 'Dictionary Management Group' (DMG), which now has full autonomy in managing dictionary updates. The rate at which these dictionaries have appeared has slowed markedly since the publication of Volume G of International Tables in 2005. The current triennium has seen the publication of one long-awaited dictionary defining data items for describing twinning.

Given that it is now almost a decade since the publication of Volume G, COMCIFS has recently initiated a review of the core CIF dictionaries to determine what new datanames might be necessary and which existing definitions require updating.

Exploiting DDLm. For historical reasons, CIF dictionaries are currently written using one of two 'Dictionary Definition Languages' (DDLs). Recognizing that a single DDL would be preferable, around a decade ago COMCIFS commissioned work on a replacement DDL that would incorporate the advantages of the earlier DDLs. The new DDL, dubbed 'DDLm', was accepted in draft form at the Osaka Congress and the required enhancements to CIF syntax were largely agreed to at the Madrid Congress in 2011. The recent triennium saw the publication of two key papers describing the basis of the new standards [DDLm: A New Dictionary Definition Language, Spadaccini, N. and Hall, S. R., J. Chem. Inf. Model. (2012), 52(8), 1907-1916 and dREL: A Relational Expression Language, Spadaccini, N., Castleden, I. R., du Boulay, D. and Hall, S. R., J. Chem. Inf. Model. (2012), 52(8), 1917-1925]. Work during the current triennium has been focused on developing tools and dictionaries capable of exploiting these new standards. One ground-breaking aspect of these standards is that they allow machine-readable description of the mathematical relationships between datanames. As a demonstration of the power of this approach, web-browser software has now been developed that allows interactive calculation and verification of dataitem values (for example, structure factors), based solely on the values already present in the data file and the contents of an arbitrary dictionary loaded into the web page. This software is immediately useful, as the new DDLm dictionaries include equivalent datanames from previous dictionaries, which means that this software works also for archival CIF data files written using datanames from current dictionaries. This software and related topics were presented and discussed at an intense and fruitful two-day workshop prior to the 2013 ECM meeting in Warwick, UK. Efforts in the coming triennium will focus on improving DDLm tools, converting dictionaries to DDLm, and supporting moves to use DDLm technology in production within the IUCr offices. As the primary changes are at the dictionary level, there is no requirement to change current CIF data-file writing software.

Macromolecular developments. The macromolecular CIF dictionary (mmCIF) is by far the largest CIF dictionary, and is augmented by the even larger PDBx dictionary, resulting in close to 10000 definitions in total. To address the limitations in its historical record-oriented data format, the Worldwide Protein Data Bank (wwPDB, http://www.wwpdb.org) has engaged the macromolecular user community to identify a viable future format for their archive. As a result, in 2012 wwPDB announced that PDBx/mmCIF would become the primary deposition and archiving format for the PDB archive. The wwPDB assembled developers from leading structure refinement software packages in a working group to provide recommendations on nomenclature extensions required to represent current and anticipated large macromolecular structure entries. In early 2013, the PDBx/mmCIF Working group (Chair: Paul Adams, http://wwpdb.org/workshop/ wgroup.html) delivered both recommendations and implementations (http://wwpdb.org/news/news_2013.html\#22-May2013) for PDBx/mmCIF deposition using CCP4/REFMAC (http://www.ccp4.ac.uk/html/refmac5.html) and Phenix.refine (http://www.phenix-online.org/documentation/refinement. $\mathrm{htm})$. This PDBx/mmCIF Working Group continues to provide guidance to the wwPDB on dictionary extensions to 
enrich the content of PDB entries in order to keep pace with rapidly evolving methodologies in macromolecular crystallography.

In 2013, the wwPDB launched a new deposition and annotation system that will be deployed at all of the wwPDB partner sites. This system is built atop the $\mathrm{PDBx} / \mathrm{mmCIF}$ framework using dictionary aware software components. In support of the transition to the $\mathrm{PDBx} / \mathrm{mmCIF}$ format, the wwPDB conducted PDBx/mmCIF workshops at the Center for Integrative Proteomics Research at Rutgers University (http://www.proteinmodelportal.org/workshop-2013/) and at Protein Data Bank Europe (PDBe).

Software. Uptake of CIF is heavily dependent on the availability of CIF-conversant software. In the first decades of CIF, end-user software would usually include custom code for reading and writing CIF files, which increased barriers to CIF adoption, as well as multiplying opportunities for incorrect CIF reading and writing due to coding errors. Such a proliferation of custom solutions usually arises from a mismatch between the needs of a given program and the functionality and coding language of available libraries. One way of improving the match between CIF libraries and application software is to design an Application Programming Interface (API) and accompanying reference implementation that would meet the needs of the majority of CIF programs. A draft API has been developed and a standard C library conforming to this API is being prepared as a test of the design and as the reference implementation.

Interaction with other data management initiatives. At the Madrid Congress in 2011, the IUCr Executive Committee created the Diffraction Data Deposition Working Group (DDDWG). As a result of the recommendations of this working group, IUCr Commissions were tasked with determining the metadata needs of their fields. While no explicit mention of CIF (or COMCIFS) was made, COMCIFS' fundamental role within the IUCr has been to define and manage metadata and several COMCIFS members have decades of experience in doing this. A group of COMCIFS members have therefore agreed to advise any IUCr bodies that wish to take advantage of this expertise. The Executive Committee is urged to encourage and facilitate such communication between COMCIFS and IUCr Commissions so that the many false starts that dogged pre-CIF efforts at data standardization in single-crystal work are not repeated.

As other scientific fields initiate their own metadata projects, there will be increased need for harmonization between these efforts and CIF definitions. Many large-scale neutron and X-ray facilities are now storing their raw data in the NeXus framework, which is controlled by the NeXus International Advisory Committee (NIAC). In 2013 the NIAC met with COMCIFS to explore ways to harmonize the NeXus definitions for raw images produced by protein crystallography experiments with the definitions contained within the imgCIF dictionary. As a result of these discussions and the concerted efforts of a number of researchers, a unified set of definitions is now available, making it possible to convert freely between NeXus and imgCIF files. It is hoped that this effort will lead to further harmonization between NeXus and other fields covered by CIF dictionaries.

Membership. COMCIFS participants include a large number of advisers/observers and a small number of voting members. John Bollinger became a voting member following the Madrid Congress, and R. Grosse-Kunstleve resigned partway through the triennium. The other voting members are J. Hester (Chair), B. McMahon (Secretary), H. Bernstein and J. Westbrook.

\section{J. Hester, Chair}

\section{A7. IUCr Newsletter}

The IUCr Newsletter continues to be a vehicle for broadcasting and promoting the interests and activities of the IUCr and its Commissions. It also strives to enhance communication within the global community of crystallographers. Special effort is made to promote meetings and publications sponsored by the IUCr.

This report covers 12 issues (19\#1-4, 20\#1-4 and 21\#1-4). In the first two issues of 2011, the President's column was written by S. Larsen and all subsequent columns were written by G. R. Desiraju. Volumes 19, 20 and the first two issues of Volume 21 were edited by Judy Flippen-Anderson and Bill Duax. Volume 21, issues 3 and 4 were edited by Bill Duax.

Each issue contained at least two pages highlighting articles from each of the IUCr journals and news of various IUCr Commissions, notices of elections, awards to crystallographers, and information on web sites, resources, and other activities of interest to crystallographic practioners. The reports covered topics such as high-throughput protein crystallography, materials microstructure, radiation damage, crystals in art and science, crystal growth, synchrotron updates, structural genomics, methods, supramolecular chemistry, small molecules, biomaterials, electron crystallography, applied crystallography, high-pressure studies, new materials, and aperiodic crystals. Contributions are received from crystallographers in many countries and other material is gathered from the Newsletters of crystallographic associations and science news magazines. Almost all submitted contributions are published and all material is edited to varying degrees.

The reports included reviews of the meetings of $\mathrm{IUCr}$ Regional Associates and national crystallographic associations as well as extensive coverage of the Madrid Congress. Reports were published covering meetings in Argentina, Australia (2), Belgium, Canada, Croatia (3), Cuba, Germany (3), Hungary, Italy (3), Japan, Morocco, Norway, Poland (3), Singapore, Slovenia, South Korea, Spain, Switzerland, UK (2), Uruguay and USA (4).

A series of articles on crystallography in countries adhering to the Union began in 2003. In the last triennium issues appeared on South Eastern Europe (Volumes 19\#2, 19\#3 and 19\#4, P. Naumov, editor).

IUCr Regional Associates took advantage of the Newsletter to advertise their upcoming meetings. In addition, a calendar of future meetings throughout the world was published in 
every issue and, sadly, obituaries of 7 prominent crystallographers were reported during the triennium. There was one cover story on wwPDB. Covers highlighted Regional Associates and other meetings, Crystallography in South Eastern Europe, the Madrid and Montreal Congresses and IYCr.

All twelve issues published in the triennium contained 24 pages. This amounted to a total of 288 pages compared to the 340 pages for the twelve issues in the previous triennium, which included a 28-page insert for the Madrid Congress.

A significant portion of the support for the publication and distribution of the Newsletter comes from advertising revenue. There were from 8.25 to 11.75 advertisements in each issue during the triennium with an average of 10.5 advertising pages per issue. Beginning with Volume 20, we had an opportunity to increase advertising income with advertisements on the electronic issue web site. There were seven advertisements in total with Volume 20 and nine with Volume 21.

Volumes 19\#1, \#2 and \#3 had an average distribution of 18768 . For $19 \# 4$ we did a test run for electronic distribution sending the issue electronically to ACA members and had a print distribution of 9435. Beginning with Volume 20 in 2013, we began electronic distribution to approximately 11500 people with distribution coming from the World Database of Crystallographers, Regional Associate members and subscription requests. We continue to send print copies to 538 libraries and various crystallographic meetings.

Patti Potter is responsible for the desktop preparation of all copy, all negotiations with the printer, postal authorities, and distribution houses, maintenance and production of the mailing list, and solicitation and handling of all advertising. She is working remotely from Alaska. Jean Gallmeyer assisted with copy preparation and correspondence with contributors.

\section{W. L. Duax, Editor}

\section{A8. IUCr/Oxford University Press Book Series}

In the period September 2011 to 2013, the cooperation between Oxford University Press (OUP) and the IUCr/OUP Book Series Selection Committee was very productive.

The complete list of published books includes six Texts on Crystallography, one Monograph on Crystallography and one history book:

Fundamentals of Crystallography - Third Edition, by C. Giacovazzo, H. L. Monaco, G. Artioli, D. Viterbo, M. Milanesio, G. Ferraris, G. Gilli, P. Gilli, G. Zanotti and M. Catti, published 10 February 2011, IUCr Texts on Crystallography No. 15.

Electron Crystallography - Electron Microscopy and Electron Diffraction, by X. Zou, S. Hovmöller and P. Oleynikov, published 18 August 2011, IUCr Texts on Crystallography No. 16.

Symmetry in Crystallography - Understanding the International Tables, by P. G. Radaelli, published 22 September 2011, IUCr Texts on Crystallography No. 17.

Symmetry Relationships between Crystal Structures. Applications of Crystallographic Group Theory in Crystal Chem- istry, by U. Müller, published 4 April 2013, IUCr Texts on Crystallography No. 18.

Small-Angle X-ray and Neutron Scattering from Solutions of Biological Macromolecules, by D. I. Svergun, M. H. J. Koch, P. A. Timmins and R. P. May, published 8 August 2013, IUCr Texts on Crystallography No. 19.

Phasing in Crystallography. A Modern Perspective, by C. Giacovazzo, published 12 December 2013, IUCr Texts on Crystallography No. 20.

Neutron Protein Crystallography - Hydrogen, Protons, and Hydration in Bio-Macromolecules, by $\mathrm{N}$. Niimura and A. Podjarny, published 17 February 2011, IUCr Monographs on Crystallography No. 25.

Early Days of X-ray Crystallography, by A. Authier, published 1 August 2013, International Union of Crystallography History Book.

One new book has been approved by the Committee and is in the pipeline. The Committee and the OUP editing staff are now reviewing two new proposals.

The Committee encourages prospective authors to propose new volumes and readers to suggest topics and/or authors for new books on important subjects that are not well covered in the literature.

\section{Viterbo, Chair}

A9. Sponsorship of meetings: Sub-committee on the Union Calendar

The present membership of the Sub-committee comprises: R. Baggio (Argentina), D. Billing (South Africa), L. B. McCusker (Switzerland), J. M. Perez-Mato (Spain), Se Won Suh (Korea), D. Viterbo (Italy) and K. A. Kantardjieff (USA; ex officio as Chair of the Commission on Crystallographic Teaching), being chaired by H. A. Dabkowska (Canada). The Sub-committee members, including the Chair, for the next triennium will be decided in Montreal.

During the past three years, the Sub-committee has considered and analyzed many requests for sponsorship and financial support by the IUCr, and subsequently has made recommendations to the Executive Committee. The main policy consists of giving financial support to help young scientists, meaning graduate students, post-graduate students or post-doctoral fellows, with a maximum age of 30 (exceptionally 35). Additional financial support for organizational expenses was considered by the Executive Committee whenever necessary and justified. Special attention was given to applications from regions where crystallography is less developed. The entire procedure, from the submission of proposals to the final decision by the Executive Committee, was carried out by e-mail. The evaluation process was very efficiently conducted by e-mail discussions involving all members of the Sub-committee.

The total amount used for sponsoring the participation of young scientists in meetings was CHF 123,179 in 2011, CHF 154,49 in 2012 and CHF 155,924 in 2013.

The following meetings received support during this threeyear period: 
Workshop on Mathematical Crystallography, Manila, Philippines, 2-6 November 2011.

Third School of the Argentinian Crystallographic Association, Bariloche, Argentina, 7-18 November 2011.

School of Crystallization and Crystallography for Latin

America, Florianópolis, Brazil, 12-25 November 2011.

VIII International School on Crystallography and X-ray Diffraction, Havana, Cuba, 21-25 November 2011.

Workshop on Crystallography at the 6th International Conference of the African Materials Research Society, Victoria Falls, Zimbabwe, 11-16 December 2011.

Third African School and Workshop on X-rays in Materials: Some Established Techniques and Practical Applications, Dakar, Senegal, 23-28 January 2012.

Powder Diffraction and Rietveld Refinement School, Durham, UK, 25-29 March 2012.

RapiData 2012, Brookhaven, USA, 22-27 April 2012.

From Genes to Atomic Structures: an Introduction to Synchrotron-Based Structural Biology, Trieste, Italy, 23-27 April 2012.

3rd International School on Crystallization: Drugs, Foods, Agrochemicals, Minerals, New Materials (ISC2012), Granada, Spain, 21-25 May 2012.

Present and Future Methods for Biomolecular Crystallography, Erice, Italy, 31 May - 10 June 2012.

2012 Gordon Research Conference 'Crystal Engineering', Waterville Valley Resort, New Hampshire, USA, 10-15 June 2012.

Electron Crystallography School - New Methods and Applications, Stockholm, Sweden, 17-20 June 2012.

Fourth European Conference on Crystal Growth (ECCG4), Glasgow, UK, 17-20 June 2012.

Insubria International Summer School on Crystallography for Health and Biosciences, Como, Italy, 19-23 June 2012.

Sagamore XVII - Great Potentials from Advanced Probes, Hokkaido, Japan, 15-20 July 2012.

Annual Meeting of the American Crystallographic Association, Boston, USA, 28 July - 1 August 2012.

27th European Crystallographic Meeting, Bergen, Norway, 6-11 August 2012.

International Workshop on New Developments of Methods and Software for Protein Crystallography, Xi'An, People's Republic of China, 25-27 August 2012.

International Summer School on Crystal Growth and Photovoltaic Materials, Brasov, Romania, 27 August - 1 September 2012.

XXII Conference on Applied Crystallography, Targanice/

Andrychow, Poland, 2-6 September 2012.

Aperiodic 2012, Cairns, Australia, 2-7 September 2012.

Indaba 7, Kruger National Park, South Africa, 2-7 September 2012.

Applications of Precession Electron Diffraction, Manchester, UK, 14-15 September 2012.

European Charge Density Meeting (ECDM6), Strbske Pleso, Slovakia, 15-20 September 2012.

Advances in Crystallography at High Pressure, Mito, Japan, 23-27 September 2012.
Fifth K.H. Kuo Summer School of Electron Microscopy and Crystallography International Workshop of Cryo Electron Microscopy and Tomography, Hefei, People's Republic of China, 25-30 September 2012.

International Symposium on Radiation Physics (ISRP12), Rio de Janeiro, Brazil, 7-12 October 2012.

Fundamentals of Modern Methods of Biocrystallography BioCrys 2012, Oeiras, Portugal, 20-27 October 2012.

Computational Discovery for Novel Crystal Structures and Advanced Materials using the USPEX Code, Lausanne, Switzerland, 21-27 October 2012.

4th School of the Argentinian Crystallographic Association, Santa Fe, Argentina, 5-9 November 2012.

Celebration of 100 Years of X-ray Diffraction (Macromolecular Structure of Biological and Non-Biological Materials) Workshop, Hergada Red Sea, Egypt, 18-22 November 2012.

XIII Seminario Latinoamericano de Análisis por Técnicas de Rayos-X, Santa Marta, Colombia, 18-23 November 2012.

International School on Fundamental Crystallography 2012 (ISFC2012), Uberlandia, Brazil, 25 November - 2 December 2012.

AsCA '12/CRYSTAL 28, Adelaide, Australia, 2-5 December 2012.

Biomolecular Forms and Functions: A Celebration of 50 Years of the Ramachandran Map, Bangalore, India, 8-11 January 2013.

Synchrotron Charge Density School, Chicago, USA, 23-29 March 2013.

XIV Intensive Teaching School in X-ray Structure Analysis, Durham, UK, 6-14 April 2013.

Macromolecular Crystallography School 2013: From Data Processing to Structure Refinement and Beyond, Montevideo, Uruguay, 8-16 April 2013.

RapiData 2013, Brookhaven, USA, 21-26 April 2013.

Accuracy in Powder Diffraction IV, Gaithersburg, USA, 2225 April 2013.

The Future of Dynamic Structural Science, Erice, Italy, 30 May - 8 June 2013.

Gordon Research Conference on Electron Distribution and Chemical Bonding, Les Diablerets, Switzerland, 2-7 June 2013.

EMU School on Minerals at Nanoscale, Granada, Spain, 36 June 2013.

Zürich School of Crystallography - Bring Your Own Crystals, Zürich, Switzerland, 9-22 June 2013.

Dynamic Structural Photocrystallography in Chemistry and Materials Science, Buffalo, USA, 16-20 June 2013.

XX Conference of Serbian Crystallographic Society, Belgrade, Serbia, June 2013.

International Workshop on X-ray Powder and Electron Crystallography, Rio, Greece, 2-6 July 2013.

Resonant Elastic X-ray Scattering (REXS 13), Oxford, UK, 15-19 July 2013.

Annual Meeting of the American Crystallographic Association, Hawaii, USA, 20-24 July 2013. 
International Conference on Structural Genomics 2013 Structural Life Science, Hokkaido, Japan, 29 July - 1 August 2013.

15th International Summer School on Crystal Growth, Gdansk, Poland, 4-10 August 2013.

17th International Conference on Crystal Growth and Epitaxy (ICCGE-17), Warsaw, Poland, 11-16 August 2013.

28th Meeting of the European Crystallographic Association, Warwick, UK, 25-29 August 2013.

12th International Conference on Quasicrystals (ICQ12), Krakow, Poland, 1-6 September 2013.

Advances in Static and Dynamic High-Pressure Crystallography, Hamburg, Germany, 8-11 September 2013.

11th International Conference 'Biology and Synchrotron Radiation (BSR)', Hamburg, Germany, 8-11 September 2013.

MISSCA 2013, Como, Italy, 9-12 September 2013.

XXI Brazilian Crystallographic Meeting, Goiania, Brazil, 18-20 September 2013.

III International Conference 'Crystallogenesis and Mineralogy', Novosibirsk, Russia, 27 September - 1 October 2013.

International School on Fundamental Crystallography: Introduction to International Tables for Crystallography Volumes A and A1, Gjulechitza, Bulgaria, 30 September - 5 October 2013.

8th International Workshop on Bulk Nitride Superconductors 2013 (IWBNS-VIII), Kloster Seeon, Bavaria, Germany, 30 September - 5 October 2013.

School of Crystallization and Crystallography for Latin America (ECRISLA 2013), Florianópolis, Brazil, 14-25 October 2013.

Fifth Moroccan School of Crystallography - EMC5, Oujda, Morocco, 23-27 October 2013.

I Latin American Meeting on Crystallography and IX Annual Meeting of the Argentinian Crystallographic Association/V School of the Argentinian Crystallographic Association, Cordoba, Argentina, 29 October - 1 November 2013/ 4-8 November 2013.

Synchrotron Radiation Techniques and Nanotechnology: a Synergic Approach to Life Sciences and Medicine, Cape Town, South Africa, 11-22 November 2013.

12th Conference of the Asian Crystallographic Association (AsCA 2013), Hong Kong, People's Republic of China, 7-10 December 2013.

Australasian Course in Macromolecular Crystallization 2013 (ACNC-13), Melbourne, Australia, 9-13 December 2013.

School of Crystallization and Polymorphism, San José, Costa Rica, 27-31 January 2014.

Southern Africa Powder Diffraction Conference and Workshop, Johannesburg, South Africa, 27-31 January 2014.

Powder Diffraction and Rietveld Refinement School, Durham, UK, 30 March - 3 April 2014.

Electron Crystallography School - Introduction to Electron Diffraction Tomography, Darmstadt, Germany, 7-11 April 2014.

Macromolecular Crystallography School 2014: From Data Processing to Structure Refinement and Beyond, Sao Carlos, Brazil, 8-16 April 2014.
RapiData 2014, Brookhaven, USA, 13 April - 2 May 2014. International School on Fundamental Crystallography 2014 (ISFC 2014), La Plata, Argentina, 27 April - 9 May 2014.

Hot Topics in Contemporary Crystallography, Sibenik, Croatia, 10-15 May 2014.

Annual Meeting of the American Crystallographic Association, Albuquerque, USA, 24-28 May 2014.

4th International School on Crystallization: Drugs, Foods, Agrochemicals, Minerals, New Materials, Granada, Spain, 2630 May 2014.

Structural Basis of Pharmacology: Deeper Understanding of Drug Discovery Through Crystallography, Erice, Italy, 30 May - 8 June 2014.

Structural Biology: Using Synchrotron Radiation to Visualize Biological Molecules, Trieste, Italy, 2-6 June 2014.

International Expo/Sir Workshop, Bari, Italy, 10-13 June 2014.

1st International Symposium on Halogen Bonding (ISXB1), Lecce, Italy, 18-22 June 2014.

A10. Reports of Representatives on Regional and Scientific Associates

A10.1. American Crystallographic Association (ACA)

This triennial report for the activities of the ACA as a Regional Associate of the IUCr is an overview of the more detailed Annual Reports presented each year since the Madrid Congress in 2011, as well as an outline of future activities announced by the ACA. ACA officers change each year; serving as ACA Presidents during this period were Tom Koetzle (2011), George Phillips (2012) and Cheryl Stevens (2013). Martha Teeter is ACA President and Chris Cahill ACA Vice-President for 2014.

ACA finances rely heavily on individual membership dues, in part to cover expenses for the ACA headquarters office in Buffalo. The membership of the ACA was 1574 paid members by end of 2013 compared to about 1840 paid members at the end of 2010, a decrease of about $15 \%$ during the triennium. Most ACA members are from the USA and Canada, although there are many ACA members from countries around the world. Although the ACA strives to find ways to cooperate and extend regional activities to Central and South America, there are usually more attendees from Europe and Asia at ACA meetings than there are attendees from Central and South America. The ACA Council proposed and the ACA membership approved changing the ACA By-Laws to add Latin America to the areas authorized to form a national division. This was approved by a formal vote by the full membership. Thus areas currently authorized to organize as National Divisions are Canada, Latin America and United States of America. Currently a Canadian Representative is elected by the members from Canada, but there is not an elected representative specifically from the USA. How a Latin American representative will be selected is still being determined. Also, the newly proposed Latin-American Crystallographic Association will impact how this develops going forward. 
ACA activities are primarily focused on its Annual Meetings, support for its summer schools, and the publication of the Newsletter ACA RefleXions, which is an excellent source of information on all ACA activities. Past issues of RefleXions are available online from the ACA web site (http://www. amercrystalassn.org/).

$A C A$ 2011. The 2011 annual meeting took place in New Orleans from 28 May - 2 June 2011. The Programme Chair for this meeting was Chris Cahill, with Ed and Cheryl Stevens serving as Local Chairs, and Ilia Guzei as Poster Chair. The meeting was a success with about 216 posters and 394 lectures and about 650 participants. Attendees traveled from 27 different countries with $20 \%$ of the total participants coming from outside the USA. Young scientists (students and postdocs) represented $32 \%$ of the total meeting attendance. A total of 34 Travel Awards totalling USD 20000 were made, including 8 awardees from outside the United States.

The meeting featured two, full-day workshops - one on Symmetry-Mode Analysis and another on an Introduction to PHENIX for Beginning to Advanced Crystallographers. The conference also featured an ACA Transactions Symposium in honour of Philip Coppens in conjunction with his 80th birthday. ACA's Canadian Division organized a session on Evolution of Powder Diffraction Software in honour of Lachlan Cranswick. The 2011 Patterson Award lecture was given by Keith Moffat who spoke on his work in the area of time-resolved crystallography. The 2011 Wood Science Writing Award went to Daniel Nocera. The 2011 Margaret C. Etter Early Career Award went to Yurij Mozharivskyj who discussed efforts to form guiding principles for the design of new magnetocaloric materials.

ACA 2012. The 2012 Annual Meeting took place in Boston where 783 attendees met from 28 July - 1 August. The Programme Chairs for this meeting were Bruce Foxman and Bruce Noll, with Peter Mueller serving as Local Chair, and Ilia Guzei as Poster Chair. Many international students received funds from the IUCr travel grant. A total of 52 Travel Awards totalling USD 29000 were made including 11 awardees from outside the USA. The Boston meeting featured a shorter fourday format with scientific sessions running from Sunday through Wednesday. In addition, four workshops were held Refmac/Coot organized by Paul Emsley and Garib Murshudow; OLEX2 organized by Ilia Guzei; Refinement of Nanoparticle Structures organized by Thomas Proffen, Katherine Page and Reinhard Neder; and an outreach workshop for area K-12 teachers on Crystallography: World of Wonders organized by Cora Lind and Claudia Rawn. The conference also featured an ACA Transactions Symposium in honour of Bruce Foxman and his 70th birthday on Transformations and Structural Oddities in Molecular Crystals organized by Kraig Wheeler, Michael Hickey and Graciela de Delgado.

The Buerger Award went to John Spence of Arizona State who spoke on The Future of Diffraction Physics in Crystallography, the Warren Award went to Paul Fenter of Argonne for his work on liquid-solid interfaces, the Supper Instrumentation Award was given to Ron Hamlin of ADSC for his efforts to advance the development of area detectors, and the 2012 Etter Early Career Award to Emmanuel Skordalakes of the Wistar Institute and University of Pennsylvania for his work on the structure of telomerase.

A number of talks in Boston reflected on the history of crystallography, which was particularly appropriate since the UN had just approved designating 2014 as the International Year of Crystallography earlier that month. Don Casper gave a Plenary Lecture on The History of Structural Biology, Jenny Glusker, Fox Chase Cancer Centre, reflected on 100 Years of Structure Determination, Sue Byram, Bruker AXS, described the Evolution of Small Molecule Crystallographic Instrumentation in North America, and Ron Hamlin Supper Award address 2-D X-ray Detectors - What Do We Really Want and How Can We Build It? covered the development of X-ray detectors from film to the modern pixel array detectors used today.

$A C A$ 2013. The 2013 Annual Meeting took place in Honolulu, Hawaii. The Programme Chairs for the Honolulu meeting were Allen Oliver and Jeanette Krause where 767 attendees met from 20-24 July 2013. An effort was made to make this ACA meeting have more inter-regional appeal. A total of 78 Travel Awards totalling USD 57300 were made including 36 awardees from outside the USA, including awardees from Canada (14), Latin America (4), Europe (9), and Asia (9).

The Hawaii meeting continued the four-day format featuring 20 oral sessions (263 talks) and 3 evening poster sessions with 291 presentations. The meeting was preceded by three workshops: Biological SAXS - Theory and Practice; Introduction to GSAS - II Crystallographic Analysis System; and Getting the Most out of the Cambridge Structural Database. The first Bau Neutron Diffraction Award was presented to Tom Koetzle, the Fankuchen Award went to Richard Dickerson, the Trueblood Award went to Tom Terwilliger, and Eric Ortlund received the 2013 Etter Early Career Award.

The ACA has implemented a number of important actions during this triennium:

ACA Fellows. The ACA Fellows Program was created to recognize a high level of excellence in scientific research, teaching, and professional duties as well as service, leadership, and personal engagement in the ACA and the broader world of crystallography and science. During the past three years 27 fellows have been inducted. The first group of ACA Fellows in 2011 included Helen Berman, Philip Coppens, Johann Deisenhofer, Bill Duax, Judy Flippen-Anderson, Jenny Glusker, Herb Hauptman, Wayne Hendrickson, Carroll Johnson, Isabella Karle, Jerome Karle, S. N. Rao, Connie Rajnak, Michael Rossmann, George Sheldrick, and B. C. Wang. The 2012 class of ACA fellows are Donald Caspar, Dick Marsh, Virginia Pett, Jane Richardson, and Thomas Terwilliger. The 2013 class of ACA fellows are Sidney Abrahams, Wim Hol, Jim Ibers, Alex McPherson, Keith Moffat, and Alex Wlodawer.

IYCr2014. Considerable discussion was devoted to the International Year of Crystallography 2014 (IYCr2014) and how the ACA could best support this initiative. Martha Teeter, 
ACA Vice-President, is spearheading this effort. She has formed an ad hoc committee to coordinate regional celebrations and activities, as well as provide ideas for IYCr2014. In addition, she has been working with the USNCCr and others to write a proposal to submit to NSF. The Task Force is considering a range of topics, including school outreach, media, web outreach, funding, and liaisons with politicians and with other scientific organizations. The ACA Council committed USD 12000 to fund activities related to IYCr2014 in North America. Of this amount, about USD 5000 will be allocated via a call for proposals with the balance used for Task Force projects, including a National Crystal Growth Contest.

ACA Journal. The ACA has agreed with the AIP (American Institute of Physics) to co-publish a new on-line journal titled Structural Dynamics. The AIP representatives to the Board of Managers are Mark Cassar and Chris McMahon, with Judy Flippen-Anderson and Soichi Wakatuski representing the ACA. The Editor is Majed Chergui with Thomas Elsaesser, George Phillips, Franz Pfeiffer, Gwyn Williams and Linda Young as Associate Editors. Journal topics include structural dynamics of molecular systems, biological systems, solid materials, liquids and solutions, and surfaces and interfaces studies using highly coherent sources; with a time resolution from femtoseconds to milliseconds; spatial resolutions from $1 \AA$ to $1 \mathrm{~mm}$ (see sd.aip.org).

Summer Schools. The ACA Summer Course in Small Molecule Crystallography for the period 2012-2015 alternates between Northwestern (odd years) and Notre Dame (even years). The next summer school will be held from 7-16 July 2014 at Notre Dame. No ACA course in macromolecular crystallography is currently approved, but it was noted that there are other macromolecular workshops that fill much of this void.

ACA History Fund. Virginia Pett has compiled a series of Living History articles that have been published in RefleXions. The full documents with references have been archived in the AIP History Center Niels Bohr Library \& Archives (NBLANDA).

Strategic Planning. A strategic planning committee of Cheryl Stevens (Chair), Bill Duax, Judy Flippen-Anderson, S. N. Rao, Martha Teeter, George Phillips and Marcia Colquhoun met on 29-30 May 2013 at the AIP headquarters to the mission of the ACA and analyze its strengths, weaknesses, opportunities, and threats (SWOT). A list of action items resulted that include collecting information from ACA SIG members, succession planning, and developing an employee manual.

Future Meetings. Upcoming ACA Annual Meetings include 2014 in Albuquerque, New Mexico, from 20-24 May with Christine Beavers and Petrus Zwart as Programme Chairs and Zoe Fisher and Kate Page as Local Chairs. The 2014 Award winners are John R. Helliwell (Patterson Award) for his pioneering contributions to the development of the instrumentation, methods and applications of synchrotron radiation in macromolecular crystallography, and D. Borden Lacy (Etter Early Career Award). The 2015 ACA Annual Meeting will be held in Philadelphia, PA, 25-29 July with Programme CoChairs Kraig Wheeler and Louise Dawe.

The ACA IUCr Regional Representative has also been involved in plans for the 23rd IUCr Congress in Montreal in 2014 as a member of the International Programme Committee and the Executive Committee for the Local Committee. Plans for that meeting are progressing well, a web site for the Montreal Congress has been up since last year, over 2000 abstracts have been received and we hope to see 3000 crystallographers from around the world in Montreal in August.

On a sad note, the ACA lost a number of outstanding members during the past triennium, including the Colonel, William Lipscomb, Jr (1969 Nobel Laureate) 14 April 2011, Herb Hauptman (1985 Nobel Laureate) 23 October 2011; David Sayre 23 February 2012, R(obert) A(lan) 'Ray' Young 13 June 2012, Hugo Steinfink 25 August 2012, Louise Johnson 25 September 2012, Guy Dodson 24 December 2012, John Woolcock 29 January 2013, Ray Davis 29 May 2013, Charles Caughlan 25 April 2013, Jerome Karle (1985 Nobel Laureate) 6 June 2013, Dave Rognlie 29 July 2013.

\section{L. Hackert, Representative}

A10.2. Asian Crystallographic Association (AsCA) AsCA continues to play a leading role in the nurturing of collective crystallographic activities in the Asia-Pacific region with successful scientific meetings being held in those years in which there is no IUCr Congress and General Assembly.

AsCA Executive Officers and Web Secretary. In the period 2011-2013 the office bearers of AsCA were Se Won Suh (President, Korea), P. Chakrabarti (Vice-President, India) and A. Vrielink (Secretary/Treasurer, Australia). The current executive officers for the term 2013-2016 were elected in Hong Kong and are: P. Chakrabarti (President, India), Jennifer Martin (Vice-President, Australia), J. J. Vittal (Secretary/Treasurer, Singapore), and A. Vrielink (Web Secretary, Australia).

AsCA scientific meetings in the period 2011-2013. In the past three years, the AsCA calendar ran as follows: IUCr Congress (in 2011) - Joint AsCA/SCANZ meeting (in 2012) - Full triennial AsCA meeting in Hong Kong, People's Republic of China (in 2013). No AsCA scientific meetings are held in the year when the IUCr Congress takes place.

AsCA 2012. The most important activity of AsCA in 2012 was the joint AsCA '12/CRYSTAL-28 Conference, which was held in the Adelaide Convention Centre, Adelaide, Australia, 2-5 December 2012. A total of 456 delegates from 25 countries attended the meeting. There were 96 oral and 247 poster presentations. The talks were of a very high standard with broad international participation. The three Plenary speakers were Wayne Hendrickson, Xiao-Ming Chen and Henry Chapman. Professor Hendrickson, who played a key part in the development of protein crystallography, talked about the development of methods of SAD phasing. Professor Chen presented data on metallo-organic lattices that have been engineered to selectively absorb compounds and gases. Professor Chapman presented the latest results from X-ray 
free electron laser experiments on protein crystals. Three Keynote speakers, Professor Ringer, Professor Welberry, and Professor Cole, addressed the state of the art in solid solutions, optoelectronics, and diffuse scattering, respectively. AsCA thanks the efforts of Professor Ray Withers and the SCANZ Council, the International Science Advisory Committee (ISAC) chaired by Dr Jose Varghese, and the Local Organizing Committee (LOC) chaired by Professor John Carver.

Immediately following the AsCA'12/CRYSTAL-28 Conference, a special Bragg Centennial Symposium was held on 6 December 2012 in the University of Adelaide to honour the contributions of William Lawrence Bragg and his father William Henry Bragg for their pioneering and far-reaching contributions to the development of X-ray crystallography. William Bragg was the Elder Professor of Mathematics at the University of Adelaide. Lawrence Bragg was born in Adelaide and received his first degree from the University of Adelaide. November 2012 marked the centenary of the presentation of Lawrence Bragg's paper to the Cambridge Philosophical Society defining Bragg's equation. The symposium speakers included Mrs Patience Thomson (younger daughter of Sir Lawrence Bragg), John Jenkin (La Trobe University), Anthony Kelly (University of Cambridge), Brian Matthews (University of Oregon), Anders Liljas (Lund University), Thom Mason (Oak Ridge National Laboratory), Colin Humphreys (University of Cambridge), John Spence (University of California, Berkeley), Wayne Hendrickson (Columbia University), Tony Cheetham (University of Cambridge), Jenny Martin (University of Queensland), and Anthony Klein (University of Melbourne). A total of 333 delegates from 22 countries attended the symposium. Many Bragg-related papers presented at the Symposium were published in January 2013 in the special Bragg Centennial issue of Acta Crystallographica Section A. AsCA thanks the efforts of Steve Wilkins for organizing such a memorable symposium. We note the untimely passing of Steve Wilkins only months after the meeting.

AsCA 2013. The most important activity during 2013 was the AsCA 2013 Conference in Hong Kong. At the 2011 AsCA Council meeting in Madrid, it was decided that the AsCA 2013 meeting would be held in Dhaka, Bangladesh. Owing to local political instability in conjunction with a national election, the Council decided to move the venue in late March 2013. Ian Williams proposed that the meeting be held at the Hong Kong University of Science and Technology (HKUST), with new conference dates of 7-10 December 2013. The Chairs and coChairs of the Local Organizing Committee (LOC) and the International Programme Committee (IPC) were Ian Williams (People's Republic of China, LOC Chair), Takashi Kamiyama (Japan, IPC Chair), Zhi-Jie Liu (People's Republic of China, Area 1 IPC co-Chair), J. J. Vittal (Singapore, Area 2 IPC coChair), Alison Edwards (Australia, Area 3 IPC co-Chair). Several workshops and a one-day Saturday Structural Biology Symposium were also organized. The attendance at the meeting, associated symposia and workshops totalled 413 individuals from 30 countries (Japan 97, People's Republic of China 56, Korea 47, Hong Kong 46, Taipei 31, Australia 30,
India 25, UK 16, Singapore 10, USA 10, Thailand 8, Germany 5, Malaysia 4, New Zealand 4, Russia 4, Sweden 3, Switzerland 3, Italy 2, Austria 1, Bangladesh 1, Denmark 1, France 1, Indonesia 1, Ireland 1, Macau 1, Mexico 1, Netherlands 1, Pakistan 1, Poland 1, Vietnam 1). This was considered to be an excellent outcome given the very late change of venue and timing.

Future AsCA scientific meetings. AsCA 2015. In 2012 the AsCA Council accepted a proposal from the Indian delegation to host a joint AsCA meeting in Kolkata, India in 2015. The 13th Conference of AsCA (AsCA 2015) will be held as a joint meeting with the Indian Crystallographic Association at Science City, Kolkata, India, 5-8 December 2015. Pinak Chakrabarti (India) is the Chair of the LOC and Alice Vrielink (Australia) is the Chair of the IPC. IPC co-Chairs are Catherine Day (New Zealand) (Area 1: Structural Biology), Ian Williams (Hong Kong) (Area 2: Chemical Crystallography), and Masaki Takata (Japan) (Area 3: Specialized Techniques).

AsCA 2016. The AsCA Council meeting at Hong Kong decided that the 14th Conference of AsCA (AsCA 2016) would be held in Hanoi, Vietnam. Professor Duong Ngoc Huyen will be the LOC Chair. Details of the dates and local venue will be decided at the next AsCA meeting.

AsCA 2018 and beyond. New Zealand and Singapore, among others, expressed a strong interest in hosting future AsCA meetings.

AsCA Council meetings in 2011-2013. 2011 meeting. The AsCA Council meeting was held on 26 August 2011 in Madrid, Spain. Professor Sine Larsen, IUCr President, thanked the organizers of the November 2010 AsCA meeting for a very successful conference held in Busan. Professor Larsen reported on the plans to have 2013 [subsequently 2014] proclaimed as the International Year of Crystallography (IYCr). A proposal was to be made to UNESCO by Abdelmalek Thalal, Chair of the Moroccan Crystallographic Society. In addition, a proposal was prepared for presentation to the General Assembly of the United Nations. Professor Larsen emphasized the importance of all the IUCr journals and publications. Professor Ray Withers presented the progress towards the 2012 AsCA/SCANZ (Society of Crystallography in Australia and New Zealand) meeting to be held at the Adelaide Convention Centre 2-5 December 2012. Professor Steve Wilkins described the Bragg Centennial Symposium which will be held at Elder Hall, University of Adelaide, 6-7 December 2012. Professor Altaf Hussain (Bangladesh) presented a brief overview of a bid to host the 2013 AsCA meeting in Dhaka, Bangladesh. Professor Duong Ngoc Huyen (Vietnam) also presented a brief overview of a bid to host the 2013 AsCA meeting in Hanoi, Vietnam. It was decided by voting that the 2013 AsCA Meeting would be held in Dhaka, Bangladesh. The IUCr annual fee (CHF 1000) for the Regional group of five countries (Bangladesh, Malaysia, Singapore, Thailand and Vietnam) had been paid for by Japan and Australia each year for the last 3 years (2009-2011). Professor Withers proposed that AsCA pay this for the next three years (2012-2014) from its own funds. 
2012 meeting. The AsCA Council meeting was held 4-5 December 2012 in Adelaide, Australia. Professor Gautam R. Desiraju, IUCr President, presented an overview of the current activities of the IUCr. He commented on the growth of the community within AsCA and the high quality of talks and, particularly, the larger number of students in attendance. Professor Desiraju reported that the IUCr would soon appoint a project manager to promote IYCr activities. Professor Samar Hasnain, the newly appointed Editor-in-Chief of the IUCr journals, spoke about his vision for the IUCr journals. His presentation was entitled Responding to a New Era of Crystallographic-Based Science and Changes in its Global Distribution. Finally, Professor Hasnain expressed concern that relatively few Main Editors and Co-editors for the journals came from AsCA countries (41 as opposed to 156 from nonAsCA regions). Nomination of candidates should be sent to Peter Strickland or Samar Hasnain with a short CV. Professor Ray Withers reported on AsCA 2012/CRYSTAL28. He was very pleased to report that there were over 425 attendees. He also reported on the Bragg Symposium with the expectation that there would be $\sim 350$ delegates. Professor Sydney Hall reported on his organizing of a detailed recording of the history of AsCA. Amendment of the AsCA Constitution was finalized to introduce new membership categories as Category A ( 1 councillor with no vote), Category B (1 councillor with 1 vote), Category C ( 2 councillors with 2 votes), Category D ( 3 councillors with 3 votes), Category E (4 councillors with 4 votes), and Corporate/Affiliation (1 councillor with no vote). The Constitution was also amended to include the immediate Past President in the Executive Committee in addition to the three elected officers (President, Vice-President, and Secretary-Treasurer).

2013 meeting. The AsCA Council meeting was held 9-10 December, 2013 in Hong Kong, People's Republic of China. The Council elected new AsCA Officers for the 2013-2016 term: President, Pinak Chakrabarti (India); Vice-President, Jennifer Martin (Australia); Secretary-Treasurer, J. J. Vittal (Singapore). Professor Gautam R. Desiraju gave an update on the activities within the IUCr regarding other Regional Associates. He informed us that Latin-American countries were in the process of forming a Regional Association. He also stressed that belonging to an IUCr member country is very important and that regularizing membership is the best way to receive full recognition and a larger voice in international crystallographic affairs. Professor Ian Williams outlined the statistics for the AsCA 2013 meeting held 7-10 December 2013 in Hong Kong, People's Republic of China. Attendance at the meeting and associated symposia and workshops was 413 individuals from 30 countries. Professor Pinak Chakrabarti (Chair of the LOC) and Professor Alice Vrielink (Chair of the IPC) reported on the organization of the 13th Conference of AsCA (AsCA 2015), to be held jointly with the Indian Crystallographic Association at Science City, Kolkata, India, 30 November -3 December 2015. It was decided that the 14th Conference of AsCA (AsCA 2016) would be held in Hanoi, Vietnam, with Professor Duong Ngoc Huyen acting as the LOC Chair.
Initiatives for the future of $A s C A$. The following were presented as major initiatives to meet future challenges facing AsCA:

(a) Recruitment of new members, including Corporate/ Affiliation members: Agilent Technologies expressed an interest in joining AsCA as a Corporate member. Some countries such as Iran, Saudi Arabia and Uzbekistan have expressed interest in joining AsCA. Neighbouring countries such as Russia and USA are also welcome as a Category A member (no membership fee, no vote).

(b) Creation of Commissions (and/or Interest Groups) within AsCA;

(c) Creation of an Advisory Committee to steer AsCA towards its long-term goals in keeping with its historic foundations; and,

(d) Creation of Web Secretary position in the Executive Committee.

Financial status and challenges for AsCA. AsCA has accumulated a reserve of about AUD 187000 to support attendance at AsCA meetings by students and early-career scientists mainly from developing countries in the region. AsCA offers five scholarships to attend AsCA meetings, providing up to about USD 1000 each. It is the intention of the AsCA Executive that a similar or a higher level of support will be provided for forthcoming meetings. In order to sustain these initiatives in the long term, AsCA needs to secure additional sources of funding to increase the total AsCA investment portfolio.

We appreciate an agreement from the IUCr Presidents to provide direct financial support from the IUCr for attendance by two or three members of the AsCA Council, who would not otherwise be able to afford to attend Council meetings. The agreement is for three years but an individual can receive support on only one occasion. This initiative recognizes the special circumstances faced by a number of member countries of AsCA. AsCA appreciates continued support from the IUCr.

Some of the problems that the Asian crystallographic community faces today are different from those faced by other Regional Associates of the IUCr. The member countries are geographically separated by large distances and seas and there needs to be more in the way of systematic bilateral and multilateral initiatives among the countries of the region so that the scientific communities in these countries get to know each other better. Travel and research support for students and young workers is also very limited and there is a need for more funding in these areas. Economic growth in the Asian region should be paralleled by scientific and infrastructural growth. IUCr support is critical to ensure that crystallographic research in some of the more disadvantaged regions of Asia is put on a firmer footing. A greater representation of younger crystallographers from the Asia-Pacific region in the activities of the IUCr is strongly desirable. The IUCr could also become more involved in mentoring activities as some of the Asian countries are rapidly trying to become integrated with the international scientific mainstream. In conclusion, the AsCA Council thanks the strong support of the IUCr in the past to 
promote crystallography in the Asia-Pacific region and anticipates continued IUCr support in the future.

Summary. AsCA continues to grow in strength and there is no doubt that the creation and continued success of AsCA has had a positive effect on education and research in crystallography in this region. But it needs special consideration from the IUCr, especially with regard to the growth and development of crystallography in small, far-flung Asian countries. For example, AsCA needs the IUCr support to hold small bilateral and trilateral meetings within the Asian region. The student population in Asia is the largest but they are the least endowed in terms of being able to attend international scientific meetings. Scientists from Europe and North America are warmly invited to attend meetings of AsCA, which are becoming scientifically very competitive. AsCA is a good role model for other regions of the world such as Africa and Latin America in terms of organizing themselves into a critical mass of scientific activity.

I thank Se Won Suh and P. Chakrabarti for their assistance in preparing this document.

\section{J. M. Guss, Representative}

\section{A10.3. European Crystallographic Association (ECA)}

The link between IUCr and ECA functions well. The IUCr Representative was on the mailing list of the ECA Executive Committee. She attended on a regular basis the sessions of the ECA Council and of the ECA Executive Committee, and was a member of the Programme Committee of the ECM - in 2012 in Bergen and in 2013 in Warwick. In 2012 the ECA membership of the Executive Committee was changed according to the regular rotation. The membership has a good country-gender-research field balance. Every member of the Executive Committee has a well defined scope of duties and responsibilities. The work is very well organized. The spirit is highly democratic. A very good continuity is ensured by preserving some co-opted members from the previous term to share their experience. The present President of the ECA is Andreas Roodt (South Africa), Vice-President Alessia Bacchi (Italy), Immediate Past President Santiago Garcia-Granda (Spain), Secretary Georgina Rosair (UK), and the Treasurer Christian W. Lehmann (Germany). The officers of the ECA are Udo Heinemann (Germany), Joke Hadermann (Belgium), Olga Yakubovich (Russia), Fermín Otalora (Education Coordinator) (Spain) and Paolo Scardi (EPDIC Representative) (Italy). Co-opted members from the previous term are Petra Bombicz (ex-Secretary) (Hungary) and Radomir Kuzel (ex-Treasurer) (Czech Republic). The ECA Executive Committee winter meeting took place in Budapest, Hungary, in 2012 and in 2013, and in Rovinj, Croatia, in 2014, to see the location of the forthcoming ECM-29 in 2015. All three meetings were very efficient.

The ECA Executive Committee consistently makes the effort to invite countries from the 'ECA region', namely Europe and Africa as well as the Middle East, that are not yet members of the ECA, to join the Association, either as members or perhaps as 'Observer countries'. The Irish Crys- tallographic Association, representing the interests of the crystallographic community in both the Republic of Ireland and Northern Ireland, was formed in 2011. It has applied to join the European Crystallographic Association as a national member; this proposal was warmly commended by the Executive Committee for approval to the ECA Council at ECM-27 in Bergen, Norway. Since 2012 Olga Yakubovich is the officer responsible for encouraging new countries to join the ECA. She has a complete list of contact people and tries negotiating, but the real situation in the countries is often an obstacle of entering any international scientific union, ECA not being an exception.

The activities of the Special Interest Groups (SIGs) are reviewed from year to year. The number of individual members registered with SIGs has increased significantly in the last year. The ECA does a lot to encourage individual memberships (IMs), including giving IMs more visibility at the ECMs. Two thirds of SIGs/GIGs now have their web sites active, one quarter have a mailing list. A new system of social and academic networking groups was introduced at ECM-25 and ratified by the ECA Council in Madrid. These 'General Interest Groups' (GIGs) follow the similar constitutional rules as the SIGs. GIG1 - Young Crystallographers had already started to operate enthusiastically at ECM-25, ad interim, and at the Madrid Congress where it was formally constituted. This GIG organized a MS 'How to...' at the ECM in Bergen, and a very interesting MS in Warwick. GIG1 also had one-day satellite meeting preceding ECM-27 and ECM-28, in Bergen, Norway, and in Warwick, UK, and these were a great success. GIG2 - Senior Crystallographers has been formed, and had its opening session at ECM-27 in Bergen. GIG2 was very active at ECM-28 in Warwick. The founding of a GIG for Teaching is emerging and others may be called into being in the future.

After the representation of Corporate Affiliate Members in the ECA Council was formalized in Madrid in the form of a CAM Councillor, Tony Savill was elected by the CAMs. This formation has already led to improved guidelines about the requirements and recommendations for commercial exhibitions at ECMs. These guidelines, together with an improved 'How to prepare and submit a bid to host a future ECM' and 'Guidance for ECM Organizers', will assist future bidders to host and organize European Crystallographic Meetings (http://www.ecanews.org/Guidlines_ECM.php). The ECA is very grateful to Tony Savill as well as to Sandy Blake for their detailed assistance in these revisions.

The ECA is aware of the general economic climate and that this might be presenting hardship to crystallographer colleagues at all stages of their careers as well as causing difficulty to attend an ECM. Thus the Executive Committee has launched a call for donations from those that can help other colleagues to attend the ECMs by contributing to their costs. ECA Council has formally launched these ECA Scholarships; these are in addition to the long-time existing ECA Student Bursaries for ECMs. Applicants have to have been an IM for at least three years to qualify to apply for an ECA Scholarship to attend an ECM; detailed rules are made available. An important initiative of the ECA is that not only young 
researchers, but also senior crystallographers, if retired, can register with a reduced registration fee at ECMs.

The ECA places strategic importance and effort on the education of future generations of crystallographers at all levels. In the process of the establishment of a European Graduate School of Crystallography an improved proposal for an ERASMUS MUNDUS Masters Course was submitted several times, which was expected to involve a collaboration of several European universities and companies, to the European Community Offices in Brussels. Unfortunately, though the proposal has received high ranking, this was not sufficient for final approval. The ECA for a long time enthusiastically and regularly has provided financial support to Conferences/ Workshops/Schools within the ECA region. Whilst still being committed to give regular support to these local initiatives, the ECA also promoted a high-level European School (ECS) for continuous, and rigorous, education in crystallography, initiated by the Italian Crystallographic Association. The plan is that this ECS will be held annually in a different European country. This initiative of a series of schools with an official commitment by the ECA is to have a direct involvement of ECA through an ad interim Sub-Committee on Education (ECA-SE). The Executive Committee has worked out the guidelines that are available to all potential applicants for these European Crystallography Schools. This proposal has been approved by ECA councillors. The First European Crystallography School will thus take place in Pavia, Italy, 28 August - 6 September 2014. ECS1 is directed to young researchers and $\mathrm{PhD}$ students involved in all different fields of structural sciences, and aims at diffusing and sharing the idea of crystallography as a unique discipline. The School will include lectures and practical sessions, as well as dissemination seminars open to the public, in order to increase the awareness and ignite an interest in crystallography among young students. Moreover, a series of satellite events will be organized to celebrate IYCr2014.

One should emphasize once again a very high educational activity within the ECA. There are many annual schools and advanced study courses throughout Europe and outside it organized by the ECA. Special MS on teaching crystallography take place at the ECM, and are very well attended. Among others, one should mention a new initiative - the ECA is also very active and successful in providing electronic platforms for disseminating information on various types of activity related to crystallography in general and the IYCr in particular. They can be used well by all the IUCr community. Professor Garcia-Granda is the contact person. The ECA is one of the most active contributors to the events of the IYCr. One can visit the www.iycr.org site to see all the numerous events organized in Europe, and in most of them active ECA members and officers are involved. The ECA Executive Committee asked to forward to the Executive Committee of the IUCr and to the organizers of the Montreal Congress a request to give more visibility at the official ceremony dedicated to the IYCr to the Regional Associations - ECA, ACA and AsCA, since, regretfully, at the IYCr Opening Ceremony of the IYCr this was not done.
The annual ECMs belong to the most important meetings organized by ECA. The Chairs of the ECMs, namely ECM-27 in Bergen in 2012, ECM-28 Warwick 2013 and ECM-29 Rovinj 2015, present regularly their organization's progress at the Executive Committee. In 2014 the ECA Executive Committee winter meeting was combined with the site inspection of the forthcoming ECM-29, and the location was found excellent with very flexible facilities and an attractive environment. The ECMs in Bergen in 2012 and in Warwick in 2013 were very successful, and both related to the forthcoming IYCr. Very interesting Special Events, Lectures and Exhibitions were organized both in Bergen and in Warwick. Details can be found at the sites of both meetings (links from the ECA site). At ECM-27 a special Microsymposium on quasicrystals was funded by the Nobel Foundation. There was also a special Laue Centennial Lecture given by Professor Dr Dieter Schwarzenbach, which commemorated the 100th anniversary of the discovery of X-ray diffraction by Laue, Friedrich, and Knipping. At ECM-28 Professor Daniel Shechtman, Nobel Laureate in Chemistry 2011, delivered a Plenary Lecture.

At ECM-27 and ECM-28 the Perutz Prize and the Bertaut Prize were awarded. The sixth Max Perutz Prize of the ECA went in 2012 to Professor Hartmut Fuess from the Department of Materials Science at the University of Technology in Darmstadt (Germany). Hartmut Fuess was recognized for his outstanding contributions to structure research of functional materials such as zeolites, fuel cells, and magnetic materials, the construction of scientific instruments at large-scale synchrotron and neutron facilities and his skilled and enthusiastic service to crystallography in Europe and the broader international community. The Fifth Erwin Felix Lewy Bertaut Prize of the ECA and the European Neutron Scattering Association (ENSA) in 2012 was awarded to Dr Pavel V. Afonine from the Lawrence Berkeley National Laboratory, Berkley, USA. Pavel Afonine was recognized for his notable work on the theoretical and methodological aspects of X-ray and neutron macromolecular crystallography and specifically has developed software to use neutron diffraction data in combination with or separately from X-ray diffraction data. The ECA awarded the seventh Max Perutz Prize to Professor Randy J. Read for his contribution to the development and application of advanced statistical approaches to all stages of protein structure solution.

In summary, the ECA is in a healthy state, and the IUCrECA link works well.

E. Boldyreva, Representative

A10.4. International Centre for Diffraction Data (ICDD) The Commission on Powder Diffraction maintains close links with the ICCD and also with the International X-ray Absorption Society (IXAS) (http://www.i-x-s.org/).

P. Whitfield, Representative 
A10.5. International Organization of Crystal Growth (IOCG)

The most important event concerning IOCG (http://www.iocg. org/) in the triennium 2011-2013 was the official meeting of the association, the 17th International Conference on Crystal Growth and Epitaxy (ICCGE-17), Warsaw, Poland, 11-16 August 2013. Ten general sessions and nine topical sessions were organized. The Conference was very successful (about 1200 participants) and very well organized. The week before the Conference, the 15th International Summer School on Crystal Growth (ISSCG-15) was held in Gdansk, Poland, with the participation of 120 students. Both the Conference and the School were supported by the IUCr.

Many members and consultants of the Commission (CCGCM) were involved in the organization of the Conference and the School, but I would like to mention in particular:

the contribution of Ewa Talik, Chair of the Crystal Growth School, ISSCG-15;

the activity of Abel Moreno, Kullaiah Byrappa and Thierry Duffar, who respectively co-chaired as IUCr representative the sessions: Biological and Biogenic Crystallization, Industrial Crystallization, Defect Formation/Elimination; it was the first time that sessions of the IOCG Conference were officially co-organized by IUCr representatives.

Moreover, the award of the 2013 IOCG Frank Prize to Katsuo Tsukamoto, consultant of this Commission, must be emphasized.

The new Executive Committee of the IOCG was elected and confirmed during the General Assembly of the IOCG in Warsaw. Roberto Fornari (Italy) was confirmed as President for the next triennium, Co-Vice-Presidents are T. F. Kuech (USA) and K. Kakimoto (Japan), the Secretary is H. A. Dabkowska (Canada), and the Treasurer V. Fratello (USA). The members of the Executive Committee are J. M. GarciaRuíz (Spain), Y. Mori (Japan), K. Roberts (UK), M. Heuken (Germany), F. Puel (France), E. Vlieg (The Netherlands), Mu Wang (People's Republic of China), and J. De Yoreo (USA).

Key issues for the triennium 2013-2016 of IOCG according to Roberto Fornari will be:

Promotion and coordination of regional and topical meetings on crystal growth;

Support for organization of ICCGE-18 and ISSCG-16;

Update of the IOCG web site and statistics of the visits/ downloads;

Education: promote international and regional schools 'where the potential students are', and support for existing permanent educational activities;

Prizes: Advertise the Laudise, Frank and Schieber prizes and promote nominations;

Extend the number of national organizations: establish contacts to crystal growth communities in countries with traditional activity as well as to new subjects of crystal growth research and stimulate them to join IOCG.

Contacts to other International Organizations. After the positive experience made with IUCr and E-MRS in the past, IOCG should now seek new contacts with MRS, European
Federation of Chemical Engineers-Working Party on Crystallization.

The next international meetings ICCGE-18 and ISSCG-16 (Chair K. Kakimoto, member of this Commission) will be held in Japan, respectively, in Nagoya and Otsu, in 2016, and the 2019 meetings will take place in USA. The Chair of ICCGE-18 accepted our proposal to carry forward the idea to co-organize three symposia in cooperation with IUCr representatives.

Both during the Executive Committee Meeting and the General Assembly, I was given the opportunity to underline the importance of the celebration of 2014 as the International Year of Crystallography.

Moreover, IOCG made an important contribution for the organization of the web site on artificially grown crystals (http://www.iycr2014.org/participate/crystal-growing). Bogdan Ranguelov (Bulgaria), Kevin Roberts (UK), and Elias Vlieg (The Netherlands) are part of the scientific committee of the web site as representatives of IOCG. Moreover, IOCG is helping to promote the web site.

A. Zappettini, Representative

A11. Reports of Representatives on bodies not belonging to the Union

A11.1. Interdivisional Committee on Terminology, Nomenclature and Symbols of the International Union of Pure and Applied Chemistry (IUPAC ICTNS)

(1) ICTNS continued its activities on behalf of IUPAC in reviewing and approving Technical Reports and Recommendations submitted to IUPAC for publication in Pure and Applied Chemistry, and also for approving, on behalf of IUPAC, publications emanating from international bodies on which IUPAC has representation.

(2) The following Technical Reports and Recommendations have been reviewed by referees chosen among IUCr members:

Definitions of Terms Relating to Crystalline Polymers

Definition of The Hydrogen Bond

Polymer glossary

Terminology of Polymers

A. Authier, Representative

\section{A11.2. International Council for Science (ICSU)}

The International Council for Science (ICSU) was founded in 1931. The aim of ICSU is to promote international activities in different branches of science and strengthen international science for the benefit of humanity. ICSU is unique in its dual membership of National Scientific members and International Scientific Unions (http://www.icsu.org). The membership of ICSU continues to grow steadily - the present numbers of Union members and National Scientific members are 31 and 121. The IUCr has been a member of ICSU since its start in 1948. Though it is one of the smaller Scientific Unions, the IUCr is the one with the most extensive publishing activity. Like the IUCr, ICSU has a General Assembly (GA) every 
three years, at which the ICSU Executive Board (EB) is elected, which together with the staff at the ICSU office in Paris is responsible for the daily management.

As the IUCr Representative I attended the 30th ICSU General Assembly held in Rome, Italy, 26-30 September 2011. Prior to the meeting there was a day of Open Forum meetings for members of the Scientific Unions and members of the National Committees. It was very useful to have this opportunity to discuss the issues to be addressed at the following GA with colleagues from other Unions. One of the more important points of the agenda concerned the results from the implementation of ICSU's first strategic plan 2006-2011. A number of global initiatives had been initiated, which addressed international research collaboration, science for policy and Universality of Science; among them were Regional Offices established in developing parts of the world that should stimulate interactions between member countries. Assurance of access to data and information is another important area of ICSU activities. To define the future role of ICSU in science education a special ad hoc group had been formed. The work by G. Chapuis (IUCr) as a member of this group was much appreciated. The successor to the Strategic Plan, ICSU's Strategic Plan II 2012-2017 ((http://www. icsu.org/publications/reports-and-reviews/icsu-strategic-plan2012-2017) was presented at the GA. It retained many of the goals of the first strategic plan. A keyword in the plan is global sustainability, and environmental issues play a central role. A number of the initiatives in the new strategic plan were approved. For the first time the GA contained poster expresso sessions, where participants in the General Assembly gave short presentations about the organizations. The GA elected Noble Prize winning chemist Professor Yuan Tseh Lee from Taipei as President for ICSU.

No ICSU meetings involving Union Representatives were organized during 2012. In 2013 a special ICSU meeting for Union Representatives was held 28-29 April in Paris, France, where I represented the IUCr. The meeting was attended by 47 representatives from 22 Scientific Unions, the ICSU management and representatives from ICSU's Regional Offices in Africa, Asia and Latin America. Prior to the start of the meeting, representatives of Unions belonging to the Physical, Chemical and Mathematical Science cluster met informally to discuss issues of mutual interest. The Unions IUPAC, IUPAP, IUMRS (materials research societies) and IUCr face similar problems, which made it a very useful meeting, where future relations between ICSU and the Unions were addressed.

The main aim of the Unions' meeting, which reflected the view and attitude of the ICSU President Yuan Tseh Lee, was to engage the Scientific Unions in the realization of ICSU's new Strategic Plan. During the two-day meeting two different break-out sessions were organized. The first day was devoted to the discussion of the following three issues: Future Earth; Science Education; Communication between ICSU and the Unions. The Union Representatives were divided into three groups that discussed all three items. The second day the break-out groups addressed: Urban Health; New Inter- disciplinary Horizons; Open Access to Data and Information; IRDR (Integrated Research on Disaster Risk), with the possibility to participate in two of the break-out groups. The results from the discussions in the different break-out groups were reported in plenum, and carefully noted by the ICSU management. The meeting was valuable in many aspects, it gave good insight into ICSU's strategic plan and created good contacts to other Union members of ICSU and it was also a valuable step in improving the relation between the Unions and ICSU.

The operation of ICSU's Regional Offices (RO) established in developing parts of the world as part of ICSU's first strategic plan had not been without any problems, and a couple of them had changed host country. Since the activities of ICSU's RO could have some synergy with the activities of the IUCr in Africa and South America, I accepted an invitation from ICSU's Regional Office in Latin America and the Caribbian (ROLAC) to attend a workshop on Future Earth at Varadero, Cuba, 9-10 January 2014. The workshop was well attended by representatives from most Scientific Unions and there were productive and fruitful discussions in break-out sessions, and importantly it resulted in proposals for joint actions, involving Unions in the regions.

\section{S. Larsen, Representative}

A11.2.1. ICSU Committee on Data for Science and Technology (CODATA)

CODATA is the interdisciplinary Committee on Data for Science and Technology of the International Council for Science (ICSU). It is currently a worldwide network of 22 National Data Committees (an increase of 4 since the last triennium), one Associate National Member, 17 International Scientific Unions, 3 co-opted delegates, and 20 supporting organizations from industry, government and academia, which define and lead its scientific programme. Its mission is 'to strengthen international science for the benefit of society by promoting improved scientific and technical data management and use'. Specific projects are addressed by Task Groups answerable to the CODATA General Assembly, by Working Groups, by themed workshops or conferences, and by publications on specific aspects of data handling or data compilation.

The major activities of CODATA in the past triennium were as follows.

The 23rd International CODATA Conference took place in Taipei, at the end of October 2012. Its theme was Open Data and Information for a Changing Planet. Amongst a wide and diverse programme this conference provided a good and timely overview of 'Big Data' handling by various communities (e.g. particle physicists' use of the cloud) and such details were subsequently shared with the IUCr Diffraction Data Deposition Working Group, which has reported separately to the IUCr Executive Committee. The IUCr was actively involved in two Data Mining Microsymposia sessions. J. R. Helliwell presented a talk, co-authored with Brian McMahon, on Data Archiving in Crystallography and the 
activities of the IUCr Diffraction Data Deposition Working Group. The second session was chaired by J. R. Helliwell. Two talks were presented, and an impromptu panel discussion was convened to discuss various current perspectives on data mining. Scientific data and medical data featured in inputs from the audience as well as the perceived need for incentives for scientists to link data to their publications more than is currently practised. The conference was immediately followed by the 28th CODATA General Assembly, which reviewed the 2013-2018 Strategic Plan, and approved initiatives to help Early Career workers, and to promote the work of CODATA to its members and the public at large. Full reports on these meetings can be found at http://www.iucr.org/news/meetingreports/meeting-reports/. The 2014 CODATA Conference was approved to be in New Delhi, India, 2-5 November 2014 and is to be on the theme Data Sharing and Integration for Global Sustainability.

Full details of CODATA activities are available from its web site at http://www.codata.org.

During the triennium, there were a number of activities highlighting that research data management continues to be of common interest to CODATA and ICSTI. The ICSTICODATA Task Group on Data Citation Standards and Practices (of which B. McMahon was a member 2010-2012) produced a report in 2012: For Attribution - Developing Data Attribution and Citation Practices and Standards (summarizing the August 2011 Workshop in Berkeley, CA, USA) and a second report Out of Cite, Out of Mind, on current practices and policies across a range of scientific disciplines [Data Science Journal (2013), 12, pp. CIDCR1-75]. Details of ICSTI meetings such as its Winter Workshop 2012, Delivering Data in Science, are given in the report of the IUCr Representative to ICSTI.

The IUCr has been an active participant in the CODATAVAMAS Joint Working Group on the Description of Nanomaterials, with participation in a questionnaire on existing practices in different disciplines, and representation by Reinhard Neder and Daniel Chateigner at two Workshops in Paris.

Katherine Cass retired as CODATA Executive Director in July 2013 and has been succeeded by Simon Hodson, formerly with the UK Joint Information Services Committee (JISC).

B. McMahon, Representative 2011-2012

J. R. Helliwell, Representative 2012-

A11.2.2. ICSU Committee on Space Research (COSPAR) COSPAR (http://cosparhq.cnes.fr/) is a Scientific Committee of ICSU. Its main objective is to promote international collaboration in scientific research in space, with an emphasis on the exchange of results, information and opinions. Developing world standards for the space environment and its protection requires the creation of national and international organizations and specialist working groups..

COSPAR acts mainly as a body responsible for organizing biennial Scientific Assemblies, and the 39th COSPAR Scientific Assembly (SA) was held in Mysore, India, 14-22 July,
2012. The next will be held in Moscow, Russia, 2-10 August 2014.

The International Year of Crystallography (IYCr) provides an opportunity for stronger collaboration between IUCr and COSPAR. At the Mysore Assembly, the IUCr representative submitted the information to the COSPAR Council about IYCr 2014.

At the IYCr Opening Ceremony on 21 January at UNESCO in Paris (http://iycr2014.org/events/other/iycr2014-openingceremony), Professors David Bish and David Blake (USA) were chosen to present talks about recent applications of crystallography in the study of Mars during the session Crystallography for Society and the Future.

COSPAR was represented at the IYCr Opening Ceremony by its Associate Director, Mr A. Janofsky, and by the Chair of the Panel of Capacity Building, Professor Mariano Mendez from the University of Groningen, The Netherlands. A summary of the ongoing IYCr activities will be also presented to COSPAR's SA in Moscow in 2014.

The main activities of COSPAR are related to space topics (astronomy, astrobiology, geophysics, atmosphere studies, investigation of natural and artificial ecosystems, as well as space travel). Recently the most fascinating results about the mineralogy of the Mars surface and potential presence of water there were obtained with the help of - among others $\mathrm{X}$-ray powder diffraction.

The most interesting COSPAR division for the IUCr, the Scientific Commission on Materials Science in Space (MSS Commission G), is chaired by V. Shevtsova (Belgium) and cochaired by S. Amiroudine (France), T. Koenemann (Germany) and S. Yoda (Japan). This Commission coordinates fundamental experiments in materials and fluid sciences performed in space, utilizing reduced gravity for their objectives.

Advances in Space Research (ASR, the impact factor 1.183 is its highest ever) (http://ees.elsevier.com/asr/) is an official journal of COSPAR. It covers all areas of space research, including - but not limited to - space studies of the earth surface, meteorology, climate, fundamental physics in space, materials physics in space, space debris, weather and earth observation of space phenomena. ASR also includes COSPAR's Information Bulletin, Space Research Today.

COSPAR's President for the period 2010-2014 is Professor Giovanni Bignami (Italy) and the Vice-President is $\mathrm{J}$. Wu (People's Republic of China). Members of the Bureau are: I. S. Batista (Brazil), K.-H. Glassmeier (Germany), A. Jayaraman (India), S. Sasaki (Japan), J.-P. St.-Maurice (Canada) and L. Zelenyi (Russia).

The IUCr together with COSPAR are now exploring possibilities to organize a Capacity Building Workshop (https://cosparhq.cnes.fr/scientific-structure/pcb), on applying crystallographic methods in past and future space research (the topics will cover search for materials applied in building space craft, reports on crystallographic and crystal growth experiments performed in space and actual and future investigation of space debris and surfaces of Mars and the Moon by crystallographic methods). The timing and location of this potential meeting is under consideration. 
More information about COSPAR can be found on their very informative web site.

\section{H. A. Dabkowska, Representative}

A11.3. International Council for Scientific and Technical Information (ICSTI)

ICSTI offers a unique forum for interaction among organizations that create, disseminate, and use scientific and technical information. ICSTI is a Scientific Associate of ICSU, the International Council for Science. ICSTI's mission cuts across scientific and technical disciplines as well as international borders, to give member organizations the benefit of a truly global community.

The summer ICSTI Congress for 2011 was held in Beijing, People's Republic of China. The Congress was hosted by ISTIC, the Institute of Scientific and Technical Information of China, and the theme of the meeting was Upgrading Information to Knowledge. The IUCr could not be represented.

The winter ICSTI Workshop was held in February 2012 on Delivering Data in Science, which was organized by DataCite, and held at ICSU in Paris, France. A detailed report by J. R. Helliwell and B. McMahon was published on the IUCr web site and in the IUPAC publication Chemistry International (http://www.iupac.org/publications/ci/2012/3404/cc1_050312. html).

The ICSTI Annual Congress and ICSTI Business Meetings for 2012 were held in Washington, DC, USA, in October. The Congress was hosted by the USA National Library of Congress and was entitled Science, Law and Ethics (http://www.icstiannual.com/meeting-program/). The conference focused on the importance of counterbalancing science, ethics and the law to ensure the healthy development of scientific innovation, globalized information sharing, and technological advancement. The conference was hosted by the Library of Congress, and featured research scientists, information scientists, lawyers, diplomats, and other experts who each provided the attendees with unique perspectives on the intersection of science, ethics and the law in today's global society. This was followed by a Workshop organized by Elsevier entitled Research Evaluation in Practice: Towards Sustainable Scientific Investments (see http://www.researchtrends.com/researchtrends-seminar/). This focused on assessing research. A highlight of the ICSTI business meetings in Washington, DC included that the ICSTI Insight: The Living Publication authored by J. R. Helliwell, B. McMahon and T. Terwilliger, was very well received.

The ICSTI 2013 Annual Members' Meeting was held 16-17 March 2013 in Hannover, Germany, hosted by the German National Library of Science and Technology - TIB. It was organized in conjunction with a Conference on NonTextual Information on 18-19 March. B. McMahon presented a lecture (http://www.nontextualinformation2013.de/images/ Downloads/Brian_McMahon_lecture.pdf) and represented IUCr at ICSTI.
The ICSTI Annual Congress and ICSTI Business Meetings for 2013 were hosted by the National Research Council Canada in Ottawa, 14-15 October 2013, along with the annual meeting of the WorldWideScience Alliance. In addition, ICSTI held a Workshop on Data and Non-Data Integration A Journey Across Disciplines in the framework of the 2nd Annual CASRAI Conference, the central theme for which was 'Big Data: The Advance of Data-Driven Discovery'. At IUCr's suggestion John Westbrook of the RCSB agreed to present a talk at this Workshop and this presentation can be found at http://www.icsti.org/IMG/pdf/icsti-2013-v2.pdf. The IUCr could not be represented.

A one-day consultation meeting, convened by the ICSU Secretariat, was held in Paris, France, 25 September 2013, entitled Open Access to Scientific Data and Literature and Assessment of Research by Metrics. The IUCr Representative to ICSTI attended this meeting so as to represent ICSTI. ICSU had previously circulated a letter to its entire membership requesting information and opinions on open access and evaluation by metrics. The IUCr Representative to ICSTI submitted a document to the IUCr Past President summarizing the IUCr journals as a community driven ('learned society') publisher for authors and readers globally, who endorsed it and submitted it to ICSU. The Chair of the consultation meeting was Sir John Ball, FRS, and a Member of the ICSU Executive Board. A report from the consultation meeting is in preparation. A notable point of principle was agreed of scientific data and literature ideally needing to be 'free for authors and free for readers', i.e. as an aim for science communication. The IUCr journals satisfy this principle via their suite of titles, i.e. combining some (Acta A, B, C,D,F, $J A C, J S R)$ as being free for authors [i.e. with no compulsory article processing charge (APC) but costs mainly paid by subscribers] and some (IUCrJ and Acta E) as being free for readers (i.e. where authors or their research sponsors pay the APC).

The ICSTI 2014 Annual Members' Meeting is to be held in Philadelphia on 22 February 2014 and includes two Miniworkshops on: (i) New Trends in Publication and Data Metrics, which will span the use of traditional and alternative metrics to evaluate and measure the results, productivity and outcomes of basic and applied research programmes, as well as developments in the reporting and tracking of funding sources; and (ii) Science and Social Media: the Importance of an Online Presence, which will provide an overview of the interactive media and their use by the science community to gather, disseminate and disambiguate information. These activities are in combination with the National Federation of Advanced Information Services Annual Conference which will address topics such as 'linking data and literature', 'trust in scholarly content' and 'the future involving big data'.

I acknowledge with gratitude the close collaboration with Brian McMahon, R\&D Officer of the IUCr, and with the IUCr Journals Executive Managing Editor, Peter Strickland.

J. R. Helliwell, Representative 
Table 6

Estimated budget for the General Fund.

\begin{tabular}{lrr}
\hline & CHF & CHF \\
\hline Income & & \\
Subscriptions from Adhering Bodies & 486000 & \\
Yield from investments and banking accounts & 300000 & \multirow{2}{*}{786000} \\
\cline { 2 - 2 } & & \\
Expenditure & 1407200 & \\
Administration & 36000 & \\
Subscriptions to ICSU and bodies of ICSU & 296000 & \\
Administrative meetings & 39000 & \multirow{2}{*}{1778200} \\
Scientific meetings & & \\
& & -992200 \\
\hline
\end{tabular}

A11.4. International Organization for Standards (ISO) In 2013 the Liaison between ISO/Technical Committee 12 (TC 12) Quantities and Units and the IUCr was confirmed, and the Chair of the Commission on Crystallographic Nomenclature was appointed Liaison Representative.

A12. Budget estimates for period to Twenty-Fourth General Assembly: determination of unit contribution

\section{A12.1. Budget estimates}

The estimated budget for the General Fund is set out in Table 6 , for the period until the next General Assembly. Since the budget estimates had to be prepared at a time when the decisions on many activities were still to be made, these estimates should be considered with due reserve. With this proviso, and in accordance with Statute 9.3, the Executive Committee presents to the General Assembly the following estimates for the three-year period 1 January 2014 - 31 December 2016.

A12.2. Unit Contribution

According to Statute $5.10(k)$, the General Assembly has to determine the Unit Contribution to be paid by the Adhering Bodies for the period to the next General Assembly. The Executive Committee recommends to the General Assembly that the Unit Contribution should remain at its present level of CHF 1000 (set at the Beijing Congress in 1993) for the years 2015-2017.

\section{APPENDIX $B$}

Statutes and By-Laws of the International Union of Crystallography

as Adopted by the Fourth General Assembly in 1957 and Amended by the Fifth General Assembly in 1960, the Sixth General Assembly in 1963, the Seventh General Assembly in 1966, the Eighth General Assembly in 1969, the Ninth General Assembly in 1972, the Tenth General Assembly in 1975, the Eleventh General Assembly in 1978, the Seventeenth General Assembly in 1996, the Eighteenth General Assembly in 1999, by unanimous postal agreement of the Adhering Bodies in 2010 and the Twenty-Second General Assembly in 2011

\section{Statutes}

1. Objects of the Union

1.1. The objects of the Union are

(a) to promote international cooperation in crystallography;

(b) to contribute to the advancement of crystallography in all its aspects, including related topics concerning the noncrystalline states;

(c) to facilitate international standardization of methods, of units, of nomenclature and of symbols used in crystallography;

(d) to form a focus for the relations of crystallography to other sciences.

1.2. For these purposes the Union shall have the power

(a) to adhere to the International Council for Science;

(b) to organize international meetings and conferences on subjects falling within the purview of the Union;

(c) to promote international publication of crystallographic research and of crystallographic works;

(d) to set up Commissions or other bodies for special objects;

(e) to initiate, promote and coordinate crystallographic research requiring international cooperation;

(f) to organize Special Projects which shall be financed indepen- dently of the regular operations of the Union;

( $g$ ) to participate in Joint Commissions with other Unions or other scientific bodies in matters of interest to the Union;

(h) to perform all such other legal acts as are essential for or conducive to the objects of the Union including the constitution or organization of separate or independent bodies having an appropriate legal status;

(i) to receive into association existing regional organizations of crystallographers having substantially the same aims and objects as the Union; these organizations shall be known as Regional Associates of the Union;

$(j)$ to receive into association existing international scientific organizations whose interests overlap with the aims and activities of the Union; these organizations shall be known as Scientific Associates of the Union.

\section{Organization and Legal Domicile}

2.1. Under the name of International Union of Crystallography an Association has been organized and incorporated; it is governed by Articles 60 and following of the Swiss Civil Code and by the present Statutes of Incorporation.

2.2. The duration of the Union is not limited.

2.3. The legal domicile of the Union is in Geneva, Switzerland.

\section{Membership}

3.1. The members of the Union are its Adhering Bodies.

3.2. There shall be only one member for each country. Only under extraordinary circumstances the General Assembly may admit a suitably designated additional Adhering Body from a country, provided a corresponding Adhering Body of that country has already been admitted as a National Member of the International Council for Science (ICSU). In this case, 
each Adhering Body will have separate delegates and will be treated separately in questions of voting and finances.

3.3. The Adhering Body can be a National Academy, National Research Council or similar body, or a scientific society or group of such societies. Each Adhering Body shall form a National Committee for Crystallography to represent it in the Union.

3.4. Any number of Countries may agree to form a group in order to name or establish a single Adhering Body. This Body shall form a joint National or Regional Committee for Crystallography. Wherever the terms Country and National Committee for Crystallography are used in these Statutes or in the By-Laws, they shall be taken to include such groups of Countries and joint National or Regional Committees for Crystallography.

3.5. Membership in the Union shall be fully effective when the nature of the Adhering Body and the membership of the National Committee have been reported to and accepted by the General Assembly. Any replacement of an Adhering Body is subject to the approval of the Executive Committee and acceptance by the General Assembly. Any major change in the nature of an Adhering Body shall be considered valid only after it has been reported to and accepted by the General Assembly.

3.6. Adherence to the Union shall be in one of five Categories I-V with corresponding voting powers and contributions as set out in Statutes 5.5 and 9.4. A Body applying for adherence to the Union shall specify in which Category it wishes to adhere; this choice of Category, or any desired change in the Category, is subject to the approval of the Executive Committee and confirmation by the General Assembly.

3.7. Any extension of a joint adherence formed in accordance with Statute 3.4 is subject to the approval of the Executive Committee and acceptance by the General Assembly.

3.8. Participation in Special Projects [Statute 1.2(f)] shall not be obligatory. The extent of financial participation shall be a matter for special negotiation for each such project, except that the relationship between contribution and voting power within the project shall be that of the Category scheme defined in Statutes 5.5 and 9.4 to determine this relationship in the General Assembly.

3.9. Each National Committee has the right to submit to the Union through the General Secretary questions within the competence of the Union.

3.10. Any Adhering Body may withdraw from the Union if it has given notice of withdrawal at least six months before the end of the current financial year; it is required to fulfil its obligations relating to the time period when it was a member of the Union. Its membership and any further obligations shall then be suspended by the Executive Committee at the expiry of the notice of withdrawal. The withdrawal shall take effect when it has been reported to the General Assembly.

3.11. An Adhering Body which withdraws from the Union in accordance with Statute 3.10, or any Adhering Body whose membership is cancelled in accordance with Statutes 5.12 or 9.6, loses all rights in connexion with the Union.

3.12. If the Countries of a group formed in accordance with Statute 3.4 agree that the group should be dissolved, or if a Country wishes to withdraw from such a group, with or without the agreement of the other Country or Countries of the group, the adherence of the original group shall be suspended by the Executive Committee at the expiry of an appropriate notice, provided that the original group has fulfilled its obligations. The termination of the original adherence shall take effect when the matter has been reported to the General Assembly. Pending this report, the Countries of the group, or any of them, may submit proposals for the continuation of their representation in the Union. In each of such proposals the nature of the Adhering Body, the membership of the National Committee and the desired Category of adherence shall be specified. These proposals are subject to the approval of the Executive Committee, which shall then make ad interim arrangements concerning these adherences. These arrangements are subject to acceptance by the General Assembly.

\section{Administration}

4.1. The work of the Union shall be conducted by

(a) the General Assembly;

(b) the Officers of the Union, constituting the Executive Committee;

(c) the Commissions as defined in Statute 8.1.

The composition and function of these bodies are defined in the following paragraphs, whose application is governed by the By-Laws.

\section{General Assembly}

5.1. The work of the Union shall be directed by the General Assembly which is composed of delegates appointed by the Adhering Bodies.

5.2. The Executive Committee is responsible to the General Assembly and shall participate in its deliberations. Members of the Executive Committee have no voting power in the General Assembly, except for the casting vote of the Chair [Statute 5.8].

5.3. The General Assembly shall, as a rule, hold an ordinary meeting once every three years. The date and the place of the meeting, unless determined by the previous General Assembly, shall be determined by the Executive Committee. The General Secretary shall communicate the date and the place of the meeting to the National Committees and to the Commissions at least twelve months in advance.

5.4. In special cases, the President of the Union, with the consent of the Executive Committee, may call an extraordinary meeting of the General Assembly. This shall be performed at the request of one-fifth of the Adhering Bodies. The routine business of a General Assembly prescribed in Statute 5.10 shall normally be omitted, unless specifically included in the agenda; but an extraordinary General Assembly shall have the same powers, and be subject to the same rules, as an ordinary General Assembly, except where 
otherwise is stated in the Statutes and By-Laws. The General Secretary shall communicate the date and the place of the extraordinary General Assembly to the National Committees and to the Commissions at least eight months in advance if amendment of the Statutes is contemplated, or at least four months otherwise.

As an alternative, in special cases not requiring an amendment to or a change of the Statutes, the President of the Union with the consent of the Executive Committee may ask for a postal or electronic ballot of the Adhering Bodies. This shall be performed at the request of one-fifth of the Adhering Bodies. The voting power of an Adhering Body in a postal or electronic ballot is the same as that at General Assemblies. The General Secretary will communicate the matter for determination to the National Committees and to the Commissions four months before the deadline for the votes to be received by the General Secretary. In order to facilitate a full discussion between the participants in the postal or electronic ballot, the comments and questions of the Adhering Bodies, the responses of the President as well as any amendment to the initial proposal will be circulated among the Adhering Bodies using fast means of communications at the latest one month before the deadline.

5.5. The voting power of an Adhering Body at General Assemblies and in postal or electronic ballots shall be in accordance with its Category of adherence, as follows:

\begin{tabular}{llllll}
\hline Category & I & II & III & IV & V \\
Number of votes & 1 & 2 & 3 & 4 & 5 \\
\hline
\end{tabular}

5.6. Each Adhering Body, through its National Committee, shall make known to the General Secretary before the opening of each General Assembly the names of its delegates (and of their alternates, if any), and also the name of the Chair of the national or regional delegation. No Officer of the Union may be a member of any delegation, nor shall any person serve as a member of more than one delegation.

5.7. Normally each of the delegates present at a General Assembly shall have one vote only, but when for special reasons an Adhering Body cannot be fully represented at a General Assembly it may distribute its votes among a number of delegates smaller than the number of votes which that Adhering Body has in accordance with the Category in which it adheres; such a decision has to be made known to the General Secretary before the opening of the General Assembly concerned. Any Adhering Body not represented at a General Assembly may forward its views to the General Secretary by letter, and such views shall be made known to the General Assembly if received before voting takes place.

5.8. Except where otherwise provided in the Statutes and By-Laws, decisions of the General Assembly are taken by a majority of the votes cast. In the event of an equal division of votes the Chair shall take the final decision.

5.9. No question which has not been placed on the agenda of business to be transacted at the General Assembly shall be discussed or put to the vote unless a proposal to that effect be approved by at least two-thirds of the votes there represented.

5.10. The General Assembly shall

(a) take appropriate action on any matters concerning membership in the Union [Statutes 3.5, 3.6, 3.7, 3.10, 3.12 and 5.12];

(b) elect the President, the Vice-President, the General Secretary, the Treasurer and the other Officers of the Union [Statutes 6.1 and 6.3];

(c) consider, and make decisions regarding, the confirmation of the appointments of Editors of publications of the Union [Statute 7.1];

(d) determine the number of elected members of each Commission set up by the General Assembly [Statutes 5.11(c) and 8.2];

(e) elect the Chairs and members of the Commissions [Statute 8.2];

$(f)$ elect representatives of the Union on Joint Commissions with other Unions, and on other scientific bodies [Statutes 1.2( $g)$ and 8.5];

(g) receive the reports on the activities of the Union and of its Commissions [Statutes 6.8 and 8.4];

(h) receive the audited accounts for the years elapsed since the previous General Assembly [Statute 9.1];

(i) on receipt of satisfactory reports or accounts, release the Treasurer, or any other Officer, or the Chair or any member of any Commission or other body, from financial or other liability to the Union;

(j) determine the budget for general expenditure for the period to the next General Assembly, on the basis of the estimate prepared by the Executive Committee [Statutes 9.2 and 9.3];

(k) determine the unit contribution for the period to the next General Assembly [Statute 9.5];

(l) determine the general policy and the timetable for the period to the next General Assembly;

$(m)$ give preliminary consideration to the activities of the Union for the three-year period following the next General Assembly.

5.11. The General Assembly shall have the power

(a) to amend these Statutes in accordance with Statute 13.1;

(b) to formulate and amend By-Laws on any matters not covered by these Statutes;

(c) to set up any Commission or other body it may deem necessary for the administrative and scientific work of the Union, and to determine the terms of reference of such a body [Statute 1.2(d)];

(d) to dissolve any Commission or other body set up in accordance with Statute 5.11(c) when its existence is deemed no longer necessary;

(e) to determine the nature of Special Projects which shall be financed independently of the regular operations of the Union [Statute 1.2(f)];

$(f)$ to accept Regional Associates, to determine the nature of the association in each case, and to determine any mutual financial commitments; 
( $g$ ) to accept Scientific Associates, to determine the nature of the association in each case, and to determine any mutual financial commitments;

(h) to decide on all other questions falling within the competence of the Union.

5.12. The General Assembly may cancel the membership of any Adhering Body of the Union for any serious cause; such a decision may only be taken after the member in question has been previously given an opportunity to furnish an explanation to the Executive Committee for forwarding to the General Assembly. At least three-fourths of the total number of the votes of all Adhering Bodies are required for cancellation.

\section{Executive Committee}

6.1. The Officers of the Union constituting the Executive Committee are

(a) the President;

(b) the Vice-President;

(c) the General Secretary;

(d) the Treasurer;

(e) the immediate Past President;

$(f)$ six ordinary members.

6.2. The election of Officers of the Union shall be arranged in such a way that there will not be more than two Officers from any one Country and that amongst the six ordinary members there will be at least one Officer from a Country from each of the three geographical regions (i) Europe and Africa, (ii) the Americas and (iii) Asia/Oceania. A person is regarded as belonging to the Country in which he or she is normally resident and where the main part of his or her work is conducted. In cases of doubt the General Assembly shall decide to which Country a person is considered to belong.

If during the period between General Assemblies the number of Officers from a Country is increased above two because of any change of Country of residence, the Officer or Officers who changed their Country of residence may continue to serve until the close of the next General Assembly. If at that time the number of Officers from the Country concerned would remain above two, one or more of the Officers who changed their Country of residence shall be considered to have resigned.

6.3. The offices of General Secretary and Treasurer may be combined and shall then be considered as a single office. Otherwise no person shall hold more than one office simultaneously. The voting power of the Officer holding the combined office of General Secretary and Treasurer shall not be more than that of either the General Secretary or the Treasurer.

6.4. The President holds office as President until the close of the ordinary General Assembly following his or her election, and continues as a member of the Executive Committee until the close of the ordinary General Assembly next but one following that of his or her election. $\mathrm{He}$ or she is not then eligible for immediate re-election to the office of President, nor to any other office in the Executive Committee.
The Vice-President holds office until the close of the ordinary General Assembly following his or her election. He or she is not eligible for immediate re-election to the same office.

The General Secretary and the Treasurer hold office until the close of the ordinary General Assembly following that of their election. They are eligible for immediate re-election to the same office, but shall not serve in that office for more than three full consecutive terms.

Three ordinary members are elected at each ordinary General Assembly and hold office until the close of the ordinary General Assembly next but one following that of their election. They are not eligible for immediate re-election to the same office.

In the event of a vacancy, through resignation, death or other cause, any Officer elected by the General Assembly to fill the unexpired term of office shall serve only to the end of the normal term of the Officer he or she replaces; at the end of this service he or she may be nominated for re-election for a full term to the same office.

6.5. The Executive Committee shall carry out the decisions of the General Assembly and give effect to the general policy of the Union as determined by the General Assembly.

6.6. During the periods between General Assemblies the Executive Committee shall have full power to carry on the business of the Union in all matters not specifically assigned by the Statutes, the By-Laws or the General Assembly to individuals or to Commissions or other bodies. If necessary, it may make ad interim arrangements in all matters assigned by the Statutes and By-Laws to the General Assembly.

6.7. In the event of an individual, a Commission or another body of the Union failing to act in any matter assigned to him or her or it by the Statutes, By-Laws or the General Assembly, the Executive Committee may, after reasonable notice to the individual or body in question, take action on behalf of the Union.

6.8. The Executive Committee shall report on its activities to the General Assembly. The action taken by the Executive Committee in accordance with Statutes 3.5, 3.6, 3.7, 3.10, 3.12, 6.6, 6.7, 7.1, 7.2, 8.2, 9.6 and 9.9 shall be included in this report. The report to the General Assembly shall be dispatched by the General Secretary to the National Committees and to the Commissions at least ten weeks before the meeting.

\section{Publications of the Union}

7.1. The Editors of the publications of the Union are appointed by the Executive Committee for initial terms extending through not more than six years beyond the ordinary General Assembly following the appointment. Each initial appointment is subject to confirmation by that General Assembly. Reappointments may be made by the Executive Committee for terms of not more than three years, and are subject to confirmation by the ordinary General Assembly following the reappointment.

7.2. Co-editors and Assistant Editors are appointed by the Editors for terms of not more than three years, but they may be reappointed immediately for terms of the same length. The 
appointments and reappointments are subject to the approval of the Executive Committee.

7.3. Editors and Co-editors are members of the Commissions set up for their respective publications.

\section{Commissions and Joint Commissions}

8.1. The term Commission shall be understood to include all Commissions, Committees, and other bodies of the Union with the exception of National Committees for Crystallography, and the Executive Committee and its subcommittees.

8.2. The Chairs and members of the Commissions are elected at each General Assembly. Subject to the approval of the Executive Committee, Commissions may coopt further members during the periods between General Assemblies, and may fill vacancies arising from resignation, death or other cause. Members (but not Chairs) may be nationals of or residents in a Country not adhering to the Union.

8.3. The Commissions shall be responsible to the General Assembly. They shall generally have full freedom in arranging their internal structure and work. They may formulate their own Rules of Procedure within the framework of the Statutes and By-Laws of the Union, and within their terms of reference.

8.4. The Chairs shall report on the activities of the Commissions to the General Assembly. These reports shall reach the General Secretary at least fourteen weeks before the General Assembly and shall be dispatched by him or her to the National Committees and the Commissions at least ten weeks before the meeting.

8.5. The representatives of the Union on Joint Commissions and on other scientific bodies [Statute 1.2(g)] are elected at each General Assembly. For each such body one representative shall be designated as the chief representative of the Union. His or her obligations to report are the same as those of the Chairs of the Commissions.

\section{Finance}

9.1. The Executive Committee shall be responsible to the General Assembly for all the financial affairs of the Union.

9.2. The Chair of each Commission (or other member approved by the Executive Committee) shall be responsible to the Executive Committee for any expenditure of funds by this Commission. Five months before each General Assembly he or she shall submit to the Executive Committee an estimate of the budget of the Commission for the period between that General Assembly and the one following it. He or she shall submit annually to the Executive Committee a revised budget for the ensuing year and a statement of accounts for the preceding year. These accounts shall be available for audit by the Executive Committee or its appointees.

9.3. The Executive Committee shall prepare an estimate of the budget for the period between the next General Assembly and that following it. This estimate shall be dispatched by the General Secretary to the National Committees and to the Commissions at least ten weeks before the meeting.
9.4. Each Adhering Body shall pay an annual subscription in accordance with its Category of adherence, as follows:

\begin{tabular}{llllll}
\hline Category & I & II & III & IV & V \\
Number of unit contributions & 1 & 3 & 6 & 10 & 15 \\
\hline
\end{tabular}

The annual subscriptions are payable during the calendar year to which they apply.

9.5. The unit contribution, stated in terms of a currency to be designated by the Executive Committee, shall be determined by the General Assembly for the period to the next General Assembly.

9.6. Any Adhering Body which is in arrears with its subscription for two years shall be warned and shall be deprived of its voting power. The membership of any Adhering Body which is in arrears for four years shall be automatically suspended and may be cancelled by the General Assembly under Statute 5.12. An Adhering Body whose membership has been suspended shall receive no privileges of the Union and incur no further responsibility for dues; it may be reinstated by action of the Executive Committee.

9.7. The financing and management of publications of the Union shall be kept distinct from general expenditure. Editors and Co-editors shall be responsible to the Executive Committee for any receipts or expenditure of funds by them with respect to their publications.

9.8. The financing and management of Special Projects of the Union shall be kept distinct from the regular operations of the Union.

9.9. No funds may be solicited or accepted on behalf of the Union or any of its Commissions from any international, governmental or other agency or person without the prior approval of the Executive Committee. Any National Committee for Crystallography may however solicit funds within its own Country for the support of its own activities or in its capacity as host for a General Assembly, Congress or other meeting sponsored by the Union. Any funds, in the form of donations, legacies, or grants, accepted by the Executive Committee shall be used so far as is possible in accordance with the wishes of the donors.

\section{Liability}

10.1. The Union is liable only to the extent of its assets, and the Adhering Bodies are not individually liable for its corporate debts and liabilities.

10.2. The liabilities of the Adhering Bodies are limited to the payment of their annual subscriptions and to such contributions to the Special Projects of the Union as they may have pledged.

10.3. No Officer of the Union shall be individually liable for the corporate debts and liabilities of the Union. The Union shall indemnify any Officer or former Officer in respect of any claims laid against him or her in respect to his or her authorized actions on behalf of the Union. At its discretion the Executive Committee may extend this indemnity to other persons in respect of their authorized actions on behalf of the Union. 
Timetable in preparation for General Assembly

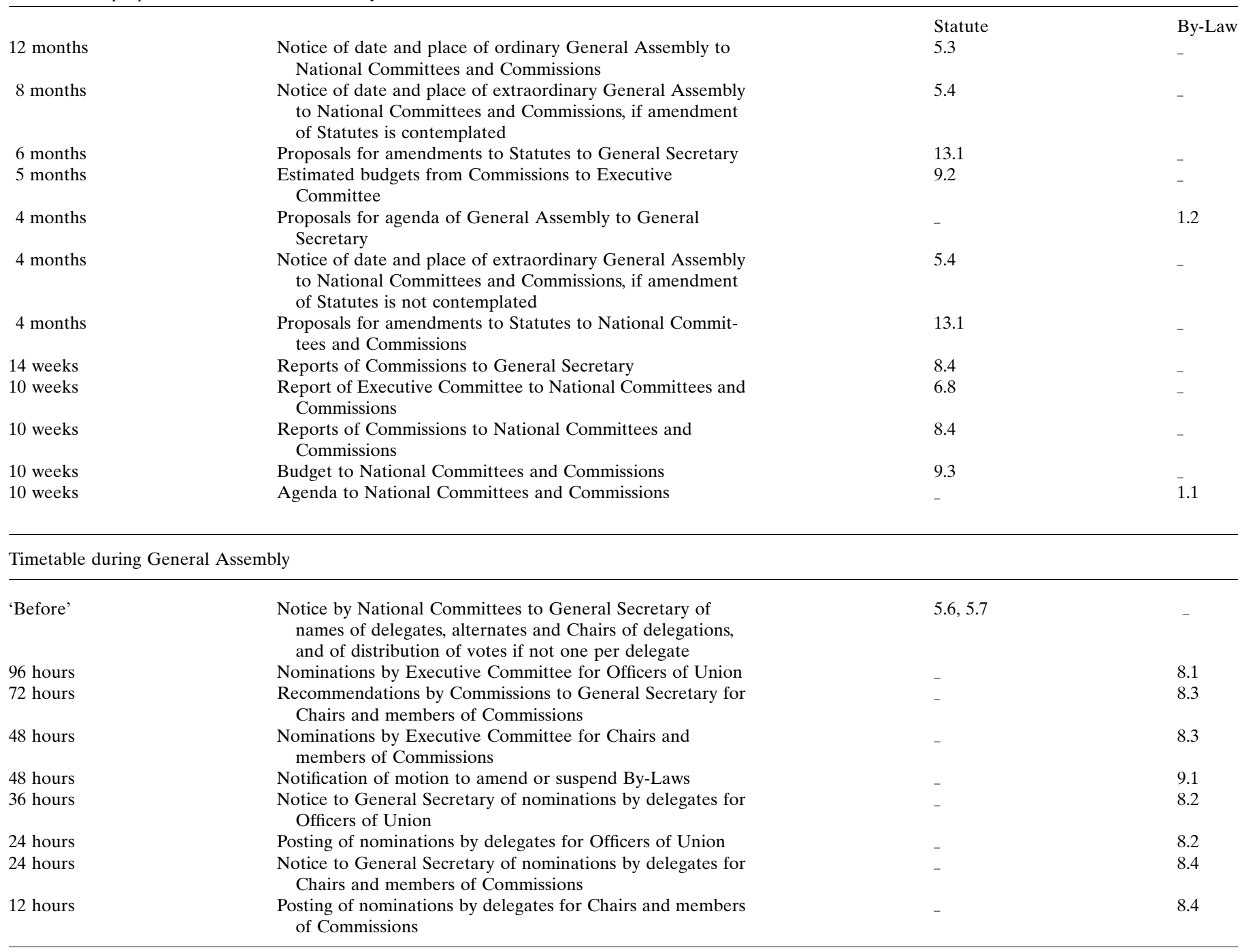

10.4. The Union shall not accept any liability for any personal loss, damage or accident sustained by an individual, not being an employee of the Union, engaged in any activity, including travel, on behalf of the Union.

\section{Auditor and Representation of the Union}

11.1. The Auditor of the Union shall be a person or corporation authorized to act as a public accountant. The Auditor shall be appointed by the Executive Committee on the recommendation of the Treasurer and maintained thereafter subject to the approval of the General Assembly.

11.2. With the exception of cheques, all contracts and formal agreements involving the Union shall be signed by two Officers of the Union. The Executive Committee may restrict the power to sign a particular document or type of document to specific persons among the Officers; and it shall determine rules for the signing of cheques.

11.3. The President shall be the official representative of the Union on all other civil and legal occasions and in dealing with other organizations. The President may in this respect dele- gate his or her powers to another Officer of the Union, or, with approval of the Executive Committee, to any other person.

\section{Dissolution of the Union}

12.1. The Union shall not be dissolved except on a motion presented at a General Assembly. If a motion to dissolve is to be presented, the notice for that General Assembly as given under Statute 5.3 or 5.4 shall include a statement of the motion to dissolve and shall refer specifically to this Statute. Such a motion shall be presented to the General Assembly without amendment and at least three-fourths of the votes there represented shall be required for dissolution.

In the event that less than three-fourths of the total number of the votes of all Adhering Bodies are represented at the General Assembly, a postal or electronic ballot may be arranged, and in such a postal or electronic ballot at least three-fourths of the total number of the votes of all Adhering Bodies shall be required for dissolution.

12.2. In the event of dissolution of the Union in accordance with Statute 12.1, the General Assembly shall appoint a 
special Committee, reporting to the International Council for Science, for the liquidation of the assets of the Union. The available assets will be entirely attributed to one or more institutions in pursuit of a goal of similar public interest to that of this association and that also benefits from tax exemption. In no case can the property be returned to its current or founding members, nor be used for their profit in whole or part in any manner whatsoever.

\section{Statutes}

13.1. Amendments to the Statutes require action at a General Assembly. An amendment is adopted at such an Assembly only if (i) at least two-thirds of the votes represented at the General Assembly are affirmative and (ii) if these affirmative votes amount to more than half the total number of the votes of all Adhering Bodies. In the event that the vote on a proposed amendment satisfies condition (i) but not condition (ii), the Executive Committee may refer the proposed amendment to a postal or electronic ballot of the Adhering Bodies. If the proposed amendment then obtains affirmative votes amounting to more than half the total number of the votes of all Adhering Bodies, the amendment is adopted.

Proposals for amendments may be made by the Executive Committee or by any National Committee. Such proposals made by National Committees shall reach the General Secretary at least six months in advance of the General Assembly. The General Secretary shall dispatch these proposals, and those made by the Executive Committee, to the National Committees and to the Commissions at least four months before the meeting.

13.2. The present English text shall be considered the authoritative text in the interpretation of these Statutes. Where disputes arise concerning this interpretation, the matter shall be decided by the General Assembly, or, during the periods between General Assemblies, by a ruling of the President of the Union.

\section{By-Laws}

\section{General Assembly}

1.1. The agenda of business to be transacted at a General Assembly shall be determined by the Executive Committee and shall be dispatched by the General Secretary to the National Committees and to the Commissions at least ten weeks before the meeting.

1.2 Any National Committee and any Commission of the Union may propose business to be transacted at a General Assembly. Such proposals shall reach the General Secretary at least four months before the meeting, and shall be included in the agenda of the General Assembly.

1.3. The General Assembly may determine the date and the place of the next but one ordinary meeting of the General Assembly.

1.4. Chairs of the National Committees and of the Commissions, and representatives of Regional Associates and Scientific Associates may attend the General Assembly and take part in the discussions but shall have no voting power. The President may invite representatives of scientific bodies, or individuals, to attend the General Assembly; such invited guests may take part in the discussions but shall have no voting power. Other interested persons may also attend the General Assembly but they shall not take part in the discussions, unless specifically invited or permitted to do so by the Chair, and they shall have no voting power.

At the discretion of the Chair any or all of the persons attending the General Assembly under this By-Law may be required to withdraw.

1.5. If a delegate to a General Assembly is absent from a session of the Assembly, his or her place may be taken by any of the alternates nominated to the Assembly under Statute 5.6 provided that the Secretary of the Assembly is notified before the beginning of the session of the name of the delegate and of the name of the alternate, either by the delegate or by the Chair of his or her delegation. In general no such substitution may take place during a session of the Assembly, but the Chair of the Assembly may permit substitution to be made under special circumstances.

1.6. The names of the representatives of a Body whose application for adherence to the Union has been received and declared in good order by the Executive Committee under ByLaw 2.9(a) shall be made known to the General Secretary as prescribed in Statute 5.6. These representatives shall be seated with the delegates of the Adhering Bodies during the preliminary ceremonies and the initial business of the General Assembly. At the discretion of the Chair or by a vote of the Assembly, the representatives may be required to withdraw during the discussion of and voting on matters concerning adherence to the Union. The delegates of a new member may take their seats among the other delegates as soon as the General Assembly has accepted their Adhering Body as a member of the Union.

1.7. Unless decided otherwise by the General Assembly, matters concerning adherence to the Union shall take precedence over all other business at the first business session of the General Assembly, and shall normally precede the reading of the minutes and the discussions of matters arising therefrom.

1.8. Delegates of an Adhering Body may not vote on any matter concerning its membership in the Union.

1.9. In the event of the General Assembly considering a change in a group of Countries according to Statute 3.12, the delegates from the Countries belonging or previously belonging to the group may not vote on any matters concerning the representation in the Union of any of these Countries. After acceptance of the ad interim arrangements made by the Executive Committee under Statute 3.12, these delegates have full voting power.

1.10. The delegates of new members may not vote on any matters concerning adherence to the Union, nor on any matters concerning the adoption of the minutes of the previous General Assembly, during the General Assembly at which they themselves are admitted.

1.11. The General Secretary shall post on the official bulletin board of the General Assembly the names of the 
Chairs and members (and alternates, if any) of the delegations and the numbers of votes represented by them.

1.12. During the General Assembly any delegate (or alternate) and any Officer of the Union is considered to have been notified of any action of the General Assembly, or of the Executive Committee, or of any Commission, if one of the two following procedures is adopted

(a) a notice is placed in the mail box or other location at which the delegate (or alternate) or the Officer is accustomed to receive mail during the course of the General Assembly, or

(b) a notice is handed to the designated Chair of each delegation with the specific request that he or she communicate its contents to his or her delegation, and to the General Secretary with the specific request that he or she communicate its contents to the Executive Committee, provided that in either case a similar notice is posted on the official bulletin board.

1.13. Minutes of the meetings of the General Assembly shall be made. Copies of the draft minutes shall be communicated by the General Secretary to the National Committees, to the Officers of the Union and to the Chairs of its Commissions. After approval at a subsequent General Assembly, two copies of the definitive minutes shall be signed by the Chair and the Secretary of the session at which they are approved, and shall be kept by the President and the General Secretary.

\section{Executive Committee}

2.1. The Executive Committee shall meet at each General Assembly. There shall be at least two additional meetings during the period between General Assemblies, unless the Executive Committee by a postal or electronic vote decides otherwise.

2.2. The Executive Committee shall make nominations to the General Assembly for the Officers of the Union, for the Chairs and members of the Commissions, and for representatives on Joint Commissions and on other scientific bodies. Normally these nominations shall be made after a preceding postal or electronic communication with the National Committees. In each case in which an Officer of the Union is nominated for another office, either by the Executive Committee or by delegates to the General Assembly [By-Law 8.2], the Executive Committee shall also include a nomination for the office which would be vacated if the election to the other office occurs. If the election to the other office does not occur and if the Officer's term has not expired, the nomination to the office which would have been vacated shall not be considered.

2.3. In the event of the resignation, death or disability of the President, the Vice-President shall assume the office of President until the close of the next ordinary General Assembly.

In the event of the resignation, death or disability of the Vice-President, the Executive Committee may appoint one of its members to serve as Vice-President until the close of the next ordinary General Assembly.

In the event of such circumstances that the General Secretary or the Treasurer cannot carry out his or her duties, the other shall assume those duties until the Executive Committee has considered the situation. In that event the Executive Committee may, but need not, appoint a new General Secretary or Treasurer to serve until the close of the next ordinary General Assembly.

In the event of the resignation, death or disability of an ordinary member of the Executive Committee, the Executive Committee may co-opt a new member to serve until the close of the next ordinary General Assembly.

The accession of an Officer of the Union to a new office under the conditions of this By-Law shall be accompanied by his or her resignation from the office to which he or she was previously elected, but service under this By-Law shall not affect his or her eligibility for immediate re-election to the new office.

2.4. Any Officer unable to attend a meeting of the Executive Committee may designate a deputy to attend that meeting. Such a deputy shall be named in writing to the President or the General Secretary. He or she shall have no voting power and shall not be counted as part of a quorum.

2.5. The President, on his or her own initiative or at the request of the Executive Committee, may invite any individual to be present at a meeting of the Executive Committee; such an invited guest may take part in the discussions but shall have no voting power.

2.6. At a meeting of the Executive Committee two-thirds (fractional parts neglected) of the Officers specified by Statutes 6.1 and 6.3, excluding any who have resigned or died, shall constitute a quorum; and decisions shall be taken by a simple majority of the Officers present and voting. The Chair of the meeting shall not vote in open ballots; but in the event of an equal division of votes the Chair may take the final decision. In secret ballots required by the Statutes or By-Laws or ordered by the Chair, he or she may vote at his or her discretion. If the Chair does not vote and there is an equal division of votes, he or she may take the final decision. If the Chair has voted in a secret ballot, he or she may not take the final decision, and must leave it to further discussion and ballot.

2.7. During the period between meetings of the Executive Committee, voting may take place by post or electronic means. Adoption of a proposal shall require affirmative votes from two-thirds (fractional parts neglected) of the Officers specified by Statutes 6.1 and 6.3, excluding any who have resigned or died. No decision on any proposal other than calling or cancelling a meeting of the Executive Committee shall be made by postal or electronic vote in the event that at least two Officers express the wish that the matter concerned should first be given more or further consideration, either by correspondence or at a meeting of the Executive Committee.

2.8. Minutes of the meetings of the Executive Committee shall be made. Two copies of the minutes shall be signed by the Chair and the Secretary of the meeting at which they are approved, and shall be kept by the President and the General Secretary. A summary of the draft minutes of meetings of the Executive Committee shall be despatched by the General Secretary to the National Committees within ten weeks of the conclusion of each meeting. 
2.9. In addition to the obligations described in the Statutes and elsewhere in these By-Laws, the Executive Committee shall

(a) receive and report on applications for adherence to the Union if the nature of the applying Body and the membership of the National Committee have been duly reported to and considered to be in good order by the Executive Committee; pending the next General Assembly the Executive Committee may in the case of such applications provide such services of the Union as it deems proper;

(b) consider and report on any other questions concerning adherence to the Union;

(c) present an annual report, including an audited statement of receipts and expenditure, to the National Committees;

(d) report to the Commercial Registry of Geneva any changes in the registered information concerning the Union;

(e) have the power to appoint representatives on scientific bodies not belonging to the Union.

\section{President}

3.1. The President of the Union is Chair of the General Assembly and of the Executive Committee. In the absence of the President from a session or meeting, the Vice-President, or if he or she is not present another Officer of the Union designated by the Executive Committee, shall act as Chair.

3.2. The President of the Union is an ex officio member, with voting power, of all Commissions of the Union.

\section{General Secretary}

4.1. The General Secretary of the Union is Secretary of the General Assembly and of the Executive Committee. In the absence of the General Secretary from a session or meeting, another Officer of the Union designated by the Executive Committee shall act as Secretary.

4.2. The General Secretary of the Union is an ex officio member, with voting power, of all Commissions of the Union.

4.3. The General Secretary is responsible for conducting the ordinary business of the Union, with the exception of the financial administration, and for keeping its records.

4.4. The General Secretary may appoint a permanent Executive Secretary to assist with the running of the Union. In the event that an Executive Secretary is appointed the posts of General Secretary and Treasurer will be combined. In these Statutes and By-Laws administrative tasks assigned to the General Secretary will be considered to have been fulfilled if carried out by the Executive Secretary.

\section{Treasurer}

5.1. The Treasurer of the Union is responsible for the financial administration of the Union and for keeping its accounts.

5.2. The Treasurer is an ex officio member of all Commissions of the Union, with voting power only for those questions which may involve the Union in financial commitments.

\section{Sub-committees of the Executive Committee}

6.1. The Finance Committee is appointed by the Executive Committee to advise on finances, establishment and salaries. The Convener of the Finance Committee should normally be a resident of the same country as the Union Secretariat. If the Convener is not an elected member of the Executive Committee he or she will attend ex officio the meetings of the Executive Committee without voting rights.

6.2. The Sub-committee on the Union Calendar is appointed by the Executive Committee to advise on the sponsorship of the Union for meetings, symposia and schools. The Chair of the Calendar Sub-committee should be a member of the Executive Committee.

6.3. The Executive Committee may establish, modify or abolish any other Sub-committees.

\section{Commissions of the Union}

7.1. The Chairs of the Commissions and the chief representatives on Joint Commissions or other bodies shall forward records of all meetings of the Commissions to the President and the General Secretary. They shall report annually on the activities of these bodies to the Executive Committee.

7.2. If funds are provided for the use of a Commission, it may make its own financial arrangements, with the prior approval of the Executive Committee and subject to the provisions of the Statutes and By-Laws. In cases where the Executive Committee has given prior approval, payments toward travelling expenses of Chairs and members of Commissions may be made from the general funds of the Union.

7.3. No person who has served for three consecutive full terms of office on a Commission is eligible for nomination for a fourth consecutive term of service on the same Commission except as Chair. In no case is any person eligible for more than four consecutive full terms of service on the same Commission. These limitations do not apply to Editors [Statute 7.1], Co-editors [Statute 7.2] and ex officio members. Any Commission, in its Rules of Procedure, may reduce the length of service specified here.

7.4. In the event of the resignation, death or disability of the Chair of any Commission, the Executive Committee shall appoint a member of that Commission to serve as Chair until the close of the General Assembly following this appointment.

\section{Nominations and Elections}

8.1. All delegates (and alternates) shall be notified of the nominations presented by the Executive Committee under By-Law 2.2 for the Officers of the Union as early as possible and at least ninety-six hours before the scheduled commencement of the session of the General Assembly at which the vote is to be taken.

8.2. After the delegates have been notified of the nominations by the Executive Committee as prescribed in By-Law 8.1, other nominations for Officers of the Union may be made by any six or more delegates. Such nominations shall be made in writing to the General Secretary not less than thirty-six 
hours before the voting session and shall be accompanied by a written statement that the consent of the nominees has been obtained. These nominations shall be posted by the General Secretary on the official bulletin board not less than twentyfour hours before that session.

8.3. Recommendations from each Commission for the Chair and members of the Commission shall be made in writing to the General Secretary not less than seventy-two hours before the voting session of the General Assembly. These recommendations shall be approved by a majority of the members of the Commission and shall be accompanied by a written statement that the consent of the persons recommended has been obtained. All delegates (and alternates) shall be notified of the nominations presented by the Executive Committee under By-Law 2.2 for the Chair and members of each Commission at least forty-eight hours before the voting session.

8.4. After the delegates have been notified of the nominations by the Executive Committee as prescribed in By-Law 8.3 , other nominations for the Chair and members of each Commission may be made by any six or more delegates. Such nominations shall be made in writing to the General Secretary not less than twenty-four hours before the voting session and shall be accompanied by a written statement that the consent of the nominees has been obtained. These nominations shall be posted by the General Secretary on the official bulletin board not less than twelve hours before that session.

8.5. In voting for the President, Vice-President, General Secretary and Treasurer of the Union, each of these offices shall be taken separately and voting shall be by secret ballot. A simple majority of the votes represented by the delegates present at the voting session shall be required for election. If there is only one candidate for one of these offices, his or her nomination shall be presented to the General Assembly and the candidate concerned shall be considered as elected. If there are two candidates or more, and an election is not achieved after two ballots, the candidate receiving the smallest number of votes in the second ballot shall be removed from the list unless this will lead to a candidate being elected without receiving a simple majority of the votes. If an election is not achieved after a third ballot, this procedure shall be repeated until an election is achieved. Any ballot form showing more than one mark shall be invalid. Any contingency arising during the balloting shall be resolved by a ruling of the Chair of the General Assembly.

8.6. The election of the ordinary members of the Executive Committee shall be by secret ballot, the ballot form showing the nominations presented by the Executive Committee and the nominations made by delegates. Balloting shall be conducted in such a way that the requirements of Statute 6.2 are met. A simple majority of the votes represented by delegates present at the voting session shall be required for election. If there are not more candidates than vacancies, the nominations shall be presented to the General Assembly and the candidates shall be considered as elected. If there are more candidates than vacancies and all vacancies are not filled by election at the first ballot, a second ballot shall be arranged containing the names of the candidates not elected. If there are vacancies after the second ballot, the balloting procedure shall be repeated until all vacancies are filled; for second and subsequent ballots the name of the candidate receiving the smallest number of votes on the preceding ballot shall be removed from the list unless this will lead to a candidate being elected without receiving a simple majority of the votes. Any ballot form showing more marks than the appropriate number of vacancies shall be invalid. Any contingency arising during the balloting shall be resolved by a ruling of the Chair of the General Assembly.

8.7. In the event that an election must be held to fill the unexpired term of an office vacated by an ordinary member [Statute 6.4], the nominations for this office shall be distinct from the nominations for ordinary members for full terms. A person may be nominated for both categories, but can be elected to only one office [Statute 6.3]. If ballots are required in the elections for both categories, the ballots for the full-term offices shall take place first. A person who has been elected to two consecutive non-full terms is not eligible, on completion of his or her second term, for immediate re-election as an ordinary member of the Executive Committee.

8.8. In voting for the Chairs and members of the Commissions each Commission shall be considered separately. For the election of the Chairs the procedure described in By-Law 8.5 shall be followed. For the election of the members of the Commissions the procedure described in By-Law 8.6 shall be followed except that no more than two ballots shall be held. Any vacancies still remaining may be filled as provided in Statute 8.2.

8.9. The procedure for the nomination and election of representatives of the Union on Joint Commissions and on other scientific bodies is so far as is possible the same as that for the nomination and election of the Chairs and members of the Commissions.

\section{By-Laws}

9.1. These By-Laws may be amended or suspended at any General Assembly and at least two-thirds of the votes there represented are required for an amendment or suspension. A motion to amend or suspend, if not already included in the agenda of business of the General Assembly, may be placed there by the procedure of Statute 5.9. No notice is required for a proposal to suspend the time limits prescribed by By-Laws 8.2 and 8.4. Notification of any other motion to amend or suspend the By-Laws must be given by its originators to all delegates (and alternates) and to all Officers of the Union in accordance with the procedure prescribed in By-Law 1.12, at least forty-eight hours before the session of the General Assembly at which the motion is to be considered.

9.2. The present English text shall be considered the authoritative text in the interpretation of these By-Laws. Where disputes arise concerning this interpretation, the matter shall be decided by the General Assembly, or during the periods between General Assemblies, by a ruling of the President of the Union. 


\section{APPENDIX C}

\section{Committees, Commissions and Representatives}

C1. Membership of bodies belonging to the Union

Executive Committee

President

M. L. Hackert, Department of Molecular Biosciences, University of Texas at Austin, Austin, TX 78712, USA

Vice-President

A. M. Glazer (UK)

General Secretary and Treasurer

L. Van Meervelt (Department of Chemistry, Katholieke Universiteit Leuven, Celestijnenlaan 200F, BE-3001, Leuven, Belgium)

Immediate Past President

G. R. Desiraju (India)

Ordinary members

H. A. Dabkowska (Canada), W. Depmeier (Germany), S. Garcia-Granda (Spain) J. M. Guss (Australia), R. Kuzel (Czech Republic), M. Takata (Japan)

[M. L. Hackert, A. M. Glazer, L. Van Meervelt, G. R. Desiraju, H. A. Dabkowska, J. M. Guss and M. Takata will hold office until the close of the Twenty-Fourth General Assembly (2017). W. Depmeier, S. Garcia-Granda and R. Kuzel will hold office until the close of the Twenty-Fifth Assembly (2020).]

\section{Executive Secretary}

M. H. Dacombe (International Union of Crystallography, 2 Abbey Square, Chester CH1 2HU, UK)

\section{Commission on Journals}

Chair and Editor-in-Chief of IUCr journals

S. S. Hasnain (Faculty of Health and Life Sciences, University of Liverpool, Life Sciences Building, Crown Street, Liverpool L69 7ZB, UK; Acta $A+B+C+D+E+F ; J A C$; JSR; IUCrJ)

Section Editors of Acta Crystallographica

S. J. L. Billinge (Department of Applied Physics and Applied Mathematics, Columbia University, 200 Mudd, 500 W 120th Street, New York, NY 10027, USA; Acta A), J. Miao (Department of Physics and Astronomy, University of California, Box 951547, Los Angeles, CA 90095-1547, USA; Acta $A$ ), A. J. Blake (School of Chemistry, the University of Nottingham, University Park, Nottingham NG7 2RD, UK; $A c t a B$ ), M. de Boissieu [Science de l'Ingénierie des Matériaux et Procédés (SIMaP), 1130 Rue de la Piscine, BP 75, 38402 Saint Martin d'Hères CEDEX, France; Acta B], A. Linden (Institute of Organic Chemistry, University of Zürich, Winterhurerstrasse 190, CH-8057 Zürich, Switzerland; Acta $C$ ), P. R. Raithby (Department of Chemistry, University of Bath, Bath BA2 7AY, UK; Acta C), Z. Dauter (Argonne National Laboratory, Biosciences Division, Bldg 202, Room Q142, Argonne, IL 60439, USA; Acta D), J. L. Martin (Institute for Molecular Bioscience, University of Queensland, Brisbane, QLD 4072, Australia; Acta D), R. J. Read
(Department of Haematology, University of Cambridge, Cambridge Institute for Medical Research, Wellcome Trust/ MRC Building, Hills Road, Cambridge CB2 0XY, UK; Acta $D$ ), S. Wakatsuki (Photon Science, SLAC National Accelerator Laboratory, and Department of Structural Biology, School of Medicine, Stanford University, 2575 Sand Hill Road, MS 69, Menlo Park, CA 94025, USA; Acta D), W. T. A. Harrison (Department of Chemistry, University of Aberdeen, Aberdeen AB24 3UE, UK; Acta E), H. Stoeckli-Evans (Institute of Physics, University of Neuchâtel, Switzerland; Acta E), E. R. T. Tiekink (Department of Chemistry, University of Malaya, Kuala Lumpur 50603, Malaysia; Acta $E)$, L. Van Meervelt (Department of Chemistry, Katholieke Universiteit Leuven, Celestijnenlaan 200F, BE-3001, Leuven, Belgium; Acta E), M. Weil (Institute of Chemical Technologies and Analytics, Division of Structural Chemistry, Vienna University of Technology, Getreidemarkt 9/164-SC, Austria; Acta E), W. N. Hunter (School of Life Sciences, University of Dundee, Dundee DD1 5EH, UK; Acta F), M. S. Weiss (EMBL Hamburg Outstation, c/o DESY, Notkestrasse 85, D-22603 Hamburg, Germany; Acta F).

Section Editors of IUCr]

E. N. Baker (School of Biological Sciences, University of Auckland, Private Bag 92-019, Auckland, New Zealand), G. R. Desiraju (Solid State and Structural Chemistry Unit, Indian Institute of Science, Bangalore 560 012, India), C. R. A. Catlow (Department of Chemistry, UCL, 20 Gordon Street, London WC1H 0AJ, UK), S. Larsen (Department of Chemistry, University of Copenhagen, Universitetsparken 5, DK2100 Copenhagen, Denmark), J. C. H. Spence (Department of Physics, Arizona State University, Rural Rd, Tempe, AZ 85287, USA)

Editors of Journal of Applied Crystallography

A. J. Allen (National Institute of Standards and Technology, 100 Bureau Drive, Gaithersburg, MD 20899-8523, USA), J. Hajdu (Laboratory of Molecular Biophysics, Institute of Cell and Molecular Biology, Uppsala University, Box 596, 75124 Uppsala, Sweden), A. Kaysser-Pyzalla (Helmholtz-Zentrum Berlin für Materialien und Energie $\mathrm{GmbH}$, Hahn-MeitnerPlatz 1, 14109 Berlin, Germany)

Editors of Journal of Synchrotron Radiation

G. E. Ice (Materials Science and Technology Division, Oak Ridge National Laboratory, PO Box 2008, Oak Ridge, TN 37831-6132, USA), I. Schlichting (Department of Biomolecular Mechanisms, Max Planck Institute for Medical Research, Jahnstrasse 29, 69120 Heidelberg, Germany), J. F. van der Veen (Paul Scherrer Institut, 5232 Villigen PSI, Switzerland)

Co-editors of Acta, IUCrJ, JAC and JSR

D. Albov (Russia; Acta E), F. A. Almeida Paz (Portugal; Acta C), A. Altomare (Italy; Acta A), R. F. Baggio (Argentina; Acta $E$ ), A. Barty (Germany; JAC), L. J. Beamer (USA; Acta F), T. M. Bergfors (Sweden; Acta F), S. Bernès (Mexico; Acta E), D. G. Billing (South Africa; Acta B+E), O. Blacque (Switzerland; Acta E), E. Boldyreva (Russia; Acta B), N. B. Bolotina (Russia; Acta B), P. Bombicz (Hungary; Acta E), A. D. Bond 
(Denmark; IUCrJ + Acta C), C. S. Bond (Australia; Acta D), A. Borbély (France; JAC), P. Bordet (France; Acta B), S. Boutet (USA; $J A C$ ), I. D. Brown (Canada; Acta E), D. Bushnell (USA; IUCrJ), O. Büyükgüngör (Turkey; Acta E), R. Cerny (Switzerland; Acta B), H. Chapman (Germany; IUCrJ), K.W. Chapman (USA; Acta $B+J A C$ ), V. V. Chernyshev (Russia; Acta E), E. Y. Cheung (USA; Acta C), A. M. Chippindale (UK; Acta E), A. N. Cormack (USA; IUCrJ), A. F. Craievich (Brazil; JSR), P. Dastidar (India; Acta E), Z. S. Derewenda (USA; Acta D), M. Du (People's Republic of China; Acta B), M. T. L. Duarte (Portugal; Acta C), P. Dunten (USA; Acta F), M. Dusek (Czech Republic; Acta B), M. Eddaoudi (Saudi Arabia; IUCrJ), U. Englert (Germany; Acta $C)$, J. G. Eon (Brazil; Acta A), L. Fabian (UK; Acta E), L. R. Falvello (Spain; Acta $C$ ), P. E. Fanwick (USA; Acta C), L. J. Farrugia (UK; Acta E), K. Fejfarova (Czech Republic; Acta $E)$, A. N. Fitch (France; IUCrJ), U. Flörke (Germany; Acta E), V. T. Forsyth (France; IUCrJ $+J A C$ ), C. S. Frampton (UK: $A c t a C$ ), J. M. García-Ruiz (Spain; $J A C$ ), E. F. Garman (UK; Acta $D+J S R$ ), R. C. Garratt (Brazil; Acta D), M. Gdaniec (Poland; Acta E), E. P. Gilbert (Australia; $J A C$ ), D. Gratias (France; IUCrJ), G. Grübel (Germany; JSR), T. N. Guru Row (India; Acta B+E), Q. Hao (People's Republic of China; Acta $D$ ), B. Hazes (Canada; Acta F), S. M. Heald (USA; IUCrJ + $J S R$ ), P. C. Healy (Australia; Acta E), E. F. C. Herdtweck (Germany; Acta E), V. Holý (Czech Republic; JAC), C. J. Howard (Australia; Acta B), N.-H. Hu (People's Republic of China; Acta E), W. Imhof (Germany; Acta E), H. Ishida (Japan; Acta E), T. Ishikawa (Japan; IUCrJ), J. P. Jasinski (USA; $A c t a ~ E$ ), K. A. Kantardjieff (USA; JAC), A. Katrusiak (Poland; Acta B), D. A. Keen (UK; Acta A), A. R. Kennedy (UK; Acta C), V. N. Khrustalev (Russia; Acta E), G. J. Kleywegt (Sweden; Acta D), G. Kostorz (Switzerland; JAC), M. Kubicki (Poland; Acta C), W. F. Kuhs (Germany; Acta A), P. Langan (USA; Acta D), V. Langer (Sweden; Acta C), C. Lecomte (France; IUCrJ), U. Lee (Korea; Acta E), S. V. Lindeman (USA; Acta E), J. S. Lipkowski (Poland; Acta B), Z. J. Liu (People's Republic of China; IUCrJ), M. LopezRodriguez (Spain; Acta E), A. J. Lough (Canada; Acta E), T. B. Lu (People's Republic of China; Acta C), N. Lugan (France; Acta C), P. McArdle (Republic of Ireland; Acta E), R. McKenna (USA; Acta D), J. T. Mague (USA; Acta E), L. D. Marks (USA; Acta A), K. Mereiter (Austria; Acta E), P. Metrangolo (Italy; Acta B), K. Miki (Japan; Acta D), K. Moffat (USA; IUCrJ), A. Momose (Japan; JSR), Y. Murakami (Japan; $I U C r J$ ), A. Nakagawa (Japan; Acta F), J. M. Newman (Australia; Acta D +F), G. S. Nichol (USA; Acta E), M. Nieger (Finland; Acta E), Y. Ohgo (Japan; Acta C), A. G. Oliver (USA; Acta C), D. Pandey (India; JAC), S. Parkin (USA; Acta $E)$, S. Parsons (UK; Acta B), R. A. Pauptit (UK; Acta F), V. Petricek (Czech Republic; Acta A), F. A. A. Paz (Portugal; $A c t a C$ ), P. A. Pianetta (USA; JSR), A. A. Pinkerton (USA; Acta B), T. J. Prior (UK; Acta E), G. G. Privé (Canada; Acta F), T. Proffen (USA; $J A C$ ), M. L. Pusey (USA; Acta F), D. A. Reis (USA; $J S R$ ), G. Renaud (France; $J A C$ ), J.-P. Renaud (France; Acta F), C. Rizzoli (Italy; Acta E), I. Robinson (UK; IUCrJ), P. Roussel (France; Acta E), V. B. Rybakov (Russia; Acta E), R.
Sankaranarayanan (India; Acta F), B. D. Santarsiero (USA; $A c t a C$ ), S. Sasaki (Japan; JAC), H. Schenk (The Netherlands; Acta A), M. Schiltz (Switzerland; Acta D), G. Smith (Australia; Acta E), J. L. Smith (USA; IUCrJ), A. L. Spek (The Netherlands; Acta $C$ ), R. L. Stanfield (USA; Acta F), R. W. Strange (UK; JSR), N. Sträter (Germany; Acta F), C. Y. Su (People's Republic of China; IUCrJ), S. W. Suh (Korea; Acta F), S. Svensson (Sweden; $J S R$ ), D. Svergun (Germany; $J A C$ ), M. Takata (Japan; IUCrJ), I. Tanaka (Japan; Acta F), T. C. Terwilliger (USA; Acta F), J. Trewhella (Australia; IUCrJ), F. T. Tsai (USA: Acta F), K. Tsuda (Japan; Acta C), H. Uekusa (Japan; Acta C), A. Van der Lee (France; Acta E), T. R. Welberry (Australia; Acta B), J. D. Westbrook (USA; Acta F), J. White (Australia; Acta C), T. J. White (Singapore; $J A C$ ), P. R. Wilmott (Switzerland; Acta A), D. J. Xu (People's Republic of China; Acta E), M. Yabashi (Japan; $J S R$ ), G. P. A. Yap (USA; Acta C), A. V. Yatsenko (Russia; Acta E), T. O. Yeates (USA; Acta D), D. S. Yufit (UK; Acta C), M. Zeller (USA; Acta E), X. Zhang (People's Republic of China; IUCrJ)

Book-Review Editor

M. Nespolo (France; Acta, JAC, JSR)

Commission on International Tables

Chair

C. P. Brock (Department of Chemistry, University of Kentucky, 505 Rose St, Lexington, KY 40506-0055, USA)

Editor of Volume A

M. I. Aroyo (Spain)

Editor of Volume B

G. Chapuis (Switzerland)

Editor of Volume C

T. R. Welberry (Australia)

Editor of Volume D

A. Authier (France)

Editors of Volume $\mathbf{E}$

V. Kopský (Czech Republic), D. B. Litvin (USA)

Editors of Volume $\mathrm{F}$

E. Arnold (USA), D. M. Himmel (USA), M. G. Rossmann (USA)

Editor of Volume G

B. McMahon (UK)

Editor of Volume A1

U. Müller (Germany)

Editors of Volume $\mathrm{H}$

C. J. Gilmore (UK), J. A. Kaduk (USA), H. Schenk (The Netherlands)

Editors of Volume I

C. T. Chantler (Australia), F. Boscherini (Italy), B. Bunker (USA) 
Commission on Aperiodic Crystals

Chair

U. Grimm (Department of Mathematics and Statistics, The Open University, Walton Hall, Milton Keynes MK7 6AA, UK)

Elected members

G. Borgstahl (USA), M. Dusek (Czech Republic), A. Goldman (USA), J. Hadermann (Belgium), N. K. Mukhopadhyay (India), O. Perez (France), H. Takakura (Japan), J. Wolny (Poland)

Commission on Biological Macromolecules

Chair

T. Terwilliger (Bioscience Division, Los Alamos National Laboratory, Mail Stop M888, Los Alamos, NM 87545, USA) Elected members

C. S. Bond (Australia), R. C. Garratt (Brazil), P. L. Howell (Canada), K. Miki (Japan), W. Minor (USA), S. Onesti (Italy), W. Rypniewski (Poland), D. M. Salunke (India), V. Samygina (Russia), J. Sanz-Aparacio (Spain), B. Schneider (Czech Republic), N. Sträter (Germany), M. S. Weiss (Germany)

Ex officio member

S. Burley (USA; as a Director of the PDB)

Commission on Charge, Spin and Momentum Densities

Chair

P. Macchi (Department of Chemistry and Biochemistry, University of Bern, Freiestrasse 3, CH 3012 Bern, Switzerland)

Elected members

P. Dominiak (Poland), E. Espinosa (France), L. J. Farrugia (UK), J. M. Gillet (France), A. Gukasov (France), J. Kozisek (Slovakia), E. Nishibori (Japan), Y. Sakurai (Japan), W. Scherer (Germany)

Ex officio member

G. McIntyre (Australia; as representative from Commission on Neutron Scattering)

Commission on Crystal Growth and Characterization of Materials

Chair

A. Zappettini (Istituto Materiali Elettronica Magnetismo, Consiglio Nazionale delle Ricerche, Parco Area delle Scienze 37/a, Parma 43010, Italy)

Elected members

S. Baldochi (Brazil), K. Kakimoto (Japan), T. Kuech (USA), D. Klimm (Germany), J. Kumar (India), H. Luo (People's Republic of China), A. Moreno (Mexico), E. Talik (Poland) Ex officio members

E. Vlieg (The Netherlands; as Representative of the International Organization of Crystal Growth), A. Kaysser-Pyzalla (Germany; as an Editor of $J A C$ )
Commission on Crystallographic Computing

Chair

H. R. Powell (Medical Research Council Laboratory of Molecular Biology, Francis Crick Avenue, Cambridge Biomedical Campus, Cambridge CB2 0QH, UK)

Elected members

A. van der Lee (France), M. Lutz (The Netherlands), P. Mercier (Canada), L. Palatinus (Czech Republic), S. Panjikar (Australia), K. Sekar (India), R. Von Dreele (USA), M. Yao (Japan)

Commission on Crystallographic Nomenclature

Chair

C. P. Brock (Department of Chemistry, University of Kentucky, 505 Rose St., Lexington, KY 40506-0055, USA)

Ex officio members

S. S. Hasnain (UK; as Editor-in-Chief of IUCr journals), S. J. L. Billinge (USA; as a Main Editor of Acta Cryst. Section A), J. Miao (USA; as a Main Editor of Acta Cryst. Section A), A. J. Blake (UK; as a Main Editor of Acta Cryst. Section B), M. de Boissieu (France; as a Main Editor of Acta Cryst. Section B), A. Linden (Switzerland; as a Main Editor of Acta Cryst. Section C), P. R. Raithby (UK; as a Main Editor of Acta Cryst. Section C), Z. Dauter (USA; as a Main Editor of Acta Cryst. Section D), J. L Martin (Australia; as a Main Editor of Acta Cryst. Section D), R. J. Read (UK; as a Main Editor of Acta Cryst. Section D), S. Wakatsuki (USA; as a Main Editor of Acta Cryst. Section D), W. T. A. Harrison (UK; as a Main Editor of Acta Cryst. Section E), H. Stoeckli-Evans (Switzerland; as a Main Editor of Acta Cryst. Section E), E. R. T. Tiekink (Malaysia; as a Main Editor of Acta Cryst. Section E), L. Van Meervelt (Belgium; as a Main Editor of Acta Cryst. Section E), M. Weil (Austria; as a Main Editor of Acta Cryst. Section E), W. N. Hunter (UK; as a Main Editor of Acta Cryst. Section F), M. S. Weiss (Germany; as a Main Editor of Acta Cryst. Section F), A. J. Allen (USA; as a Main Editor of $J A C$ ), J. Hajdu (Sweden; as a Main Editor of $J A C$ ), A. KaysserPyzalla (Germany; as a Main Editor of $J A C$ ), G. E. Ice (USA; as a Main Editor of $J S R$ ), I. Schlichting (Germany; as a Main Editor of $J S R$ ), J. F. van der Veen (Switzerland; as a Main Editor of JSR), M. I. Aroyo (Spain; as Editor of Volume A of International Tables for Crystallography), G. Chapuis (Switzerland; as Editor of Volume B of International Tables for Crystallography), T. R. Welberry (Australia; as Editor of Volume C of International Tables for Crystallography), A. Authier (France; as Editor of Volume D of International Tables for Crystallography), V. Kopský (Czech Republic; as an Editor of Volume E of International Tables for Crystallography), D. B. Litvin (USA; as an Editor of Volume E of International Tables for Crystallography), M. G. Rossmann (USA; as an Editor of Volume F of International Tables for Crystallography), E. Arnold (USA; as an Editor of Volume F of International Tables for Crystallography), D. M. Himmel (USA; as an Editor of Volume F of International Tables for Crystallography), B. McMahon (UK; as an Editor of Volume $\mathrm{G}$ of International Tables for Crystallography), U. Müller 
(Germany; as an Editor of Volume A1 of International Tables for Crystallography), C. J. Gilmore (UK; as an Editor of Volume $\mathrm{H}$ of International Tables for Crystallography), J. A. Kaduk (USA; as an Editor of Volume $\mathrm{H}$ of International Tables for Crystallography), H. Schenk (The Netherlands; as an Editor of Volume $\mathrm{H}$ of International Tables for Crystallography), C. T. Chantler (Australia; as an Editor of Volume I of International Tables for Crystallography), F. Boscherini (Italy; as an Editor of Volume I of International Tables for Crystallography), B. Bunker (USA; as an Editor of Volume I of International Tables for Crystallography), D. Viterbo (Italy; as Chair of the IUCr/OUP Book Series Selection Committee), K. A. Kantardjieff (USA; as Chair of the Commission on Crystallographic Teaching), J. Hester (Australia; as Chair of the Committee for the Maintenance of the CIF Standard)

\section{Commission on Crystallographic Teaching}

Chair

K. A. Kantardjieff (College of Science and Mathematics, Craven Hall 6211, California State University San Marcos, 333 South Twin Oaks Valley Road, San Marcos, CA 92096-0001, USA)

Elected members

S. Grazulis (Lithuania), M. Rademeyer (South Africa), M. Rossi (USA), S. Schmid (Australia), L. Suescun (Uruguay), H. Uekusa (Japan), M. S. Weiss (Germany), M. Zema (Italy)

Commission on Crystallography in Art and Cultural Heritage Chair

G. Artioli (Dip. Geoscienze, Università di Padova, Via Gradenigo 6, I-35131 Padova, Italy)

Elected members

C. Abad-Zapatero (USA), P. Bezdicka (Czech Republic), E. Makovicky (Denmark), I. Nakai (Japan), F. Otalora Munoz (Spain), A. Rafalska-Lasocha (Poland), A. Thalal (Morocco)

ad interim Commission on Crystallography of Materials Chair

A. R. Oganov (Department of Geosciences, State University of New York, Stony Brook, NY 11794-2100, USA)

Elected members

B. Albert (Germany), E. Antipov (Russia), Wenhui Duan (People's Republic of China), J. D. Gale (Australia), J.-F. Halet (France), M. Parrinello (Switzerland), B. I. Yakobson (USA)

Commission on Electron Crystallography

Chair

E. Orlova (Institute for Structural and Molecular Biology, Department of Biological Sciences, Birkbeck College, Malet Street, London WC1E 7HX, UK)

Elected members

K. Balzuweit (Brazil), L. Meshi (Israel), J. Neething (South Africa), L. Palatinus (Czech Republic), H. Stahlberg (Switzerland), K. Tsuda (Japan), Da-Neng Wang (USA), J. Zhu (People's Republic of China)
Commission on High Pressure

Chair

A. Katrusiak (Faculty of Chemistry, Adam Mickiewicz University, Umultowska 89b, 61-614 Poznan, Poland)

Elected members

R. Angel (Italy), E. Boldyreva (Russia), S. Clark (Australia), W. Crichton (France), F. Fabbiani (Germany), Haozhe Liu (People's Republic of China), Y. Ohishi (Japan), C. Sanloup (UK), G. Shen (USA)

Commission on Inorganic and Mineral Structures

\section{Chair}

J. Rocha (Department of Chemistry, CICECO, University of Aveiro, Campus de Santiago, Aveiro, 3810-193, Portugal)

Elected members

P. C. Burns (USA), T. M. Gesing (Germany), F. Hatert (Belgium), P. Mercier (Canada), R. Oberti (Italy), T. J. White (Australia), M. Wolcyrz (Poland), O. V. Yakubovich (Russia), A. Yoshiasa (Japan)

\section{Commission on Magnetic Structures}

Chair

B. Campbell (Physics \& Astronomy, Brigham Young University, N261 ESC, BYU, Provo, Utah 84062, USA)

Elected members

A. Cornia (Italy), D. B. Litvin (USA), J. M. Perez-Mato (Spain), V. Petricek (Czech Republic), A. Pirogov (Russia), V. Pomjakushin (Switzerland), J. Rodriguez-Carvajal (France), T. Sato (Japan), W. Sikora (Poland)

Commission on Mathematical and Theoretical Crystallography

Chair

M. I. Aroyo (Departamento de Fisica de la Materia Condensada, Facultad de Ciencias, Universidad del Pais Vasco, Apartado 644, 48080 Bilbao, Spain)

Elected members

J. Hadermann (Belgium), S. Hyde (Australia), G. McColm (USA), K. Momma (Japan), D. Pandey (India), M. L. A. de la Penas (Philippines), D. M. Proserpio (Italy), E. E. Rams (Cuba), L. Suescun (Uruguay), P. Zeiner (Germany)

Commission on Neutron Scattering

Chair

P. Langan (CSMB, Oak Ridge National Laboratory, PO Box 2008, Oak Ridge, TN 37831, USA)

Elected members

S. Chaplot (India), J. Hernandez-Velasco (Spain), T. Ishigaki (Japan), G. J. McIntyre (Australia), R. Przenioslo (Poland), Th. Proffen (USA), P. Radaelli (UK), W. W. Schmahl (Germany)

Commission on NMR Crystallography and Related Methods Chair

P. Taulelle (Institute Lavoisier, Université de Versailles Saint Quentin en Yvelines \& CNRS, 45 avenue des Etats Unis, Versailles 78035, France) 
Elected members

R. K. Harris (UK), M. A. Mehta (USA), T. Polenova (USA), M. J. Potrzebowski (Poland), R. E. Wasylishen (Canada)

Commission on Powder Diffraction

Chair

P. Whitfield (Spallation Neutron Source, Oak Ridge National Laboratory, PO Box 2008, MS6475, Oak Ridge, TN 37831, USA)

Elected members

A. Altomare (Italy), D. Billing (South Africa), E. Granado (Brazil), T. Ida (Japan), B. Kennedy (Australia), A. Mukherjee (India), D. Rafaja (Germany), J. Rius (Spain), K. Shankland (UK), B. H. Toby (USA)

Ex officio member

J. A. Kaduk (USA; as Representative of the International Centre for Diffraction Data)

Commission on Small-Angle Scattering

Chair

J. Trewhella (School of Molecular Bioscience, The University of Sydney, Jane Foss Russell Building G02, Sydney, NSW 2006, Australia)

Elected members

D. Babonneau (France), P. R. Jemian (USA), U.-S. Jeng (Taipei), T. Kanaya (Japan), D. McGillivray (New Zealand),

R. Serimaa (Finland), V. V. Volkov (Russia)

Commission on Structural Chemistry

Chair

S. Batten (School of Chemistry, PO Box 23, Monash University, Victoria 3800, Australia)

Elected members

C. Aakeroy (USA), J. Ellena (Brazil), C. Esterhuysen (South Africa), C. W. Lehmann (Germany), A. Nangia (India), S. M. Peng (Taipei), E. Pidcock (UK), G. Resnati (Italy), U. Rychlewska (Poland)

Commission on Synchrotron Radiation and XFEL Radiation

Chair

R. F. Garrett (ANSTO Building 1, Private Mail Bag 1, Menai, NSW 2234, Australia)

Elected members

S.-L. Chang (Taipei), M. A. Garcia-Aranda (Spain), E. Granadao (Brazil), P. Grochulski (Canada), J.-L. Hodeau (France), Y. Murakami (Japan), S. Pascarelli (France), J. L. Smith (USA), T. Tschentcher (Germany)

Commission on XAFS

Chair

C. T. Chantler (School of Physics, University of Melbourne, Parkville, Victoria 2010, Australia)

Elected members

G. Aquilanti (Italy), J. Chaboy (Spain), S. Diaz-Moreno (UK), P. Glatzel (France), S. M. Heald (USA), F. Jalilehvand (Canada), K. Lawniczak-Jablonska (Poland), B. Ravel (USA), M. Tabuchi (Japan)

\section{C2. Regional Associates}

American Crystallographic Association

Representative

H. A. Dabkowska (Brockhouse Institute for Materials Research, McMaster University, 1280 Main Street, Hamilton, Ontario, L8S 4M1, Canada)

Asian Crystallographic Association

Representative

M. Takata (Institute of Multidisciplinary Research for Advanced Materials, Tohoku University, Japan)

European Crystallographic Association

Representative

R. Kuzel (Department of Condensed Matter Physics, Charles University, Faculty of Mathematics and Physics, Ke Karlovu 5, 12116 Prague 2, Czech Republic)

Latin-American Crystallographic Association

Representative

S. Garcia-Granda (Faculty of Chemistry, C/Julain Claveria 8, 33006-Oviedo, Asturias, Spain)

\section{C3. Scientific Associates}

International Centre for Diffraction Data

Representative

P. Whitfield (Canada; ex officio as Chair of the Commission on Powder Diffraction)

International Organization of Crystal Growth

Representative

A. Zappettini (Italy; ex officio as Chair of the Commission on Crystal Growth and Characterization of Materials)

Worldwide Protein Data Bank (wwPDB)

Representative to wwPDB Advisory Board

E. N. Baker (School of Biological Sciences, University of Auckland, Private Bag 92-019, Auckland, New Zealand)

C4. Representatives on bodies not belonging to the Union

Interdivisional Committee on Terminology, Nomenclature and Symbols of the International Union of Pure and Applied Chemistry

Representative

C. P. Brock (Department of Chemistry, University of Kentucky, 505 Rose St, Lexington, KY 40506-0055, USA)

International Council for Scientific and Technical Information

Representative

A. M. Glazer (Physics Department, University of Oxford, Parks Road, Oxford OX1 3PU, UK) 
International Council for Science (ICSU)

Representative

G. R. Desiraju (Solid State and Structural Chemistry Unit, Indian Institute of Science, Bangalore 560 012, India)

ICSU Committee on Data for Science and Technology (CODATA)

Representative

J. R. Helliwell (School of Chemistry, The University of Manchester, Brunswick Street, Manchester M13 9PL, UK)

ICSU Committee on Space Research (COSPAR)

Representative

H. A. Dabkowska (Brockhouse Institute for Materials Research, McMaster University, 1280 Main Street, Hamilton, Ontario, L8S 4M1, Canada)

International Standards Organization (ISO)

Representative

C. P. Brock (Department of Chemistry, University of Kentucky, 505 Rose St, Lexington, KY 40506-0055, USA)

\section{APPENDIX $D$}

Adhering Bodies and National Committees for Crystallography

D1. Adhering Bodies

Details of the Adhering Bodies are given in Table 7.

\section{D2. National Committees for Crystallography}

Algeria

H. Merazig (Chair), A. Bekka, N. Benali-Cherif, S. Bouacida,

C. Boudaren, M. Boudraa, A. Boutarfaia, D. Mezaoui, F. Setifi

Argentina

R. Baggio (Chair), D. Lamas, G. Punte, D. R. Vega

Australia

J. M. Guss (Chair), S. Batten, J. Etheridge, B. Heras, B. J. Kennedy, S. Kennedy, B. Kobe, K. Nugent, A. Vrielink, R. Withers

Austria

C. Kratky (Chair), F. Belaj, H. Brandstetter, K. DjinovicCarugo, U. Griesser, V. Kahlenberg, R. Miletich-Pawlizek, O. Paris, G. Redhammer, K.-H. Schwarz, J. Stangl, M. Weil

Belgium

D. Maes (Chair), F. Hatert (Vice-Chair), L. Aerts, F. Blockhuys, J. Elsen, Y. Filinchuk, J. Hadermann, L. Henrard, D. Lamoen, D. Poelman, K. Robeyns, M. Van Bael, L. Van Meervelt, B. Vertruyen, J. Wouters

Brazil

N. L. Speziali (Chair), Y. P. Mascarenhas, I. Torriani

Bulgaria

O. Petrov (Chair), R. Petrova
Cameroon

I. Tonle Kenfack (Chair), J. Ngoune

Canada

J. F. Britten (Chair), P. Whitfield (Vice-Chair), T. S. Cameron, M. Fraser, L. A. Groat, P. L. Howell, D. R. Rose, J. D. Schrag Chile

M. T. Garland (Chair), J. A. Costamagna, J. Garin, M. Suwalsky, A. Vega

China, People's Republic of

Min Nai-Ben (Chair), Bai Chun-Li, Chang Wen-Rui, Chen Xiao-Long, Fan Hai-Fu, Jin Xiang-Lin, Lin Shao-Fan, Mai Zhen-Hong, Miao Fang-Ming, Niu Li-Wen, Peng Lian-Mao, Rao Zi-He, Tao Kun, Wang Ji-Yang, Wu Xin-Tao, Xian DingChang, Xiao-Dong Su, Zhang Ze, Zheng Qi-Tai

China, Taipei

Yu Wang (Chair), S. L. Chang, C. H. Lee, Y. C. Liaw, K. H. Lii, L. K. Liu, C. P. Tang, S. C. Yu, S. H. Yuan

Costa Rica

J. R. Vega Baudrit (Chair), E. Jimenez Alvarado, A. M. Araya Sibaja, R. Arguedas Rodriguez, D. Valverde Barquero, J. Calderon Castro, M. Camacho Elizonso, R. Coy Herrera, M. Esquivel Alfaro, R. Gonzalez Paz, R. Hernandez Chaverri, G. Jimenez Villalta, S. Madrigal Carballo, V. Montero Campos, S. Nikolaeva, G. Piedra Marin, G. Porras Brenes, C. Redondo, G. Madrigal Redondo, O. Rojas Carrillo, J. Saavedra, G. Saenz Arce, V. H. Soto Tellini, R. Vegas Zuniga

Croatia

S. Popović (Chair), D. Matković-Calogović (Vice-Chair), M. Cetina, M. Dakovic, M. Luić, A. Santic, D. Tibljas, A. Tonejc, A. Visnjevac

Czech and Slovak Republics

R. Kuzel (Chair), M. Koman (Vice-Chair), L. Caplovic, J. Cernak, N. Ganev, J. Kozisek, I. Kuta-Smatanova, P. Mikulik

Denmark

K. Mortensen (Chair), A. D. Bond, R. K. Feidenhans'1, K. Frydenvang, A. Horsewell, J. S. Pedersen, K. Ståhl, T. B. Zunic Egypt, Arab Republic of

K. M. El-Sayed (Chair), Y. M. Abbas (Vice-Chair), A. M. M. Moustafa

Finland

K. Rissanen (Chair), S. Huotari (Vice-Chair), T. Glumoff, M. Karppinen, J. Rouvinen

France

R. Guinebretière (Chair), N. Audebrand (Vice-Chair), P. Bordet (Vice-Chair), C. Mayer (Vice-Chair), F. Bonnete, A. Dautant, P. Launois, O. Perez, J. Timmins, B. Toudic, A. van der Lee, L. Vendier

Germany

S. Schorr (Chair), B. Dittrich, R. Ficner, R. X. Fischer, D. C. Meyer, W. W. Schmahl, J. Schreuer

Greece

S. E. Zographos (Chair), D. D. Leonidas (Vice-Chair), I. Margiolaki, I. M. Mavridis, K. Petratos 
Table 7

Adhering Bodies.

Adherence to the Union is in one of five Categories I-V, with corresponding voting powers and contributions as set out in Statutes 3.6, 5.5 and 9.4.

\begin{tabular}{|c|c|c|}
\hline Country & Category & Adhering Body \\
\hline Algeria & I & $\begin{array}{l}\text { Algerian Association of Crystal- } \\
\text { lography }\end{array}$ \\
\hline Argentina & I & $\begin{array}{l}\text { Consejo Nacional de Investiga- } \\
\text { ciones Científicas y Técnicas }\end{array}$ \\
\hline Australia & III & Australian Academy of Science \\
\hline Austria & I & $\begin{array}{l}\text { Österreichische Akademie der } \\
\text { Wissenschaften }\end{array}$ \\
\hline Belgium & II & $\begin{array}{l}\text { The Royal Academies for Science } \\
\text { and the Arts of Belgium }\end{array}$ \\
\hline Brazil & I & $\begin{array}{l}\text { Brazilian Crystallographic Asso- } \\
\text { ciation }\end{array}$ \\
\hline Bulgaria & I & $\begin{array}{l}\text { Bulgarian Crystallographic Asso- } \\
\text { ciation }\end{array}$ \\
\hline Cameroon & I & $\begin{array}{l}\text { Cameroon Crystallographic Asso- } \\
\text { ciation }\end{array}$ \\
\hline Canada & III & National Research Council \\
\hline Chile & I & $\begin{array}{l}\text { Comision Nacional de Investiga- } \\
\text { ción Cientifica y Tecnologia }\end{array}$ \\
\hline China, People's Republic of & IV & $\begin{array}{l}\text { Chinese Association for Science } \\
\text { and Technology }\end{array}$ \\
\hline China, Taipei & II & $\begin{array}{l}\text { The Academy of Sciences Located } \\
\text { in Taipei }\end{array}$ \\
\hline Costa Rica & I & $\begin{array}{l}\text { Centro Nacional de Alta Tecno- } \\
\text { logia (CeNAT) (subject to } \\
\text { confirmation by General } \\
\text { Assembly) }\end{array}$ \\
\hline Croatia & I & $\begin{array}{l}\text { Croatian Crystallographic Asso- } \\
\text { ciation (under the auspices } \\
\text { of the Croatian Academy } \\
\text { of Science and Arts) }\end{array}$ \\
\hline Czech and Slovak Republics & II & $\begin{array}{l}\text { Regional Committee of Czech and } \\
\text { Slovak Crystallographers }\end{array}$ \\
\hline Denmark & I & $\begin{array}{l}\text { Royal Danish Academy of } \\
\text { Sciences and Letters }\end{array}$ \\
\hline Egypt, Arab Republic of & $\mathrm{I}$ & $\begin{array}{l}\text { Academy of Scientific Research } \\
\text { and Technology }\end{array}$ \\
\hline Finland & I & Tiedeakatemiain Neuvottelukunta \\
\hline France & IV & $\begin{array}{l}\text { Académie des Sciences (Institut de } \\
\text { France) }\end{array}$ \\
\hline Germany & IV & $\begin{array}{l}\text { Deutsche Gesellschaft für } \\
\text { Kristallographie (DGK) }\end{array}$ \\
\hline Greece & I & $\begin{array}{l}\text { Hellenic Crystallographic Associa- } \\
\text { tion }\end{array}$ \\
\hline Hungary & I & Magyar Tudományos Akadémia \\
\hline India & III & Indian National Science Academy \\
\hline Ireland, Republic of & I & Irish Crystallographic Association \\
\hline Israel & I & $\begin{array}{l}\text { Israel Academy of Sciences and } \\
\text { Humanities }\end{array}$ \\
\hline Italy & III & Consiglio Nazionale delle Ricerche \\
\hline Japan & IV & Science Council of Japan \\
\hline Korea, Republic of & I & $\begin{array}{l}\text { Korean Crystallographic Associa- } \\
\text { tion }\end{array}$ \\
\hline Mexico & I & $\begin{array}{l}\text { Consejo Nacional de Ciencia y } \\
\text { Tecnologia }\end{array}$ \\
\hline
\end{tabular}

Secretary of National Committee

D. Mezaoui, Laboratoire Sciences des Matériaux, Université des Sciences et de la Technologie Houari Boumedienne, BP 32 ElAlia, 16111 Bab-Ezzouar Alger, Algeria

D. R. Vega, Comision Nacional de Energía Atómica, Departamento de Física, TANDAR, Av. Gral Paz 1499, 1650 San Martin, Buenos Aires, Argentina

M. Dzundza, National Relations Officer, Australian Academy of Science, GPO Box 783, Canberra, ACT 2601, Australia

K. Hradil, X-ray Center, Vienna University of Technology, Getreidemarkt 9, 1060 Vienna, Austria

L. Van Meervelt, Biomolecular Architecture, Chemistry Department, K. U. Leuven, Celestijnenlaan 200F, B-3001 Leuven (Heverlee), Belgium

I. Torriani, Institut de Física, Universidade Estadual de Campinas, CP 6165, 13083-970 Campinas SP, Brazil

R. Petrova, Institute of Mineralogy and Crystallography, Acad. G. Bonchev str., Block 107, Bulgaria

J. Ngoune, Department of Chemistry, Faculty of Science, University of Dschang, PO Box 67 Dschang, Cameroon

J. D. Schrag, Biotechnology Research Institute, NRC, 6100 Royalmount Avenue, Montreal, Quebec H4P 2RZ, Canada

A. Vega, Departamento de Ciencias Quimicas, Universidad Andres Bello, Republica 275, Santiago, Chile

Xiao-Dong Su, Life Science College, Peking University, Beijing 100871, People's Republic of China

S. M. Peng, Department of Chemistry, National Taiwan University, Taipei

A. M. Araya Sibaja, Chemistry, University of Costa Rica, San Pedro de Montes de Oca, San José, 2060, Costa Rica

M. Luic, Ruder Boskovic Institute, Bijenicka cesta 54, POB 180, 1002 Zagreb, Croatia

R. Kuzel, Faculty of Mathematics and Physics, Charles University, Ke Karlovu 3, 12116 Praha 2, Czech Republic

A. Ø. Madsen, Department of Chemistry, University of Copenhagen, Universitetsparken 5, Copenhagen, DK-2100, Denmark

A. M. M. Moustafa, Physics Division, Solid State Department, National Research Centre, El-Buhous Street, Dokki, Cairo, Egypt

M. Blomberg, Department of Physical Sciences, PO Box 64, University of Helsinki, FIN-00014 Helsinki, Finland

F. Bonnete, Institut des Biomolécules Max Mousseron, Université d'Avignon, France

S. Schorr, Helmholtz-Zentrum Berlin, Hahn-Meitner-Platz 1, D-14109 Berlin, Germany

K. Petratos, IMBB-FORTH, Nikolaou Plastira 100, PO Box 1385 , GR-70013, Heraklion, Crete, Greece

P. Bombicz, Institute of Chemistry, Chemical Research Center, Hungarian Academy of Sciences, H-1525 Budapest, POB 17, Hungary

D. M. Salunke, Executive Director, Regional Centre for Biotechnology, 180 Udyog Vihar Phase I, Gurgaon, India

S. E. Lawrence, Department of Chemistry, University College, Cork, Ireland

M. Harel, Department of Structural Biology, The Weizmann Institute of Science, Rehovot 76100, Israel

M. Saviano, Istituto di Cristallografia del CNR, via Amendola 122/ O, 70126 Bari, Italy

M. Takata, Institute of Multidisciplinary Research for Advanced Materials, Tohoku University, Japan

S. W. Suh, Department of Chemistry, College of Natural Sciences, Seoul National University, Seoul, 151-747, Republic of Korea

L. Bucio Galindo, Instituto de Fisica, UNAM, Departamento de Estado Solido, Circuito de la Investigacion Cientifica s/n, Cd. Universitaria, Mexico, DF, PO Box 20-364, CP 04510, Mexico 
Table 7 (continued)

\begin{tabular}{|c|c|c|c|}
\hline Country & Category & Adhering Body & Secretary of National Committee \\
\hline Morocco & I & $\begin{array}{l}\text { Moroccan Crystallographic Asso- } \\
\text { ciation }\end{array}$ & $\begin{array}{l}\text { D. Zakaria, Laboratoire de Physico-Chimie des Matériaux, } \\
\text { Université Chouaib Doukkali, Faculté des Sciences, BP 20, } 2400 \\
\text { El Jadida, Morocco }\end{array}$ \\
\hline Netherlands & II & $\begin{array}{l}\text { The Dutch Association for } \\
\text { Crystallography (NVK) }\end{array}$ & $\begin{array}{l}\text { M. Lutz, Crystal and Structural Chemistry, Utrecht University, } \\
\text { Padualaan 8, Utrecht, } 3584 \mathrm{CH} \text {, The Netherlands }\end{array}$ \\
\hline New Zealand & I & The Royal Society of New Zealand & $\begin{array}{l}\text { J. Reid, The Royal Society of New Zealand, PO Box 598, } \\
\text { Wellington, New Zealand }\end{array}$ \\
\hline Norway & I & Det Norske Videnskaps-Akademi & $\begin{array}{l}\text { B. Fjaertoft, Institute of Pharmacy, University of Oslo, PO Box } \\
\text { 1068, Blindern, } 0316 \text { Oslo, Norway }\end{array}$ \\
\hline Pakistan & I & $\begin{array}{l}\text { International Center for Chemical } \\
\text { and Biological Sciences }\end{array}$ & $\begin{array}{l}\text { M. I. Choudhary, International Center for Chemical and } \\
\text { Biological Sciences, University of Karachi, Karachi-75270, } \\
\text { Pakistan }\end{array}$ \\
\hline Poland & I & Polska Akademia Nauk & $\begin{array}{l}\text { U. Rychlewska, Department of Chemistry, Adam Mickiewicz } \\
\text { University, Grunwaldzka 6, 60-780 Poznan, Poland }\end{array}$ \\
\hline Portugal & I & Sociedade Portuguesa de Fisica & $\begin{array}{l}\text { M. M. R. R. Costa, Departamento de Fisica, Universidade de } \\
\text { Coimbra, 3004-516 Coimbra, Portugal }\end{array}$ \\
\hline Regional Committee - AsCA & I & $\begin{array}{l}\text { Regional Committee of Crystal- } \\
\text { lographers from Bangladesh, } \\
\text { Indonesia, Malaysia, Singapore, } \\
\text { Thailand and Vietnam }\end{array}$ & $\begin{array}{l}\text { Duong Ngoc Huyen, Hanoi University of Science and Technology, } \\
\text { No. } 1 \text { Daicoviet, Hanoi, Vietnam }\end{array}$ \\
\hline Regional Committee - ECA & I & $\begin{array}{l}\text { Regional Committee of Crystal- } \\
\text { lographers from Latvia, Tunisia } \\
\text { and Ukraine }\end{array}$ & To be appointed \\
\hline Russia & $\mathrm{V}$ & Russian Academy of Sciences & $\begin{array}{l}\text { N. I. Sorokina and O. A. Alekseeva, Shubnikov Institute of } \\
\text { Crystallography, Russian Academy of Sciences, Leninsky pr. 59, } \\
\text { Moscow 119333, Russia }\end{array}$ \\
\hline Serbia & I & $\begin{array}{l}\text { Serbian Ministry for Science and } \\
\text { Technology }\end{array}$ & $\begin{array}{l}\text { A. Rosic, Belgrade University Computing Center, Kumanovska } \\
\text { bb, Belgrade, Serbia }\end{array}$ \\
\hline Slovenia & I & $\begin{array}{l}\text { Slovenian Ministry of Science and } \\
\text { Technology }\end{array}$ & $\begin{array}{l}\text { A. Meden, Faculty of Chemistry and Chemical Technology, } \\
\text { University of Ljubljana, PO Box 537, SI-1001 Ljubljana, } \\
\text { Slovenia }\end{array}$ \\
\hline South Africa & II & National Research Foundation & $\begin{array}{l}\text { B. Mnyatheli, South African ICSU Secretariat, National Research } \\
\text { Foundation, PO Box 2600, Pretoria 0001, South Africa }\end{array}$ \\
\hline Spain & III & $\begin{array}{l}\text { Subdirección General de Orga- } \\
\text { nismos y Programas Internacio- } \\
\text { nales, Ministerio de Ciencia y } \\
\text { Tecnologia }\end{array}$ & $\begin{array}{l}\text { E. Gutiérrez Puebla, Instituto de Ciencia de Materiales de } \\
\text { Madrid, CSIC, Cantoblanco, E-28049 Madrid, Spain }\end{array}$ \\
\hline Sweden & II & Kungliga Vetenskapsakademien & $\begin{array}{l}\text { A. Sjögren, Svenska Kemistsamfundet, Wallingatan 24, } 11123 \\
\text { Stockholm, Sweden }\end{array}$ \\
\hline Switzerland & II & $\begin{array}{l}\text { Schweizerische Gesellschaft für } \\
\text { Kristallographie }\end{array}$ & $\begin{array}{l}\text { M. Hennig, F. Hoffmann - La Roche, Pharma Research 65/319, } \\
\text { CH-4070 Basel, Switzerland }\end{array}$ \\
\hline Turkey & I & Ulusal Kristallografi Dernegi & $\begin{array}{l}\text { S. Ide, Department of Engineering Physics, Haceteppe University, } \\
06532 \text { Beytepe, Ankara, Turkey }\end{array}$ \\
\hline UK & V & $\begin{array}{l}\text { The British Crystallographic } \\
\text { Association }\end{array}$ & $\begin{array}{l}\text { C. Wilson, National Crystallography Service, Diamond Light } \\
\text { Source, Diamond House, Didcot, Oxfordshire OX11 0DE, UK }\end{array}$ \\
\hline Uruguay & I & $\begin{array}{l}\text { Academia Nacional de Ciencias } \\
\text { del Uruguay }\end{array}$ & $\begin{array}{l}\text { L. Suescun, Facultad de Quimica, Av. Gral. Flores 1224, Casilla } \\
\text { 1157, } 11800 \text { Montevideo, Uruguay }\end{array}$ \\
\hline USA & $\mathrm{V}$ & $\begin{array}{l}\text { National Academy of Sciences } \\
\text { - National Research Council }\end{array}$ & $\begin{array}{l}\text { C. J. Rawn, The University of Tennessee, Department of Materials } \\
\text { Science and Engineering, } 409 \text { Ferris Hall, } 508 \text { Middle Drive, } \\
\text { Knoxville, TN 37996-2100, USA }\end{array}$ \\
\hline Venezuela & I & $\begin{array}{l}\text { Sociedad Venezolana de Cristalo- } \\
\text { grafia }\end{array}$ & $\begin{array}{l}\text { J. M. Delgado, Laboratorio de Cristalografia, Departamento de } \\
\text { Quimica, Facultad de Ciencias, Universidad de Los Andes, Le } \\
\text { Hechicera, Merida 5101, Venezuela }\end{array}$ \\
\hline
\end{tabular}

Hungary

G. Faigel (Chair), A. Benyei, P. Bombicz, A. Kálmán,

L. Koszegi, L. Kovacs, J. Labar, G. Naray-Szabo, G. Radnóczi,

K. Simon, E. Svab, T. Ungár, T. Weiszburg

India

D. M. Salunke (Chair), K. Byrappa, G. R. Desiraju, A. Nangia,

M. K. Sanyal, K. Suguna

Ireland, Republic of

P. McArdle (Chair), A. Khan, J. F. Gallagher, N. Hamill, S. E.

Lawrence, T. Soulimane

Israel

R. Zarivach (Chair), O. Dym, M. Harel
Italy

R. Oberti (Chair), V. R. Albertini, G. Artioli, E. Chiancone, C. Mealli, M. Milani, M. Saviano, G. Zanotti

Japan

M. Takata (Chair), Y. Fujii, K. Kakimoto, K. Kurihara, R. Kuroda, K. Ogawa, Y. Sugawara, A. Takahara

Korea, Republic of

S. W. Suh (Chair), J. T. Ahn, U. U. Chi, S. I. Cho, Y. K. Cho, S. J. Chung, H. J. Kim, H. S. Kim, Y. H. Kim, Y. J. Park

Mexico

L. Bucio Galindo (Chair), J. L. Aragon Vera, L. Banos Lopez, S. Bernes Flouriot, J. L. L. Boldu Olaizola, G. Cabanas 
Moreno, O. Cano Corona, M. A. Castellanos Roman, A. E. Cordero Borboa, N. E. Garcia Calderon, M. Hesiquio Garduno, E. Horjales Reboredo, V. M. Malpica Cruz, E. A. Munoz Picone, J. Ornelas Tabares, J. Palacios Gomez, A. Reyes Arellano, J. Reyes Gasga, J. Rickards Campbell, D. Rios Jara, R. Rodriguez Mijangos, D. Romeo Casajuana, H. Terrones Maldonado, R. Alfredo Toscano, E. Villafuerte Castrejon

Morocco

A. Thalal (Chair), D. Zakaria

Netherlands

R. B. G. Ravelli (Chair), M. Lutz, C. A. Reiss, H. Raaijmakers,

A. C. Terwisscha Van Scheltinga

New Zealand

E. N. Baker (Chair), V. Arcus, S. Brooker, C. Fitchett, J. Reid, M. Ryan, C. Squire, S. Telfer

Norway

C. H. Görbitz (Chair), B. Fjaertoft, J. K. Gjønnes, K. W. Törnroos

Pakistan

Atta-ur-Rahman (Chair), M. I. Choudhary (Vice-Chair), M. Ahmed, A. Baig, Moaz-ur-Rahman, S. Yousuf

Poland

M. Gdaniec (Chair), J. Lipkowski (Vice-Chair), G. D. Bujacz, A. Pietraszko, U. Rychlewska, D. Stróż, A. Szytuła, J. Żmija Portugal

J. A. Paixao (Chair), M. M. R. R. Costa, M. T. Duarte

Regional Committee - AsCA

J. J. Vittal (Chair), Siti Nadiah Abdul Halim, A. Hussain, Y.

Permana, Duong Ngoc Huyen, Thammarat Aree

Regional Committee - ECA

A. Bekka, N. Bouhmaida, M. Bulanova, M. Debbabi, R. Gladyshevskii, A. Haddad, A. Mishnev

Russia

M. V. Kovalchuk (Chair), V. L. Aksenov (Vice-Chair), V. M. Kanevsky (Vice-Chair), S. M. Aldoshin, E. V. Antipov, L. A. Aslanov, A. S. Avilov, E. V. Boldyreva, N. B. Bolotina, E. V. Chuprunov, S. N. Chvalun, G. N. Kulipanov, V. V. Kvardakov, V. V. Kveder, S. G. Konnikov, S. V. Krivovichev, I. S. Lyubutin, I. P. Makarova, V. V. Osiko, V. O. Popov, D. Yu. Pushcharovsky, M. K. H. Rabadanov, O. G. Sinyashin, A. E. Voloshin
Serbia

A. Kremenović (Chair), A. Kapor (Vice-Chair), B. Antic, B. Bogdanović, A. Rosic, S. Stanković, S. Trifunović

Slovenia

V. Kaučič (Chair), A. Golobic, N. Lah, A. Meden

South Africa

S. A. Bourne (Chair), C. Esterhuysen (Vice-Chair), L. J. Barbour, D. G. Billing, A. Jacobs, G. J. Kruger, D. C. Levendis, L. R. Nassimbeni (observer), A. Roodt, K. Stewart, A. Venter Spain

C. Miravitlles Torras (Chair), M. I. Arriortua Marcaida, S. Garcia Granda, J. M. Garcia Ruiz, P. Gomez Sal, E. Gutiérrez Puebla, F. J. Lahoz Diaz, J. Rius Palleiro

Sweden

S. Nordholm (Chair), L. I. Elding, A. Hartmanis, K. Holmberg, Y. Lindqvist, J.-E. Nyström, E. Sauer-Eriksson, A. Sjögren

Switzerland

W. Steurer (Chair), M. Hennig, H. J. Scheel, J. Schefer, M. Schiltz, K. Yvon

Turkey

S. Ozbey (Chair), S. Ide

UK

L. Brammer (Chair), D. Beveridge, R. Cooper, S. Coles, A. Griffin, D. Keen, S. McKellar, P. Parois, M. Roe, P. Saines, C. H. Schwalbe, M. Senn, A. L. Thompson, A. Thorn, P. Williams, C. Wilson

Uruguay

A. Buschiazzo (Chair), D. Ariosa, L. Fornaro, A. W. Mombru, L. Suescun

USA

J. Ng (Chair), C. Lind (Vice-Chair), J. Aitken, O. A. Asojo, S. Burley, C. Cahill, B. Campbell, A. Gonzalez, C. Groom, M. L. Hackert, M. Hickey, J. Hildebrand, J. A. Kaduk, B. Matthews, S. Misture, P. Moeck,M. Olmstead, C. J. Rawn, J. Reibenspies, A. Sarjeant, P. Stephens, T. Swager, T. Terwilliger, D. Walt, K. Wheeler

Venezuela

A. Briceno (Chair), R. Atencio, J. Bruno-Colmenarez, J. M. Delgado, G. Diaz de Delgado, O. Gonzalez 